\title{
Engineering Design Elements of a Two-Phase Thermosyphon to Transfer NGNP Thermal Energy to a Hydrogen Plant
}

Piyush Sabharwall

July 2009

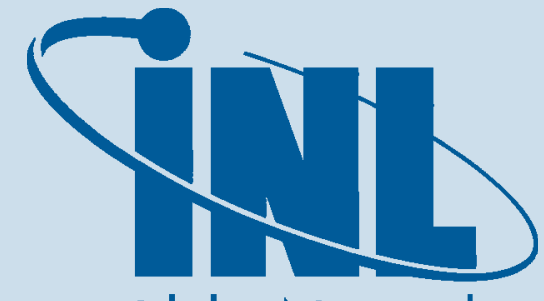

Idaho National Laboratory

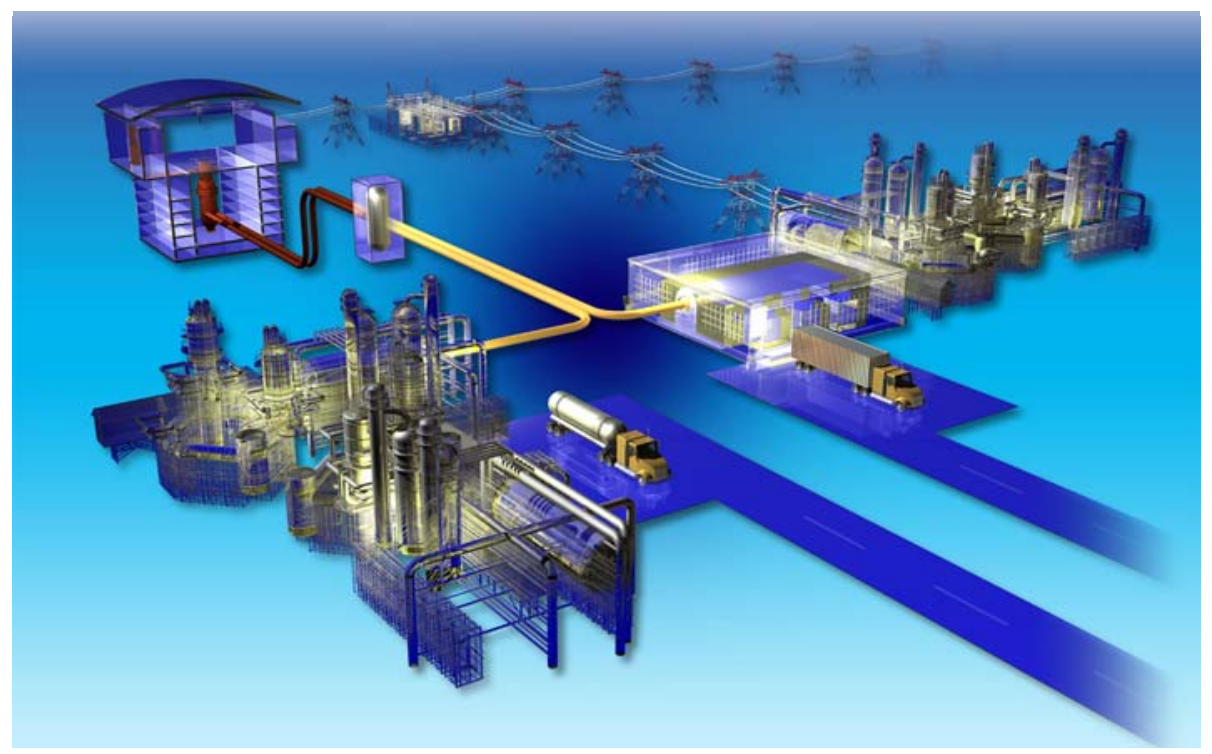

The INL is a U.S. Department of Energy National Laboratory operated by Battelle Energy Alliance. 


\section{DISCLAIMER}

This information was prepared as an account of work sponsored by an agency of the U.S. Government. Neither the U.S. Government nor any agency thereof, nor any of their employees, makes any warranty, expressed or implied, or assumes any legal liability or responsibility for the accuracy, completeness, or usefulness, of any information, apparatus, product, or process disclosed, or represents that its use would not infringe privately owned rights. References herein to any specific commercial product, process, or service by trade name, trade mark, manufacturer, or otherwise, does not necessarily constitute or imply its endorsement, recommendation, or favoring by the U.S. Government or any agency thereof. The views and opinions of authors expressed herein do not necessarily state or reflect those of the U.S. Government or any agency thereof. 
INL/EXT-09-15383

Revision 0

\title{
Engineering Design Elements of a Two-Phase Thermosyphon to Transfer NGNP Thermal Energy to a Hydrogen Plant
}

\author{
Piyush Sabharwall
}

July 2009

\begin{abstract}
Idaho National Laboratory
Next Generation Nuclear Plant Project

Idaho Falls, Idaho 83415
\end{abstract}

Prepared for the

U.S. Department of Energy

Office of Nuclear Energy

Under DOE Idaho Operations Office

Contract DE-AC07-05ID14517 
This page intentionally left blank 
Next Generation Nuclear Plant Project

\title{
Engineering Design Elements of a Two-Phase Thermosyphon to Transfer NGNP Thermal Energy to a Hydrogen Plant
}

\author{
INL/EXT-09-15383 \\ Revision 0 \\ Fobruary 2009 \\ July \\ TKA 7=20.09
}

Approved by:

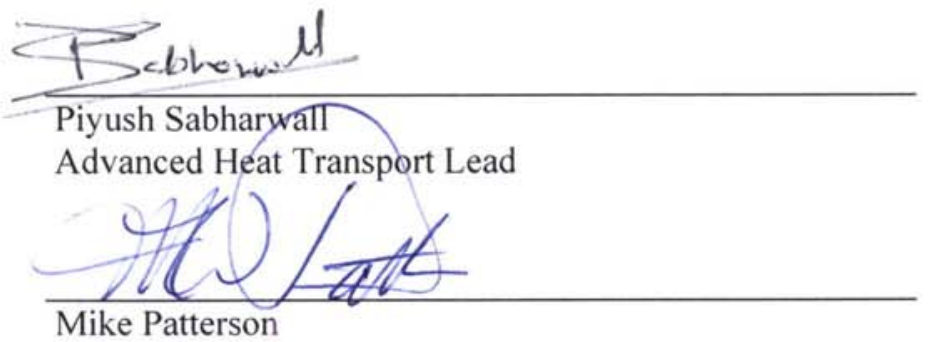

Mike Patterson

Heat Transport \& $\mathrm{H}_{2}$ Process Project Manager
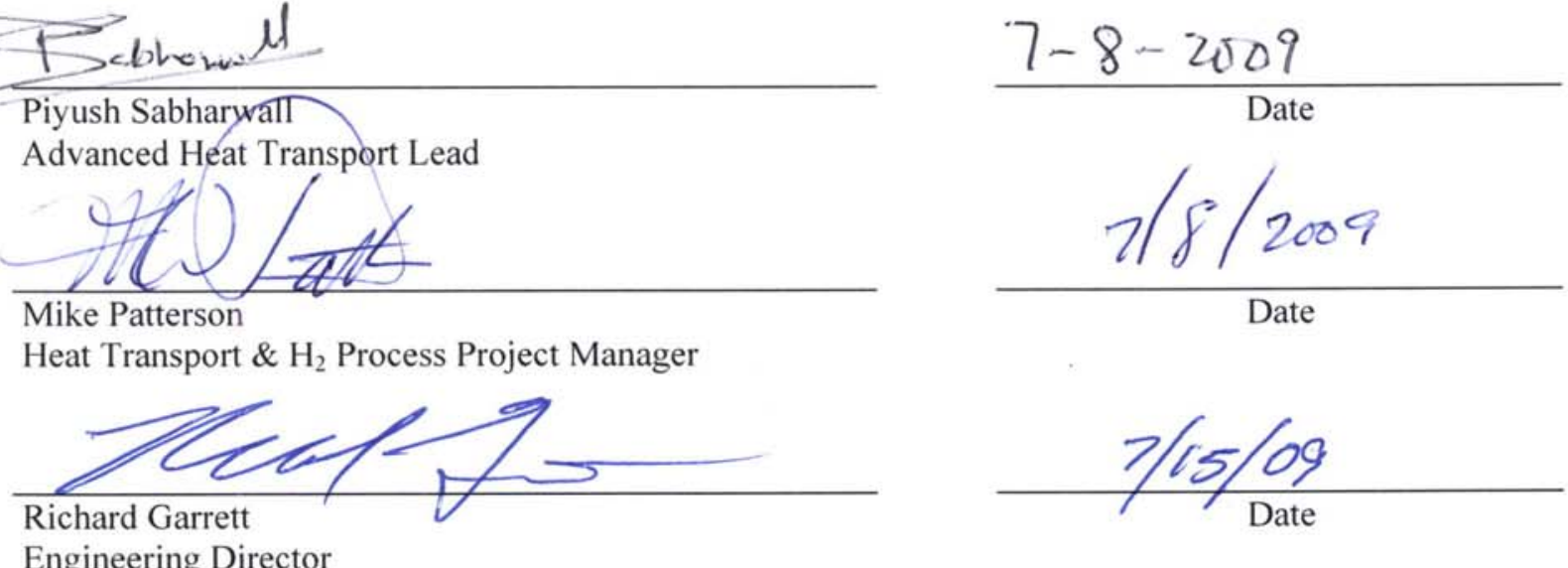
This page intentionally left blank 


\section{ABSTRACT}

Three hydrogen production processes, powered by a Next Generation Nuclear Plant (NGNP), are currently under investigation at Idaho National Laboratory. The first is high-temperature steam electrolysis, which uses both heat and electricity; the second is thermo-chemical production through the sulfur iodine process primarily using heat; the third is a hybrid sulfur process (not part of this study) which incorporates sulfur acid decomposition and sulfur dioxide depolarized electrolysis, all processes require a high temperature $\left(>850^{\circ} \mathrm{C}\right)$ for enhanced efficiency; temperatures indicative of the NGNP. Safety and licensing mandates prudently dictate that the NGNP and the hydrogen production facility be physically isolated, perhaps requiring separation of over $100 \mathrm{~m}$.

Several options are being considered to transfer multi-megawatt thermal power over such a distance. One option is simply to produce only electricity, transfer it by wire to the hydrogen plant, and then reconvert the electric energy to heat via Joule or induction heating. Electrical transport, however, suffers energy losses of $60-70 \%$ because of the thermal-to-electric conversion inherent in the Brayton cycle. A second option is thermal energy transport via a single-phase forced convection loop where a fluid is mechanically pumped between heat exchangers at the nuclear and hydrogen plants. High temperatures, however, present unique material and pumping challenges. Single phase, low pressure helium is an attractive option for the NGNP, but is unsuitable for a single purpose facility dedicated to hydrogen production because low-pressure helium requires higher pumping power and makes the process very inefficient. A third option is two-phase heat transfer using a high temperature thermosyphon. Heat transport occurs via evaporation and condensation and the heat transport fluid is recirculated by gravitational force. Thermosyphon has the capability to transport heat at high rates over appreciable distances, virtually isothermally, and without any requirement for external pumping devices.

Intermediate heat exchangers (IHX) are preferred for transferring heat from the NGNP to the hydrogen plant in the most efficient way. Power production at higher efficiency using the Brayton Cycle and hydrogen production require hightemperature heat, at temperatures up to $1,000^{\circ} \mathrm{C}$, and highly effective compact heat exchangers to transfer heat to either the power or process cycle. The compact heat exchanger was selected to maximize the heat transfer surface area per volume of heat exchanger, which has the benefit of reducing heat exchanger size and heat loss. The IHX design requirements are governed by the allowable temperature drop between the outlet of the NGNP $\left(900^{\circ} \mathrm{C}\right.$, based on the expected capabilities of NGNP) and the temperatures in the hydrogen production plant. Spiral heat exchangers (SHEs) have superior heat transfer characteristics and are less susceptible to fouling. Further, heat losses to surroundings are minimized because of its compact configuration. SHEs have never been examined for phasechange heat transfer applications. The research presented provides useful information on thermosyphon designs and SHEs.

This research presents useful insights into making decisions regarding the thermosyphon heat transfer system between the nuclear reactor and chemical plant. Developing very high-temperature reactor technologies for producing electricity, hydrogen, and other energy products is a high priority for a successful national energy future. 
This page intentionally left blank 


\section{CONTENTS}

ABSTRACT vi

ACRONYMS xiv

NOMENCLATURE xvi

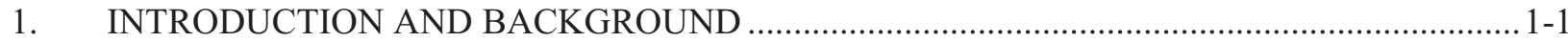

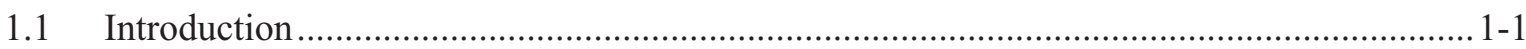

1.2 Historical Development and Background of Thermosyphon and Heat Pipe ...................... 1-2

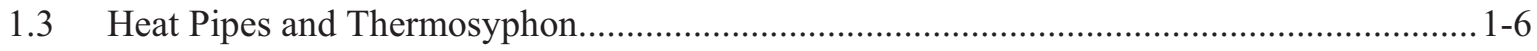

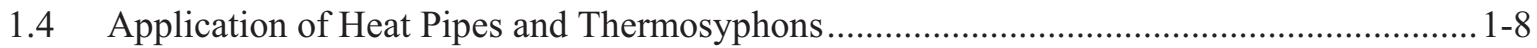

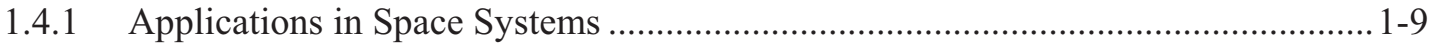

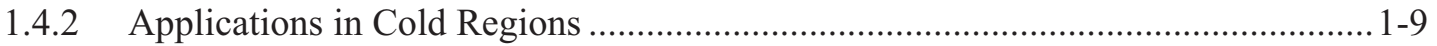

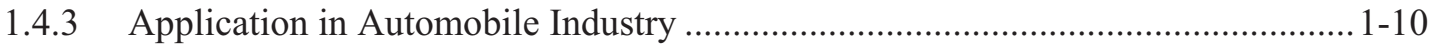

1.4.4 Application in Railroad Industry................................................................. 1-10

1.4.5 Application in Electrical, Electronics, and Nuclear Industries ............................ 1-10

1.4.6 Summary Statement ...................................................................................... 1-11

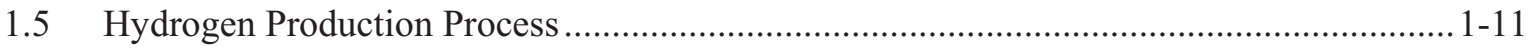

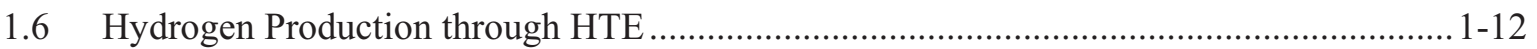

1.7 Thermochemical Production of Hydrogen (SI Cycle) .................................................. 1-15

1.8 Safety Issues of Nuclear Hydrogen Production ................................................................. 1-17

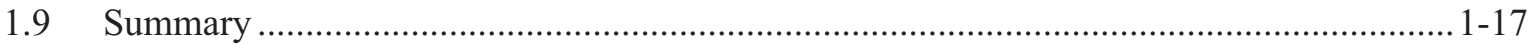

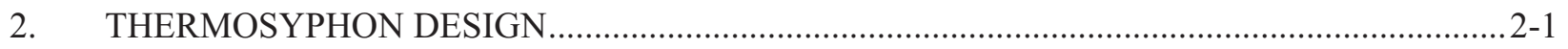

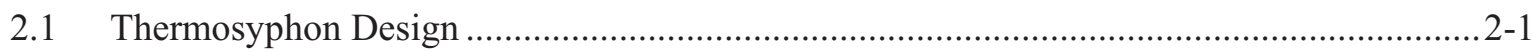

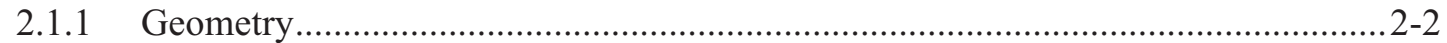

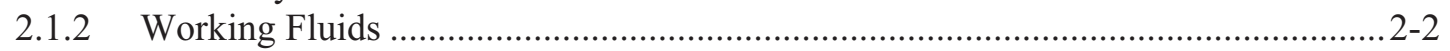

2.2 Mass Flow Rate and Sonic Velocity Analysis ..................................................................

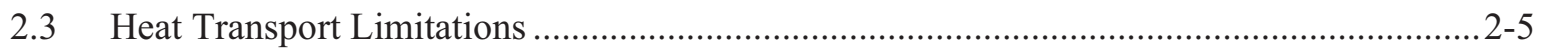

2.3.1 Sonic Limit (Choking) of Vapor Flow ................................................................ 2-6

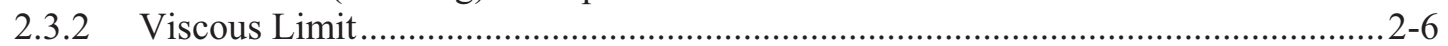

2.4 Comparison of Alkaline Metals Thermosyphon with Convective Loop ............................2-8

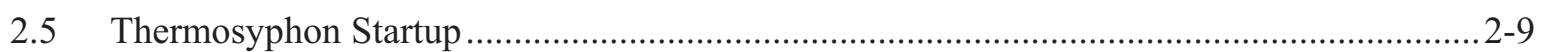

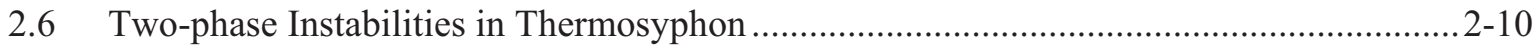

2.6.1 Surging (Chugging) and Geysering Instability …............................................... $2-11$

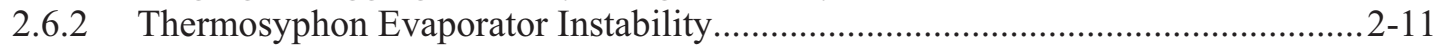

2.6.3 Fluid Superheating (Alkaline Metals) ..............................................................2-11

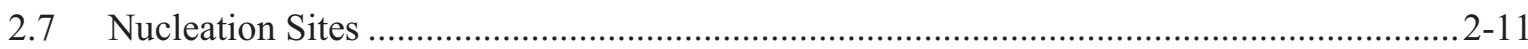

2.8 Inclination Effects on a Thermosyphon Performance..................................................2-14

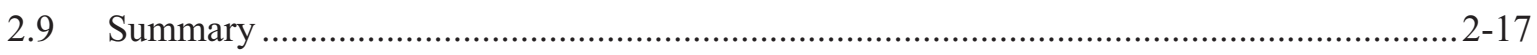

3. THERMODYNAMIC ANALYSIS OF THERMOSYPHONS …...............................................

3.1 General Model (Vertical Thermosyphon) and Flooding ..................................................... 3-2 
3.2 Thermodynamic Analysis of Two-phase Thermosyphon with Spiral Heat

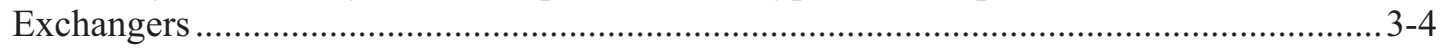

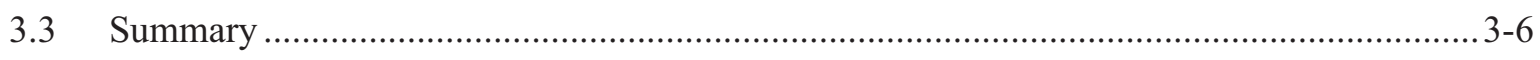

4. DIMENSIONLESS NUMBERS IN BOILING FLUID FLOW FOR THERMOSYPHON

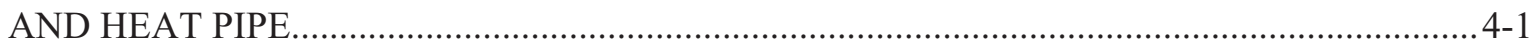

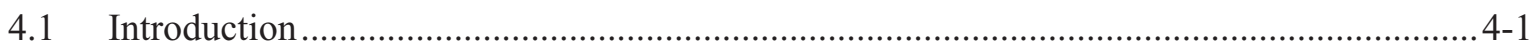

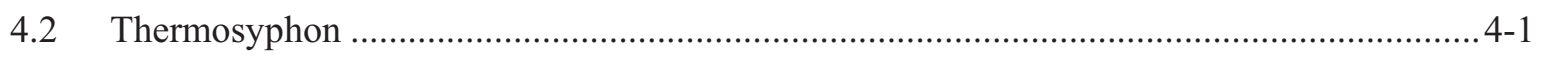

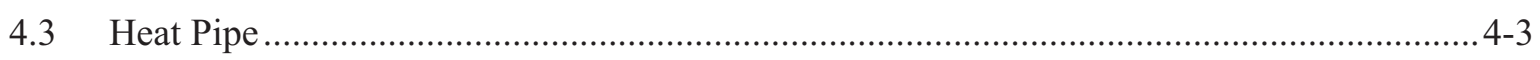

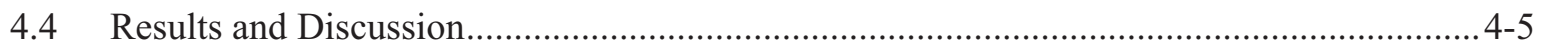

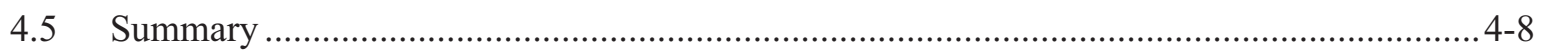

5. INTERMEDIATE HEAT EXCHANGERS ......................................................................

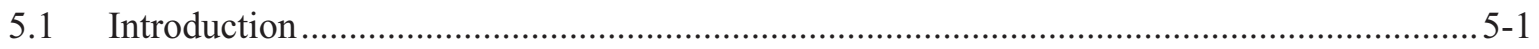

5.2 Heat Exchangers for the NGNP Intermediate Loop................................................... 5-1

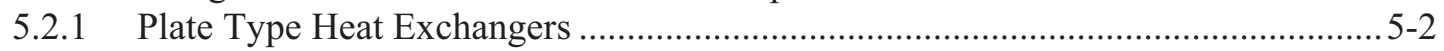

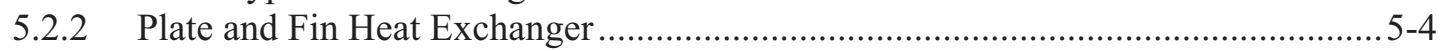

5.2.3 Printed Circuit Heat Exchanger ....................................................................... 5-5

5.2.4 Single and Two-phase Spiral Heat Exchanger .................................................... 5-9

5.2.5 Shell and Tube Heat Exchanger ..................................................................... 5-11

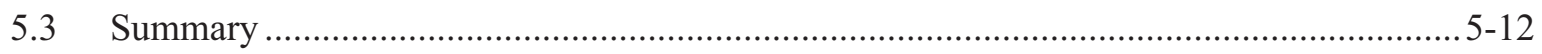

6. PHASE CHANGE HEAT TRANSFER ANALYSIS …............................................................. $6-1$

6.1 Liquid Metal Phase Change Heat Exchanger................................................................. 6-1

6.2 Mathematical Model Development.............................................................................. 6-1

6.2.1 Convective Boiling Heat Transfer for Liquid Metal (Sodium) ................................ 6-2

6.2.2 Heat Transfer Coefficients Estimation...................................................................... 6-5

6.2.3 Convective Boiling Heat Transfer for Two-phase Na ............................................ 6-8

6.2.4 Pressure Drop Evaluation for $\mathrm{Na}$ (Boiling) Region ........................................ 6-12

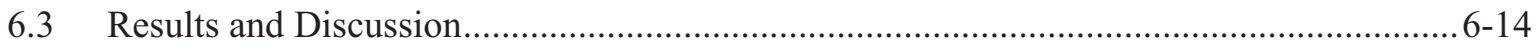

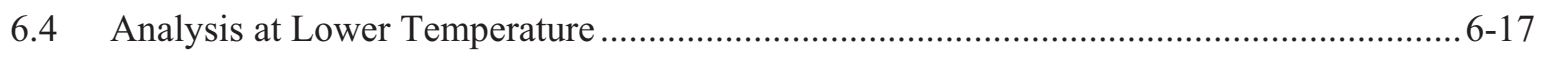

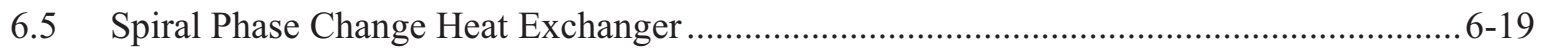

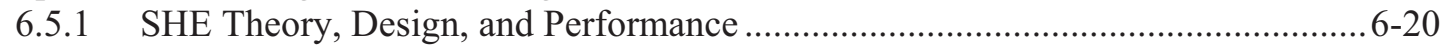

6.5.2 Geometric Characteristics of SHEs................................................................ 6-22

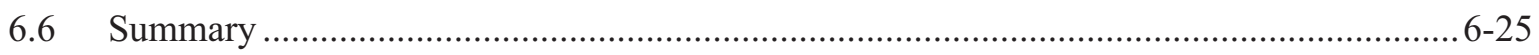

7. HIGH TEMPERATURE MATERIALS ….........................................................................

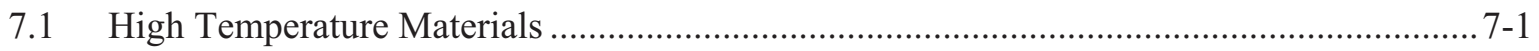

7.2 Ductility and Creep Rupture Life..............................................................................

7.3 Effects of Constituents for Alloy 617 .......................................................................... $7-5$

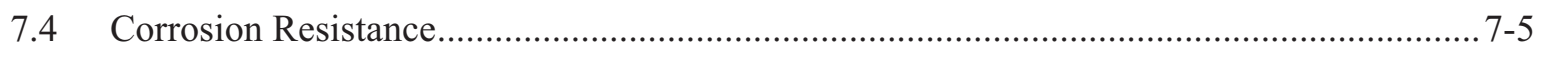

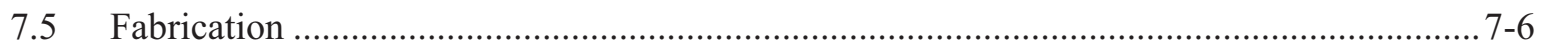

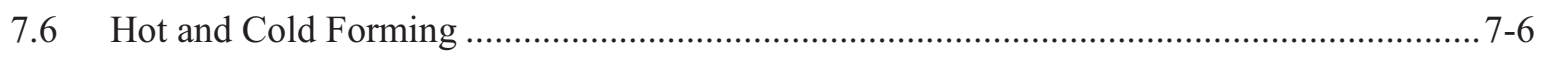

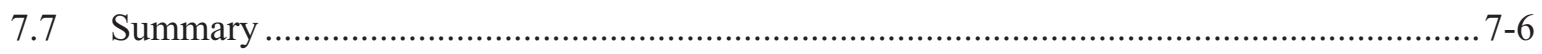

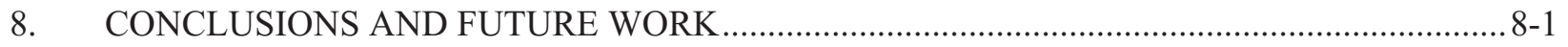




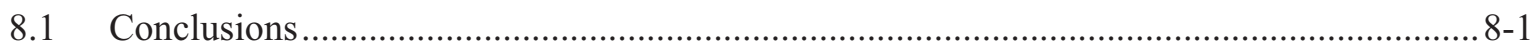

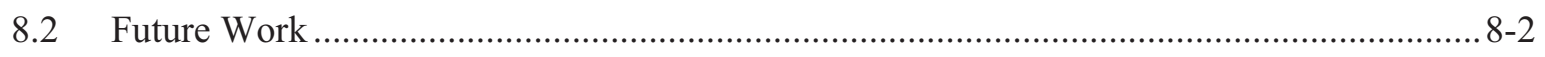

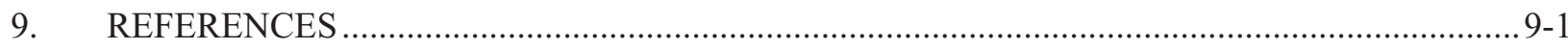

\section{FIGURES}

Figure 1-1. NGNP with process heat transfer (modified from NGNP Preliminary Project Plan 2007). $1-1$

Figure 1-2. Perkins boiler (Reay and Kew 2006). ........................................................................ 1-3

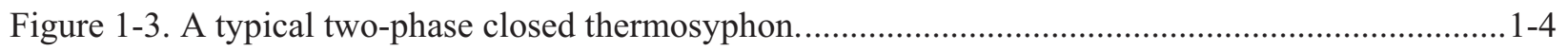

Figure 1-4. Two-phase closed U tube thermosyphon loop (Zuo 1995).................................................1-5

Figure 1-5. Evaporator-controlled two-accumulator PPM systems (Feldman 1987).............................1-6

Figure 1-6. The main regions of the heat pipe (www.acrolab.com). .................................................... 1-7

Figure 1-7. The heat pipe and thermosyphon (Reay and Kew 2006). ................................................ 1-8

Figure 1-8. Typical vertical support member with heat pipes for trans-Alaska oil pipeline.....................1-9

Figure 1-9. NGNP conceptual schematic of power generation and hydrogen production (NGNP

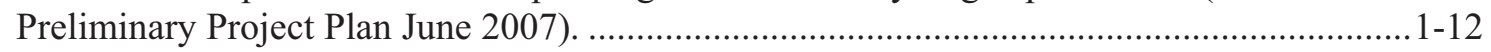

Figure 1-10. Schematic of a thermal water-splitting process operating between $T_{H}$ and $T_{L}$ (Hori

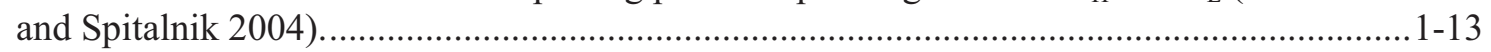

Figure 1-11. Theoretical thermal water-splitting efficiencies (Hori and Spitalnik 2004).....................1-14

Figure 1-12. Comparison of thermal to hydrogen efficiencies of HTE and SI thermochemical

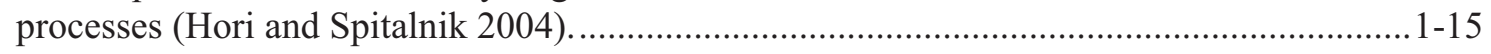

Figure 1-13. Thermochemical SI cycle (Hori and Spitalnik 2004)................................................1-16

Figure 2-1. Schematic of a simple controllable thermosyphon (Sabharwall and Gunnerson 2008).........2-1

Figure 2-2. Mass flow rates of alkaline metal vapors, required to transport $50 \mathrm{MW}$...........................2-5

Figure 2-3. Maximum separation distance possible between NGNP and hydrogen production

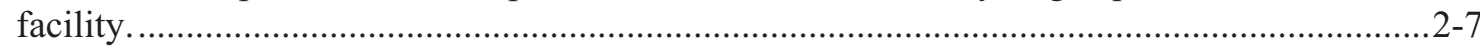

Figure 2-4. Maximum separation distance possible for an allowable pressure drop. ............................2-8

Figure 2-5. Enthalpy for saturated sodium: liquid and vapor (thermodynamic data from Fink and

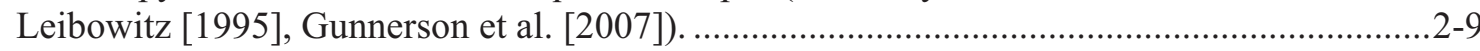

Figure 2-6. Na filling procedure for a thermosyphon (Gunnerson and Sanderlin 1994)......................2-10

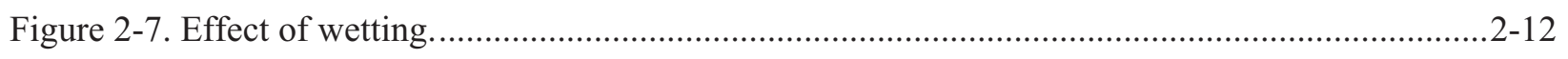

Figure 2-8. Sketch of the contact angle between surface and liquid.................................................2-13

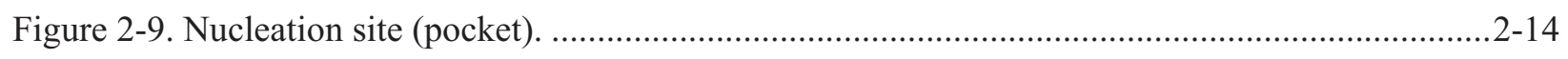

Figure 2-10. Progressive displacement of the stagnation point at the hot end of the tilted

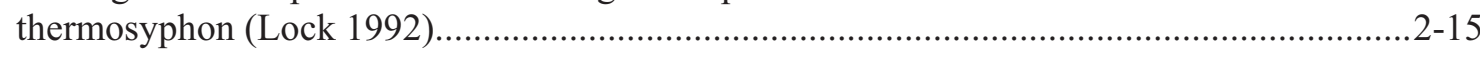

Figure 2-11. Operation regimes at various inclination angles (Terdtoon et al. 1990)..........................2-16

Figure 3-1. Working fluid circulation inside a vertical two-phase thermosyphon.................................. 3-3 
Figure 3-2. Pressure-temperature diagram (Single 1990) .................................................................

Figure 3-3. Schematic diagram of the thermodynamic process........................................................... 3-4

Figure 3-4. Pressure-specific volume and temperature-specific entropy diagrams. ...............................3-5

Figure 4-1. Variation in $\mathrm{E}_{\mathrm{r}}$ with respect to temperature for alkaline metals. .........................................4-6

Figure 4-2. Variation in $\mathrm{E}_{\mathrm{M}}$ with respect to diameter for alkaline metals............................................4-7

Figure 5-1. Flat plate CHE (Sherman and Chen 2008) .......................................................................

Figure 5-2. Bavex welded plate heat exchanger (Fisher and Sindelar 2008).........................................5-3

Figure 5-3. Plate type heat exchanger. Laser welded pairs of plates, stacked to form flow paths between the welded pairs. Installed in a $100 \mathrm{~kW}(\mathrm{e})$ micro-gas-turbine generating plant

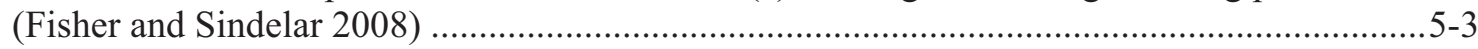

Figure 5-4. Elements of diffusion bonded plate and fin heat exchanger (Fisher and Sindelar 2008)........5-4

Figure 5-5. Plate-fin heat exchanger (Sherman and Chen 2008) ........................................................5-4

Figure 5-6. Diffusion-bonded titanium plate-fin heat exchanger.........................................................5-5

Figure 5-7. First step — plate passages (Heatric ${ }^{\mathrm{TM}}$ Homepage 2007) ....................................................5-5

Figure 5-8. Second step — diffusion bonding of plates (Heatric ${ }^{\text {TM }}$ Homepage 2007) ............................5-6

Figure 5-9. Diffusion bonded printed circuit heat exchanger section (Heatric ${ }^{\mathrm{TM}}$ Homepage 2007). ........5-6

Figure 5-10. Third step - block composed of diffusion bonded plates (Heatric ${ }^{\mathrm{TM}}$ Homepage

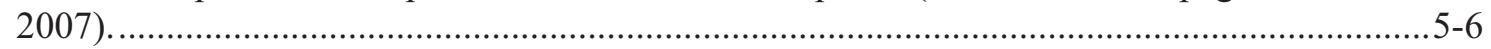

Figure 5-11. Cross sectional view of the semi circular passages (Heatric ${ }^{\mathrm{TM}}$ Homepage 2007)...............5-6

Figure 5-12. Side view of passage shapes (Hesselgreaves 2001) ......................................................5-6

Figure 5-13. Finished heat exchanger (Heatric ${ }^{\mathrm{TM}}$ Homepage 2007). ..................................................5-7

Figure 5-14. Fluid flow paths (Gezelius 2004) ............................................................................... 5-7

Figure 5-15. Current operating experience of Heatric ${ }^{\text {TM }}$ PCHEs (Gezelius 2004) .................................5-7

Figure 5-16. Simple crossflow (left) and cross-counterflow (right) configuration (Hesselgreaves

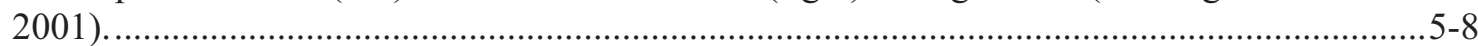

Figure 5-17. PCHE in front of a shell-and-tube heat exchanger designed for the same thermal duty and pressure drop (Heatric ${ }^{\mathrm{TM}}$ Homepage 2007). ...........................................................

Figure 5-18. Schematic of a SHE (Katzel 2000) .................................................................................... 5

Figure 5-19. SHE with counter flow arrangement (Sherman and Chen 2008)......................................5-9

Figure 5-20. Manufacturing of a SHE (Fisher and Sindelar 2008) ........................................................10

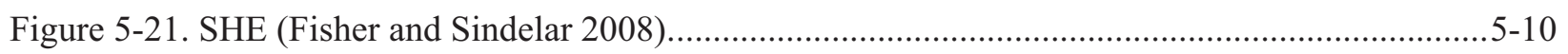

Figure 5-22. Schematic of a SHE (Modified from www. alfalaval.com). ............................................5-11

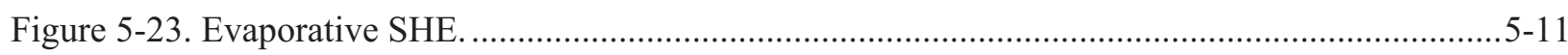

Figure 5-24. Shell and tube heat exchanger with baffles (Sherman and Chen 2008)..........................5-12

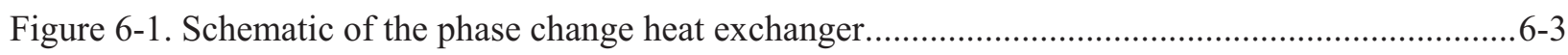

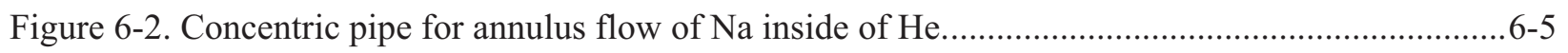


Figure 6-3. Suppression factor (S) (Chen 1963(ii)) ......................................................................... $6-9$

Figure 6-4. Reynolds number factor (F) (Chen 1963 (ii)) ...................................................................

Figure 6-5. Temperature profiles for pool boiling and for convective boiling with same total

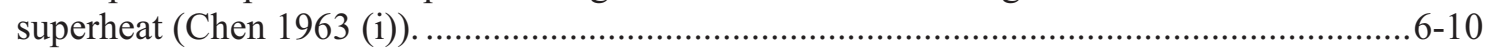

Figure 6-6. Overall heat transfer characteristics operating at Vs/2 and at 1,300 K..........................6-15

Figure 6-7. Overall heat transfer characteristics operating at improved condition at 1,300 K.............6-16

Figure 6-8. Nusselt number dependence on Reynolds number for Na liquid metal. ............................6-17

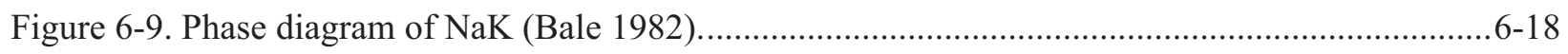

Figure 6-10. Overall heat transfer characteristics operating at 1,173 $\mathrm{K}$ for $\mathrm{NaK}$ eutectic.....................6-18

Figure 6-11. Overall heat transfer characteristics operating at 1,123 $\mathrm{K}$ for $\mathrm{NaK}$ eutectic....................6-19

Figure 6-12. Plate forming process of SHE (Egner 2003)..............................................................6-19

Figure 6-13. Detailed schematic of a SHE (Modified from Wu 2003) ................................................6-22

Figure 6-14. Heat transfer characteristics for straight tube and SHE operating at 1,300 K.................6-25

Figure 7-1. Comparison of ASME allowable stress for high temperature alloys ( $\mathrm{Li}$ et al. 2006). ............7-2

Figure 7-2. Creep strength of solution-annealed Alloy 617 (www.specialmaterials.com)......................7-3

Figure 7-3. Rupture strength of solution-annealed Alloy 617 (www.specialmaterials.com)....................7-4

Figure 7-4. Thermal expansion for the various alloys at elevated temperatures (Dewson and Li

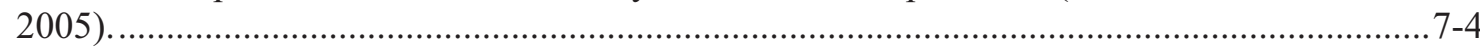

Figure 7-5. Thermal conductivity for the various alloys at elevated temperatures (Dewson and Li

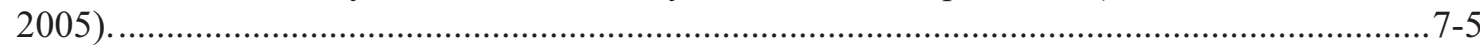

Figure 7-6. Comparison of nitriding resistance (Dewson and Li 2005) .............................................. 7-5

Figure 7-7. Effect of cold reduction on hardness (www.specialmaterials.com). ................................... 7-6

\section{TABLES}

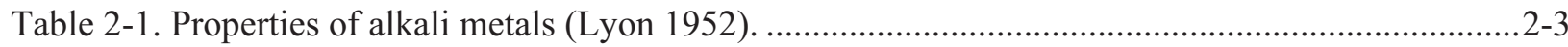

Table 6-1. Parameters in macroconvective equation (Chen 1963 (ii)) .................................................6-11

Table 6-2. Heat transfer and geometric parameters for helium duct...................................................6-14

Table 6-3. Single phase parameters (operating at $\mathrm{Vs} / 2$ ) ................................................................... 6-14

Table 6-4. Two-phase boiling Na parameters (operating at Vs /2 \&Q $\mathrm{Q}_{\mathrm{L} 2}$ ) ............................................6-15

Table 6-5. Single phase parameters (improved design). ......................................................................6-16

Table 6-6. Two-phase boiling Na parameters (improved design)......................................................6-16

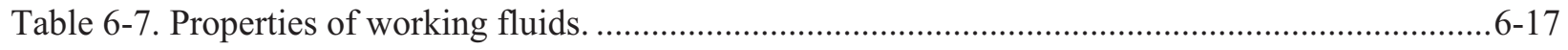

Table 7-1. Candidate material for construction of a thermosyphon (Dewson and Li 2005)....................7-1

Table 7-2. Candidate material ranking based on ductility (Dewson and Li 2005)................................7-2

Table 7-3. Candidate material ranking based on creep rupture life (Dewson and Li 2005).....................7-3 
This page intentionally left blank 


\section{ACRONYMS}

ASME American Society of Mechanical Engineers

CHE compact heat exchanger

CLTPT closed loop two phase thermosyphon

GT-MHR Gas Turbine Modular High-Temperature ReactorHEM homogeneous equilibrium model

HTE high temperature electrolysis

HTES high temperature electrolysis of steam

HTGR high temperature gas-cooled reactor

IHX intermediate heat exchanger

LMTD $\quad \log$ mean temperature difference

NGNP Next Generation Nuclear Plant

PPM passive pumping module

PCHE printed circuit heat exchanger

SHE spiral heat exchanger

SI sulfur iodine

SOFC solid-oxide fuel cell

TAPS Trans-Alaska Pipeline System

TEMA Tubular Exchange Manufacturers Association 
This page intentionally left blank 


\section{NOMENCLATURE}

A Cross-sectional flow area $\left[\mathrm{m}^{2}\right]$

$\mathrm{A}_{\mathrm{f}} \quad$ Cross-sectional flow area for the annulus $\left[\mathrm{m}^{2}\right]$

$b_{1}, b_{2} \quad$ Width of spiral passage [m]

$\mathrm{C}_{\mathrm{P}} \quad$ Heat capacity $\left[\mathrm{kJ} \mathrm{kg}^{-1} \mathrm{~K}^{-1}\right.$; Equations (6-39), (6-40), (6-41): Btu lb ${ }^{-1} \operatorname{deg} \mathrm{F}^{-1}$ ]

dp Change in pressure $[\mathrm{Pa}]$

$\mathrm{dz} \quad$ Change in location $[\mathrm{m}]$

$d_{11} \quad$ Initial semicircle diameter of the inner lateral line for spiral plate $1[\mathrm{~m}]$

$d_{21} \quad$ Initial semicircle diameter of the inner lateral line for spiral plate $2[\mathrm{~m}]$

$\mathrm{d}_{\mathrm{fl}} \quad$ Initial semicircle diameter of the central line of the spiral plate [m]

D Diameter [m; Equation (6-43): $\mathrm{ft}]$

$\mathrm{D}_{\mathrm{w}} \quad$ Porosity in wick (spacing) [m]

$\mathrm{D}_{\mathrm{e}}, \mathrm{D}_{\mathrm{h}} \quad$ Equivalent diameter or Hydraulic diameter $[\mathrm{m}],\left(\mathrm{D}_{\mathrm{e}}, \mathrm{D}_{\mathrm{h}}=4 \frac{\mathrm{A}_{\mathrm{f}}}{\mathrm{P}_{\mathrm{w}}}\right)$

$\overline{\mathrm{D}}_{\mathrm{Na}} \quad$ Average diameter $[\mathrm{m}],\left(\overline{\mathrm{D}}_{\mathrm{Na}}=\frac{\mathrm{D}_{\mathrm{Na}, \mathrm{v}}+\mathrm{D}_{\mathrm{Na}, \mathrm{L}}}{2}\right)$

f Friction factor

F Reynolds number factor $\left(\operatorname{Re} / \operatorname{Re}_{\mathrm{L}}\right)^{0.8}$

$\mathrm{F}_{\mathrm{c}} \quad$ Log mean temperature difference correction factor

$\mathrm{F}_{\mathrm{DA}} \quad$ Dengeler and Addoms correction factor

$\mathrm{F}_{\mathrm{N}} \quad$ Heat pipe fluid number

$\mathrm{g} \quad$ Gravitational constant $\left[\mathrm{m} \mathrm{s}^{-2}\right.$; Equations (6-39), (6-41): $\left.\mathrm{ft} \mathrm{s}^{-2}\right]$

$\Delta \overline{\mathrm{g}}_{\mathrm{f}} \quad$ Change in Gibbs free energy $\left[\mathrm{kJ} \mathrm{mole}^{-1}\right]$

$\mathrm{G}_{\mathrm{m}} \quad$ Mass flux $\left[\mathrm{kg} \mathrm{m}^{-2} \mathrm{~s}^{-1}\right]$

$\mathrm{h} \quad$ Convective heat transfer coefficient $\left[\mathrm{W} \mathrm{m} \mathrm{m}^{-2} \mathrm{~K}^{-1}\right.$;

Equations (6-34), (6-35), (6-36), (6-37), (6-38), (6-41), (6-43), (6-44): $\mathrm{Btu} \mathrm{hr}^{-1} \mathrm{ft}^{-2} \mathrm{deg} \mathrm{F^{-1 }}$ ]

$\mathrm{h}_{\mathrm{r}} \quad$ Radiative heat transfer coefficient $\left[\mathrm{W} \mathrm{m} \mathrm{m}^{-2} \mathrm{~K}^{-1}\right.$

$\mathrm{h}_{\mathrm{c}} \quad$ Combined convective and conductive heat transfer coefficient $\left[\mathrm{Wm}^{-2} \mathrm{~K}^{-1}\right]$

$\mathrm{h}_{\mathrm{fg}} \quad$ Latent heat of vaporization [ $\mathrm{kJ} \mathrm{kg}^{-1}$; Equations (6-39), (6-40), (6-41): Btu $\mathrm{lb}^{-1}$ ]

$\Delta \mathrm{h} \quad$ Specific enthalpy change of the transport fluid $\left[\mathrm{kJ} \mathrm{kg}^{-1}\right]$

$\Delta H_{R} \quad$ Enthalpy of reaction $\left[\mathrm{kJ} \mathrm{kg}^{-1}\right]$ 


\begin{tabular}{|c|c|}
\hline $\mathrm{K}$ & $\begin{array}{l}\text { Thermal Conductivity }\left[\mathrm{W} \mathrm{m} \mathrm{K}^{-1} \mathrm{~K}^{-1}\right] \\
\left.\text { Equations }(6-35),(6-37),(6-38),(6-39),(6-40),(6-41): \mathrm{Btu} \mathrm{hr}^{-1} \mathrm{ft}^{-1} \mathrm{deg} \mathrm{F}^{-1}\right]\end{array}$ \\
\hline$l, \mathrm{~L}$ & Length of the thermosyphon or heat pipe used in dimensionless analysis $[\mathrm{m}]$ \\
\hline $\mathrm{L}_{\mathrm{a}}$ & Adiabatic section length $[\mathrm{m}]$ \\
\hline $\mathrm{L}_{\mathrm{c}}$ & Condenser section length $[\mathrm{m}]$ \\
\hline $\mathrm{L}_{\mathrm{e}}$ & Evaporator section length [m] \\
\hline$L_{f}$ & Length of the central line of the spiral passage $[\mathrm{m}]$ \\
\hline$\dot{\mathrm{m}}$ & Mass flow rate $\left[\mathrm{kg} \mathrm{s}^{-1}\right]$ \\
\hline $\mathrm{n}_{\mathrm{di}}$ & Integer in the number of rounds \\
\hline$n_{\text {odi }}$ & Decimal in the number of rounds \\
\hline $\mathrm{n}_{0}$ & Variable \\
\hline $\mathrm{N}$ & Number of spiral turns \\
\hline $\mathrm{P}$ & Pressure $[\mathrm{Pa}]$ \\
\hline $\mathrm{P}_{\mathrm{c}}$ & Capillary pressure $[\mathrm{Pa}]$ \\
\hline $\mathrm{P}_{\mathrm{V}}$ & Vapor pressure inside the nucleus $[\mathrm{Pa}]$ \\
\hline$P_{L}$ & $\begin{array}{l}\text { Imposed liquid pressure corresponding to a saturation temperature } \mathrm{T}_{\text {sat }} \\
\text { [Pa] }\end{array}$ \\
\hline$P_{g}$ & Gas pressure in cavity at nucleation (due to dissolved gas, such as air) $[\mathrm{Pa}]$ \\
\hline $\mathrm{P}_{\mathrm{w}}$ & Wetted perimeter $[\mathrm{m}]$ \\
\hline $\mathrm{P}_{\mathrm{z}}$ & Pressure gradient for the mixture along $\mathrm{z}$ direction $[\mathrm{Pa}]$ \\
\hline$\Delta \mathrm{P}$ & Pressure drop $[\mathrm{Pa}]$ \\
\hline$\Delta \mathrm{P}_{1}$ & Difference in vapor pressure corresponding to $\Delta T$ [Equation 41: psf] \\
\hline q & Heat Transfer [W] \\
\hline Q & Process heat rate from NGNP [W] \\
\hline $\mathrm{Q}_{\mathrm{H}}$ & Heat Transfer corresponding to $\mathrm{T}_{\mathrm{H}}\left[\mathrm{kJ} \mathrm{kg}^{-1}\right]$ \\
\hline $\mathrm{Q}_{\mathrm{L}}$ & Heat Transfer corresponding to $\mathrm{T}_{\mathrm{L}}\left[\mathrm{kJ} \mathrm{kg}^{-1}\right]$ \\
\hline$Q^{\prime \prime}$ & Rate of thermal energy transport per unit flow area $\left[\mathrm{Wm}^{-2}\right]$ \\
\hline$\Delta \mathrm{Q}$ & Net gain from insulation $\left[\mathrm{Wm}^{-1}\right]$ \\
\hline $\mathrm{r}$ & Radius $[\mathrm{m}]$ \\
\hline $\mathrm{r}_{\mathrm{b}}$ & Radius of bubble (m; Equations (6-38), (6-39): ft) \\
\hline$r_{0}$ & Outer radius of insulation $[\mathrm{m}]$ \\
\hline$r_{i}$ & Inner radius of the insulation $[\mathrm{m}]$ \\
\hline
\end{tabular}




\begin{tabular}{|c|c|}
\hline $\mathrm{r}_{01}$ & Pole radius of the inner lateral line starting point for spiral plate $1[\mathrm{~m}]$ \\
\hline $\mathrm{r}_{02}$ & Pole radius of the inner lateral line starting point for spiral plate $2[\mathrm{~m}]$ \\
\hline $\mathrm{R}$ & Radius of the duct $[\mathrm{m}]$ \\
\hline $\mathrm{R}_{0}$ & Minimum spiral-coil radius $[\mathrm{m}]$ \\
\hline $\mathrm{R}_{\mathrm{N}}$ & Average radius of curvature value $[\mathrm{m}]$ \\
\hline $\mathrm{S}$ & Specific entropy $\left[\mathrm{kJ} \mathrm{K}^{-1}\right]$ \\
\hline S & Suppression function, $\left(\Delta \mathrm{T}_{\mathrm{e}} / \Delta \mathrm{T}\right)^{0.99}$ \\
\hline $\mathrm{S}_{\mathrm{d}}$ & Allowable design stress $[\mathrm{MPa}]$ \\
\hline$\Delta S_{R}$ & Entropy of reaction $\left[\mathrm{kJ} \mathrm{K}^{-1}\right]$ \\
\hline $\mathrm{T}$ & Temperature $\left[\mathrm{K}\right.$ or $\left.{ }^{\circ} \mathrm{C}\right]$ \\
\hline $\mathrm{T}_{\mathrm{i}}$ & Inner temperature of the insulation $[\mathrm{K}]$ \\
\hline $\mathrm{T}_{\text {ambient }}$ & Ambient temperature $[\mathrm{K}]$ \\
\hline $\mathrm{T}_{\mathrm{H}}$ & Higher temperature for the reservoir $[\mathrm{K}]$ \\
\hline $\mathrm{T}_{\mathrm{L}}$ & Lower temperature for the reservoir $[\mathrm{K}]$ \\
\hline $\mathrm{T}_{\mathrm{m}}$ & Log mean temperature difference $[\mathrm{K}]$ \\
\hline$\Delta \mathrm{T}$ & Superheat, T- $\mathrm{T}_{\mathrm{s}}[\mathrm{K}$; Equations (6-40), (6-41), (6-42): deg R] \\
\hline$\Delta \mathrm{T}_{\mathrm{e}}$ & Effective superheat with flow \\
\hline $\mathrm{U}$ & Overall heat transfer coefficient $\left[\mathrm{Wm}^{-2} \mathrm{~K}^{-1}\right]$ \\
\hline $\mathrm{v}$ & Specific volume $\left[\mathrm{m}^{3} \mathrm{~kg}^{-1}\right]$ \\
\hline $\mathrm{v}_{\mathrm{fg}}$ & Specific volume change from liquid to vapor $\left[\mathrm{m}^{3} \mathrm{~kg}^{-1}\right]$ \\
\hline $\mathrm{V}$ & Average flow velocity $\left[\mathrm{m} \mathrm{s}^{-1}\right]$ \\
\hline $\mathrm{V}_{\mathrm{S}}$ & Sonic velocity $\left[\mathrm{m} \mathrm{s}^{-1}\right]$ \\
\hline $\mathrm{X}$ & Quality, weight fraction of vapor \\
\hline $\mathrm{X}_{\mathrm{tt}}$ & Martinelli Parameter, $\left(\frac{Z}{x}\right)^{0.9}\left(\frac{\rho_{v}}{\rho_{L}}\right)^{0.5}\left(\frac{\mu_{L}}{\mu_{v}}\right)^{0.1}$ \\
\hline $\mathrm{z}$ & Location [m] \\
\hline Z & Weight fraction of liquid \\
\hline
\end{tabular}

\section{Greek Symbols}

$\alpha \quad$ Inclination angle of the thermosyphon [degree]

$\alpha_{1} \quad$ Linear coefficient of thermal expansion $\left[\mathrm{K}^{-1}\right]$

$\alpha_{r} \quad$ Rate of change of radius [m] 


$\begin{array}{ll}\alpha_{0} & \text { Parameter defined in Table 6-1 } \\ \beta & \text { Parameter defined in Table 6-1 } \\ \beta_{\mathrm{S}} & \text { Vapor adiabatic compressibility }\left[\mathrm{Pa}^{-1}\right] \\ \gamma_{1} & \text { Parameter defined in Table 6-1 } \\ \gamma & \text { Ratio of Specific Heat } \\ \delta & \text { Parameter defined in Table 6-1 } \\ \delta_{\mathrm{t}} & \text { Thickness of spiral plate [m] } \\ \varepsilon & \text { Exponential parameter } \\ \varepsilon_{R} & \text { Bend factor of curved duct } \\ \rho & \left.\text { Density of the fluid [kg m }{ }^{-3} ; \text { Equations }(6-39),(6-40),(6-41): \mathrm{pcf}\right] \\ \sigma & \left.\text { Surface tension [N m }{ }^{-1} ; \text { Equation }(6-41): 1 \mathrm{~b} \mathrm{ft}^{-1}\right] \\ \mu & \left.\text { Dynamic viscosity [N s m-2; Equations }(6-40),(6-41): 1 \mathrm{bft}^{-1} \mathrm{hr}^{-1}\right] \\ \tau & \left.\text { Shear stress [N m }{ }^{-2}\right] \\ \theta & \text { Angle [radians] } \\ \varphi_{\mathrm{fo}} & \text { Friction factor multiplier } \\ \eta_{\mathrm{T}} & \text { Thermal to hydrogen efficiency of thermal water splitting process [\%] } \\ \Delta & \text { Difference }\end{array}$

\section{Subscripts}

$\begin{array}{ll}\text { b } & \text { Bubble } \\ \text { bo } & \text { Boiling } \\ 0 & \text { Stagnation vapor properties (in evaporator) } \\ \text { e } & \text { Evaporator section } \\ \mathrm{He} & \text { Helium } \\ \mathrm{i} & \text { Values ranging between } 1 \text { to } 3 \text { (i.e., representing different sections) } \\ \text { in } & \text { Inlet } \\ \mathrm{L} & \text { Liquid } \\ \mathrm{m} & \text { Mixture } \\ \mathrm{macro} & \text { Macroscopic } \\ \text { micro } & \text { Microscopic } \\ \text { max } & \text { Maximum } \\ \mathrm{Na} & \text { Sodium }\end{array}$




$\begin{array}{ll}\text { o } & \text { Original } \\ \text { ou } & \text { Outlet } \\ \text { TP } & \text { Two phase } \\ \text { V } & \text { Vapor } \\ 1,2,3 & \text { Location } \\ 1-5 & \text { Position number for Figure 3-3 and 3-4 }\end{array}$

\section{Fundamental Dimensions}

M Fundamental dimension representing mass [kg]

L Fundamental dimension representing length [m]

$\mathrm{T} \quad$ Fundamental dimension representing time [s]

$\theta \quad$ Fundamental dimension representing temperature [K]

\section{Dimensionless Numbers}

Ca Capillary number, $\left(C a=\frac{\mathrm{V}_{\mathrm{S}} \mu_{\mathrm{L}}}{\sigma}\right)$

$\mathrm{E}_{\mathrm{M}} \quad$ Dimensionless numbers as described by Equation (4-26)

$\mathrm{E}_{\mathrm{r}} \quad$ Dimensionless numbers as described by Equation (4-7)

$\mathrm{Nu} \quad$ Nusselt number, $\left(\mathrm{Nu}=\frac{\mathrm{h} D}{\mathrm{~K}}\right)$

Pe Peclet number, $(\mathrm{Pe}=\mathrm{Re} * \mathrm{Pr})$

Pr Prandtl number, $\left(\operatorname{Pr}=\frac{\mu \mathrm{Cp}}{\mathrm{K}}\right)$

$\operatorname{Re} \quad$ Reynolds number, $\left(\operatorname{Re}=\frac{\rho \mathrm{VD}_{\mathrm{h}}}{\mu}\right)$ 
This page intentionally left blank 


\section{Engineering Design Elements of a Two-Phase Thermosyphon to Transfer NGNP Thermal Energy to a Hydrogen Plant}

\section{INTRODUCTION AND BACKGROUND}

\subsection{Introduction}

Recent technological developments in next generation nuclear reactors have created renewed interest in nuclear process heat for industrial applications. The Next Generation Nuclear Plant (NGNP) will most likely produce electricity and process heat for use in hydrogen $\left(\mathrm{H}_{2}\right)$ production or other technologies such as iron ore extraction, coal gasification, and enhanced oil recovery. A thermal device is needed to use process heat to transfer the thermal energy from NGNP to an hydrogen plant in the most efficient way possible. A conceptual schematic of an advanced nuclear reactor coupled to an hydrogen production plant is shown in Figure 1-1.

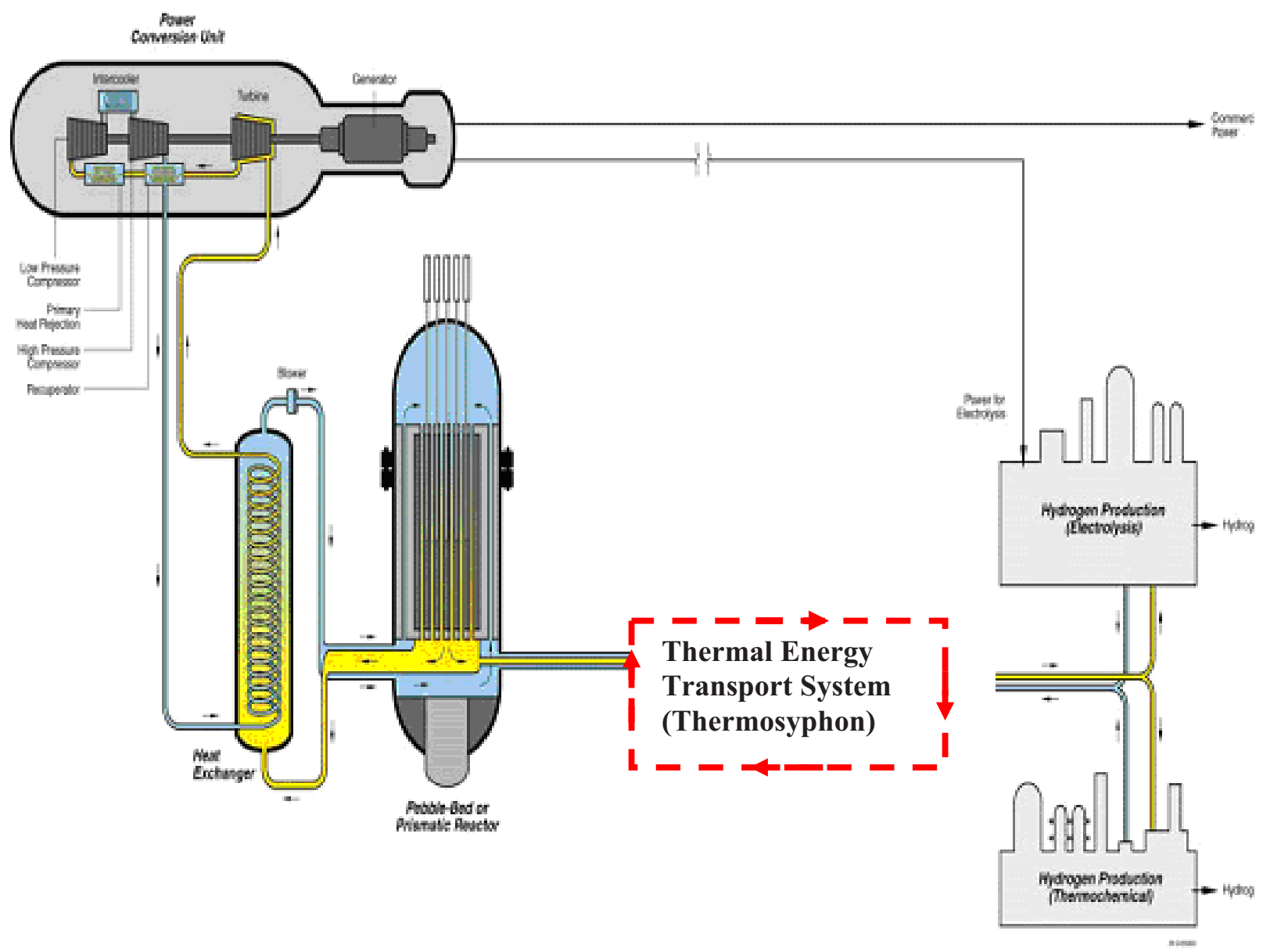

Figure 1-1. NGNP with process heat transfer (modified from NGNP Preliminary Project Plan 2007).

The high temperature gas-cooled reactor (HTGR) supplies thermal energy to drive a Brayton power cycle and process heat for high temperature electrolysis (HTE) or a thermochemical sulfur iodine (SI) 
hydrogen production process. Prismatic and pebble-bed advanced gas-cooled reactors are the primary reactor designs being considered to provide the high process heat required for hydrogen production. As Figure 1-1 shows, a portion of the hot helium outlet stream serves as the working fluid in a gas-turbine power cycle, and a separate helium stream flows through a high temperature heat exchanger, providing process heat to the hydrogen production plant. The heat transfer system is particularly challenging because of elevated temperatures (up to 1,300 K), industrial-scale power transport ( $50 \mathrm{MW}$ ), and the potentially large separation distance between the nuclear and industrial plants $(100+\mathrm{m})$ dictated by safety and licensing mandates.

Several options could transfer multi-megawatt thermal power over such a distance. One option is simply to produce only electricity, transfer it by wire to the hydrogen plant, and then reconvert the electric energy to heat via Joule heating. However, this option suffers energy losses of 60-70\% because of the thermal-to-electric conversion inherent in the Brayton cycle. A second option is thermal energy transport via a single-phase forced convection loop where a fluid is mechanically pumped between heat exchangers at the nuclear and hydrogen plants. However, the high temperatures required (up to 1,300 K) in this option present unique materials and pumping challenges. As previously determined by Davis et al. (2005), low pressure helium (He) is an attractive option for NGNP, but is not suitable for a single purpose facility dedicated to hydrogen production because low pressure helium requires higher pumping power and makes the process very inefficient. A third option is two-phase heat transfer utilizing a high temperature thermosyphon. One of the most significant advantages of heat transfer by thermosyphon is the characteristic of nearly isothermal, phase-change, heat transfer, which makes the thermosyphon an ideal candidate for applications where the temperature gradient is limited and high delivery temperatures are required; such is the case in thermochemical and high temperature electrolysis hydrogen production. The nature of isothermal heat transport results in an extremely high thermal conductance (defined as the heat transfer rate per unit temperature difference). The report presents design considerations for a thermosyphon system to transfer thermal energy from NGNP to the hydrogen production facility.

\subsection{Historical Development and Background of Thermosyphon and Heat Pipe}

Natural convection refers to the process wherein heat, transferred to a fluid, raises its temperature and reduces its density, giving rise to buoyant forces that lift the fluid (due to density difference) and transport the absorbed heat to some other location where it can be removed. Natural convection occurs in a similar manner in two-phase systems. Here, the application of the liquid phase produces a low-density vapor that is free to rise through the liquid and condense at some other location. In either case, continuous circulation of the heat transfer fluid is maintained (Silverstein 1992).

The Perkins tube, a two-phase flow device, is attributed to Ludlow Patton Perkins in the mid nineteenth century. As shown in Figure 1-2, the Perkins tube, which was actually a single-phase, closed-loop thermosyphon, was used to transfer heat from the furnace to the evaporator of a steam boiler (Reay and Kew 2006). A demonstration of the excellence of this design is the air expansion tube, which provides a space for the air inside the tube when the liquid (water) expands and also functions as a valve for regulating the operating pressure. Early applications of the Perkins tube include steam generation, domestic heating, warming greenhouses, preventing window fogging, removing heat from dairy products, cooling car engines, and in heat exchangers. The development of modern thermosyphon technology and applications did not start until the 1940s. In 1942 and 1944, Gaugler proposed a two-phase closed thermosyphon tube incorporating a wick or porous matrix for capillary liquid return. In 1963, Grover studied this phase heat transfer device and named it "heat pipe" (Cheng and Zarling 1993). Tremendous effort has since been invested in thermosyphon and heat pipe research, resulting in broad applications. The heat pipe differs from the thermosyphon by virtue of its ability to transport heat against gravity by an evaporation-condensation cycle. 


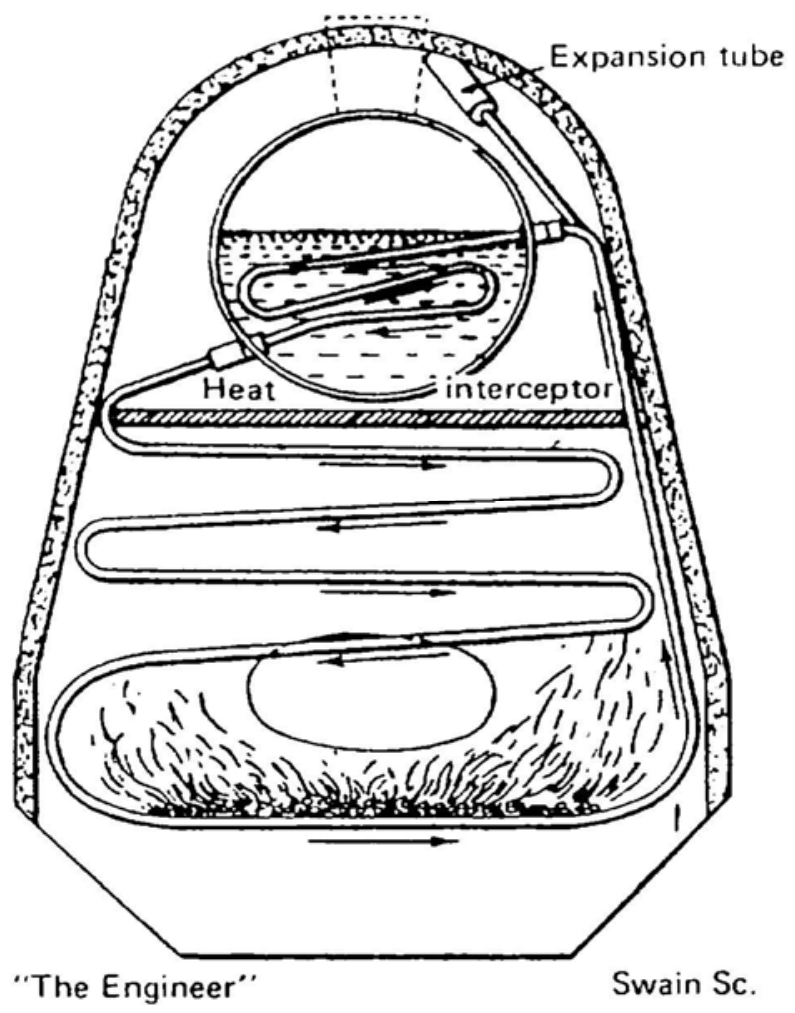

Figure 1-2. Perkins boiler (Reay and Kew 2006).

Thermosyphon heat transfer has certain operating and limiting mechanisms that need to be considered before further discussing thermosyphon technologies and applications. Figure 1-3 illustrates a typical two-phase closed thermosyphon, which consists of a metal pipe with a fixed amount of working fluid sealed inside. During operation, heat is added through the bottom section (evaporator) and the working fluid becomes vapor. The vapor travels through the middle section (adiabatic section) to the top section (condenser) of the tube. In the condenser, the vapor releases the latent heat to the condenser wall and becomes liquid. In contrast to a heat pipe, which utilizes capillary forces for liquid return, the thermosyphon relies on gravitational or centrifugal force to return the condensed liquid to the evaporator.

Heat transfer performance of the thermosyphon is a function of many factors, including properties of the working fluid, geometry and orientation of the thermosyphon, gravity field, and operating temperature or pressure. Fundamental heat transfer theory dictates that any mode of heat transfer is driven by a temperature difference and the larger the temperature difference $\left(\mathrm{T}_{\text {hot }}-\mathrm{T}_{\text {cold }}\right)$, the higher the heat transfer rate. However, in many applications, it is desirable to transport large amounts of heat over a long distance, but at a relatively small temperature difference $\left(\mathrm{T}_{\mathrm{in}}-\mathrm{T}_{\mathrm{ou}}\right)$. Inside an operating thermosyphon, the vapor (at constant saturation temperature) carries a large amount of latent heat from the evaporator to the condenser. One of the most significant advantages of the thermosyphon heat transfer is the characteristic of nearly isothermal phase change heat transfer, which makes the two-phase thermosyphon an ideal candidate for applications where the temperature gradient is limited. The characteristics of isothermal heat transfer results in an extremely high transfer coefficient (defined as the heat transfer rate per unit temperature difference). 


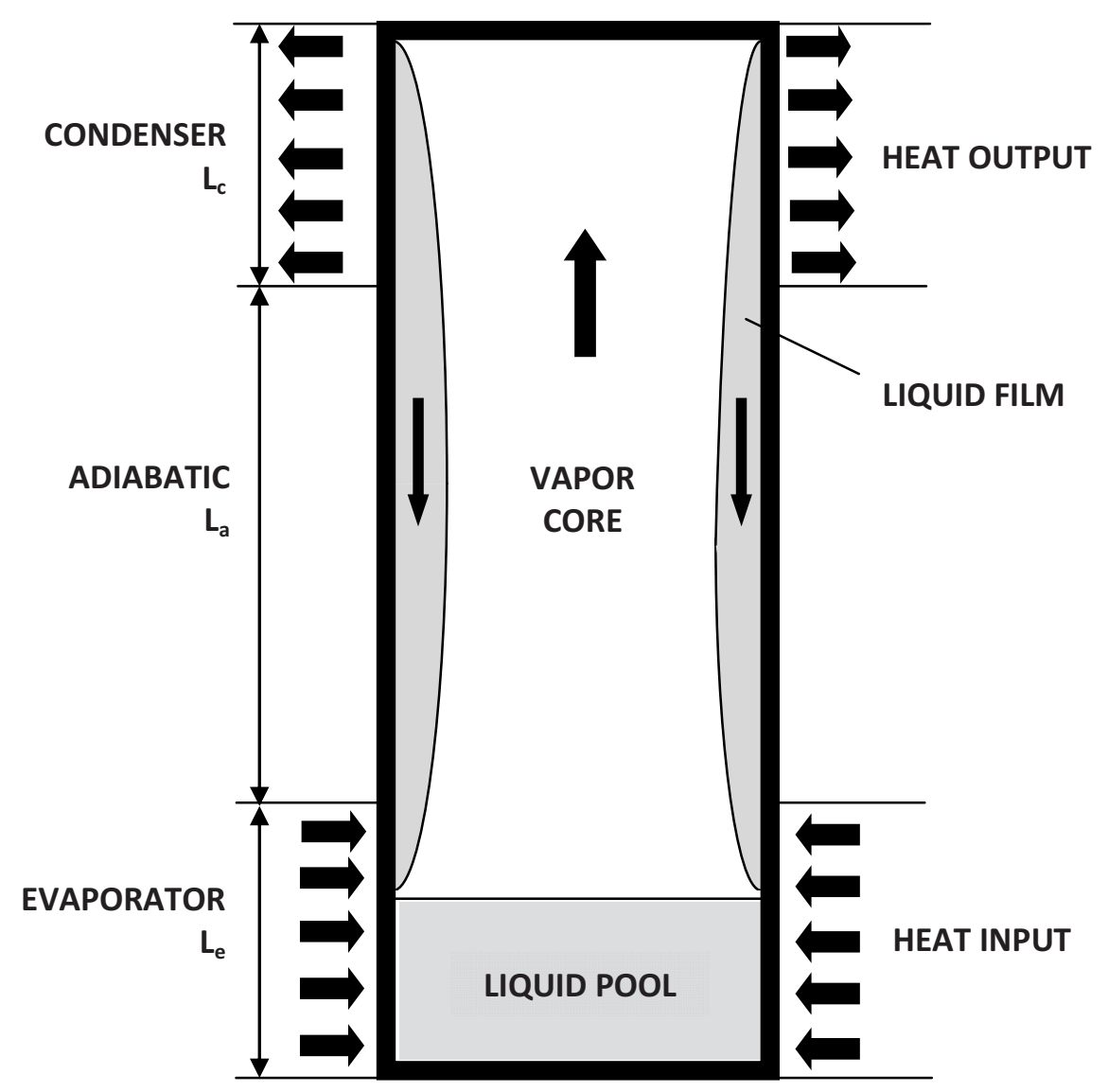

Figure 1-3. A typical two-phase closed thermosyphon.

The adiabatic section, which serves as the passage for vapor and liquid flows, can have various geometric structures. The flexibility in geometry makes the thermosyphons more welcome in applications where the geometric accommodation is restrained by the system. Another important advantage of the thermosyphon is the adjustable heat transfer performance. Unlike conventional heat transfer devices, which usually cannot be regulated and consequently always remain "on" in the presence of a temperature gradient, a thermosyphons' performance can be adjusted by tilting, altering the thermal reservoirs (heat source and sink), and regulating of the condensate return. This characteristic of controllable heat transfer is favored in many applications including thermal radiators in spacecraft where the heat load may drastically vary. The phase change cycle inside the thermosyphon itself is self-actuated and requires no external power (other than the heat supply) or auxiliary equipment, which makes the thermosyphon a reliable and low-cost heat transfer device. Because of these advantages, the thermosyphon is well suited for applications with challenging operating conditions and high reliability requirements, such as transferring process heat from the NGNP to the production facility. There have been many different types of thermosyphons developed for various applications. In addition to the most common circular two-phase thermosyphons (as shown in Figure 1-4), thermosyphons with triangular, rectangular, elliptic and concentric annular cross-sections have been widely used. 


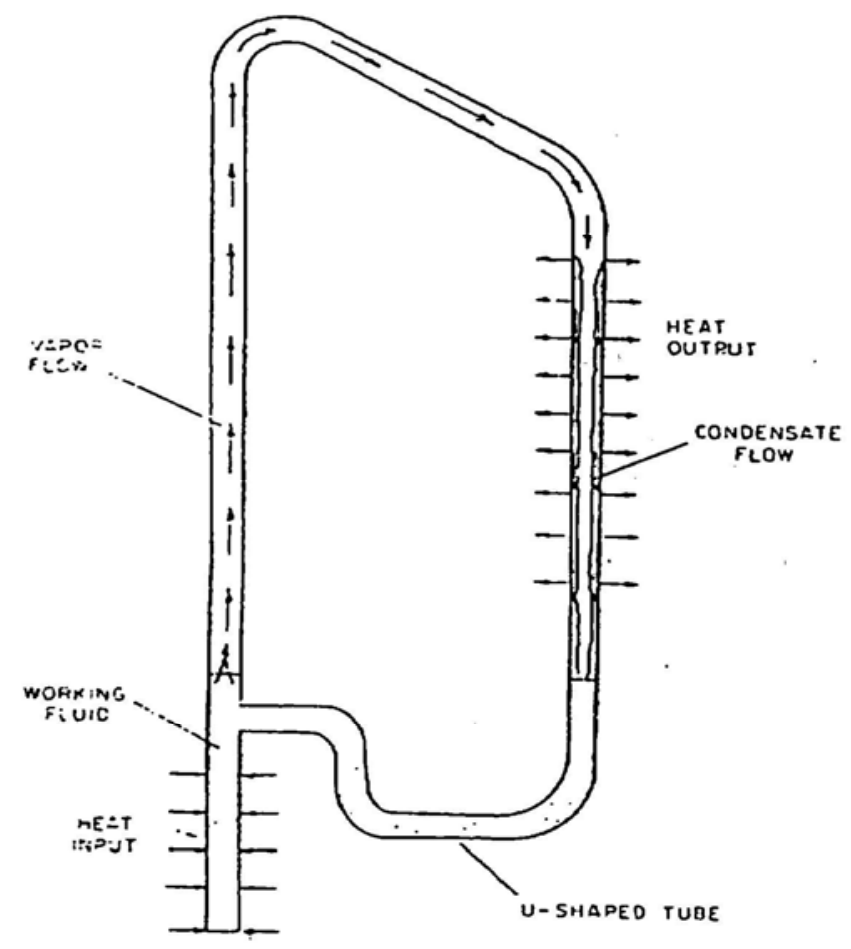

Figure 1-4. Two-phase closed U tube thermosyphon loop (Zuo 1995).

The only restriction on the geometric design of the condenser, adiabatic, or evaporator sections is that the condenser must be installed at a higher elevation than the evaporator to utilize gravitational force in returning the condensed liquid to evaporator. Thermosyphons have been designed with a vertical, horizontal, inclined, cranked, or flexible evaporator or condenser for various applications. Each section of the thermosyphon can have a different shape and dimension. Inside a counter-current type thermosyphon, the vapor core and the liquid film flow in opposite directions, resulting in liquid-vapor interfacial shear stress. The liquid-vapor interfacial shear stress can be very large for thermosyphons at high heat transfer levels because of the correspondingly large mass flow rate of the vapor. Once the interfacial shear force overcomes the gravitational force on the liquid film, the liquid flow may be reversed and the flooding limit is reached. Many novel designs have been put forward to improve the flooding limited thermosyphon heat transfer capacity, which include an internal physical barrier along the adiabatic section by-pass line for liquid return, a cross-over flow separator, and others. The main advantage of these designs is that the liquid and vapor flows have partially separate passages, which can result in a higher flooding-limited heat transfer capacity.

To reduce the reliance of thermosyphon operation on gravitational force and thus promote broader applications, several designs have been patented or published. Feldman (1987) invented a passive down-pumping thermosyphon and demonstrated his design later in the Heat Pipe Laboratory at the University of New Mexico. Feldman's system, as shown in Figure 1-5, uses a three-way passive pumping module (PPM) float control valve that allows switching the hot vapor flow to either the condenser during the heat transfer mode or to the accumulator during the pumping mode. The improvement in this design is that the evaporator can be located higher than the condenser. However, two main disadvantages include the discontinuity of heat transfer and reliability problems of floating control valves. 


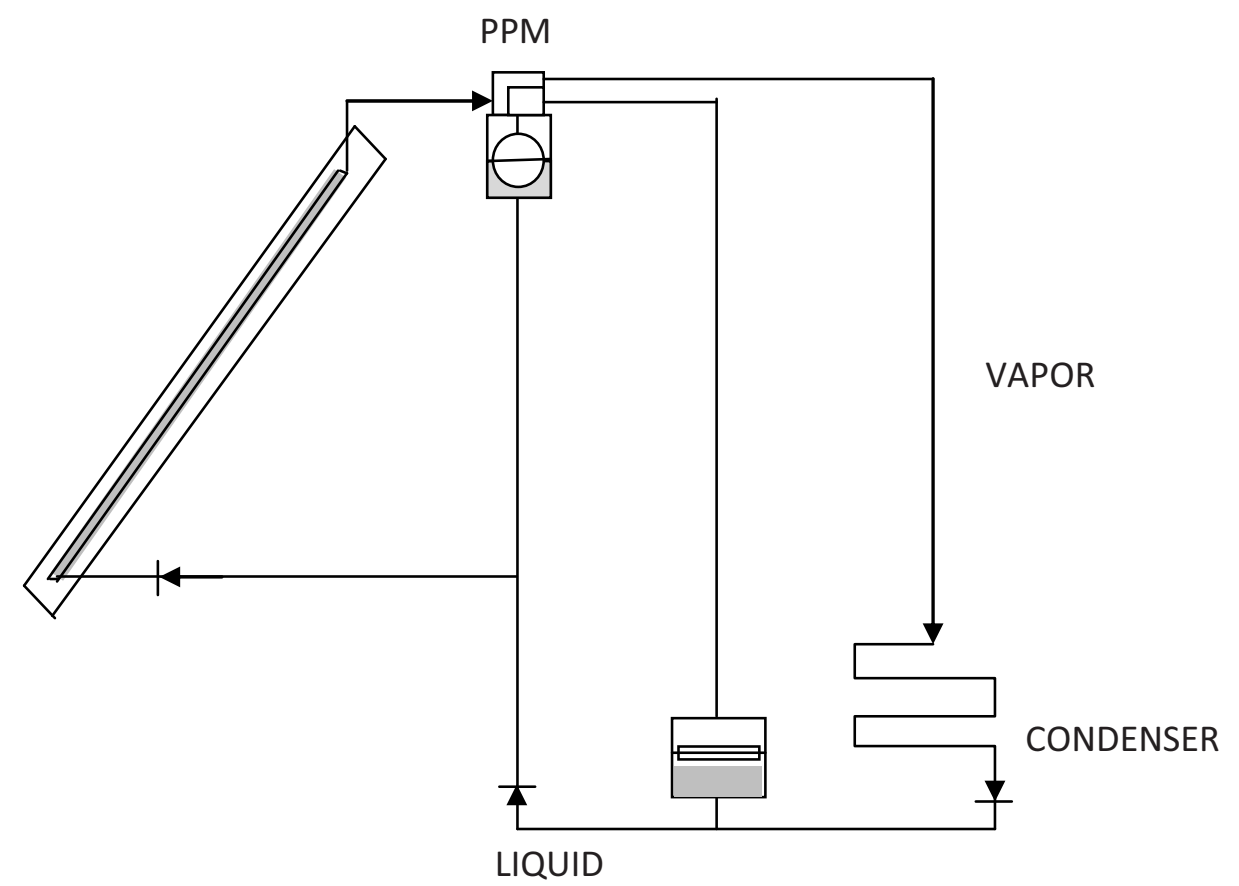

Figure 1-5. Evaporator-controlled two-accumulator PPM systems (Feldman 1987).

The work done here addresses industrial-scale recovery options for NGNP process heat. NGNP is a graphite-moderated, gas-cooled reactor intended to deliver high temperature fluids that can be used in generating electricity, producing hydrogen, and other process applications. In contrast to single-phase, forced convective heat transferred by pumping a fluid through a thermosyphon (also called a wickless heat pipe) transfers latent heat through the vaporization/condensation process. It uses a highly efficient, controllable, and nearly isothermal vapor heat transfer process with gravity liquid return, and requires no pumps or compressors. It can deliver heat to the industrial plant with essentially no temperature loss. The work done here also analyzes the development of new heat transfer methodology - fluids ( Li [lithium], $\mathrm{Na}$ [sodium], K [potassium], and Cs [cesium]), material needs for the construction of the thermosyphon, understanding the physics behind thermosyphon performance based on thermodynamics, analyzing phase change liquid metal spiral heat exchanger (SHE), which enables the thermal system to have enhanced efficiency and economic benefits. This research provides valuable insight and options useful in the design and development of NGNP process heat recovery.

\subsection{Heat Pipes and Thermosyphon}

The heat pipe shown in Figure 1-6 is essentially a constant temperature, heat transfer device. It consists of a closed container in which vaporization and condensation of a fluid takes place. The choice of a fluid depends on the temperature range in which the heat pipe will be used. Heat is applied to one end of the heat pipe (evaporator), which raises the local temperature leading to evaporation of the working fluid. Because of the saturation conditions this temperature difference results in a difference in vapor pressure, which in turn causes vapor to flow from the heated section to the cold section of the pipe (condenser). The rate of vaporization is equal with heat absorbed in the form of latent heat of evaporation. The resulting condensate is returned to the heated end (evaporator) of the container by the action of capillary forces in the liquid layer, which is contained in a wick lining inside the cavity. A typical wick might consist of layers of metal screen or some porous metallic structure. A wick is used in the heat pipes to return the working fluid from the condenser to the evaporator. 


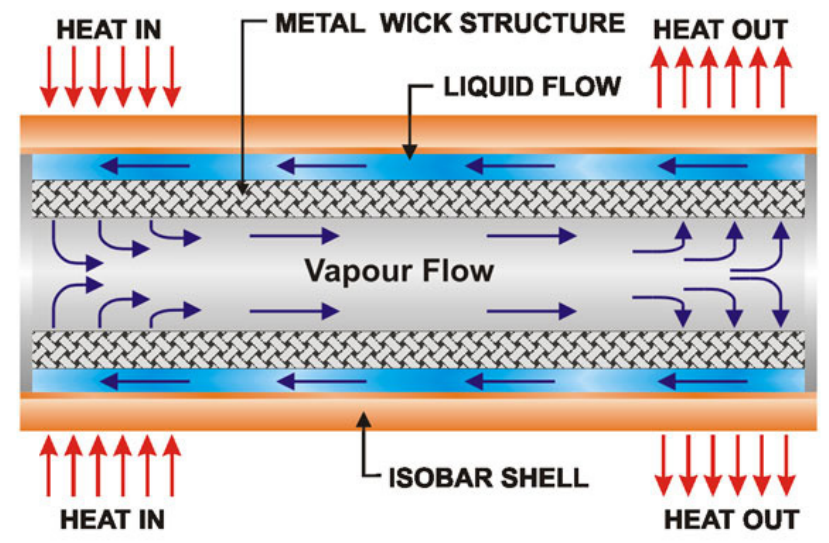

Figure 1-6. The main regions of the heat pipe (www.acrolab.com). ${ }^{a}$

Wicking material is used in regions to facilitate the path of the vapor to the pipe. Typically a good wicking material maximizes the movement of the fluid, has uniform porosity, has very small pores such that the wick can generate a large capillary pressure, is resistant to degradation by temperature, and does not react or degrade chemically with the working fluid. Heat pipes can have a number of different geometric configurations. These configurations include cylindrical, spherical, square, or any other geometry such that inner volume of the heat pipe forms a channel from the evaporator section to the condenser section. Metals used to fabricate the heat pipes should be compatible with the working fluid as well as with the external media in contact with the evaporator and the condenser. The outermost shell of the heat pipe is referred to as the container. The container encloses the functioning parts of the heat pipe and provides structural rigidity. The liquid flow takes place in a porous material usually referred to as wick. The interior space of the heat pipe is called the vapor core, which provides passage for the vapor flow. Heat pipes have been used extensively in a variety of energy storage systems such as chemical reactors and space craft temperature equalization. Heat pipes are well suited to thermal storage systems, particularly in the roles of heat delivery and removal, because of their highly effective thermal conductivity and passive operation.

The heat pipe, as can be seen in Figure 1-7, is similar to a thermosyphon in some respects; the main difference is the mechanism in which the fluid is returned from the condenser to the evaporator section. The operation of a heat pipe relies on the capillary head within the wick, which is sufficient to overcome the pressure drops associated with the liquid and vapor flow and the gravitational head. In a thermosyphon, the condensate is further returned to the hot end (evaporator) by gravity. Since the latent heat of evaporation is large, a considerable amount of heat can be transported with a very small temperature difference from end to end. The main limitation of the thermosyphon is that the evaporator region has to be located at the lowest point in the system so that the condensate can be returned to the evaporator region by gravitational force. In the case of a heat pipe, a wick is constructed from a few layers of fine gauze fixed to the inside surface, and the capillary forces return the condensate to the evaporator. The heat pipe has more flexibility in terms of evaporator location, but having the evaporator region in the lowest position will allow gravitational forces to assist the capillary forces.

a. "Heat Pipe-Main Regions of Heat Pipe," available at http://www.acrolab.com accessed on 14 $4^{\text {th }}$ May, 2008. 


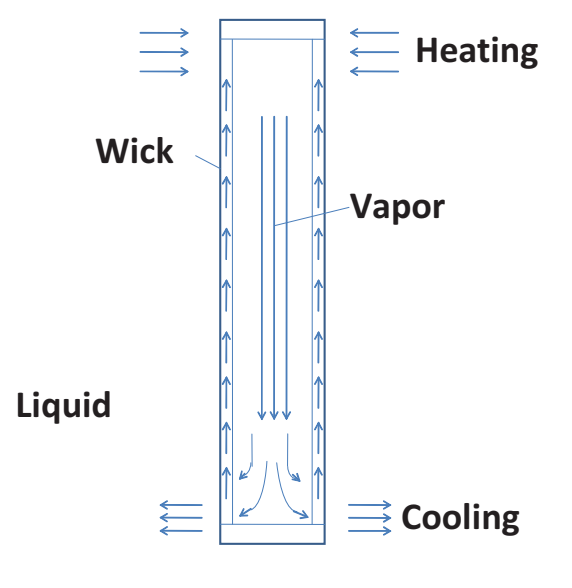

(a) Heat pipe

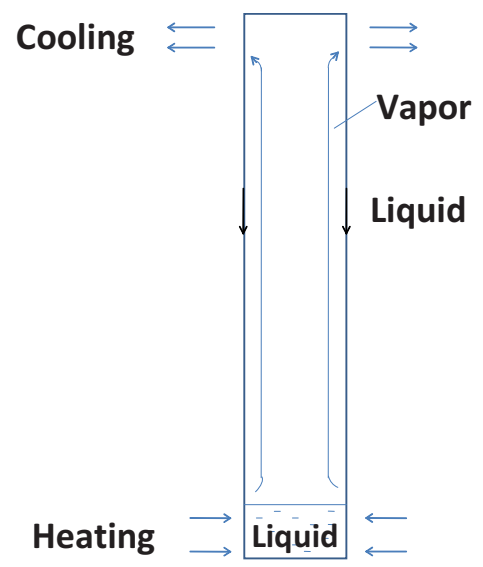

(b) Thermosyphon

Figure 1-7. The heat pipe and thermosyphon (Reay and Kew 2006).

\subsection{Application of Heat Pipes and Thermosyphons}

Thermal energy devices such as heat pipes and thermosyphons possess many advantages such as high heat recovery effectiveness, high compactness, no moving parts, and high reliability. Since the 1970s, heat pipes and thermosyphons have been extensively applied as waste heat recovery systems in many industries such as energy engineering, chemical engineering, and metallurgical engineering (Noie 2005). The heat pipe has been, and currently is being, studied for a wide variety of applications, covering almost the complete spectrum of temperatures encountered in heat transfer processes (Reay and Kew 2006). The ability of the heat pipe to transport heat over appreciable distances without any need for external power to circulate the heat transfer fluid is one of its most useful properties. Elimination of the fluid pump and power supply leads to greater reliability of the heat transport system and reduced weight, in addition to the saving in power consumption (Silverstein 1992).

Heat pipes and thermosyphons have the following unique characteristics:

1. High heat transport capability due to latent heat

2. Small temperature variations

3. The ability to act as a heat flux transformer

4. Heat transfer in one direction only (thermal diodes and switches)

5. Passive heat transfer device

6. Separation of heating (heat source) and cooling (heat sink) parts

7. Heat transport capability through long distance

8. Constant temperature control (variable conductance heat pipe)

9. Heat transport with low temperature drop between heat source and sink.

Heat pipes and thermosyphons have the ability to transport very large quantities of heat with small temperature differences over relatively long distances. The applications of heat pipes and thermosyphons require heat sources for heating and heat sinks for cooling. The original development of the heat pipe and thermosyphon was directed towards space applications. The recent emphasis on energy conservation has promoted the use of the heat pipe and thermosyphon as a component in terrestrial heat recovery units and solar energy utilizations. For a thermosyphon the thermal resistance is smaller, the operating limits are 
wider (as in a heat pipe the integrity of the wick material might not hold at very high temperatures), and the fabrication cost is lower than that of the capillary heat pipe, which makes a thermosyphon a better heat recovery thermal device. Primarily, the most important aspect of the thermosyphon is that it can easily be turned off when required, whereas a heat pipe cannot be turned off. This added safety feature of a thermosyphon makes licensing of the NGNP process heat transfer system comparatively easier. The results of research and development on heat pipes and thermosyphons over the past 25 years are well documented.

Heat pipes are classified according to operating temperature ranges, as follows (Reay 2006):

1. Cryogenic heat pipes, $\mathrm{T}<200 \mathrm{~K}$

2. Low temperature, $200<\mathrm{T}<550 \mathrm{~K}$

3. Medium temperature, $500<\mathrm{T}<750 \mathrm{~K}$

4. High temperature, $750<\mathrm{T}<2800 \mathrm{~K}$.

The physical size and configuration of heat pipes and thermosyphons can vary widely. Thermosyphons have become a unique and versatile heat transfer devices with a seemingly unlimited range of applications. Examples of these applications are presented below, but technical details are not included.

\subsubsection{Applications in Space Systems}

Space systems are one of the most important and original applications of heat pipes and thermosyphons. In 1968, heat pipes were used as components of the thermal control system in the American GEOS-2 satellite. China used heat pipes in a recoverable satellite in 1976 (Hou and Wen 1987). In the French-German TDF-1 and TV-SAT direct broadcasting satellite, a heat pipe network was incorporated for thermal control (Amidieu et al. 1987). Japan has developed heat pipe payload radiators for its 2-ton geostationary satellite (Mitsuma et al. 1987). Heat pipes and thermosyphons were proposed to cool the leading edge of returning hypersonic vehicles to reduce drag forces (Chen and Faghri 1990).

\subsubsection{Applications in Cold Regions}

\subsubsection{Ground Temperature Control}

Heat pipes and thermosyphons were originally designed to transport heat in power plants for space vehicles in the 1960s, but the basic technology was applied to the largest terrestrial application project in the 1970s involving the extensive use of heat pipes for the stabilization of permafrost (perennially frozen ground) in the construction of the Trans-Alaska Pipeline System (TAPS). This well known application of heat pipes runs $1,285 \mathrm{~km}$ long and transports crude oil from Prudhoe Bay in Alaska's North Slope to the ice-free port of Valdez on Alaska's south coast. To ensure foundation stabilization, the permafrost layers must be preserved during any season. Due to their large heat transfer efficiency and high reliability, heat pipes were chosen as the thermal

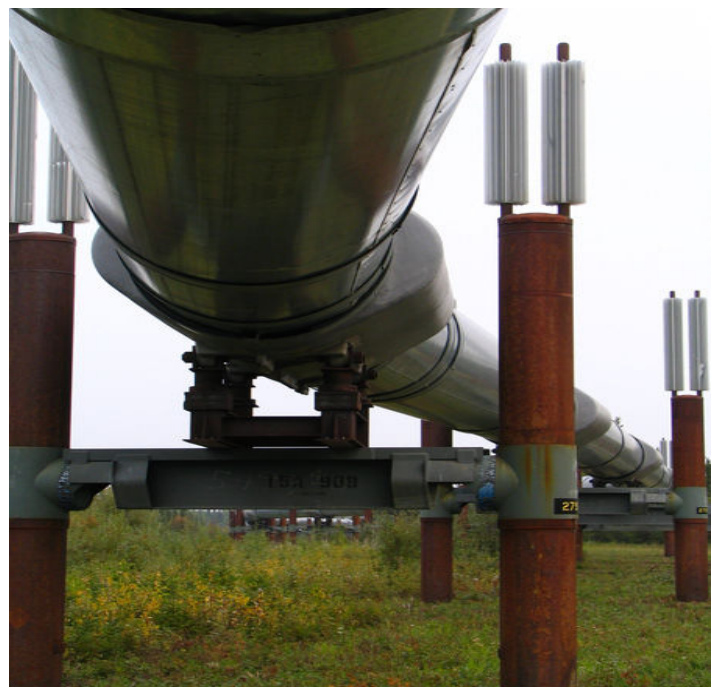

Figure 1-8. Typical vertical support member with heat pipes for trans-Alaska oil pipeline. ${ }^{b}$

b. Typical Vertical Support Member with Heat Pipes for Trans-Alaska Oil Pipeline," available at

http://en.wikipedia.org/wiki/Image:Alaska_Pipeline_Closeup_Underneath.jpg accessed on $14^{\text {th }}$ June, 2007. 
control device for permafrost preservation. As shown in Figure 1-8, heat pipes extract heat from the ground during the winter, forming an ever increasing block of frozen soil bulb beneath the support pilings to prevent frost heave and differential thaw settlement. In the summer, the vertical heat pipes act as thermal diodes and prevent heat transfer into the soil. Over 122,000 ammonia-charged closed heat pipes were installed along the entire pipeline (Cheng and Zarling 1993). Heat pipes were made of mild carbon steel; ammonia was chosen as the working fluid.

\subsubsection{Snow Melting and Deicing System}

Thermosyphons have been used to de-ice and melt snow on roofs, roadways, ramps, bridges, airport runways, etc. In 1970, Bienert et al. proposed the use of gravity operated heat pipes to transport low grade energy from the ground beneath runways and highway structures to the surface in order to reduce or possibly prevent their icing. This idea has been tested by placing heat pipes in a small concrete slab at the Fairbank Highway Research Station in McLean, Virginia, and in a $366 \mathrm{~m}$ long interchange ramp in Oak Hill, West Virginia. The technical feasibility of the heat pipe extracting heat stored in the ground for de-icing and removing ice from pavement surfaces has been demonstrated (Cheng \& Zarling 1993).

\subsubsection{Application in Automobile Industry}

Mercedes-Benz has used heat pipes and thermosyphons in its passenger cars to recover exhaust heat for cabin heating and prevention of window fogging (Munzel 1987).

\subsubsection{Application in Railroad Industry}

The Hudson Bay Railroad in Canada runs $820 \mathrm{~km}$ from the Pas, Manitoba, to Churchill, Manitoba, on Hudson Bay. The route passes over seasonal, discontinuous, and permafrost terrain. Thaw settlement of localized zones, referred to as sinkholes, has occurred along the line. A total of 40 ammonia charged thermosyphons were installed at four test sites along the railroad right-of-way in 1978. Temperature monitoring has shown a decrease in ground temperature over a 4-year period indicating the successful application of thermosyphons to stabilizing the thaw settlement problem (Cheng \& Zarling 1993).

\subsubsection{Application in Electrical, Electronics, and Nuclear Industries}

The particular purpose of industrial application of heat pipes/thermosyphons is to save energy and material, raise the quality of products by conditioning thermal parameters, and intensify cooling in electro-techniques, mechanical engineering and chemical industry.

\subsubsection{Electrical Industry}

So far, research in using heat pipes in electrical industry has been aimed at cooling electric motors, power semiconductor elements, power supply sources, acoustic techniques, magnets, plasma cathodes, etc. (Gerak et al. 1987). More and more heat pipes and thermosyphons are being used to cool electronic circuits on the micro scale. The original technique was to attach the thermosyphon or heat pipe directly to the hot spots. However, large contact thermal resistance can significantly affect heat transfer capacity. Some laboratory experiments have shown the feasibility of incorporating thermosyphons or heat pipes as integral parts of the circuit substrate by etching the flow channels directly into the silicon wafer to form the thermosyphons or heat pipes (Peterson et al. 1993). 


\subsubsection{Electronics}

Closed loop two-phase thermosyphon (CLTPT) involving co-current natural circulation was modeled and consisted for four major components: evaporator, rising tube, condenser, and falling tube (Haider et al. 2002).

\subsubsection{Heating and Cooling}

A novel method for controlling and regulating wickless heat pipes has been developed and tested at the University of Central Florida Heat Transfer Laboratory. However, the unique design presented allows the system to be controlled during operation from the "off" to "fully on" positions, thereby permitting control of the heat transfer rate. In addition, the method of control can be extended so that a single heat pipe system may be used for both heating and cooling without requiring any physical modifications (Gunnerson and Sanderlin 1994).

\subsubsection{Passive Decay Heat Removal System of the Modular HTR}

One of the key features of the Modular HTR is the ability of passive decay heat removal under the primary system depressurization accident or the loss of forced circulation accident. The passive decay heat removal is performed by the cooling system installed outside the reactor pressure vessel. Decay heat of the core is passively transferred by radiation and convection to the reactor pressure vessel and then to the decay heat removal system. The evaporator part of the heat pipe is installed on the reactor cavity wall. In the evaporator part, the heat from the reactor pressure vessel is changed into the latent heat of the working fluid and flows to the condenser part outside of the reactor building. The condenser part comprises heat exchanging pipes cooled by the atmospheric air through natural convection strengthened by the stack. Decay heat of the core is transferred to the atmosphere in this condenser part, and condensed working fluid returns to the evaporator part by gravity. In this system there are no active components and the core decay heat is removed by fully passive measures (Ohashi et al. 1998).

\subsubsection{Summary Statement}

Based on the above discussion, one can concluded that heat pipes and thermosyphons have become unique and versatile heat transfer devices with seemingly unlimited applications.

\subsection{Hydrogen Production Process}

The objective of this discussion is to propose a reengineered world energy supply architecture optimized for nuclear rather than fossil fuel. The development of very high temperature reactor technologies for the production of hydrogen and other energy products, and technologies to close the nuclear fuel cycle is a high priority research and development issue for a successful nuclear future. Over time, this nuclear-driven energy supply architecture would displace fossil based architecture, providing energy to support a global energy infrastructure that meets all aspects of sustainable, development-secure longevity, ecological compatibility, and social acceptability. Electricity itself can be used for producing hydrogen by electrolysis of water, but this involves conversion of thermal energy (generated in the nuclear reactor) to electrical energy - an inefficient conversion step. The overall efficiency of electrolytic hydrogen production can be improved by conducting the electrolysis of water vapor at high temperature (high temperature electrolysis or HTE), which has reduced electrical energy requirements as compared to the conventional alkaline electrolysis. The thermochemical SI cycle uses thermal energy directly, avoiding the thermal-to-electrical energy conversion, and is potentially more attractive as the process alternative for hydrogen production. Both the HTE and the SI process are in the early stages of development, but the transfer of thermal energy (heat) from the NGNP to the hydrogen production facility is required for either process. 


\subsection{Hydrogen Production through HTE}

A leading candidate technology for large-scale hydrogen production is the high-temperature electrolysis of steam (HTES). HTES uses a combination of thermal energy and electricity to split water in a solid-oxide electrolysis fuel cell (Hoogers 2003). Solid-oxide fuel cells (SOFCs) have been studied extensively for their application to power generation systems. SOFCs operate at high temperatures (600 to $1,000^{\circ} \mathrm{C}$ ), which allows for internal reforming, promotes rapid kinetics with nonprecious materials, and produces high-quality process heat as a byproduct (Larminie and Dicks 2000).

From a thermodynamic standpoint, the electrical energy demand for electrolysis, represented by the Gibbs free energy change $\Delta \overline{\mathrm{g}}_{\mathrm{f}}$, decreases with temperature. However, for large-scale hydrogen production, operating temperatures will probably be limited to the range of 800 to $850^{\circ} \mathrm{C}$, even with coupling to a high-temperature advanced reactor.

High-temperature electrolytic water splitting supported by nuclear process heat and electricity has the potential to produce hydrogen with an overall system efficiency near those of the hydrocarbon and the thermochemical processes, but without the corrosive conditions of thermochemical processes and without the fossil fuel consumption and greenhouse gas emissions associated with hydrocarbon processes (IAEA 1999). Specifically, a high-temperature advanced nuclear reactor coupled with a high-efficiency hightemperature electrolyzer could achieve a competitive thermal-to-hydrogen conversion efficiency of 45 to 55\% (Hori and Spitalnik 2004).

A conceptual schematic of an advanced nuclear reactor coupled to a hydrogen production plant is shown in Figure 1-9. The reactor, in this case an HTGR, supplies thermal energy to drive the power cycle and heat steam for the electrolysis process.

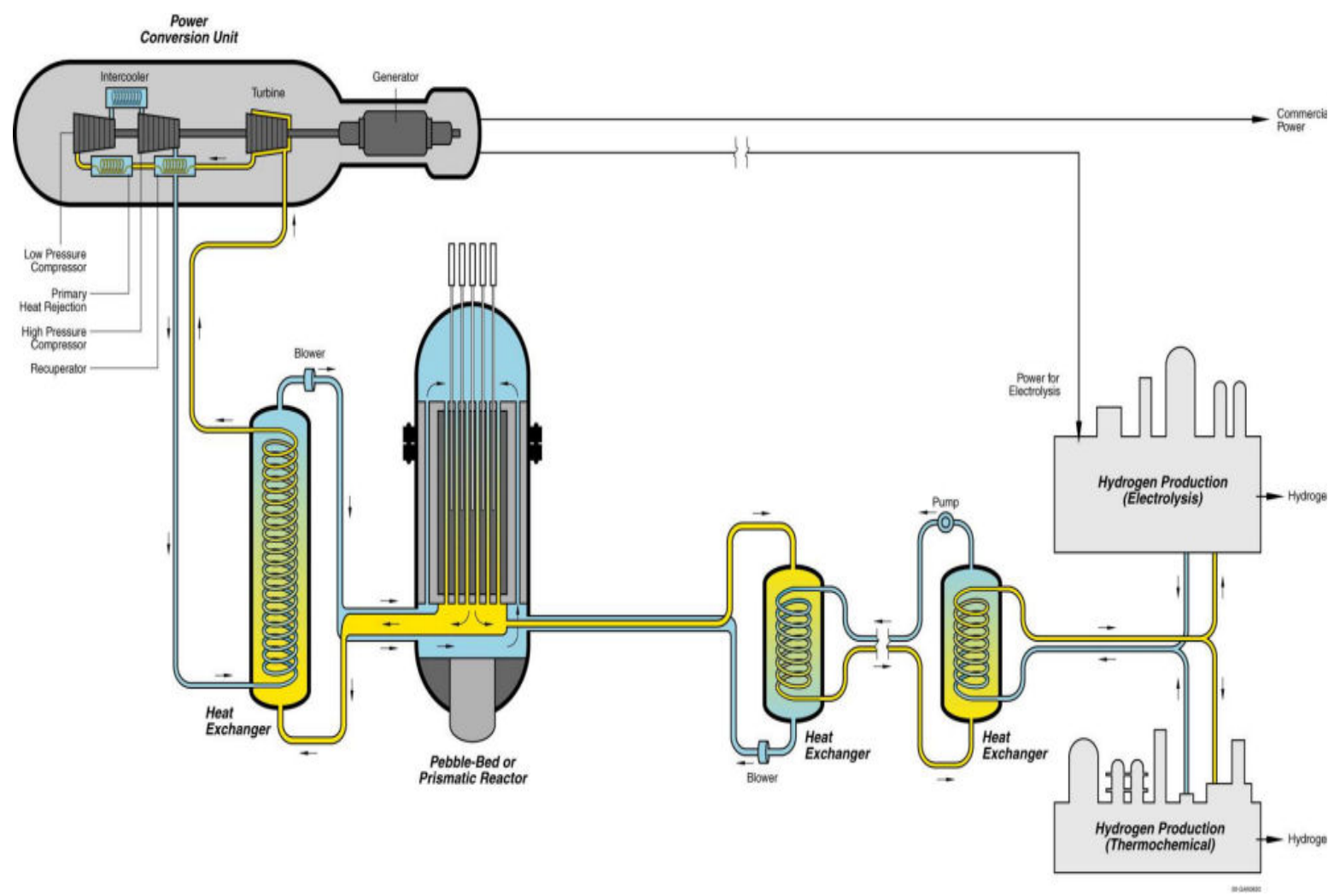

Figure 1-9. NGNP conceptual schematic of power generation and hydrogen production (NGNP Preliminary Project Plan June 2007). 
In the NGNP design, the primary helium coolant is heated in the reactor to outlet temperatures ranging from 850 to $1,000^{\circ} \mathrm{C}$. A portion of the hot helium outlet stream serves as the working fluid in a gas-turbine power cycle, and a separate helium stream flows through a high-temperature heat exchanger, providing process heat to a steam-hydrogen gas mixture. This gas mixture is then fed to a hightemperature steam electrolysis device, such as a regenerative solid-oxide cell, which produces one outlet stream of pure oxygen and another steam-hydrogen outlet stream that is significantly enriched in hydrogen. Both the steam-hydrogen stream and oxygen stream are mainly at pressures of $\sim 5 \mathrm{MPa}$. The steam-hydrogen outlet mixture is passed through a heat exchanger and a separator (e.g., steam condenser) to yield a high-purity hydrogen gas product.

Thermally insulated pipes would be used for transferring heat from the reactor (or the intermediate heat exchanger) to the hydrogen production facility (the chemical reactor). The distance can be a few hundred meters, which is not sufficient to consider them as independent facilities. On the contrary, they must be considered as belonging to the same installation (or site) where accidents in one can affect the other, which is why the use of a thermosyphon to transfer heat can be crucial.

Some specific safety issues will appear in relation to the coolant needed to reach high temperatures required for hydrogen production. Candidate coolants are gases (particularly inert gases), molten salts, molten metals (particularly lead), and alkali metals. In the case of gases, very high pressures needed for effective cooling can present a threat to the mechanical integrity of some containment barriers. Moreover, residual heat removal is difficult to achieve in some types of accidents after a depressurization.

Molten metals and salts can work at atmospheric pressure, but they can present severe problems of corrosion, which increase enormously with the temperatures. The nonexistence of data at high temperatures restricts the usage of molten metals and salts. In this analysis, alkali metals ( $\mathrm{Li}, \mathrm{Na}, \mathrm{K}$, and $\mathrm{Cs}$ ) were used as the working fluids and the best available working fluid is proposed for the process heat transfer system.

The HTE plant would be devoted primarily to the production of hydrogen, although it is important to note that output of the electrical generator could also be sent to the grid if demanded. Conversely, the steam flow rate could be increased, and the electrolyzer could be operated at a higher current density to profitably accept power from the grid for increased hydrogen production in times of low electrical demand. Thus, HTE can play an important role in matching the constant output of future reactors to varying electrical demands.

A basic thermodynamic analysis can be applied to the water-splitting process to determine the thermodynamic efficiency limit as a function of temperature. A schematic of a generic thermal water-splitting process is shown in Figure 1-10. Water enters the control volume from the left. Since the ultimate feedstock for any large scale water-splitting operation will be liquid water, it is reasonable to consider the case in which water enters the control volume in the liquid phase at temperature $(\mathrm{T})$ and pressure $(\mathrm{P})$. Pure hydrogen and oxygen streams exit the control volume on the right, also at $\mathrm{T}$ and $\mathrm{P}$. Two heat reservoirs are available, one at temperature $\left(\mathrm{T}_{\mathrm{H}}\right)$ and one at temperature $\left(\mathrm{T}_{\mathrm{L}}\right)$. Heat transfer between these reservoirs and the control valve is indicated in the figure as $\left(\mathrm{Q}_{\mathrm{H}}\right)$ and $\left(\mathrm{Q}_{\mathrm{L}}\right)$.

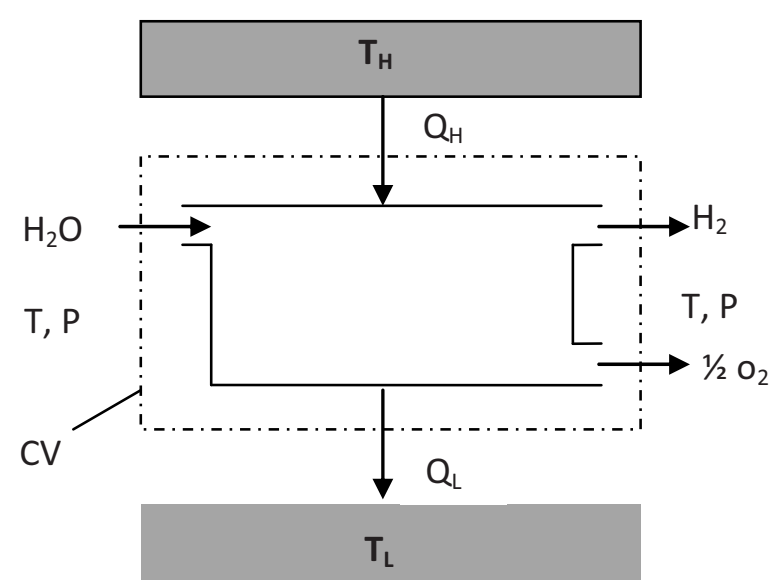

Figure 1-10. Schematic of a thermal water-splitting process operating between $\mathrm{T}_{\mathrm{H}}$ and $\mathrm{T}_{\mathrm{L}}$ (Hori and Spitalnik 2004). 
From the chemical reaction standpoint, the water-splitting process corresponds to the dissociation of water:

$$
\mathrm{H}_{2} \mathrm{O} \quad \mathrm{H}_{2}+1 / 2 \mathrm{O}_{2}
$$

The first and second laws of thermodynamics can be applied to this process as follows:

First law: $\quad \mathrm{Q}_{\mathrm{H}}-\mathrm{Q}_{\mathrm{L}}=\Delta \mathrm{H}_{\mathrm{R}}$

Second law: $\quad \Delta \mathrm{S}_{\mathrm{R}} \geq \frac{\mathrm{Q}_{\mathrm{H}}}{\mathrm{T}_{\mathrm{H}}}-\frac{\mathrm{Q}_{\mathrm{L}}}{\mathrm{T}_{\mathrm{L}}}$

where $\Delta H_{R}$ is the enthalpy of reaction and $\Delta S_{R}$ is the entropy change of the reaction. The thermal-to-hydrogen efficiency of thermal water-splitting processes can be defined in terms of the net enthalpy change of the working fluid, divided by high-temperature heat added to the system

$\eta_{\mathrm{T}}=\frac{\Delta \mathrm{H}_{\mathrm{R}}}{\mathrm{Q}_{\mathrm{H}}}$

Combining the first and second-law equations for the reversible case and substituting into the efficiency definition yields

$\eta_{T, \max }=\frac{1-\frac{T_{L}}{T_{H}}}{1-\frac{T_{L} \Delta S_{R}}{\Delta H_{R}}}$

In Figure 1-11 the top curve represents the maximum possible water-splitting efficiency. The bottom curve is simply $65 \%$ of this thermodynamic limit. The $65 \%$ value is based on the typical percentage of Carnot efficiency that can be achieved with a well-engineered modern power cycle.

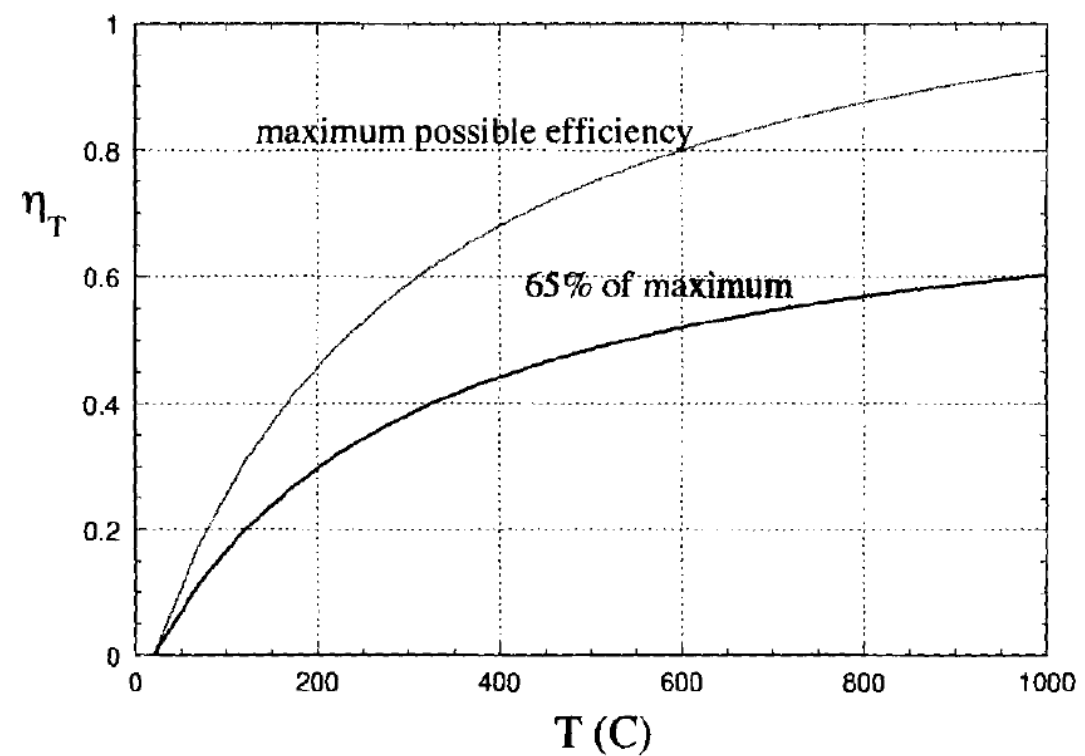

Figure 1-11. Theoretical thermal water-splitting efficiencies (Hori and Spitalnik 2004). 
A comparison of expected efficiencies of several thermochemical and HTE water-splitting processes was prepared by Yildiz and Kazimi (2003). The energy efficiencies are plotted in Figure 1-12 for the leading candidate thermochemical cycle, SI, and for the HTES process coupled to two advanced-reactor nuclear power cycles. GT-MHR is the gas-turbine modular high-temperature reactor and AGR-S-CO is an advanced gas-cooled reactor supercritical $\mathrm{CO}_{2}$ power cycle. The HTES efficiency values presented in this figure are similar to the $65 \%$ values presented in Figure 1-11 over the entire temperature range. The HTES technology coupled to the direct-cycle supercritical- $\mathrm{CO}_{2}$-cooled AGR promises higher efficiency values at lower operating temperatures than the SI and HTES coupled to the GT-MHR technology.

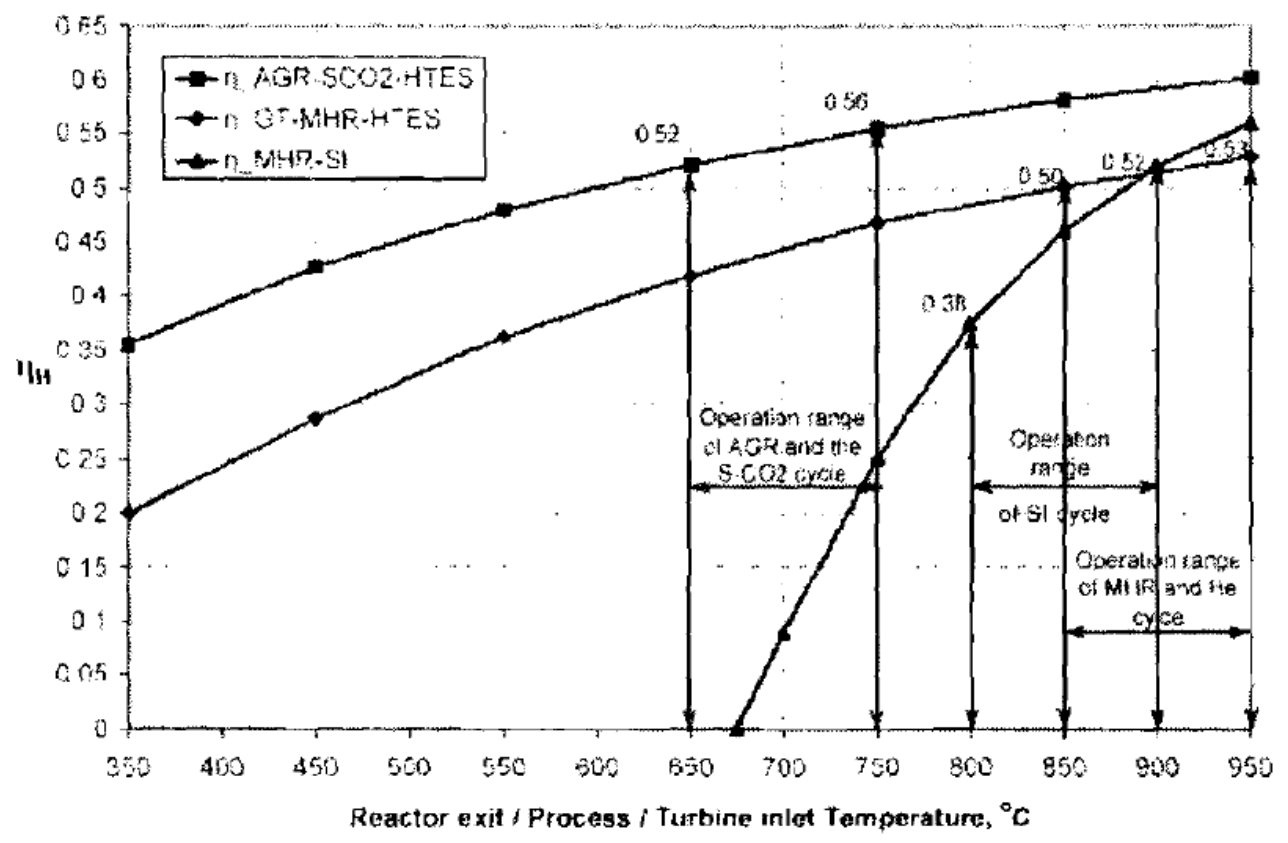

Figure 1-12. Comparison of thermal to hydrogen efficiencies of HTE and SI thermochemical processes (Hori and Spitalnik 2004).

The possibility of achieving high efficiency at lower temperatures is a significant advantage in favor of HTES. Furthermore, the power cycle for HTES could be used both for supplying power to the grid and for the hydrogen production, thereby providing increased flexibility.

\subsection{Thermochemical Production of Hydrogen (SI Cycle)}

Thermochemical cycles, in which the SI process is considered the most promising and the best suited to couple with a high-temperature reactor, have the potential of high conversion efficiency from nuclear heat to hydrogen and are receiving worldwide research and development attention. Thermochemical cycles produce hydrogen through a series of chemical reactions in which the net result is the production of hydrogen and oxygen from water at a much lower temperature than in the direct thermal decomposition (temperature higher than $2,000^{\circ} \mathrm{C}$ ).

This solution for massive production of hydrogen seems very attractive, because it fulfills the fundamental criterion of "sustainable development." Production is supplied from water, an inexhaustible and uniformly distributed resource, and the production is greenhouse gas emission free, as long as heat is supplied according to this criterion, which is the case with nuclear energy supply. Nevertheless, the thermochemical option will lead to a viable process only if it respects the two criteria of economic competitiveness: demonstrated technical viability and efficiency. 
From an efficiency standpoint, thermochemical cycles may have theoretical advantages over the alternative of high-temperature electrolysis, because their efficiency is not burdened with the detraction of the efficiency of electricity. Thermochemical cycles for massive hydrogen production from a nuclear high-temperature source were studied and evaluated extensively in the 1970s in the context of the 1973 oil crisis, but none led to an industrial application. The main reasons were (Hori and Spitalnik 2004):

- The difficulty in acquiring reliable thermodynamic and kinetic data in the fields of interest for proper evaluation of the viability of an industrial process.

- The lack of tools, especially simulation tools, for flow-sheet generation necessary to screen and survey solutions for industrial feasibility.

Thermochemical cycles have to prove viability and feasibility leading to the near-term steps demonstration included in the roadmap of Generation IV reactor development.

The SI cycle is a pure thermochemical cycle initially proposed in the mid-1970s. It consists mainly of the following reactions, also seen in Figure 1-13:

1. $\mathrm{I}_{2}+\mathrm{SO}_{2}+2 \mathrm{H}_{2} \mathrm{O} \rightarrow 2 \mathrm{HI}+\mathrm{H}_{2} \mathrm{SO}_{4}$

2. $2 \mathrm{HI} \rightarrow \mathrm{H}_{2}+\mathrm{I}_{2}$

3. $\mathrm{H}_{2} \mathrm{SO}_{4} \rightarrow \mathrm{SO}_{2}+\mathrm{H}_{2} \mathrm{O}+\frac{1}{2} \mathrm{O}_{2}$

The first reaction (the Bunsen reaction) proceeds exothermically at low temperature as an $\mathrm{SO}_{2}$ gas absorption reaction with a mixture of solid $\mathrm{I}_{2}$ and liquid $\mathrm{H}_{2} \mathrm{O}$. The second reaction, in which hydroiodic acid is decomposed into iodine and hydrogen, is slightly endothermic and takes place at $450^{\circ} \mathrm{C}$. The third reaction, in which $\mathrm{H}_{2} \mathrm{SO}_{4}$ is decomposed into a mixture of $\mathrm{SO}_{2}, \mathrm{H}_{2} \mathrm{O}$, and $1 / 2 \mathrm{O}_{2}$, is also an endothermic reaction and takes place at $850^{\circ} \mathrm{C}$. Except for hydrogen and oxygen, the products of reactions two and three are recycled as reactants in the Bunsen reaction.

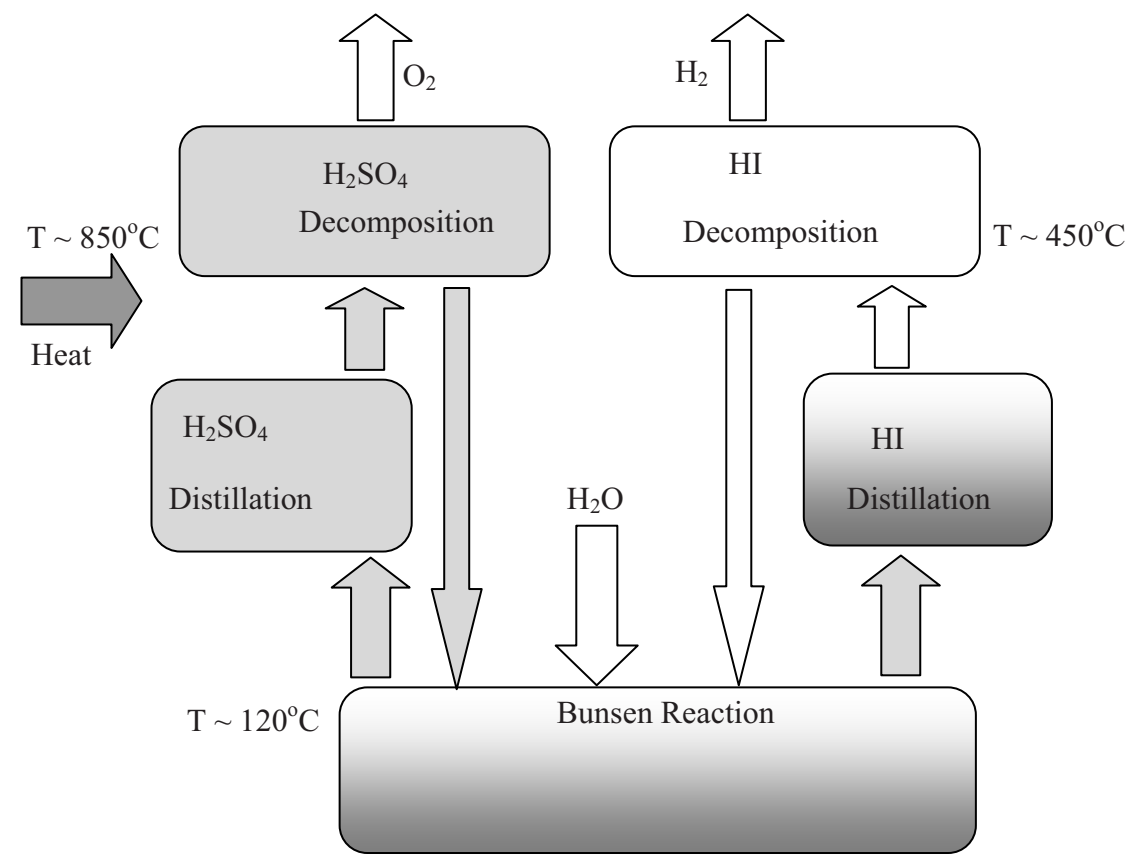

Figure 1-13. Thermochemical SI cycle (Hori and Spitalnik 2004). 
In the 1980s, General Atomics described a processing scheme for the SI cycle in which the reactants and products were fluids only. Iodine's melting point being $\sim 114^{\circ} \mathrm{C}$, the Bunsen reaction was then carried out at $\sim 120^{\circ} \mathrm{C}$. This reaction lacks favor at such a temperature, but conversion can be improved by diverging from the stoichiometric Bunsen conditions, e.g., by increasing initial amounts of $\mathrm{I}_{2}$ and $\mathrm{H}_{2} \mathrm{O}$ (Hori and Spitalnik 2004).

Moreover, an excess of $\mathrm{I}_{2}$ and $\mathrm{H}_{2} \mathrm{O}$ is quite unfavorable. Hence, research and development efforts are being devoted to testing new designs of the Bunsen reaction with lesser amounts of $\mathrm{I}_{2}$ and $\mathrm{H}_{2} \mathrm{O}$ to find the best compromise between thermodynamic improvement, phase separation, and energy loss.

\subsection{Safety Issues of Nuclear Hydrogen Production}

In 1766, the very famous and reclusive scientist Henry Cavendish discovered a gas that he called "flammable air." In 1781 he was able to demonstrate that flammable air, in combination with oxygen, produced water. Two years later, Lavoisier proposed the name hydrogen for Cavendish's flammable air, placing it in the emerging systematic context of chemistry. Some decades later, hydrogen became accepted as the lightest of all the chemical elements (Hori and Spitalnik 2004).

By then it was evident that all the hydrogen in our planet occurs in compound molecules, mainly water. To set it free, it must be chemically reduced from the molecules. Once isolated, hydrogen clearly deserves Cavendish's name, flammable air, because its combustion is easily initiated, is extremely energetic, and releases a huge amount of heat. This creates very high temperatures and can produce explosive overpressures.

Regardless of how nuclear power is converted into hydrogen, no special safety features arise, provided there is enough physical distance between the nuclear power plant and the chemical plants. As already noted in relation to the Generation IV initiative, scenarios of nuclear hydrogen production would need safe and economically competitive reactors. This in turn requires a suitable nuclear fuel cycle, as studied in the Advanced Fuel Cycle Initiative of the U.S. Department of Energy. To become relevant in the hydrogen economy, nuclear fission will require the following (Hori and Spitalnik 2004):

- Proliferation resistance for the whole fuel cycle

- Enhanced efficiency in exploiting nuclear ores (natural uranium and thorium)

- Minimization of radiotoxicity contained in long-term nuclear waste

- High safety standards, i.e., ruling out any nuclear accident that is not essentially confined within containment.

\subsection{Summary}

Recent technological developments in next generation nuclear reactors have created renewed interest in nuclear process heat for industrial applications. To utilize process heat, a thermal device is needed to transfer the thermal energy from NGNP to the hydrogen plant in the most efficient way possible. One of the most significant advantages of heat transfer by thermosyphon is the characteristic of nearly isothermal phase change heat transfer, which makes the thermosyphon an ideal candidate for applications where the temperature gradient is limited and high delivery temperatures are required, as in thermochemical hydrogen production. Inside an operating thermosyphon, the vapor (at constant saturation temperature) carries a large amount of latent heat from the evaporator to the condenser.

Thermal energy devices such as heat pipes and thermosyphons possess many advantages, including high heat recovery effectiveness, high compactness, no moving parts, and high reliability. Because of these advantages, heat pipes and thermosyphons have been extensively applied in many industries. 
Developing very high temperature reactor technologies for the production of hydrogen and other energy products and developing technologies to close the nuclear fuel cycle are high priority research and development issues for a successful nuclear future. Both HTE and the SI processes are in the early stages of development, but both will require technology to transfer thermal energy (heat) from the NGNP to the hydrogen production facility. From an efficiency standpoint, thermochemical cycles may have theoretical advantages over the alternative of high-temperature electrolysis, because their efficiency is not burdened with the detraction of the efficiency of electricity. 


\section{THERMOSYPHON DESIGN}

\subsection{Thermosyphon Design}

Heat pipes and thermosyphons have been recognized for decades as effective thermal devices for transporting large amounts of heat with small temperature gradients. The heat pipe differs from the thermosyphon only by virtue of its capillary wick and ability to transport heat against gravity; both utilize an evaporation-condensation cycle. The development of modern thermosyphon technology and applications started in the 1940s when Gaugler (1944) proposed a two-phase closed thermosyphon tube incorporating a wick or porous matrix for capillary liquid return. Grover (1963) studied this heat transfer device and named it "heat pipe" as described by Cheng and Zarling (1993). Since then, considerable effort has been invested in thermosyphon and heat pipe development and has resulted in broad applications. One significant advantage of heat transfer by thermosyphon is the characteristic of nearly isothermal phase change heat transport, which makes the thermosyphon an ideal candidate for applications where the temperature gradient is limited and high delivery temperatures are required, as in the case of thermochemical hydrogen production (Sabharwall and Gunnerson 2008). The nature of isothermal heat transport results in an extremely high thermal conductance (defined as heat transfer rate per unit temperature difference). A schematic diagram of a thermosyphon system is shown in Figure 2-1.

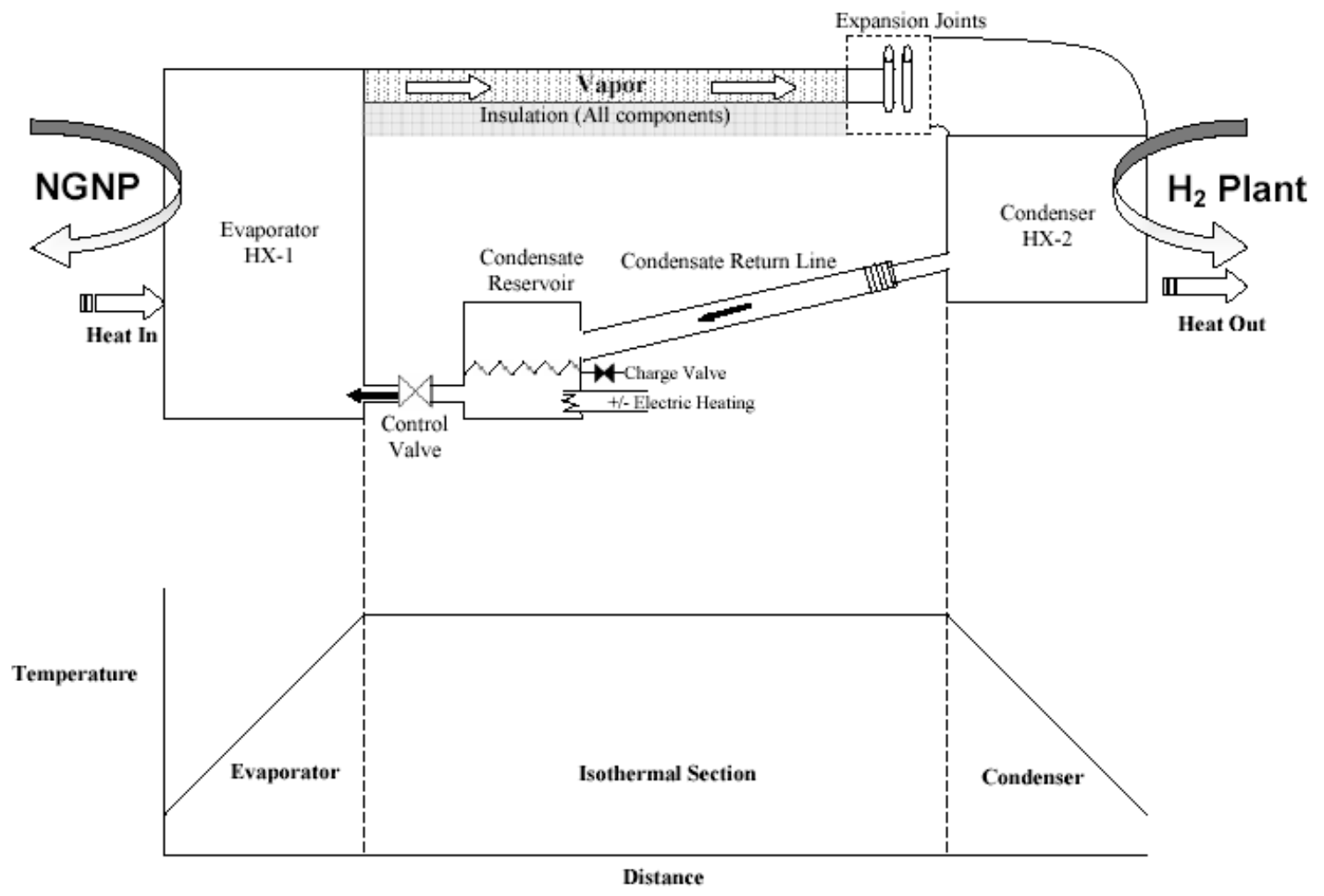

Figure 2-1. Schematic of a simple controllable thermosyphon (Sabharwall and Gunnerson 2008).

Reported within this section are design considerations for a thermosyphon system that transfers thermal power from NGNP to a hydrogen production facility. 


\subsubsection{Geometry}

A thermosyphon is a two-phase heat transfer device that may be used to transfer process heat from the NGNP plant to the hydrogen plant. A controllable thermosyphon, conceptually illustrated in Figure 2-1, is a wickless heat pipe with a separate liquid return line. It is an intriguing option to traditional pumped fluid heat transfer. Thermosyphons rely on convection to transport thermal energy inside pipes and high temperature heat exchangers for the evaporation and condensation end processes. Ideally, no pumping power is required in contrast to single-phase gas or liquid loops, which require compressors or pumps, both of which are problematic at very high temperatures.

Heat is transported by saturated or superheated vapor expanded from an evaporative heat exchanger, through a long pipe to a condensation heat exchanger. Liquid condensate returns to the evaporator assisted by gravity through a separate liquid return line with a liquid return control valve. When the thermosyphon is started by applying power (process heat from NGNP) to the evaporator, the working fluid is evaporated and the latent heat of vaporization is transported ( isothermally) along the thermosyphon to the condenser region. Expansion joints are added near the condenser section and also at the inlet to the condensate return line in order to accommodate the thermal expansion of the thermosyphon piping at higher temperature. The condensate returns to the evaporator region through a liquid bypass line containing a liquid storage reservoir and a control check valve as shown in Figure 2-1. The storage reservoir and part of the liquid lines may incorporate electric resistance heating, if necessary, in order to melt the working fluid and restart the thermosyphon after a long shutdown period. Liquid from the storage reservoir passes into the thermosyphon system evaporator through a control valve, which, as needed, plays a role in controlling the rate of heat transfer and shutting off or isolating the thermosyphon. In order for the thermosyphon system to be shut and completely disabled from heat transfer, the control valve is closed wherein all the working fluid is collected in the liquid storage reservoir and the condensing-evaporating cycle is terminated. When it is desired to resume the thermosyphon action, the control valve is opened to again allow the liquid to flow into the evaporator region of the system. The heat input governs the rate of evaporation and the subsequent rate of heat transfer. The rate of thermal energy exchange can be regulated over a spectrum of conditions from "OFF" to "FULLY ON," hence the term "controllable thermosyphon."

Another salient feature that a thermosyphon construction material must accommodate is thermal expansion. The change in the length with temperature for a solid material can be expressed by the common equation for thermal expansion of a homogeneous material as

$$
\frac{\Delta \mathrm{L}}{\mathrm{L}_{\mathrm{o}}}=\alpha_{1} \Delta \mathrm{T}
$$

For a $100 \mathrm{~m}$ long thermosyphon made from a high temperature Ni alloy $\left(\alpha_{1}=13.3 \times 10^{-6}\right)$ heated from ambient temperature to $1,300 \mathrm{~K}$, the expansion is $133 \mathrm{~cm}$. Therefore, in order to accommodate the expansion, either corrugated joints or expansion joints (as shown in Figure 2-2) must be incorporated.

\subsubsection{Working Fluids}

Depending on the temperature and pressure of operation, favorable working fluids can be identified. Alkaline metals, for example may be suited for NGNP process heat transfer, because they have the characteristics of:

- High boiling temperature

- Availability and cost effectiveness

- Good heat transfer properties (latent and specific heat are both high) 
- $\quad$ Typically good chemical compatibility (except lithium).

Working fluids more suitable than alkali metals may exist, such as molten salts. Corrosive behavior at high temperatures or lack of high temperature thermodynamic properties, especially for superheated vapors, rule out fundamental analysis of many possible thermosyphon working fluids. Thermophysical properties of the alkaline metals at atmospheric pressure are given in Table 2-1.

Table 2-1. Properties of alkali metals (Lyon 1952).

\begin{tabular}{|c|c|c|c|c|l|}
\hline Working Fluids & Melting Temperature $(\mathrm{K})$ & Boiling Temperature $(\mathrm{K})$ & $\mathrm{h}_{\mathrm{fg}}(\mathrm{kJ} / \mathrm{kg}, 1223 \mathrm{~K})$ & $\rho_{v}\left(\mathrm{~kg} / \mathrm{m}^{3}, 1223 \mathrm{~K}\right)$ & Comments \\
\hline $\mathrm{Li}$ & 452 & 1590 & 21156 & $2.17 \mathrm{E}-03$ & Least favorable \\
\hline $\mathrm{Na}$ & 371 & 1156 & 3864 & $4.72 \mathrm{E}-01$ & Most favorable \\
\hline $\mathrm{K}$ & 337 & 1033 & 1794 & 2.03 & Favorable \\
\hline $\mathrm{Cs}$ & 301 & 978 & 440 & 12.46 & Less favorable \\
\hline
\end{tabular}

More salient information on the working fluids is presented below.

\subsubsection{Lithium}

Lithium ( $\mathrm{Li}$ ) is the rarest alkaline metal next to cesium (Cs). It is the least dense of the normally solid elements, and is the least typical and most reactive of the alkaline metals. Lithium is harder than other alkaline metals but is softer than lead. Lithium offers interesting characteristics as a heat-transfer fluid in high-temperature systems. It is the lightest metal and has a comparatively high conductivity, high specific heat, high boiling point, and moderately low melting point. Its low density permits high fluid velocities without encountering high pressure drops in the system. At high temperatures, lithium reacts with carbon to form acetylides that hydrolyze to give acetylene, which may be explosively flammable. Near the melting point, lithium may ignite in air and burn with an intense cloud of white smoke, the principal product is the monoxide $\mathrm{Li}_{2} \mathrm{O}$. Lithium cannot be melted in glass or in the usual laboratory ceramics because it severely attacks them. The noble gases, thoroughly freed of oxygen, water, and nitrogen, must be used to prevent contact of lithium with the atmosphere. Stainless steel has been considered unsuitable for handling liquid lithium at high temperatures; liquid lithium attacks stainless steel and dissolves nickel (Lyon 1952). Most likely the material used for the construction of the thermosyphon will be an alloy of nickel, because of its durability and sustainability at high temperatures. In our analysis Li is discarded as a coolant because its boiling point is higher than the operational temperature $\left(1,000^{\circ} \mathrm{C}\right)$ of the thermosyphon.

\subsubsection{Sodium}

Solid Sodium (Na) is a relatively soft, silvery-white metal. Molten sodium is a silvery-white metal whose outstanding characteristic is its reactivity with most gases or liquids other than the noble gases and nitrogen. Solid Na tarnishes almost immediately when exposed to air, owing to the formation of a film of oxide. Molten sodium burns readily in the normal atmosphere to form dense flumes of sodium monoxide. With pure oxygen, molten sodium burns with a yellow flame, forming a mixture of sodium monoxide and sodium peroxide. The reaction of sodium with water is energetic and possibly explosively rapid if the contact interfaces are large. Sodium and heavier alkaline metals do not react with nitrogen. Sodium reacts vigorously with halogens, acidic oxides, and mercury, and alloys with lead, tin, zinc, and bismuth. Nitrogen, argon, and helium do not react with sodium, and these gases should be used to prevent the atmosphere from contacting sodium, either in the solid or the liquid state. Sodium does not react with glass at temperatures less than $300^{\circ} \mathrm{C}$; above this temperature, pyrex glass is rapidly attacked (Lyon 1952). 


\subsubsection{Potassium}

Potassium $(\mathrm{K})$ reacts similarly to sodium with the exception that, in general, potassium is more reactive. When exposed to oxygen, potassium oxidizes to superoxide $\mathrm{KO}_{2}$. The superoxide of potassium will form at low temperatures, but the cause of explosions with combinations of potassium superoxide and potassium metal is not completely understood. When potassium reacts directly with carbon monoxide, an explosive carbonyl is formed, unlike in sodium (Lyon 1952). Whereas lithium and sodium react only superficially with liquid bromine, potassium detonates when brought into contact with it. Ordinary potassium is the lightest naturally occurring radioactive element; it contains $0.011 \%$ beta or gamma emitting ${ }_{19} \mathrm{~K}^{40}$ with a half life of $2.4 \times 10^{8}$ years.

\subsubsection{Cesium}

Cesium (Cs) is silvery-white in appearance and is very soft and ductile. It is the most electropositive of all the metals and has a high specific gravity. It catches fire in dry air and, in general reacts the same as the other alkaline metals. Cesium absorbs carbon monoxide at room temperature (Lyon 1952).

\subsection{Mass Flow Rate and Sonic Velocity Analysis}

A sodium-filled thermosyphon can transport comparable amounts of thermal energy as a single-phase convective loop, within the same diameter pipe. The ideal rate of convective heat transport through a pipe without losses, modeled in terms of enthalpy, can be written as

$$
Q^{\prime \prime}=\Delta \mathrm{h} \rho \mathrm{V}=\frac{\dot{\mathrm{m}}}{\mathrm{A}} \Delta \mathrm{h}
$$

Two-phase heat transfer by a thermosyphon has the advantage of high enthalpy transport, which includes the sensible heat of the liquid, latent heat of vaporization, and possible vapor superheat. In contrast, single-phase forced convection transports only the sensible heat of the fluid. Additionally, vaporphase velocities within a thermosyphon can be much greater than single-phase liquid velocities within a forced convective loop. For a working fluid with temperature averaged properties, the rate of transport is

$$
\begin{aligned}
& \mathrm{Q}^{\prime \prime}=\frac{\dot{\mathrm{m}}}{\mathrm{A}} \mathrm{C}_{\mathrm{P}, \mathrm{L}} \Delta \mathrm{T}_{\mathrm{L}} \text { (single phase) } \\
& \mathrm{Q}^{\prime \prime}=\frac{\dot{\mathrm{m}}}{\mathrm{A}}(\underbrace{\mathrm{C}_{\mathrm{P}, \mathrm{L}} \Delta \mathrm{T}_{\mathrm{L}}}_{\text {Sensible heat of the liquid }}+\underbrace{\mathrm{h}_{\mathrm{fg}}}_{\text {Latent heat of vaporization }}+\underbrace{\mathrm{C}_{\mathrm{P}, \mathrm{V}} \Delta \mathrm{T}_{\mathrm{V}}}_{\text {Vapor Superheat }})
\end{aligned}
$$

Q is assumed to be $50 \mathrm{MW}$ (process heat from NGNP for hydrogen production), and the necessary mass flow rate for all the different alkaline metals is compared from

$$
\dot{\mathrm{m}}=\frac{\mathrm{Q}^{\prime \prime} A}{\mathrm{C}_{\mathrm{P}, \mathrm{L}} \Delta \mathrm{T}_{\mathrm{L}}+\mathrm{h}_{\mathrm{fg}}+\mathrm{C}_{\mathrm{P}, \mathrm{v}} \Delta \mathrm{T}_{\mathrm{V}}}
$$

where,

$$
\begin{aligned}
& \Delta \mathrm{T}_{\mathrm{L}}=\mathrm{T}_{\text {bo }}-\mathrm{T}_{\text {in }} \\
& \Delta \mathrm{T}_{\mathrm{v}}=\mathrm{T}_{\text {ou }}-\mathrm{T}_{\text {bo }}
\end{aligned}
$$


The inlet temperature of $\mathrm{Na}$ is assumed at $393 \mathrm{~K}$ (based on minimum temperature required to carry out Bunsen reaction in the SI process) and the outlet temperature of $\mathrm{Na}$ is assumed at 1,223 $\mathrm{K}$, which will be needed for better efficiency of the SI process. From Table 2-1, Li can be discarded as the potential working fluid because it does not boil until $1,590 \mathrm{~K}$ at atmospheric pressure. $\mathrm{Li}$ is also discarded from consideration by virtue of its high chemical reactivity with Ni alloys; likely material for the thermosyphon system. Figure 2-2 shows the minimum mass flow rates needed for alkaline metal vapors to supply $50 \mathrm{MW}$ at 1,223 K as determined by Equation (2-5), using thermophysical properties from Bystrov et al. (1990).

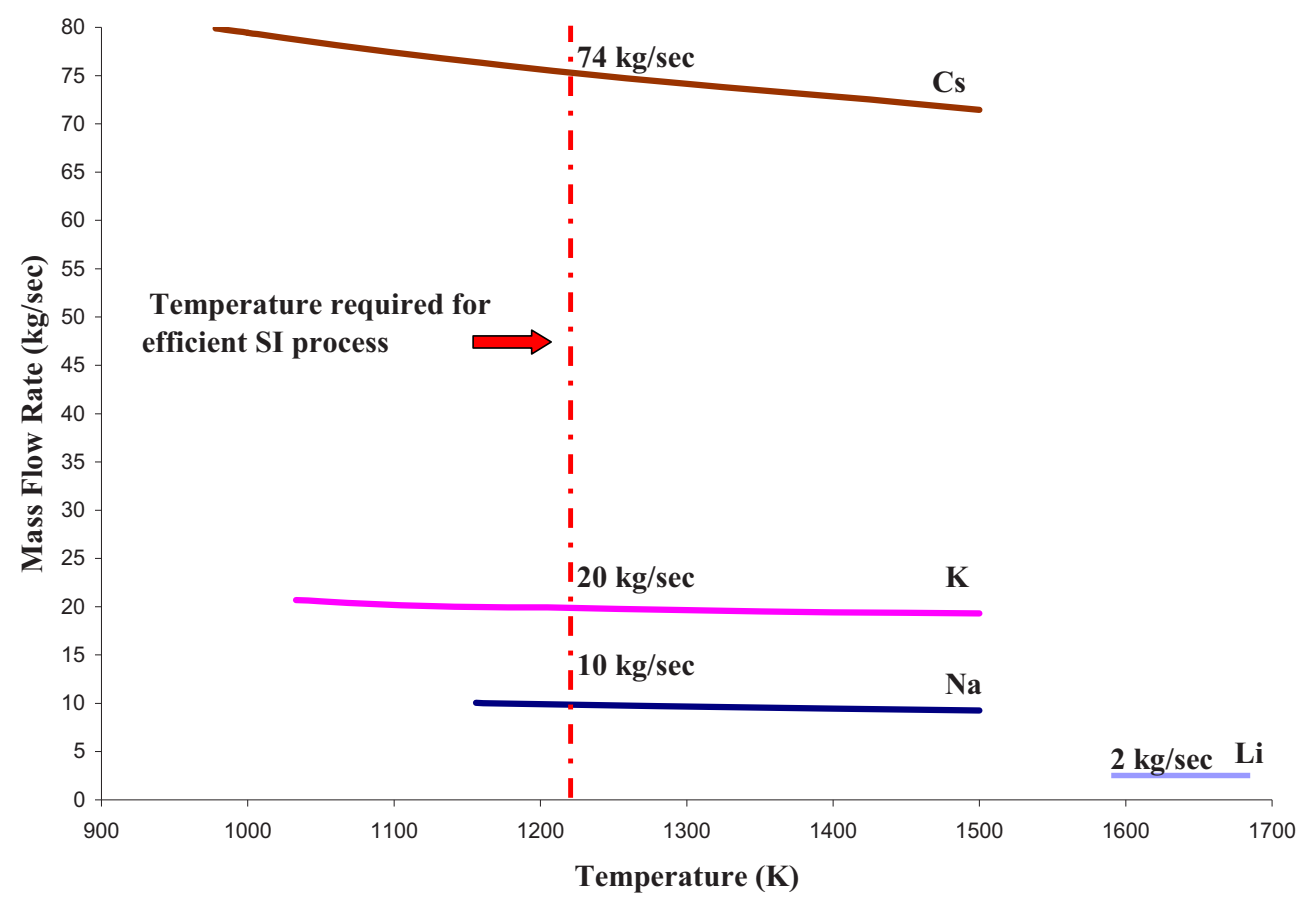

Figure 2-2. Mass flow rates of alkaline metal vapors, required to transport $50 \mathrm{MW}$.

If the alkaline metal vapor reaches sonic velocity, shock waves develop and propagate inside the thermosyphon. In order to avoid sonic shock, a thermosyphon has to operate at vapor velocity lower than sonic velocity, even though lower velocities reduce the heat transport capability. For a thermosyphon to operate near the sonic velocity with $\mathrm{Na}\left(\mathrm{V}_{\mathrm{S}} \sim 737 \mathrm{~m} / \mathrm{sec}\right.$ at atmospheric pressure) and transport $50 \mathrm{MW}$, it would require an internal pipe diameter of approximately $0.19 \mathrm{~m}$. At half the sonic velocity the diameter required is $0.268 \mathrm{~m}$.

For $50 \mathrm{MW}$, the lowest of mass flow rates is observed in $\mathrm{Na}$, when compared to other alkaline metals. Further, the diameter of the pipe is calculated such that the respective mass flow is attained at the sonic velocity limitation: for $\mathrm{Na}$ the diameter obtained is $0.19 \mathrm{~m}$. Similarly, the diameters for $\mathrm{K}$ and cesium are $0.15 \mathrm{~m}$ and $0.16 \mathrm{~m}$, respectively.

\subsection{Heat Transport Limitations}

Although the thermosyphon is a very high thermal conductance device, it possesses limitations governed by principles of heat transfer and fluid mechanics. Depending upon operational conditions, heat transport may be limited by sonic limit (choking) of vapor flow or viscous limit (Sabharwall et al. 2009 (i)) as discussed below. 


\subsubsection{Sonic Limit (Choking) of Vapor Flow}

After continuum flow is established, the evaporator-condenser pressure difference accelerates the vapor until it reaches a maximum velocity at the evaporator exit. The maximum vapor velocity that can exist at the evaporator exit corresponds to sonic velocity, or Mach 1. The limitation of such flow is similar to a converging-diverging nozzle with constant mass flow rate, where the evaporator exit corresponds to the nozzle throat. This choked flow condition is a fundamental limit on the axial vapor flow in a thermosyphon. The maximum axial heat flux at the sonic limit is obtained by calculating the mass flow rate at sonic velocity $\mathrm{V}_{\mathrm{S}}$ :

$$
\frac{\mathrm{Q}}{\mathrm{A}_{\mathrm{V}}}=\rho_{\mathrm{v}} \mathrm{h}_{\mathrm{fg}} \mathrm{V}_{\mathrm{S}}
$$

For sodium, the theoretical maximum heat transfer rate is $\sim 1,338 \mathrm{MW} / \mathrm{m}^{2}$ at $1,223 \mathrm{~K}$. Sodium is one fluid that meets the thermodynamic challenges of NGNP process heat transfer. The speed of sound in the vapor sodium is estimated from the vapor adiabatic compressibility $\left(\beta_{\mathrm{S}}\right)$ and the vapor density $\left(\rho_{\mathrm{v}}\right)$ using the thermodynamic relation given by Fink and Leibowitz (1995), which was verified with values given by Bystrov et al. (1990) as

$$
\mathrm{V}_{\mathrm{S}}=\frac{1}{\sqrt{\rho_{\mathrm{v}} \beta_{\mathrm{S}}}}
$$

Sonic velocity values for $\mathrm{Na}$ vapor in this analysis are from Fink and Leibowitz (1995). At the sonic limit, the mass flow rate per unit area and the corresponding axial heat flux depend only on the properties of the working fluid and, in turn, the operating temperature.

Reay and Kew (2006) present an equation that gives the limiting axial heat flux at sonic conditions $\left(\mathrm{V}_{\mathrm{S}, 0} \sim 806 \mathrm{~m} / \mathrm{s}\right)$ in terms of the stagnation temperature:

$$
\frac{\mathrm{Q}}{\mathrm{A}_{\mathrm{V}}}=\frac{\rho_{0} \mathrm{~h}_{\mathrm{fg}, 0} \mathrm{~V}_{\mathrm{S}, 0}}{(2(\gamma+1))^{0.5}}
$$

All the fluid properties in Equation (2-8) are stagnation properties and the maximum heat transfer rate obtained is $1,097 \mathrm{MW} / \mathrm{m}^{2}$. Once the sonic limit is reached, further increases in the mass flow rate or the heat transfer rate can occur only by increasing the stagnation pressure upstream of the choking point.

This limitation is similar to the viscous limitation in that it is typically encountered during startup or over-power transients but does not represent the failure of the system. This limitation was developed for heat pipes with internal annular wicks, but should also apply to vapor flows within a thermosyphon.

\subsubsection{Viscous Limit}

At startup for liquid metals, the vapor pressure difference between the evaporator and the condenser is zero or very small. In such cases, the viscous forces may be larger than the vapor pressure gradients and thus prevent vapor flow. This condition is the viscous limitation. It is a function of heat pipe dimensions and vapor conditions in the evaporator (Dickinson 1996) and can be expressed as

$$
\frac{\mathrm{Q}}{\mathrm{A}_{\mathrm{V}}}=\frac{\mathrm{D}_{\mathrm{v}}^{2} \mathrm{~h}_{\mathrm{fg}} \rho_{0} \mathrm{P}_{0}}{64 \mu \mathrm{L}}
$$


This limitation is mainly for heat pipes with a wick, but should also apply to a thermosyphon. The maximum viscous limit heat transfer rate per unit area with $\mathrm{Na}$ is much higher than the sonic limit mainly because of the low viscosity $\left(\mu \sim 1.86 \times 10^{-5} \mathrm{~N} \mathrm{sec} / \mathrm{m}^{2}\right)$ of $\mathrm{Na}$ vapor. Therefore, the viscous limit should not be a concern within a large-scale sodium thermosyphon.

The vapor pressure of a given working fluid plays a major role in determining the maximum allowable length of a thermosyphon. The following analysis determines the length of the thermosyphon such that it can transfer the process heat from the nuclear plant to the process plant for a given thermal load of $50 \mathrm{MW}$. The distance between the nuclear plant and the process plant is directly proportional to the operating temperature and thermal properties of the working fluid, specifically the vapor pressure of the fluid. The thermosyphon length is therefore determined as

$$
L=\frac{2 P_{\mathrm{V}} D}{4 f \rho_{v} V^{2}}
$$

Higher vapor pressure yields a longer possible thermosyphon, thus more separation distance is possible between the nuclear and process heat plant. Figure 2-3 shows the plot between half of sonic velocity for various alkaline metals with respect to temperature and the allowable length between the NGNP and hydrogen plant. Half sonic velocity is selected to avoid propagating sonic shock waves in the system and to reduce erosion potential. Also in this plot, no pressure drop is assumed, i.e., $\left(\mathrm{P}_{\mathrm{V}} \cong \Delta \mathrm{P}\right)$. Figure 2-4 shows the plot of varying length with the change in temperature for an allowable pressure drop.

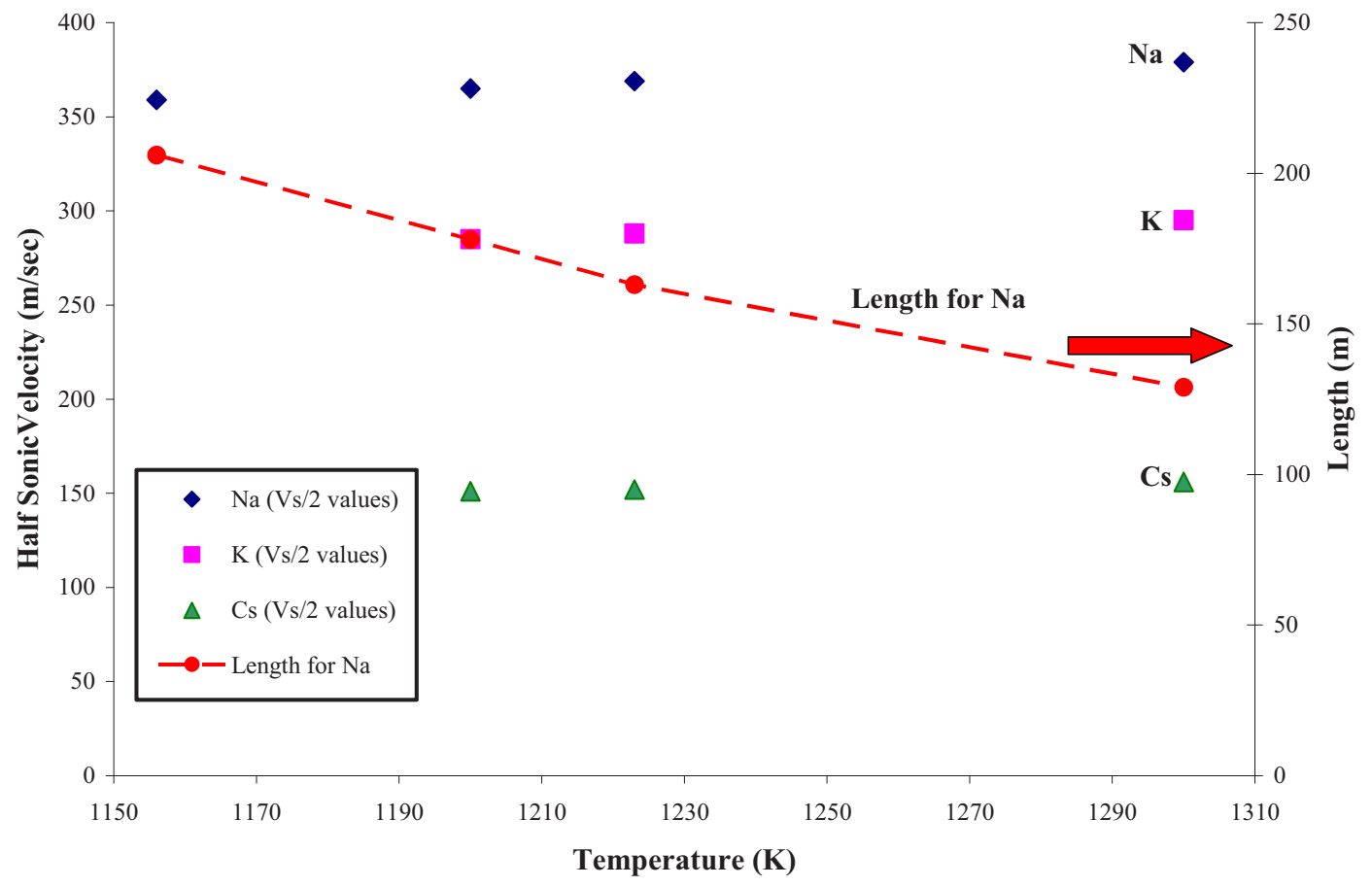

Figure 2-3. Maximum separation distance possible between NGNP and hydrogen production facility. 


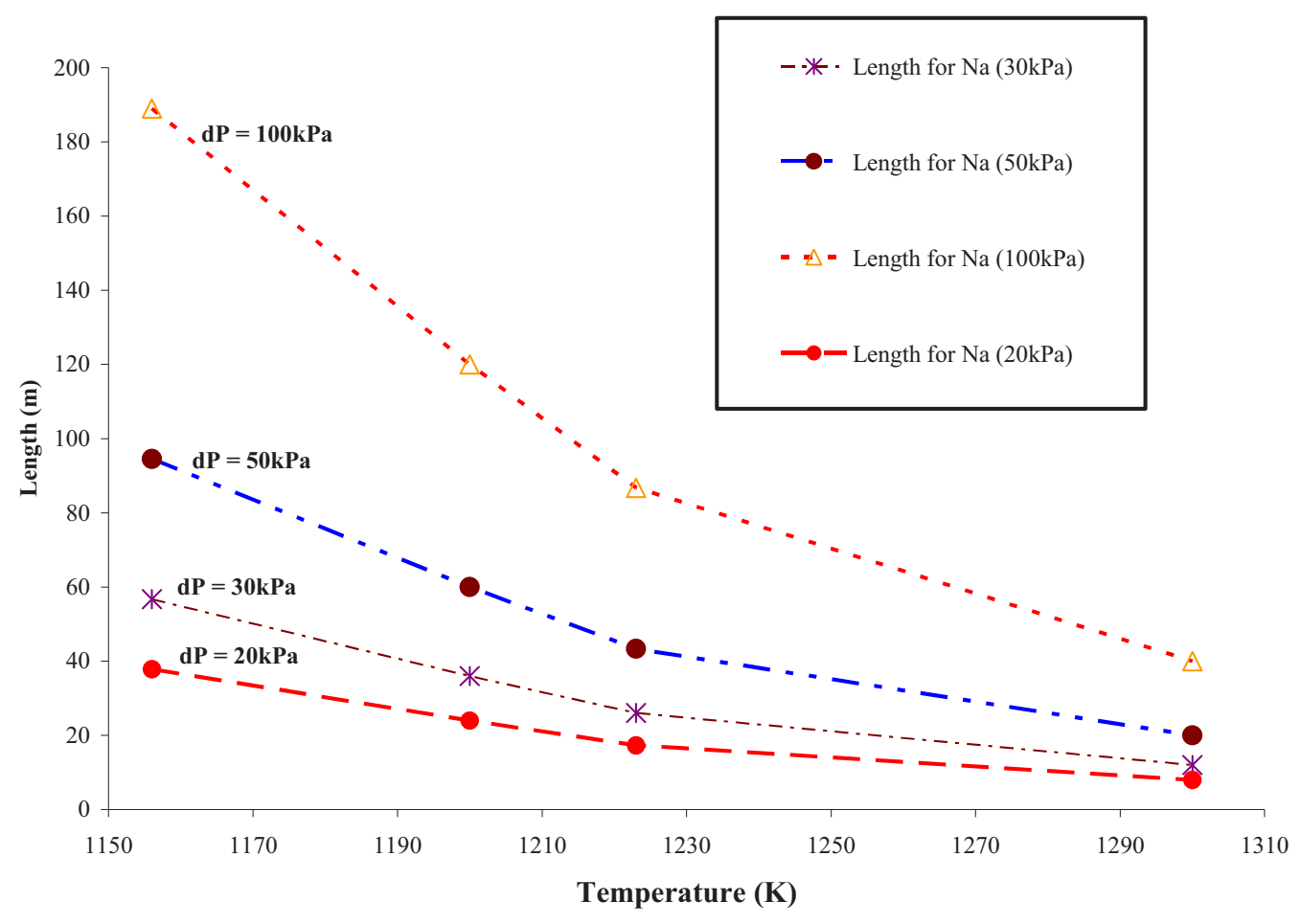

Figure 2-4. Maximum separation distance possible for an allowable pressure drop.

\subsection{Comparison of Alkaline Metals Thermosyphon with Convective Loop}

Alkaline metal thermosyphons and alkaline metal forced convective loops can both deliver comparable rates of heat transfer through a given size pipe. This can be demonstrated by considering the ideal rate of convective heat transport through a pipe without losses, modeled in terms of enthalpy by Equation (2-2).

Two-phase heat transfer by a thermosyphon has the advantage of high enthalpy transport when compared with single-phase forced convection. Additionally, vapor-phase velocities within a thermosyphon can be much greater than single-phase liquid velocities within a forced convective loop.

Figure 2-5 exemplifies the enthalpy enhancement in heat transfer afforded by a two-phase thermosyphon versus a single-phase convective loop with sodium as the working fluid. The specific enthalpy $(\Delta \mathrm{h})$ of saturated liquid and vapor, relative to the solid at $298.15 \mathrm{~K}$, is illustrated as a function of temperature. Assuming heat transfer from an HTGR to an industrial facility at 1,223 K, the maximum single-phase heat transfer is given by the enthalpy gain from points A to B in Figure 2-5, or approximately $1,190 \mathrm{~kJ}$ for each kilogram of sodium. Compare this with two-phase heat transfer from points $\mathrm{A}$ to $\mathrm{B}$ to $\mathrm{C}$ where the enthalpy gain is approximately $3,864 \mathrm{~kJ}$ per kilogram with no vapor superheat - over three times more heat per kilogram of sodium than the single-phase. The saturation pressure of sodium at $1,223 \mathrm{~K}$ is only $0.188 \mathrm{MPa}$, thus pressure and stress forces are minimized. Vapor flow through a pipe is limited by compressible choke flow when the vapor reaches its sonic velocity. The sonic velocity for sodium vapor is approximately $737 \mathrm{~m} / \mathrm{sec}$ at $1,223 \mathrm{~K}$ as given by Bystrov et al. (1990). 


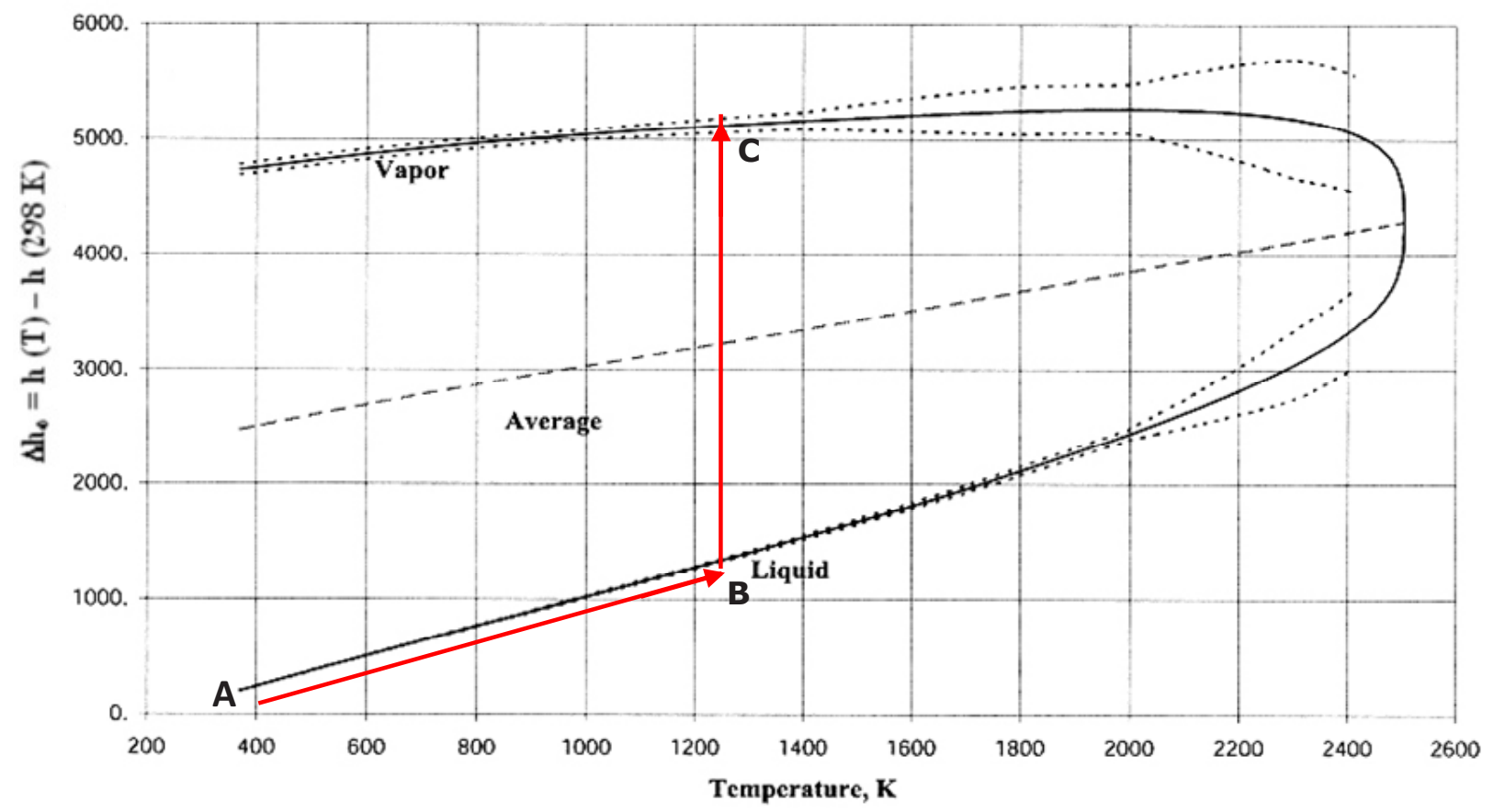

Figure 2-5. Enthalpy for saturated sodium: liquid and vapor (thermodynamic data from Fink and Leibowitz [1995], Gunnerson et al. [2007]).

The limiting heat transfer rate for an ideal sodium thermosyphon operating at 1,223 $\mathrm{K}$ can therefore be estimated by Equation (2-2):

$$
Q^{\prime \prime}=\mathrm{h}_{\mathrm{fg}} \rho_{\mathrm{V}} \mathrm{V}_{\mathrm{S}}=(3,864) \mathrm{kJ} / \mathrm{kg}(0.47) \mathrm{kg} / \mathrm{m}^{3}(737) \mathrm{m} / \mathrm{s}=1,338 \mathrm{MW} / \mathrm{m}^{2}
$$

Similarly, single-phase liquid sodium could transport the same rate of thermal energy with an average flow velocity of about $2.2 \mathrm{~m} / \mathrm{s}$, well within the capabilities of advanced liquid metal pumps. This simple analysis for sodium as the working fluid theoretically illustrates that both a thermosyphon and a forced convective loop can deliver comparable rates of heat transfer through comparable diameter pipes. The thermosyphon, however, has the luxury of controllable heat transfer without the need for high temperature pumping and can deliver the heat at the same approximate temperature as the source. For sodium, the enthalpy gain that can be achieved by two-phase heat transfer, instead of a single phase, is about 3.7 times greater. Ideally, a well-insulated $19 \mathrm{~cm}$ diameter sodium thermosyphon could transport $\sim 50 \mathrm{MW}$ of power at $1,223 \mathrm{~K}$ to a hydrogen production facility some distance $\left(100^{+} \mathrm{m}\right)$ away. In practice, a larger diameter thermosyphon would reduce the vapor velocity below the limiting sonic velocity and be beneficial in reducing the adverse effects from shock wave prorogation and erosion within the thermosyphon.

\subsection{Thermosyphon Startup}

The charging of a thermosyphon requires a transfer station wherein molten working fluid under an inert environment or vacuum is transferred to the evacuated thermosyphon pipe(s). Pure fluids without condensable gases are required for proper thermosyphon operation. Otherwise, the impurities, which are more volatile than the fluid itself, will be driven to the condenser section of the thermosyphon and less volatile impurities will be collected in the evaporator causing hot spots and reducing heat transfer. Noncondensable gases will accumulate within the condenser. Although conceptually simple, the startup of a large high-temperature thermosyphon is difficult to accurately predict. If the working fluid solidifies at ambient temperature, it must first be melted to flow into the evaporator. The subsequent boiling 
behavior will be dictated by the thermophysical nature of the working fluid and the nucleation characteristics of the evaporator. Figure 2-6 describes the procedure commonly practiced for filling up the thermosyphon. The liquid Na valve is opened till $20 \%$ by volume limit is reached for filling up the thermosyphon. The $20 \%$ by volume is a good approximation for the coolant as described by Gunnerson and Sanderlin (1994). Melting and boiling temperatures define the operating limits of a thermosyphon fluid. Clearly defined upper and lower operating temperature bounds are therefore required for proper selection of the working fluid. Upper temperature limits can challenge the pressure containment design and may influence working fluid degradation and materials compatibility. The minimum nonoperating temperature can affect the thermosyphon startup behavior, especially if operation is to be initiated from a frozen state.

For a thermosyphon to startup efficiently and effectively the working fluid has to initially be in a molten state. The liquid reservoir (as shown in Figure 2-6) has provisions for external heating. During normal start-up for both heat pipes and thermosyphons, the temperature of the evaporator section increases by a few degrees until the thermal front reaches the end of the condenser as described in Reay and Kew (2006). At this point, the condenser temperature will increase until the pipe structure becomes almost isothermal.

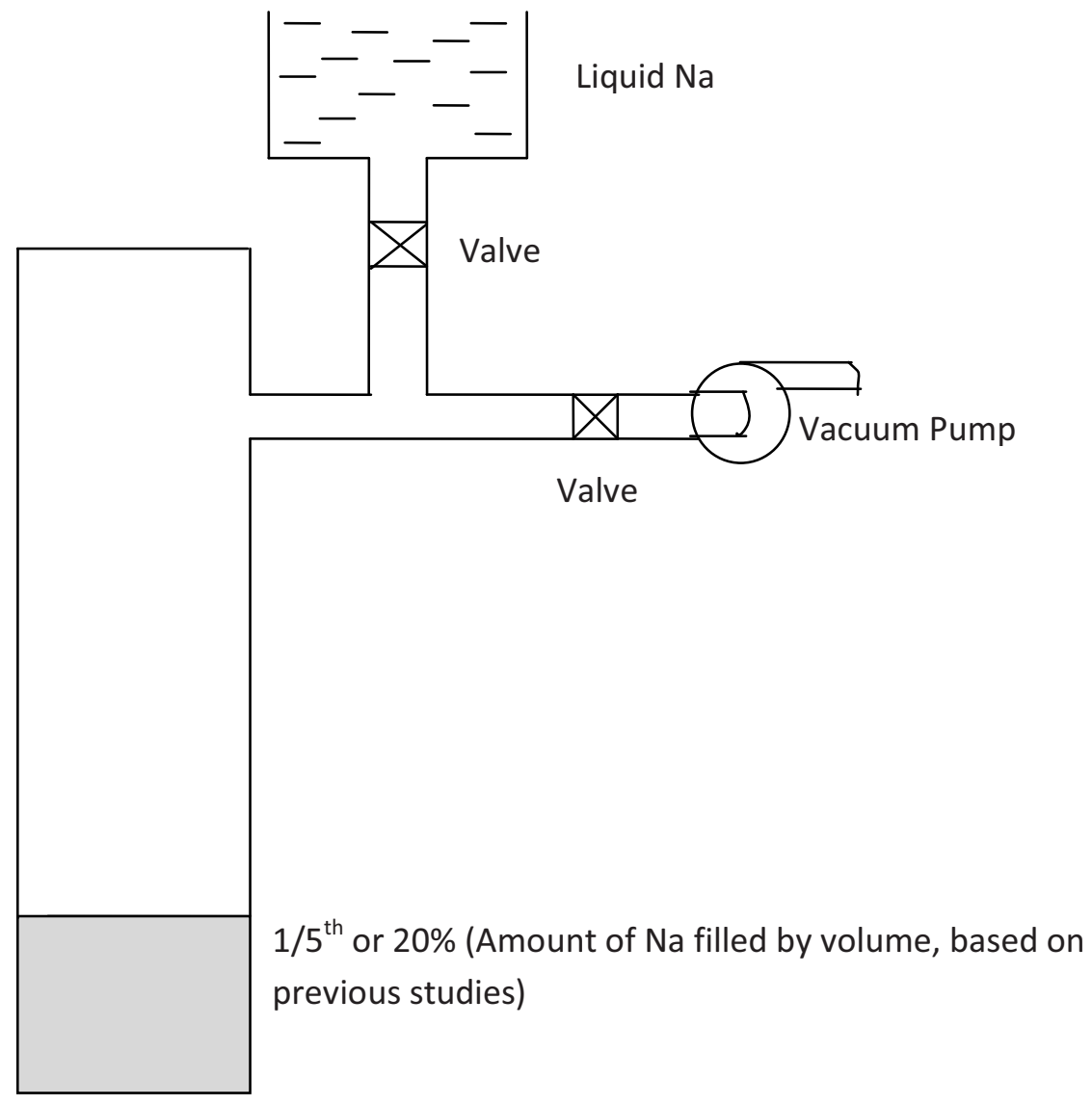

Figure 2-6. Na filling procedure for a thermosyphon (Gunnerson and Sanderlin 1994).

\subsection{Two-phase Instabilities in Thermosyphon}

Instabilities are common to both forced and natural circulation systems; the latter is more unstable than forced circulation systems. If the system stabilizes to a new steady state or oscillates with increasing amplitude, the system is considered unstable as explained by Sabharwall et al. (2004). Instabilities can 
cause operational problems in process heat transfer. Thus, it is important to classify mechanisms that can lead to unstable operational behavior of the thermosyphon. The following processes can lead to an unstable behavior for the thermosyphon.

\subsubsection{Surging (Chugging) and Geysering Instability}

Surging and geysering occur mainly because of liquid superheat. Surging occurs when boiling is initiated in the evaporator, but because of no uniformity in the temperature at the wall and bulk fluid temperature, the vapor being generated becomes trapped, eventually resulting in vapor expulsion as described by Bergles et al. (1981). This mechanism is not destructive, but can trigger other types of instability in the system. This phenomenon occurs more readily with liquids having good wettability such as sodium on steel at high temperatures. Geysering is a similar phenomenon that occurs when the heat flux is sufficiently high, and boiling is initiated at the bottom. In low pressure systems this results in a sudden increase in vapor generation due to the reduction in hydrostatic head, and usually causes an expulsion of vapor. The liquid then returns, the subcooled, nonboiling condition is restored, and the cycle starts over again. Geysering is also a naturally occurring phenomenon. A greater number of active nucleation sites in the evaporator section would help avoid surging and geysering in the system.

\subsubsection{Thermosyphon Evaporator Instability}

If the evaporator section of the thermosyphon system is not sufficiently long for vapor superheat, then instability could occur such that the fluid at the outlet of the evaporator experiences a static pressure decrease, leading to the onset of fluid condensation within the thermosyphon. Slight vapor superheat from the evaporator should reduce this concern.

\subsubsection{Fluid Superheating (Alkaline Metals)}

Alkaline metals have relatively high boiling temperatures at atmospheric pressure. If the heater surface does not have enough active nucleation sites, then boiling may not occur near saturation temperature but rather require significant superheat. The maximum superheat temperature for liquid sodium at low pressure has been estimated at 2,140 K based on a Van der Waals equation of state, as described by Gunnerson and Cronenberg (1978). At high superheat temperatures one could expect a vapor burst expulsion upon phase change, which could lead to structural damage and flow excursions. Since the superheat limit is above NGNP temperatures, alkaline metal evaporator and condenser designs should promote active nucleation sites through enhanced surface roughness and reduced interfacial wettability.

\subsection{Nucleation Sites}

A primary condition affecting boiling temperature of the alkali coolants is the density of nucleation sites. A nucleation site is a microscopic reentrant (much smaller opening than the inside of the cavity) that will retain small gas bubbles in the surface to initiate boiling at low wall superheats. It is well known that a large number of nucleation sites promote a lower superheat for a fluid. The alkaline metals like any other metals boil at the boiling point, provided nucleation sites are developed. For instance water normally boils at $100^{\circ} \mathrm{C}$ at normal atmospheric pressure, but if there are not enough nucleation sites, water boiling point may reach a temperature up to $120^{\circ} \mathrm{C}$. Therefore, understanding the nucleation phenomenon is important, especially for the evaporator section of the thermosyphon. Nucleation sites can be thought of (in the case of crystallization) as actual physical locations where energy is drawn off more easily because of the greater surface to volume ratio (high surface area) of the site. In the case of vaporization, the nucleation site can be thought of as an actual physical location where temperatures can be locally higher, and where energy transfer is more efficient - again because of the high surface area. Nucleation normally occurs at nucleation sites on surfaces containing liquid or vapor. Suspended particles 
or minute bubbles also provide nucleation sites. This is called heterogeneous nucleation. Nucleation without preferential nucleation sites is homogeneous nucleation. Homogeneous nucleation occurs spontaneously and randomly, but it requires superheating or supercooling of the medium. It is found that the liquid is superheated near the heating surface, and a nucleus of microscopic size is necessary for the birth of a bubble in the liquid. A spherical bubble has a radius such that the energy required for a pressure difference to change the volume is balanced by the energy required to change the area, i.e.,

$$
\left(P_{V}-P_{L}\right) d V=\sigma d A
$$

For a sphere, $\mathrm{dV}=4 \pi \mathrm{r}^{2} \mathrm{dr}$ and $\mathrm{dA}=8 \pi \mathrm{r} d \mathrm{~d}$. Therefore,

$$
\left(\mathrm{P}_{\mathrm{V}}-\mathrm{P}_{\mathrm{L}}\right) 4 \pi \mathrm{r}^{2} \mathrm{dr}=\sigma \quad 8 \pi \mathrm{r} \mathrm{dr}
$$

Boiling is nucleated when

$$
\mathrm{P}_{\mathrm{V}}-\mathrm{P}_{\mathrm{L}}=\frac{2 \sigma}{\mathrm{r}}
$$

At $\mathrm{r}=0, \mathrm{P}_{\mathrm{V}}-\mathrm{P}_{\mathrm{L}}=\infty$, which means that the initial pressure difference must be infinitely large for a bubble to develop without a nucleus. So, it is impossible for a bubble to grow without a nucleus. From Equation (2-13), for a bubble to exist, vapor pressure must be higher than liquid pressure; this pressure differential is required to overcome surface tension, which tends to bring the liquid molecules together.

The presence of dissolved gas, for example air, in the liquid necessitates incorporating the gas partial pressure into account, thus Equation (2-13) reduces to

$$
\mathrm{P}_{\mathrm{V}}-\mathrm{P}_{\mathrm{L}}=\frac{2 \sigma}{\mathrm{r}}-\mathrm{P}_{\mathrm{g}}
$$

The prediction of ' $r$,' remains a concern; i.e., is ' $r$ ' big enough to meet the coolant boiling requirement.

The mechanism of bubble formation depends on the wetting characteristics of the heating surface. The effect of wetting on bubble formation is shown in Figure 2-7. Bubbles form most readily if the surface is nonwetting. In addition to wetting, nucleation sites are necessary for bubble formation.

Since steels are wetted by sodium at high temperatures, i.e., a drop of sodium placed on the surface will spread out, with a low or zero contact angle. A consequence of this is that the sodium will tend to penetrate and fill any cracks or cavities in the surface. However, a cavity filled with liquid cannot act as a nucleation site, so it is necessary to assume that locally the surface is nonwetted.

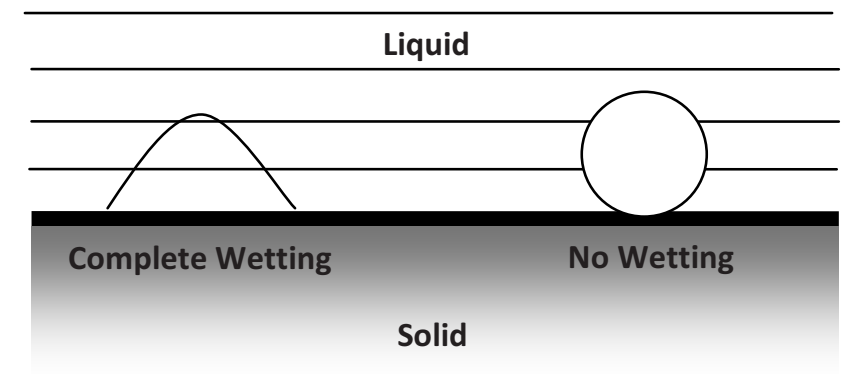

Figure 2-7. Effect of wetting. 
The contact angle $\theta$ as shown in Figure 2-8, is used as the wettability index. For $\theta<90$ degrees the liquid wet the wall (e.g., water on glass), for $\theta>90$ degrees the liquid does not wet the wall (e.g., mercury on glass) and if $\theta=0$ degrees the liquid perfectly wets the wall. The contact angle $\theta$ between the surface and the liquid can be represented by a factor $\Phi$ (Collier 1996) such that

$$
\Phi=\frac{2+2 \cos \theta+\cos \theta \sin ^{2} \theta}{4}
$$

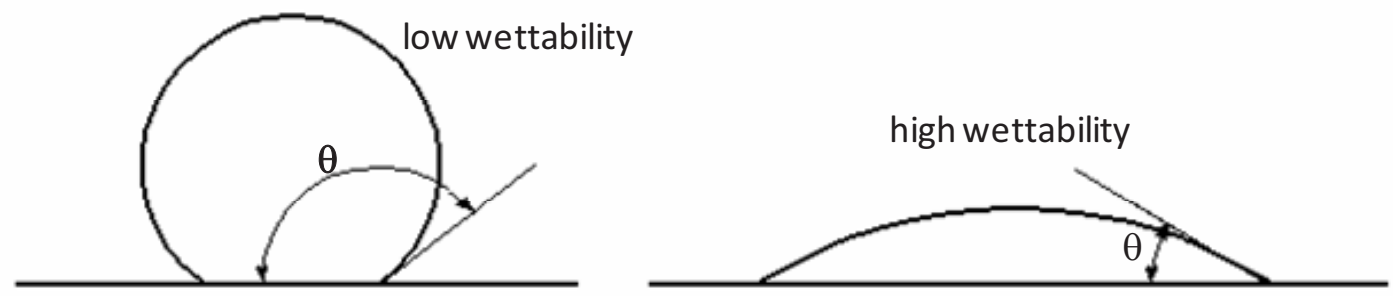

Figure 2-8. Sketch of the contact angle between surface and liquid.

If the liquid completely wets the surface $\theta=0$ degrees, $\Phi=1$ and there is no reduction of the free energy of formation of the embryo. If the surface is completely nonwetting $\theta=180$ degrees then $\Phi=0$ and no superheat is required for nucleation at the surface. Bubbles form more readily if the surface is nonwetting. In practice most solid-liquid systems lie in the range between 0 and 90 degrees and $\Phi$ lies in the range of 1 to 0.5 . In addition to wetting, nucleation sites are necessary for bubble formation. For the nucleus to continue to grow, the liquid temperature must be progressively increased above the saturation temperature to exceed the equilibrium superheat corresponding to the radius of curvature of the interface. This radius of curvature decreases as the nucleus grows until the contact angle $\theta$ with the flat surface is established, further growth then tends to increase the radius of curvature and the bubble grows spontaneously in the superheated liquid; i.e., the size of the cavity determines the superheat at which a vapor bubble will be nucleated at that site. For large cavity sizes, the growth rate decreases, the dynamic forces become small, and the bubble size at departure is set by a balance between buoyancy and surface tension forces (Johnson et al. 1966).

Bubble departure diameter $=0.0208 \theta\left[\frac{\sigma}{g\left(\rho_{L}-\rho_{V}\right)}\right]^{0.5}$

When surface tension forces are dominant, the departing bubbles tend to be spherical. With inertial forces dominant the bubble tends to be hemispherical and when both forces are significant the bubble has an oblate shape (Johnson et al. 1966).

The main objective of treatment of the evaporative section is to attain consistent nucleation in order to ensure proper heat transfer, which does not occur on polished or smooth surfaces. In order to enhance thermal nucleation, more active nucleation sites are needed (a vapor pocket is needed).

If the nucleation site becomes filled with liquid, it is referred to as an inactive nucleation site (Tw-Tsat) and becomes very large (the liquid must be superheated). For an active nucleation site, vapor must be in the pocket as shown in Figure 2-9. 


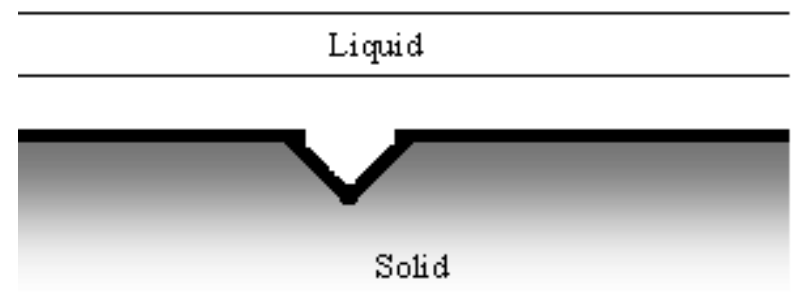

Figure 2-9. Nucleation site (pocket).

\subsection{Inclination Effects on a Thermosyphon Performance}

The performance of a two-phase, closed thermosyphon depends strongly on the gravity field. In the internal phase change circulation, gravitational force plays the role of returning the liquid from the compensation chamber to the evaporator. Any change of the gravitational influence, such as thermosyphon inclination or the gravity field itself, will have a significant impact on the heat transfer characteristics of the thermosyphon. Understanding the inclination dependence is therefore critical to both thermosyphon design and application. Inclining the thermosyphon from the horizontal plane permits buoyancy forces to play a greater role, which is reflected in thermal performance. As the thermosyphon is tilted from horizontal, the indirect effects weaken along with some direct (end) effects, while other direct effects strengthen. However, this strengthening occurs over the long walls and therefore reinforces some parts of the primary flow while opposing others. Around 5 degrees, a stagnation point appears at the bottom corner of the heated end, this is caused by alterations in the direct buoyancy forces operating over the end surface and the bottom surface near the end (Lock 1992). As the tilt increases, the stagnation point thus created moves towards the axis of the tube, as indicated in Figure 2-10. When the thermosyphon is vertical, the stagnation point lies near the axis and the flow exhibits the familiar core annulus pattern.

For many applications, thermosyphons need to be tilted to accommodate the geometric structure of the entire system. Many studies have been conducted to investigate the effects of the inclination angle on thermosyphon heat transfer performance characteristics and limits. A comprehensive review of previous work (mostly experimental) reveals the efforts and progress made over the past 15 years and points out the necessities of this work.

Nguyen - Chi and Groll (1981) modified flooding correlations for inclined thermosyphons by introducing a function that has little physical meaning and was empirically developed from curve-fitting the experimental data.

Negishi and Sawada (1983) conducted experiments to investigate the interactive influence of the inclination angle and working fluid inventory upon heat transfer performance of an inclined two-phase, closed thermosyphon. The experimental setup was designed for both visual observation and measurement of thermosyphon performance. They concluded that in order to obtain a high heat transfer rate, the working fluid inventory needs to be more than $25 \%$ of the evaporator volume, and the inclination angle should be almost 85 degrees ( from vertical position). The maximum heat flux was found at an inclination angle between 50 and 70 degrees (depending upon working fluid inventory). The heat transfer coefficient, a measure of thermosyphon efficiency, was found to slightly decrease with inclination angle.

Bontemps et al. (1987) experimentally studied evaporator and condenser heat transfer coefficients at various inclination angles and working fluid inventories. They found that evaporator heat transfer coefficients slightly decrease with inclination angle, while condenser heat transfer coefficients increase with inclination angle. It was also concluded that the critical heat flux is almost independent of inclination angle. 

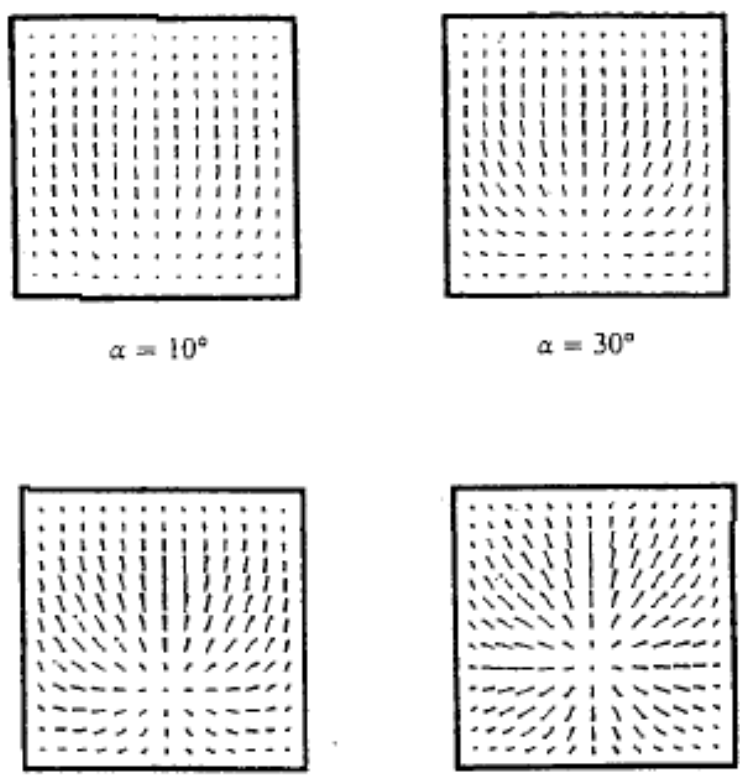

$\approx=45^{\circ}$

$\alpha=60^{\circ}$

$\alpha$ (measured from the horizontal)

Figure 2-10. Progressive displacement of the stagnation point at the hot end of the tilted thermosyphon (Lock 1992).

Terdtoon et al. (1990) found that there are four regions of the inclination angle as shown in Figure 2-11: (a) vertical position to about 20 degrees (from vertical position) - heat transfer capacity increases with inclination angle and is independent of working fluid inventory; (b) 20 to 40 degrees - heat transfer capacity increases with inclination angle and then reaches the maximum value, the working fluid inventory has an influence on the heat transfer capacity; (c) 40 degrees to minimum angle of isothermal operation - heat transfer capacity decreases with inclination angle and working fluid inventory has a large influence on both heat transfer rate and the minimum angle of isothermal operation; and (d) minimum angle of isothermal operation to limiting angle of operation - part of the evaporator section is not wetted and the thermosyphon is in a nonisothermal operational state.

For increasing tilt angles above the horizontal, the secondary vortices shrink in length. Near a tilt of 45 degrees, the vortices subside and are virtually absent for angles between this and vertical, the heat transfer rate then decreases as the vertical position is approached (Lock 1992). Due to differences in operating conditions, previous studies have resulted in diverse values of optimum inclination angle (corresponding to the maximum heat transfer rate). A few theoretical and numerical analyses have been carried out by Ma et al. (1987) and Wang and Ma (1991) starting from first principles and deriving an analytical expression for condensation heat transfer coefficient at various inclination angles. By comparing their analytical results with experimental data, they proposed a semi-empirical correlation to include the effects of vapor pressure and working fluid inventory. Zuo and Gunnerson (1995) developed numerical models based on first principles. The two-dimensional liquid film flow and one-dimensional vapor flow are coupled by appropriate boundary conditions and auxiliary equations. By numerically solving the model, performance parameters (such as temperature along the pipe wall, etc.) and performance limits (such as dry-out and flooding) were studied. For a thermosyphon with a large aspect ratio and not close to horizontal position, flooding is more important once the minimum working fluid inventory is satisfied. The minimum working fluid inventory increases with inclination angle, especially for large inclination angles. 


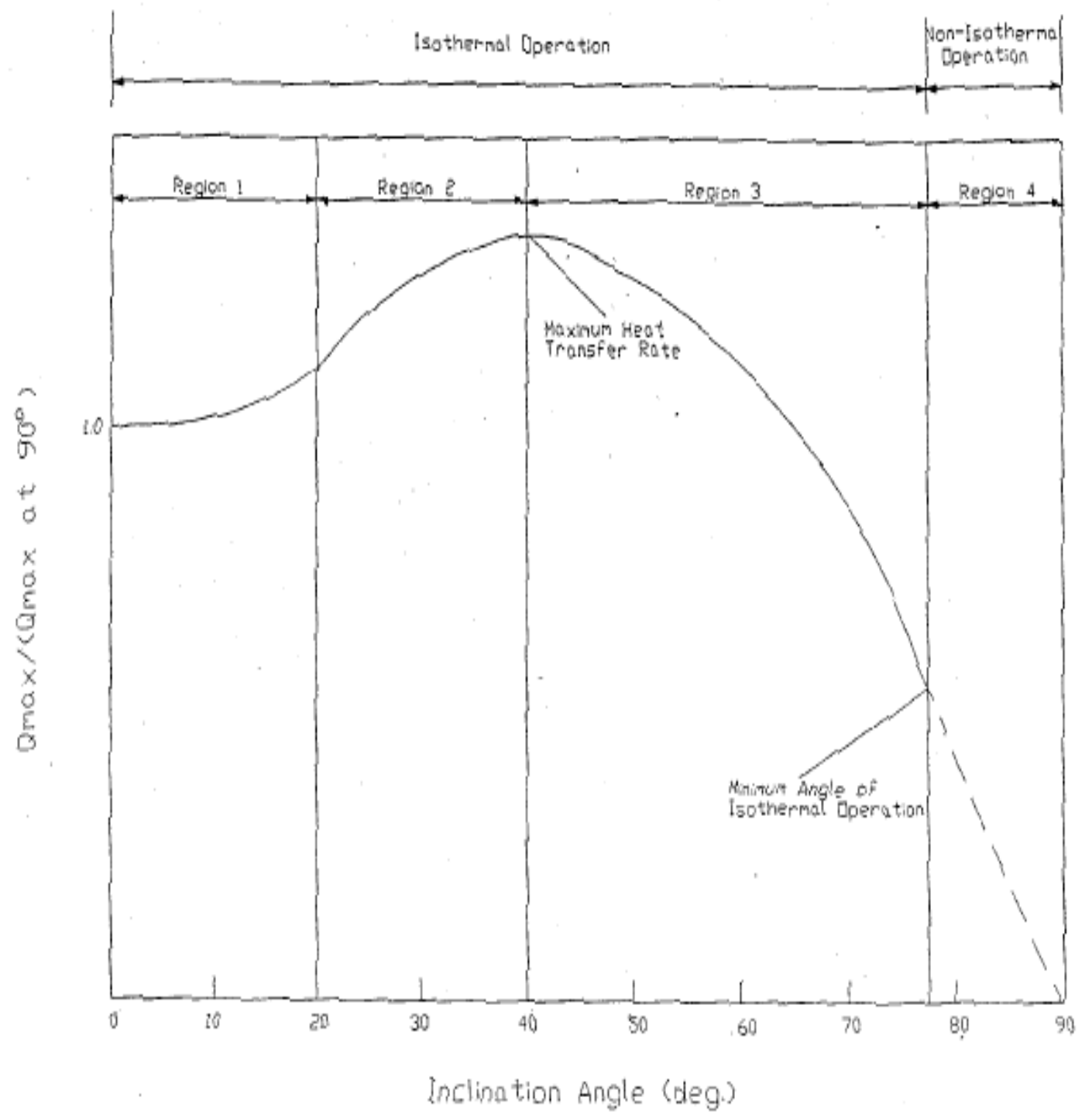

Figure 2-11. Operation regimes at various inclination angles (Terdtoon et al. 1990).

There is a range of inclination angles at which the thermosyphon shows better performance than at a vertical position, i.e., the critical heat transfer rate is higher. When the inclination angle increases from 0 degrees vertical to 90 degrees horizontal, the mean heat transfer coefficient will increase until it reaches the maximum value and then decrease (Zuo and Gunnerson 1995). When the inclination angle increases, the condenser heat transfer coefficient increases because of a thinning up-side liquid film, whereas the evaporator heat transfer coefficient decreases because of the enlargement of the liquid pool heating area and the comparatively poor liquid pool heat transfer, which has also been reported by Bontemps et al. (1987). When the thermosyphon is tilted to a small angle from a vertical position, the increase in condenser heat transfer coefficient dominates and the mean heat transfer coefficient of the thermosyphon increases. At large inclination angles, the liquid pool heating area expands, and thus the decrease in evaporator heat transfer coefficient dominates, resulting in lower mean heat transfer coefficients. 


\subsection{Summary}

The success of the next generation of nuclear reactors will depend, in part, on successfully utilizing process heat and on the selection of heat transport devices, such as the thermosyphon as discussed in this chapter. For high temperature applications requiring the transport of large amounts of thermal power at a small temperature difference between the heat source and the heat sink, the thermosyphon is one option. Thermosyphon working fluids should have a high latent heat of vaporization such as found for liquid metals, which in turn makes them a preferable choice for transporting thermal energy. Although considerable data already exists on the thermophysical properties of possible working fluids, data, especially in the vapor phase, is rarely available at the high temperatures of NGNP. Accurate performance predictions of thermosyphon startup and operational behavior is required to design and build reliable and efficient systems for high temperature process heat transfer from NGNP to a hydrogen plant.

Instabilities are common in both forced and natural circulation systems; the latter is more unstable than the former. The mechanisms that can lead to unstable operational behavior of the thermosyphon have been discussed along with the importance of having active nucleation sites in the evaporator section. Due to differences in operating conditions, previous studies have resulted in diverse values of the optimum inclination angle (corresponding to the maximum heat transfer rate) for a thermosyphon, the optimum inclination angle when the heat transfer capacity reaches its maximum is reported to be around 40 degrees (Terdtoon et al. 1990). The information in this section provides insights and options useful in the design and development of an NGNP process heat recovery system using a thermosyphon. 
This page intentionally left blank 


\section{THERMODYNAMIC ANALYSIS OF THERMOSYPHONS}

Complicated mathematical expressions and numerical schemes are helpful but sometimes may mask the real physics from a design engineer's point of view. Usually it is not desirable or necessary to get into such detail for most applications. Therefore a simple and understandable engineering method for analysis of thermosyphon performance becomes attractive in practice. This chapter provides a different view into the physics behind thermosyphon performance, based on thermodynamics.

In recent years, extensive studies have been conducted to provide a thorough understanding of thermosyphon operation and appropriate design schemes for practical use. Additionally, there are several surveys which illustrate state-of-the-art research on two-phase thermosyphons. Gross (1992) surveys condensation heat transfer inside a two-phase thermosyphon including a detailed description of fluid flow and a review of published experimental and theoretical investigations.

Grief (1988) reviewed research on natural circulation loops including the two-phase thermosyphon loop. A recent book by Lock (1992) provides a thorough discussion on various types of thermosyphons. Dobran (1989) summarizes heat pipe research and applications. A comprehensive review on flooding and entrainment inside heat pipes and thermosyphons was provided by Peterson and Bage (1991).

The first comprehensive experimental investigation on thermosyphon performance was conducted by Lee and Mital (1972). Since then, numerous experiment concentrating on various aspects of thermosyphon operation have been conducted. These studies include: Casarosa and Dobran (1988), Chen et al. (1991), Lock and Fu (1993), Gunnerson and Sanderlin (1994), and many others in the proceedings of the International Heat Pipe Conference.

The experimental thermosyphons used in previous studies were from vertical to inclined, from circular, annular to rectangular cross-section, from extra long (Haynes et al. 1992) to a very small size. The heating and cooling methods were from constant-heat flux, constant-temperature, forced-convective heating/cooling. The measurement techniques involved in these experiments ranged from conventional thermocouples, laser, thermal imaging techniques to neutron radiography (Tamaki et al. 1990).

Previous experimental studies have been able to provide useful insight into thermosyphon operation, set references for validation of theoretical models and provide database for design purposes. Additionally, many theoretical analyses incorporated empirical or semi-empirical correlations to simplify the models and the solution processes.

Since thermosyphon operation involves a series of complex processes related to phase change heat transfer, two-phase flow and interfacial phenomena, an exact theoretical analysis is difficult (if not impossible). Many previous studies have focused on isolated phenomena or regions inside the thermosyphon such as condensation heat transfer in the condenser (Gross 1992) and flooding in the condenser (Gross 1992; Peterson and Bage 1991).

The first model considering the thermosyphon as an integrated system was provided by Shiraishi et al. in 1981. Dobran (1989) developed a system model based upon conservation of mass, momentum, and energy and including thermal hydraulics of the vapor core, liquid film, and the liquid pool. Reed and Tien (1987) presented a one-dimensional model to predict steady-state and transient performance of the two-phase thermosyphon.

Harley and Faghri (1994) developed a transient two-dimensional model which includes conjugated heat transfer through the wall and the falling condensate film. In their study, vapor was assumed to be in a laminar flow regime. The effects of working fluid inventory and liquid pool were not included. Zuo and Gunnerson (1994 (i)) provided a numerical model to describe thermosyphon performance under various heating and cooling condition as well as the effects of working fluid inventory. 
Generally, previous theoretical models consist of a set of highly nonlinear partial differential equations with several empirical or semi-empirical correlations specified for shear stresses and heat transfer coefficients. The two-dimensional model provided by Harley and Faghri (1994) avoided the use of empirical correlations for interfacial mechanism because of the assumption of laminar vapor and liquid flows. However, to obtain solutions from these models, numerical techniques must be incorporated and significant programming efforts and computational time are required. Changes in geometry or boundary conditions may invalidate the models.

Recently, Gunnerson et al. (2007) performed convective loop analysis and comparison with $\mathrm{Na}$ as the coolant and stated two-phase benefits when compared with single phase for transferring the NGNP process heat, which enabled the author to carry out further analysis with the thermosyphon. This chapter provides a different but more practical view into the physics behind thermosyphon operation. The continuous phase change circulation inside an operating thermosyphon is considered as a thermodynamic cycle. Several important factors such as temperature difference (superheated vapor and saturated liquid) between the evaporator and the condenser, heat exchange between the liquid and the vapor are illustrated by classical thermodynamic diagrams and require only simple engineering calculations.

\subsection{General Model (Vertical Thermosyphon) and Flooding}

The circulation of the working fluid in a thermosyphon is the consequence of a pumping process that results from the conversion of potential thermal energy into kinetic energy in a well defined thermodynamic cycle.

As illustrated in Figure 3-1, thermosyphon operation consists of four processes:

1. In the evaporator section, the liquid receives heat and becomes vapor (process 1 to 2 )

2. The vapor travels through the adiabatic section due to pressure difference between the evaporator and the condenser (process 2 to 3 )

3. In the condenser, the vapor releases heat and becomes liquid (process 3 to 4 )

4. The condensed liquid returns to the evaporator through the adiabatic section due to gravitational force (process 4 to 1). These four processes form an internal thermodynamic cycle. The working fluid at state 2 can be slightly superheated for some cases (such as in the later case). Entropy increases during processes 2-3 and 4-1 due to irreversibilities from liquid-vapor interfacial and liquid-wall shear forces.

In order for liquid at state 4 (in condenser) to go back to the original state 1 (in evaporator), gravitational force must overcome frictional forces and move the liquid from the condenser to the evaporator. Pressure difference between the evaporator and the condenser depends on the heat transfer rate, geometric dimensions of the adiabatic section and thermophyscial properties of the working fluid. Generally, the larger the heat transfer rate and the L/D of the adiabatic section, the larger the pressure difference. 


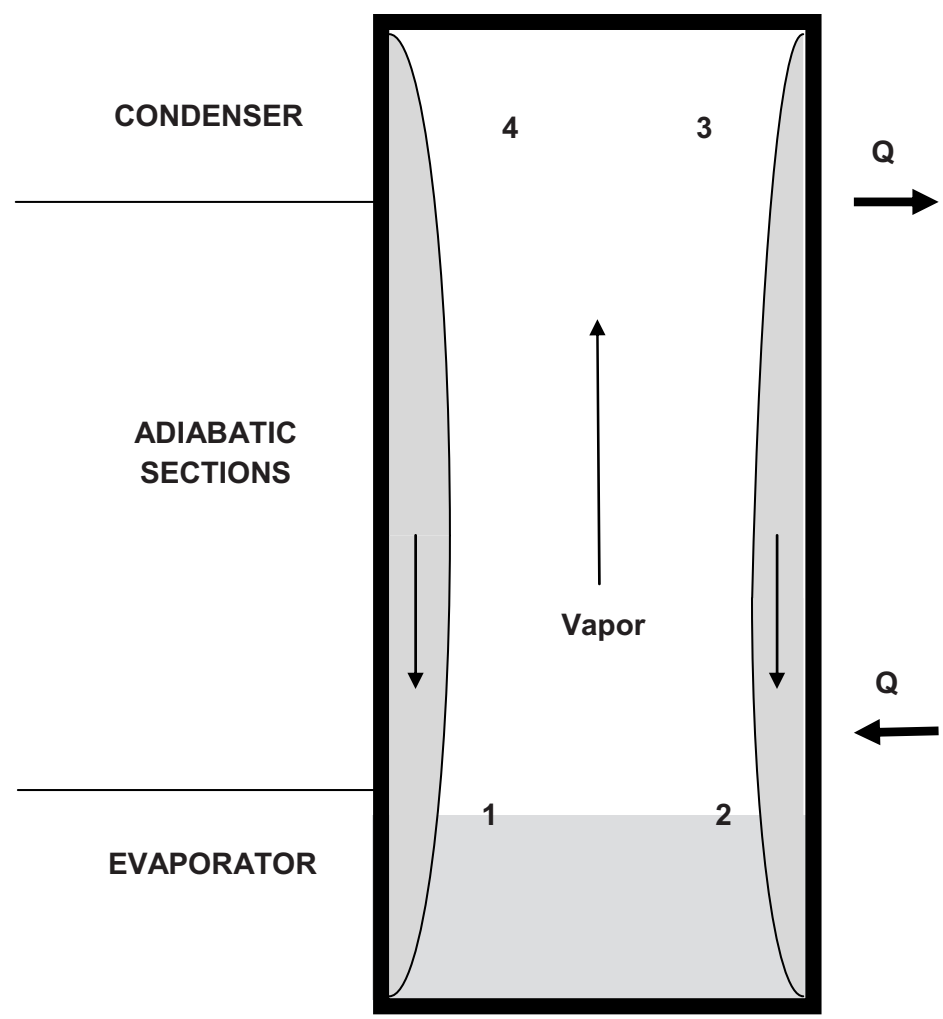

Figure 3-1. Working fluid circulation inside a vertical two-phase thermosyphon.

The flooding phenomenon in thermosyphon operation has been extensively studied (Peterson and Bage 1991; Reed and Tien 1987; Zuo and Gunnerson 1994 (ii); Kim and Peterson 1994). Whether flooding occurs when liquid flow is reversed or when liquid-vapor interface becomes unstable has been discussed (Roesler and Groll 1990). The ultimate cause of flooding is that the downward gravitational force is unable to overcome upward frictional forces.

In order for the condensate to return to the evaporator, the following condition must be satisfied:

$\rho_{\mathrm{L}} \mathrm{gL}_{\mathrm{a}} \geq \Delta \mathrm{P}_{\mathrm{f}}$

As mentioned earlier, $\Delta \mathrm{P}_{\mathrm{f}}$ corresponds to the frictional forces the liquid flow experiences and can be calculated when the thermosyphon geometry and heat transfer rate are known. For thermosyphon loops, Equation (3-1) may be viewed as a gravity limiting criterion (analogous to capillary limit in a wicked heat pipe).

From thermodynamics, a difference in saturation pressure is directly related to a difference in saturation temperature. A common P-T diagram is shown in Figure 3-2. For thermosyphon operation, the vaporization line as well as liquid and vapor zones are of interest.

Close inspection of the vaporization line shows the slope of the P-T curve (dP/dT) increasing with temperature, indicating that the same temperature difference can provide a larger $\Delta \mathrm{P}$ (more pumping power) if the thermosyphon is operating at a higher temperature. The same conclusion has been drawn by Richter and Gottschild (1994) for heat pipe operation. Additionally, with a higher operating temperature (increase in temperature) the liquid viscosity reduces and causes a higher flooding limit. 


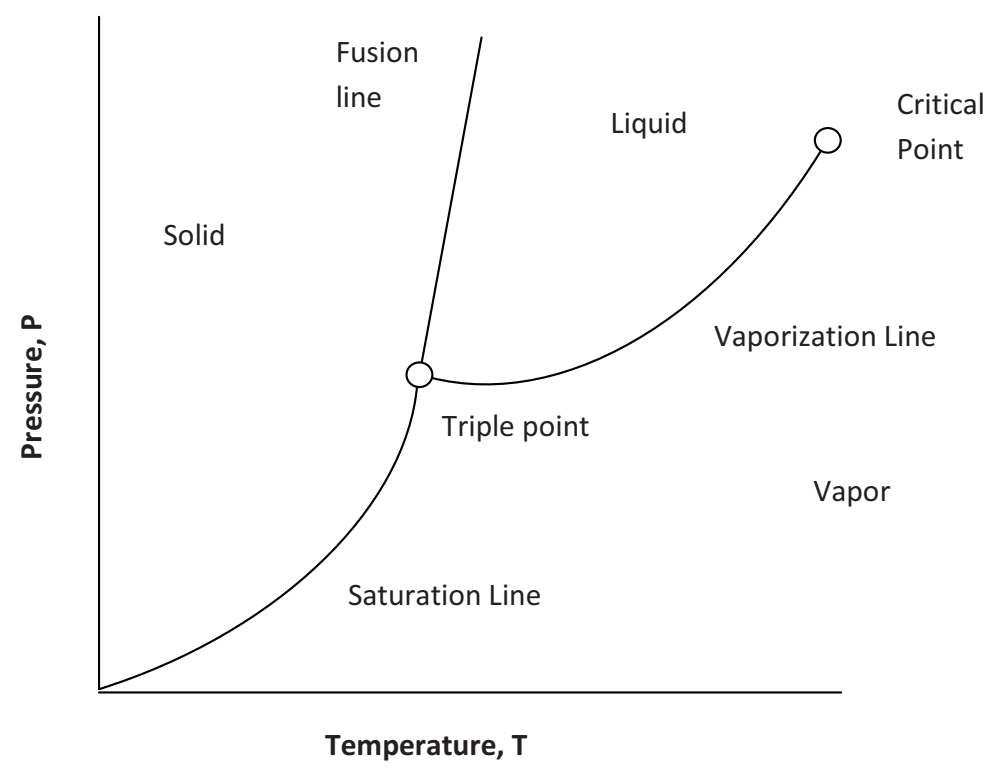

Figure 3-2. Pressure-temperature diagram (Single 1990).

\subsection{Thermodynamic Analysis of Two-phase Thermosyphon with Spiral Heat Exchangers}

Figure 3-3 shows a schematic diagram of the thermosyphon design, with SHEs and each corresponding thermodynamic state of the working fluid $(\mathrm{Na})$. The thermodynamics of thermosyphon design are illustrated in Figure 3-4. The area under T-s curve gives the net amount of heat being added to the working fluid (in the evaporator), which is ideally the same as the net amount of heat removed by the condenser. Thus, the T-s curve and P-v behavior is represented as just a single line, i.e., the net work in the closed system is zero, as shown in Figure 3-4.

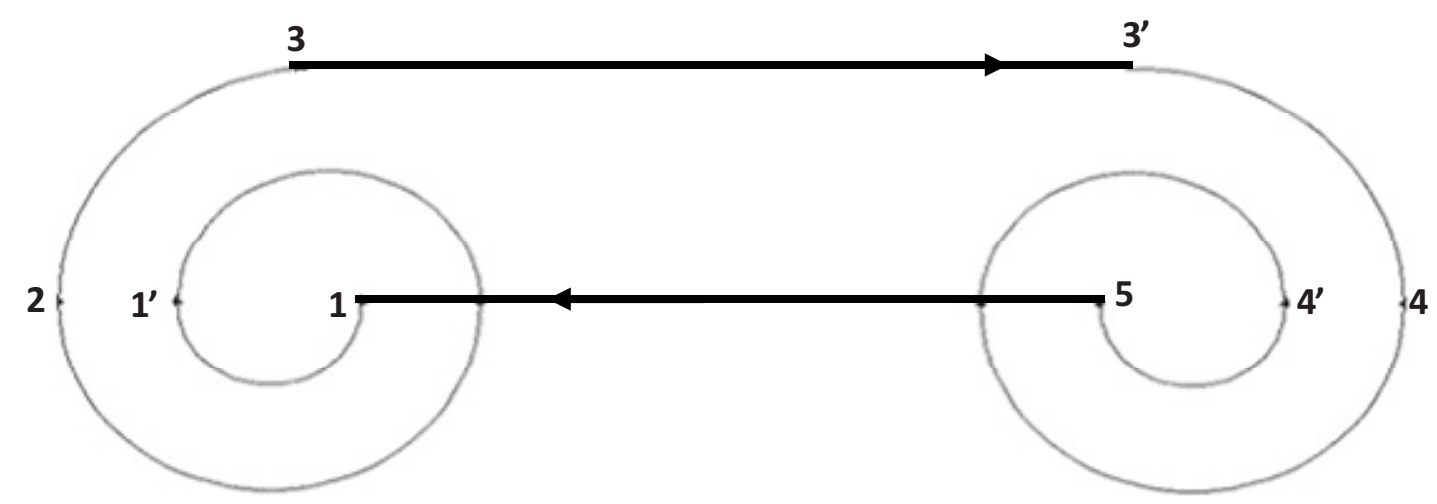

\begin{tabular}{|c|c|}
\hline Position Number & Thermodynamic State of the Fluid \\
\hline 1,5 & SubCooled Liquid \\
\hline $1^{\prime}, 4^{\prime}$ & Saturated Liquid \\
\hline 2,4 & Saturated Vapor \\
\hline $3,3^{\prime}$ & Superheated Vapor \\
\hline
\end{tabular}

Figure 3-3. Schematic diagram of the thermodynamic process. 

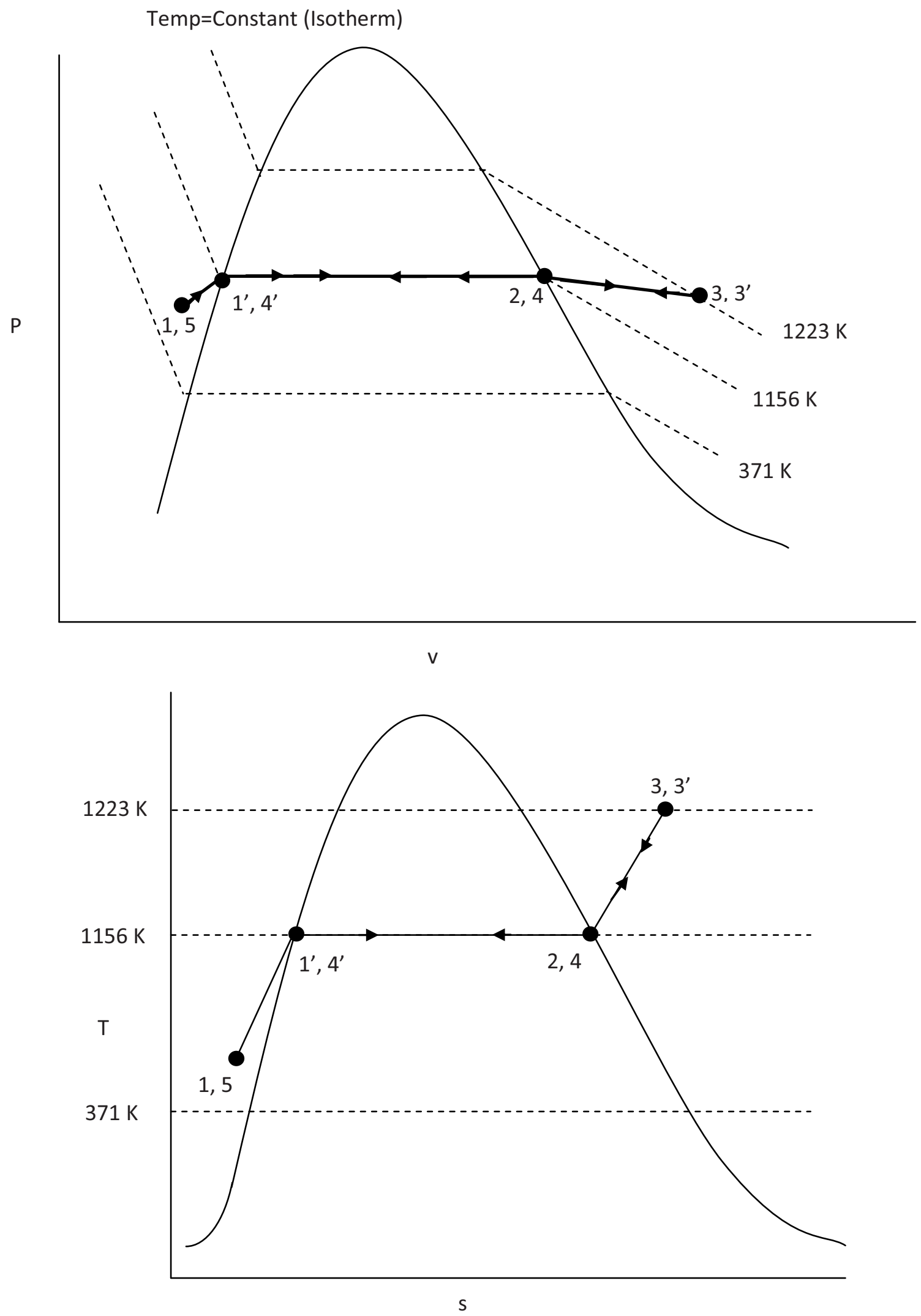

Figure 3-4. Pressure-specific volume and temperature-specific entropy diagrams. 
The heat transferred to the working fluid in the evaporator region is given by

$\mathrm{Q}_{\text {in, }}$ evaporator $=\mathrm{h}_{3}-\mathrm{h}_{1}=\Delta \mathrm{h}_{13}$

The heat rejection in the condenser is given by

$\mathrm{Q}_{\mathrm{ou},}$ condenser $=\mathrm{h}_{3^{\prime}}-\mathrm{h}_{5}=\Delta \mathrm{h}_{53^{\prime}}$

The continuous phase change circulation inside an operating thermosyphon may be viewed as a thermodynamic cycle. The working fluid (subcooled state) enters the evaporator at a temperature $\mathrm{T}_{1}$ (slightly higher temperature than its melting temperature) and is raised to the upper operating temperature $T_{1}$ (saturated liquid state) along the path 1-1'. Evaporation and expansion from the liquid volume to the vapor volume occurs along the path 1'-2 (saturated vapor state). In process 1'-2, heat is being added at constant temperature, which raises enthalpy of the working fluid from $h_{1}$ to $h_{2}$. In process 2-3, the vapor

is being superheated, which further leads to the increase in enthalpy from $h_{2}$ to $h_{3}$ but exhibits a little drop in pressure due to the frictional pressure drop, which is proportional to the square of the velocity. The maximum velocity and losses due to friction occur at the evaporator exit.

$$
\frac{\Delta \mathrm{P}_{\mathrm{e}}}{\mathrm{L}_{\mathrm{e}}}=\frac{4 \mathrm{f}_{\mathrm{e}} \rho_{\mathrm{V}} \mathrm{V}_{\mathrm{e}}^{2}}{2 \mathrm{D}_{\mathrm{e}}}
$$

For sodium vapor at half sonic velocity, $\frac{\Delta \mathrm{P}_{\mathrm{e}}}{\mathrm{L}_{\mathrm{e}}} \sim 10^{-3} \mathrm{MPa} / \mathrm{m}$. In process 3'-4, the working fluid releases its thermal energy in the form of heat rejection, which drops the temperature. By stage 4', the vapor is all condensed and a saturated liquid state remains. In process 4'-5 the fluid is all in liquid state and even after the temperature drops, the temperature at 5 is always higher than the melting point temperature of the fluid, which is now in subcooled state. If the thermosyphon is being operated after a long nonoperational period, external heating will be provided such that the fluid temperature never goes below the melting temperature (as can be seen from Figure 3-4). The subcooled liquid Na returns to the evaporator through the condensate return line by gravity. Thermosyphons can be operated without having a phase change, but with a phase change, a thermosyphon has the advantage of high-enthalpy transport, which includes the sensible heat of the liquid, the latent heat of vaporization, and possible vapor superheat.

\subsection{Summary}

Empirical mathematical expressions and numerical schemes are helpful, but sometimes they may mask the real physics from a design engineer's point of view. This section provides a different view into the physics behind thermosyphon operation and performance based on thermodynamics. The continuous phase change circulation inside an operating thermosyphon is considered as a thermodynamic cycle. Several important factors such as temperature difference (superheated vapor and saturated liquid) between the evaporator and the condenser, heat exchange between the liquid and the vapor are illustrated by classical thermodynamic diagrams and require only simple engineering calculations. 


\section{DIMENSIONLESS NUMBERS IN BOILING FLUID FLOW FOR THERMOSYPHON AND HEAT PIPE}

\subsection{Introduction}

Bridgman (Kern 1982) has by far presented the most extensive proof of the mathematical principles underlying dimensional analysis. Because it operates only upon the dimensions of the variables, it does not directly produce numerical results from the variables, but instead yields a modulus by which the observed data can be combined and the relative influence of the variables established (Kern 1982). Dimensional Analysis (Barenblatt 1996) is a mathematical technique used in research work for design and for conducting model tests. It deals with the dimensions of the physical quantities involved in the phenomenon. All physical quantities are measured by comparison, which is made with respect to an arbitrarily fixed value. Fundamental dimensions (Bansal 1983) are directly measurable quantities such as mass $(\mathrm{M})$, length $(\mathrm{L})$, time $(\mathrm{T})$, and temperature $(\theta)$. Derived or secondary dimensions are those expressed in terms of fundamental dimensions, e.g., velocity is denoted by distance per unit time $(\mathrm{L} / \mathrm{T})$ and density by mass per unit volume $\left(\mathrm{M} / \mathrm{L}^{3}\right)$. Then velocity and density become derived quantities.

\subsection{Thermosyphon}

It is useful to relate the hydraulic characteristics and thermo-physical properties of flow to the ratio of the various forces encountered in the flow to improve the heat transfer characteristics of a thermosyphon for NGNP process heat transfer (Sabharwall et al. 2009 (iv)). The physical quantities and their respective fundamental dimensions used for the analysis are: $l(\mathrm{~L}), \mathrm{V}_{\mathrm{S}}\left(\mathrm{L} \mathrm{T}^{-1}\right), \mathrm{C}_{\mathrm{p}}\left(\mathrm{L}^{2} \mathrm{~T}^{-2} \theta^{-1}\right), \mathrm{h}_{\mathrm{fg}}\left(\mathrm{L}^{2} \mathrm{~T}^{-2}\right), \rho_{1}$ $\left(\mathrm{M} \mathrm{L}^{-3}\right), \rho_{\mathrm{v}}\left(\mathrm{M} \mathrm{L}^{-3}\right), \mu_{1}\left(\mathrm{M} \mathrm{L}^{-1} \mathrm{~T}^{-1}\right), \mu_{\mathrm{v}}\left(\mathrm{M} \mathrm{L}^{-1} \mathrm{~T}^{-1}\right), \mathrm{D}(\mathrm{L}), \mathrm{K}\left(\mathrm{M} \mathrm{L} \mathrm{T}^{-3} \theta^{-1}\right), \dot{\mathrm{m}}\left(\mathrm{M} \mathrm{T}^{-1}\right), \mathrm{Q}\left(\mathrm{M} \mathrm{L}^{2} \mathrm{~T}^{-3}\right)$.

Repeating Variables: $\rho_{1}, \mathrm{D}, \mu_{1}, \mathrm{C}_{\mathrm{p}}$

The repeating variables were chosen such that in the analysis we have the effect of the fundamental property of the fluid $\left(\rho_{1}, \mu_{1}, C_{p}\right)$ and also the characteristic property of the heat transfer device (D).

Number of physical quantity (n): 12

Fundamental Dimensions (k): M, L, T, and $\theta$ i.e., 4

Therefore, the number of dimensionless pi terms: $\mathrm{n}-\mathrm{k}: 12-4=8$

$$
\begin{aligned}
& \Pi_{1}=\left(\rho_{\mathrm{L}}\right)^{\mathrm{a}}(\mathrm{D})^{\mathrm{b}}\left(\mu_{\mathrm{L}}\right)^{\mathrm{c}}\left(\mathrm{C}_{\mathrm{P}}\right)^{\mathrm{d}}(l)^{1} \\
& \Pi_{1}=\frac{l}{\mathrm{D}} \text { (First pi term) }
\end{aligned}
$$

The first pi term is just the geometric ratio or an aspect ratio of the given thermosyphon.

$$
\begin{aligned}
& \Pi_{2}=\left(_{\mathrm{L}}\right)^{\mathrm{a}}(\mathrm{D})^{\mathrm{b}}\left(\mu_{\mathrm{L}}\right)^{\mathrm{c}}\left(\mathrm{C}_{\mathrm{P}}\right)^{\mathrm{d}}\left(\mathrm{V}_{\mathrm{S}}\right)^{1} \\
& \Pi_{2}=\underbrace{\frac{\rho_{\mathrm{L}} \mathrm{V}_{\mathrm{S}} \mathrm{D}}{\mu_{\mathrm{L}}}}_{\operatorname{Re}} \text { (Second pi term) }
\end{aligned}
$$


The second pi term is the Reynolds number, which is the ratio of inertial forces $\left(\rho_{L} V_{S}\right)$ to viscous forces $\left(\frac{D}{\mu_{L}}\right)$, and it quantifies the relative importance of these two types of forces for sonic flow conditions and is also used to identify different flow regimes, such as laminar or turbulent flow. In this case, the Reynolds number can be taken as the limiting Reynolds number as maximum velocity is limited by the sonic velocity of vapor.

$$
\begin{aligned}
& \Pi_{3}=\left(\rho_{\mathrm{L}}\right)^{\mathrm{a}}(\mathrm{D})^{\mathrm{b}}\left(\mu_{\mathrm{L}}\right)^{\mathrm{c}}\left(\mathrm{C}_{\mathrm{P}}\right)^{\mathrm{d}}\left(\mathrm{h}_{\mathrm{fg}}\right)^{1} \\
& \Pi_{3}=\frac{\rho_{\mathrm{L}}^{2} \mathrm{D}^{2} \mathrm{~h}_{\mathrm{fg}}}{\mu_{\mathrm{L}}^{2}} \\
& \Pi_{3}=(\operatorname{Re})^{2} \underbrace{\left(\frac{\mathrm{h}_{\mathrm{fg}}}{\mathrm{V}_{\mathrm{S}}^{2}}\right)}_{\mathrm{E}_{\mathrm{r}}} \text { (Third pi term) }
\end{aligned}
$$

$E_{r}$ is the ratio of thermal to kinetic energy. Thermal energy is the energy given out by the evaporator to convert the liquid into its vapor state, which is traveling with sonic velocity $\mathrm{V}_{\mathrm{S}}$.

$$
\begin{aligned}
& \Pi_{4}=\left(\rho_{\mathrm{L}}\right)^{\mathrm{a}}(\mathrm{D})^{\mathrm{b}}\left(\mu_{\mathrm{L}}\right)^{\mathrm{c}}\left(\mathrm{C}_{\mathrm{P}}\right)^{\mathrm{d}}\left(\mu_{\mathrm{V}}\right)^{1} \\
& \Pi_{4}=\frac{\mu_{\mathrm{V}}}{\mu_{\mathrm{L}}} \text { (Fourth pi term) }
\end{aligned}
$$

The fourth pi term is the ratio of the viscosities of vapor to liquid. Both the viscosities vary inversely with each other with respect to increase in temperature. Vapor viscosity tends to increase making the vapor more viscous, whereas liquid viscosity tends to decrease with the increase in temperature.

$$
\begin{aligned}
& \Pi_{5}=\left(\rho_{\mathrm{L}}\right)^{\mathrm{a}}(\mathrm{D})^{\mathrm{b}}\left(\mu_{\mathrm{L}}\right)^{\mathrm{c}}\left(\mathrm{C}_{\mathrm{P}}\right)^{\mathrm{d}}(\mathrm{K})^{1} \\
& \Pi_{5}=\frac{\mathrm{K}}{\mathrm{C}_{\mathrm{P}} \mu_{\mathrm{L}}}=\frac{1}{\operatorname{Pr}} \quad \text { (Fifth pi Term) }
\end{aligned}
$$

The fifth pi term is the inverse of the Prandtl number, which approximates the ratio of thermal diffusivity to momentum diffusivity (kinematic viscosity).

$$
\begin{aligned}
& \Pi_{6}=\left(\rho_{\mathrm{L}}\right)^{\mathrm{a}}(\mathrm{D})^{\mathrm{b}}\left(\mu_{\mathrm{L}}\right)^{\mathrm{c}}\left(\mathrm{C}_{\mathrm{P}}\right)^{\mathrm{d}}(\dot{\mathrm{m}})^{1} \\
& \Pi_{6}=\frac{\dot{\mathrm{m}}}{\mu_{\mathrm{L}} \mathrm{D}}
\end{aligned}
$$




$$
\Pi_{6}=(\mathrm{Re}) \underbrace{\left(\frac{\mathrm{A}}{\mathrm{D}^{2}}\right)}_{\text {Dimensionless Geometric Parameter }} \quad \text { (Sixth pi term) }
$$

The sixth pi term has both dependence of fluid flow properties $(\mathrm{Re})$ and geometric parameters and can simply be taken as a modified Reynolds number. For a noncircular duct, 'D' should be replaced by ' $D_{h}$ ' which is the hydraulic diameter. The geometric parameter for a circular duct is equal to $\frac{\pi}{4}$, for a noncircular duct such as a square duct it is equal to 1 , and for any other geometrical shape of the thermosyphon duct this value can be easily obtained by using the following expression:

$$
\begin{aligned}
& \frac{\mathrm{A}}{\mathrm{D}^{2}}=\frac{(\text { Perimeter })^{2}}{16(\text { Area })} \\
& \Pi_{7}=\left(\rho_{\mathrm{L}}\right)^{\mathrm{a}}(\mathrm{D})^{\mathrm{b}}\left(\mu_{\mathrm{L}}\right)^{\mathrm{c}}\left(\mathrm{C}_{\mathrm{P}}\right)^{\mathrm{d}}\left(\rho_{\mathrm{V}}\right)^{1} \\
& \Pi_{7}=\frac{\rho_{\mathrm{V}}}{\rho_{\mathrm{L}}} \text { (Seventh pi term) }
\end{aligned}
$$

The seventh Pi term is the density ratio of vapor to liquid.

$$
\begin{aligned}
& \Pi_{8}=\left(\rho_{\mathrm{L}}\right)^{\mathrm{a}}(\mathrm{D})^{\mathrm{b}}\left(\mu_{\mathrm{L}}\right)^{\mathrm{c}}\left(\mathrm{C}_{\mathrm{P}}\right)^{\mathrm{d}}(\mathrm{Q})^{1} \\
& \Pi_{8}=\frac{\rho_{\mathrm{L}}^{2} \mathrm{D} \mathrm{Q}}{\mu_{\mathrm{L}}^{3}} \\
& \Pi_{8}=\left(\frac{\rho_{\mathrm{L}} \mathrm{V}_{\mathrm{S}} \mathrm{D}}{\mu_{\mathrm{L}}}\right)^{3}\left(\frac{\mathrm{Q}}{\rho_{\mathrm{L}} \mathrm{D}^{2} \mathrm{~V}_{\mathrm{S}}^{3}}\right) \\
& \Pi_{8}=(\operatorname{Re})^{3} \underbrace{\frac{\mathrm{h}_{\mathrm{fg}}}{\mathrm{V}_{\mathrm{S}}^{2}}}_{\mathrm{E}_{\mathrm{r}}}) \quad \text { (Eighth pi term) }
\end{aligned}
$$

$\mathrm{E}_{\mathrm{r}}$ is the ratio of thermal to kinetic energy. Thermal energy is the energy given out by the evaporator to convert the liquid into its vapor state, which is traveling with sonic velocity $\mathrm{V}_{\mathrm{S}}$.

\subsection{Heat Pipe}

Carrying out similar dimensional (Buckingham's- $\pi$ ) analysis for a heat pipe, the physical quantities and their respective fundamental dimensions that are used for this analysis are the same as those used previously for the thermosyphon, the only additional physical quantity is surface tension, i.e., $\sigma\left(\mathrm{M} \mathrm{T}^{-2}\right)$.

Repeating Variables: $\rho_{L}, \mathrm{D}, \mu_{\mathrm{L}}, \mathrm{C}_{\mathrm{p}}$

Number of physical quantity $\left(\mathrm{n}_{1}\right): 13$ 
Fundamental Dimensions $\left(\mathrm{k}_{1}\right): \mathrm{M}, \mathrm{L}, \mathrm{T}$ and $\theta$, i.e., 4

Therefore, number of pi terms: $\mathrm{n}_{1}-\mathrm{k}_{1}: 13-4=9$

In this case, the first 8 pi terms are the same as those obtained for the thermosyphon, the only additional pi term in this case is the $\Pi_{9}$ (ninth pi term) due to the effect of surface tension, which cannot be ignored in this case because of the wick. Although the $\Pi_{8}$ term for both the thermosyphon and the heat pipe are the same, by rearranging some terms we can also obtain the $\Pi_{8}$ term for a heat pipe as:

$$
\begin{aligned}
& \Pi_{8}=\frac{\rho_{\mathrm{L}}^{2} \mathrm{D} \mathrm{Q}}{\mu_{\mathrm{L}}{ }^{3}} \\
& \Pi_{8}=\left(\frac{\rho_{\mathrm{L}} \mathrm{V}_{\mathrm{s}} \mathrm{D}}{\mu_{\mathrm{L}}}\right)^{2}\left(\frac{\mathrm{Q}}{\mathrm{V}_{\mathrm{S}}^{2} \mathrm{D} \mu_{\mathrm{L}}}\right) \\
& \Pi_{8}=(\mathrm{Re})^{2} \underbrace{\left(\frac{\sigma}{\mathrm{V}_{\mathrm{S}} \mu_{\mathrm{L}}}\right)}_{\frac{1}{C a}}\left(\frac{Q}{\mathrm{D} \mathrm{V}_{\mathrm{S}} \sigma}\right) \\
& \Pi_{8}=(\operatorname{Re})\left(\frac{1}{\mathrm{Ca}}\right)\left(\frac{\mathrm{h}_{\mathrm{fg}}}{\frac{\sigma}{\rho_{\mathrm{L}} \mathrm{D}}}\right) \\
& \Pi_{8}=(\operatorname{Re})\left(\frac{1}{\mathrm{Ca}}\right) \underbrace{\left(\frac{\sigma \mathrm{D}^{2}}{\mathrm{~h}_{\mathrm{g}}}\right)}_{\frac{\mathrm{E}_{\mathrm{M}}}{\rho_{\mathrm{L}} \mathrm{D}^{3}}}
\end{aligned}
$$

The Reynolds, which is the ratio of inertial forces to viscous forces, also quantifies the relative importance of these two types of forces for given flow conditions. $\left(\frac{1}{\mathrm{Ca}}\right)$ is the inverse of the capillary number, which represents the relative effect of surface tension forces versus viscous forces for a fluid moving with velocity $V_{S} . E_{M}$ is the ratio of two energies. The numerator represents latent heat of vaporization, which can further be referred to as latent energy per unit mass, and the denominator represents surface tension energy per unit mass.

$$
\begin{aligned}
& \Pi_{9}=\left(\rho_{\mathrm{L}}\right)^{\mathrm{a}}(\mathrm{D})^{\mathrm{b}}\left(\mu_{\mathrm{L}}\right)^{\mathrm{c}}\left(\mathrm{C}_{\mathrm{P}}\right)^{\mathrm{d}}(\sigma)^{1} \\
& \Pi_{9}=\frac{\rho_{\mathrm{L}} \mathrm{D} \sigma}{\mu_{\mathrm{L}}^{2}}
\end{aligned}
$$




$$
\begin{aligned}
& \Pi_{9}=\underbrace{\left(\frac{\rho_{\mathrm{L}} \sigma}{\mu_{\mathrm{L}} \rho_{\mathrm{V}} \mathrm{V}_{\mathrm{S}}}\right)}_{\mathrm{F}_{\mathrm{N}}}\left(\frac{\mathrm{D} \rho_{\mathrm{V}} \mathrm{V}_{\mathrm{S}}}{\mu_{\mathrm{V}}}\right)\left(\frac{\mu_{\mathrm{V}}}{\mu_{\mathrm{L}}}\right) \\
& \Pi_{9}=\underbrace{\left(\frac{\rho_{\mathrm{L}} \sigma}{\mu_{\mathrm{L}} \rho_{\mathrm{V}} \mathrm{V}_{\mathrm{S}}}\right)}_{\mathrm{F}_{\mathrm{N}}}(\operatorname{Re})\left(\frac{\mu_{\mathrm{V}}}{\mu_{\mathrm{L}}}\right) \quad \text { (Ninth pi term) }
\end{aligned}
$$

where $\mathrm{F}_{\mathrm{N}}$ refers to the heat pipe fluid number (Sockalingam 1972) and is independent of any geometric parameters, the magnitude of $\mathrm{F}_{\mathrm{N}}$ normally decreases with an increase in temperature, for all fluids.

\subsection{Results and Discussion}

Most of the pi-groups that were obtained during the analysis are commonly used in many heat transfer applications. In this section, mainly $\mathrm{E}_{\mathrm{r}}$ and $\mathrm{E}_{\mathrm{M}}$, which are derived dimensionless numbers, are explained in detail. $\mathrm{E}_{\mathrm{r}}$ is the ratio of thermal to kinetic energies, thermal energy is the energy used up by the fluid for phase transformation from liquid to vapor state. The square of the velocity represents the kinetic energy head.

$$
\mathrm{E}_{\mathrm{r}}=\frac{\mathrm{h}_{\mathrm{fg}}}{\mathrm{V}_{\mathrm{S}}^{2}}
$$

On rearranging Equation (4-31) by multiplying the numerator and the denominator by $\rho_{v}$,

$$
\mathrm{E}_{\mathrm{r}}=\frac{\mathrm{h}_{\mathrm{fg}} \rho_{\mathrm{V}}}{\mathrm{V}_{\mathrm{S}}^{2} \rho_{\mathrm{V}}}
$$

Equation (4-32) is the ratio of thermal energy per unit volume to kinetic energy per unit volume. Because the pressure drop $\Delta \mathrm{P}$ is one of the key parameters in any heat exchanger optimization, the denominator of Equation (4-32) has been related to $\Delta \mathrm{P}$ (Sabharwall et al. 2009 (iii)).

$$
\frac{\Delta \mathrm{P}}{l}=\frac{4 \mathrm{f}_{\mathrm{V}} \mathrm{V}_{\mathrm{S}}^{2}}{2 \mathrm{D}}
$$

From Equations (4-32) and (4-33),

$$
\mathrm{E}_{\mathrm{r}}=\frac{\mathrm{h}_{\mathrm{fg}} \rho_{\mathrm{V}}}{\frac{\Delta \mathrm{P}}{2 \mathrm{f}} \frac{1}{\left(\frac{l}{\mathrm{D}}\right)}}
$$


For a given aspect ratio $\left(\frac{l}{D}\right)$ and assuming negligible change in the friction factor for a given turbulent flow range, the following appears:

$$
\frac{E_{\mathrm{r} 1}}{E_{\mathrm{r} 2}}=\frac{\left[\frac{\left(h_{\mathrm{fg}} \rho_{\mathrm{V}}\right)}{\Delta \mathrm{P}}\right]_{1}}{\left[\frac{\left(\mathrm{h}_{\mathrm{fg}} \rho_{\mathrm{V}}\right)}{\Delta \mathrm{P}}\right]_{2}}
$$

Equation (4-35) is the ratio of volumetric latent energy per unit pressure drop for two different conditions. These may be different alkaline metals at the same temperature or be for the same fluid, but at different temperatures. The above equation could be used to determine an optimum working fluid for a given set of operating conditions. For example, ratio's of $\mathrm{E}_{\mathrm{r}}$ of Li with other alkaline metals at 2,000 K shows $1.5,1.8$, and 2.6 times volumetric energy gain when compared with $\mathrm{Na}, \mathrm{K}$, and cesium respectively.

Equation (4-35) could also be used for the same coolant but at different temperatures; the volumetric latent energy decreases because of the decrease in latent heat, which could optimize the working fluid selection based on operating temperature. Thus, at lower temperatures the volumetric latent energy per unit pressure drop is higher because of higher latent heat and lower pressure drop (because $V_{S}$ increases with increase in temperature, though the density decreases but the net effect due to square dependence of pressure drop on velocity leads to a lower pressure drop), as can be seen in Figure 4-1. Li, on the other hand, shows higher thermal energy than the rest of the alkaline metals, as shown in Figure 4-1, but can be discarded as it does not boil until 1,590 $\mathrm{K}$ at atmospheric pressure, which is higher than the available temperature from NGNP.

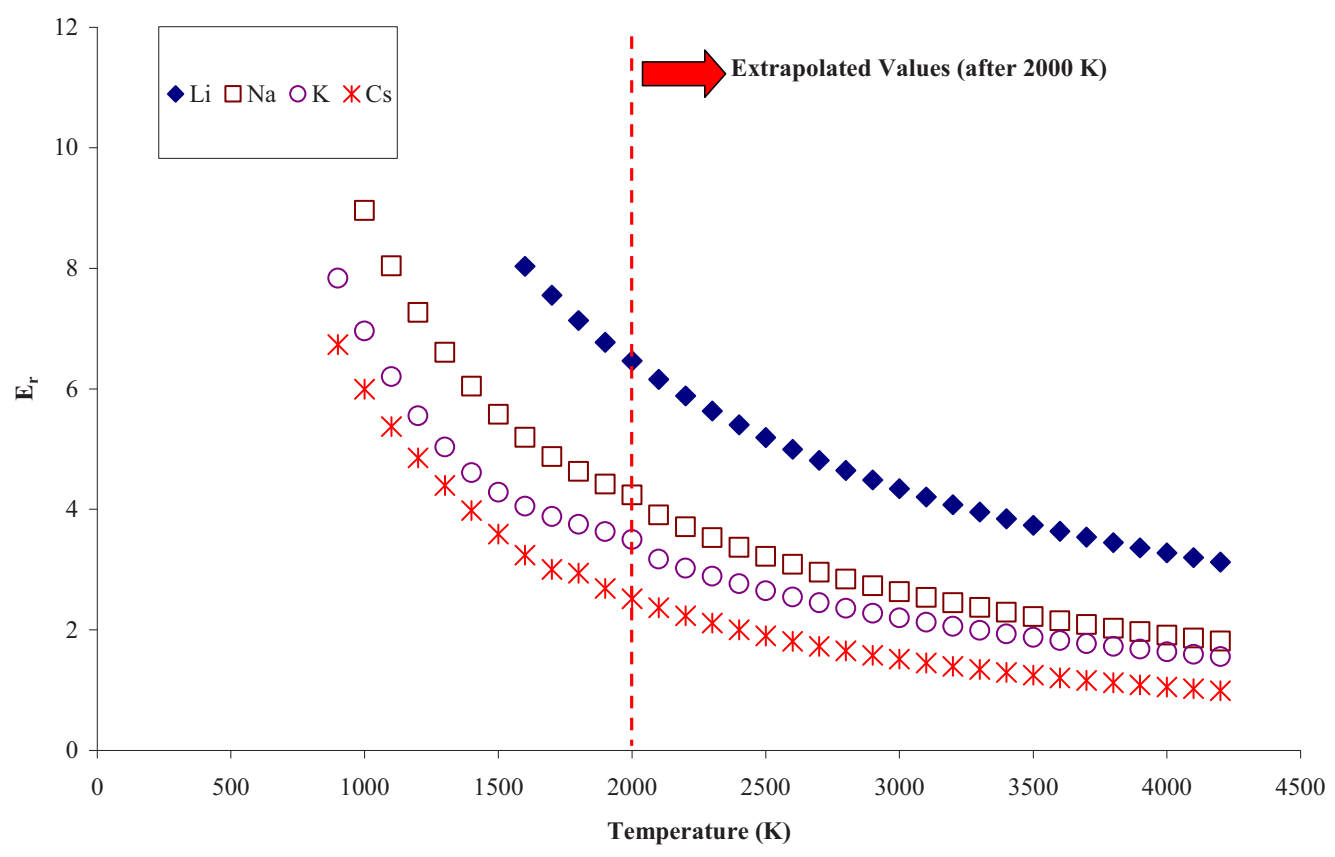

Figure 4-1. Variation in $\mathrm{E}_{\mathrm{r}}$ with respect to temperature for alkaline metals. 
In Figure 4-2, the dependence of $\mathrm{E}_{\mathrm{M}}$ is shown with varying diameters at 1,300 K. $\mathrm{E}_{\mathrm{M}}$ is the ratio of the latent heat of vaporization per unit mass to the surface tension energy per unit mass.

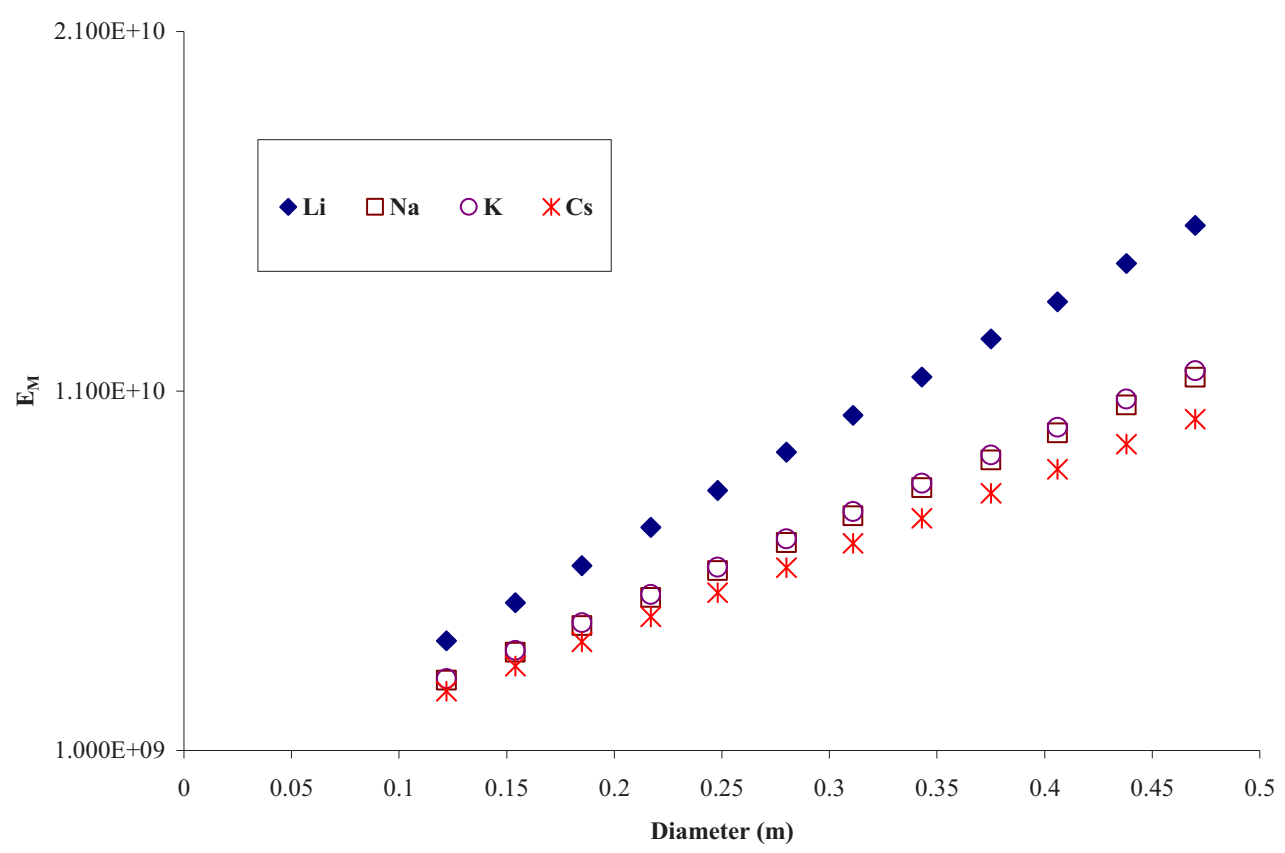

Figure 4-2. Variation in $\mathrm{E}_{\mathrm{M}}$ with respect to diameter for alkaline metals.

For a calculated value for $\mathrm{Na}$ of $\mathrm{E}_{\mathrm{M}}$ equal to $2.422 \times 10^{10}$ (at 1,300 K) and at $1 \mathrm{~m}$ diameter, in order to obtain the same $\mathrm{E}_{\mathrm{M}}$ value for $\mathrm{Li}, \mathrm{K}$, and $\mathrm{Cs}$, the diameter obtained was equal to $0.73 \mathrm{~m}, 0.98 \mathrm{~m}$, and $1.11 \mathrm{~m}$, respectively. The narrower the pipe diameter, the greater the pressure drop, therefore $\mathrm{Li}$ has the highest pressure drop among all alkaline metals for a given value of $\mathrm{E}_{\mathrm{M}}$. Capillary pressure (Sockalingam 1972) $\left(\mathrm{P}_{\mathrm{c}}\right)$ that draws the alkaline metal into the wick is determined by porosity of the wick and surface tension of the alkaline metal, as can be seen from the following equation:

$P_{c}=\frac{2 \sigma}{D_{w}}$

The wick for Li does not have to be very fine: it could be coarse, because Li has the highest surface tension when compared with other alkaline metals, thus reducing the manufacturing cost.

From Equations (4-26) and (4-36),

$\mathrm{E}_{\mathrm{M}}$ could be rewritten in terms of $\mathrm{P}_{\mathrm{c}}$ such that:

$$
\mathrm{E}_{\mathrm{M}}=\frac{\mathrm{h}_{\mathrm{fg}}}{\frac{\sigma}{\mathrm{D}_{\mathrm{w}}} \frac{\mathrm{D}_{\mathrm{w}}}{\mathrm{D} \rho_{\mathrm{L}}}}
$$




$$
\mathrm{E}_{\mathrm{M}}=\frac{\text { latent heat energy } / \text { mass }}{\text { (height of liquid column })(\mathrm{g})\left(\frac{\mathrm{D}_{\mathrm{w}}}{\mathrm{D}}\right)}
$$

From Equation (4-38), we can conclude that for an optimum working fluid for a given $\mathrm{D}$ and $\mathrm{D}_{\mathrm{w}}$ the value of $\mathrm{E}_{\mathrm{M}}$ should be as low as possible, such that greater height of the liquid can be achieved through the wick in a heat pipe. As discussed previously, for $\mathrm{E}_{\mathrm{r}}$ the magnitude should be as high as possible such that the volumetric energy gain is maximized for a given heat pipe or thermosyphon.

It is important to recognize the fundamental limitations (Soumerai 1987) and strengths of the dimensional analysis techniques from which the above written equations have been derived. Also, the dimensionless numbers would vary were different repeated variables chosen. The weakness of dimension analysis is that it sheds no light on the physical nature of a phenomenon, nor does it provide any explicit formulation for the unknown dimensionless function. Conversely, the strength of this technique is its generality, since it does not depend on any particular physical model of the phenomenon, a factor that is most important in complex situations such as the chaotic analytically intractable turbulent flow regimes. Once the conclusions derived from dimensional analysis are empirically validated, which should be done in the near future for both heat pipe and thermosyphon devices, an optimum working fluid can be chosen. The correlations are perfectly general and are therefore not restricted to only alkaline metals or any kind of fluid or the range of velocities measured, or even the particular kind of heat pipe or thermosyphon employed.

\subsection{Summary}

Dimensional Analysis is a valuable mathematical technique useful in research work for design and conducting model tests. This analysis yielded two terms $-\mathrm{E}_{\mathrm{r}}$ and $\mathrm{E}_{\mathrm{M}}$-particular to the operation of these devices in addition to those commonly used in many heat transfer applications. $\mathrm{E}_{\mathrm{r}}$ relates the latent heat of vaporization to the pressure drop across the device, while $\mathrm{E}_{\mathrm{M}}$ relates the latent heat to the capillary pressure. The significance of these two terms is discussed. The universal nature of these numbers should be useful in increasing the fundamental understanding of both thermosyphons and heat pipes. 


\section{INTERMEDIATE HEAT EXCHANGERS}

\subsection{Introduction}

The NGNP is intended to increase energy efficiency in electricity production primarily by exchanging the steam power cycle for the Brayton power cycle. Overall thermal efficiency should increase to approximately 50\% (Fisher and Sindelar 2008). The Brayton cycle operates at higher temperatures than the steam cycle and offers the opportunity to use some of the plant's energy to produce hydrogen in addition to electrical power. The production of power at higher efficiency using the Brayton Cycle and hydrogen production require both heat, at higher temperatures up to $1,300 \mathrm{~K}$, and highly effective compact heat exchangers (CHEs) to transfer heat to either the power or process cycle. Today's CHEs provide very efficient heat transfer (>95\%) (Fisher and Sindelar 2008) and approach the operating temperature of the Brayton cycle. Thus, they are ideal candidates for service in the NGNP. Very efficient heat transfer from primary to secondary fluid loops is critical to the NGNP concept and the purpose in selecting a CHE was to maximize the heat transfer surface area per volume of heat exchanger. It has the benefit of reducing heat exchanger size, making it more economical from a materials-of-construction and facility footprint perspective. However, the demands of the high-temperature Brayton cycle challenge the boundaries of existing heat exchanger technology for service in nuclear systems. Irrespective of the NGNP reactor type (prismatic core or pebble bed) and the resultant coolant, the key to high efficiency is a high effectiveness heat exchange. Efficient design of the intermediate heat exchanger (IHX) is critical for effective utilization of the energy generated in the NGNP, therefore a CHE is chosen. The design of the intermediate heat exchanger requires reconciling a large number of considerations, primarily including:

- $\quad$ CHE to improve safety and economics

- Achieving the required thermal effectiveness (boundary temperature limitation for efficient heat transfer to hydrogen plant) at minimal pressure drop

- Choosing suitable materials for construction to address the high temperature and corrosion issues

- Ensuring valid mechanical design and sustainability at a high operating temperature.

CHEs are characterized by large surface area-to-volume ratios; $300 \mathrm{~m}^{2} / \mathrm{m}^{3}$ to greater than $3,000 \mathrm{~m}^{2} / \mathrm{m}^{3}$ are available (counts all area exposed to working fluid, Fisher and Sindelar 2008). Their large surface area-to-volume ratio indicates small flow passages. This, in turn, indicates large resistance to flow, which may increase further by surface contours designed to enhance turbulence within the flow channels. The flow paths of CHEs are kept short to lower operating pressures and reduce stress on materials of construction (Fisher and Sindelar 2008).

\subsection{Heat Exchangers for the NGNP Intermediate Loop}

Due to the high temperature requirements of the heat exchangers and the relatively high cost of the associated construction materials, CHEs are receiving attention for NGNP system interfaces. The CHEs being considered for the intermediate loop are:

- Plate type heat exchanger

- Plate and fin heat exchangers

- Printed circuit heat exchangers (PCHEs)

- Spiral heat exchangers (SHEs)

- Shell and tube heat exchangers (conventional heat exchanger). 
The key characteristics of CHEs are low heat losses because of compactness, close temperature approach, and less pumping power compared to the conventional heat exchanger. In order to achieve a high degree of compactness, the tube diameters would have to be very small, causing difficulties in manufacturing (Davis et al. 2005).

\subsubsection{Plate Type Heat Exchangers}

In a plate type heat exchanger, plate or planar heat transfer surfaces are the fundamental heat transfer surfaces rather than tubes. Common plate heat exchangers deploy metal plates arranged in a stack-wise fashion and sealed with gaskets, welds, brazing, or diffusion bonding (Figure 5-1). Counter flow, cross flow, and co-current flow can be arranged by altering the design of the supply manifolds to the heat exchanger. Plate type heat exchangers consists of a series of thin, corrugated alloy plates, which are gasketed and compressed together inside a carbon steel frame. Once compressed, the plate pack forms an arrangement of parallel flow channels. Each plate has a contoured surface that provides additional surface area, tortuous flow paths, and contact points with adjacent plates (Sherman and Chen 2008). The two fluids (hot and cold) flow countercurrent to each other in alternate channels, as shown in Figure 5-1. Each plate is fitted with a gasket to direct the flow, seal the unit, and prevent fluid intermixing. Choice of gasket materials is critical to the reliable operation of plate type units (Katzel 2000). These plates act as primary heat transfer surfaces by conducting heat directly through metal plates from one fluid to another. A hybrid welded-plate heat exchanger (Bavex; see Figure 5-2) is reported to be capable of operation at $900^{\circ} \mathrm{C}$ and pressures to $6 \mathrm{MPa}$ on the plate side. It is called a hybrid because one fluid is contained inside the plates while the other flows between the plates from baffled plenums inside a pressure boundary (Fisher and Sindelar 2008). It is reminiscent of a shell and tube arrangement with substantially greater surface area. Plates can be produced up to $0.35 \mathrm{~m}$ wide and $16 \mathrm{~m}$ long (Fisher and Sindelar 2008). Other variants of the welded plate type heat exchanger are produced, some of which do not require external shells. Service conditions range up to $700^{\circ} \mathrm{C}$ and $30 \mathrm{MPa}$ (in an external shell).

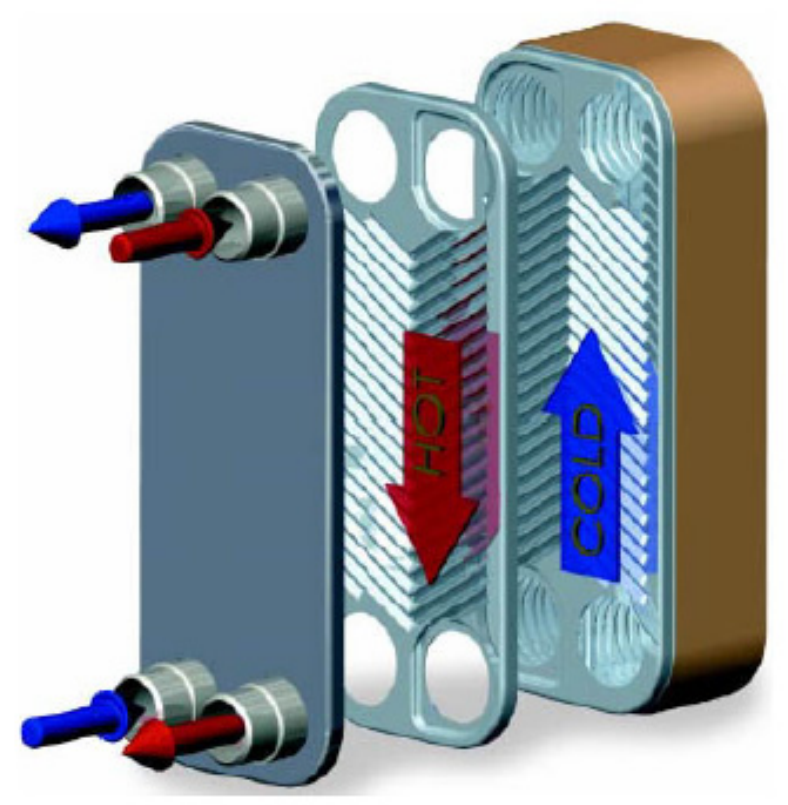

Figure 5-1. Flat plate CHE (Sherman and Chen 2008). 


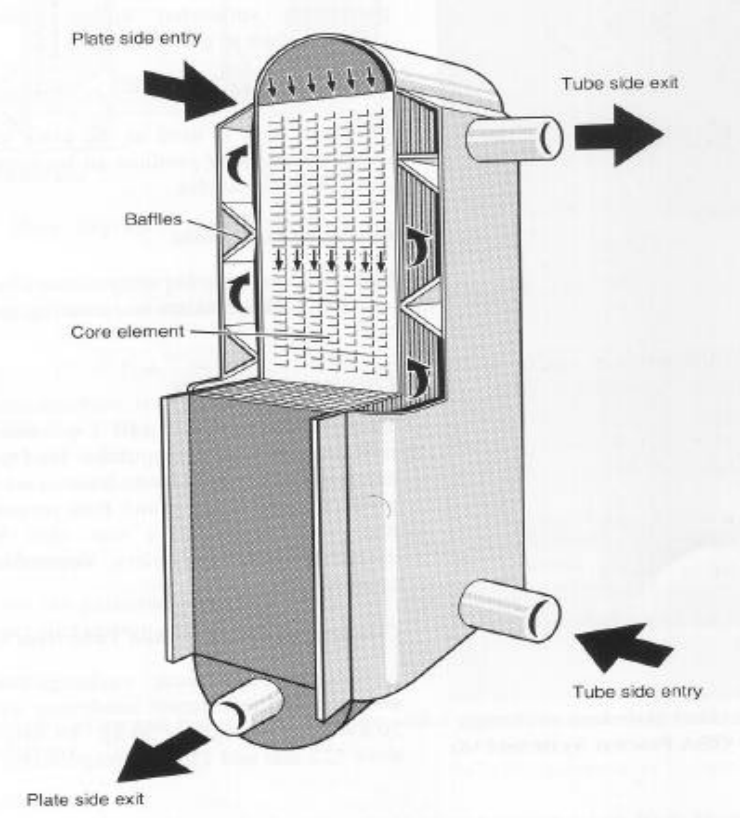

Figure 5-2. Bavex welded plate heat exchanger (Fisher and Sindelar 2008).

The metal plates can be stacked together in quantities to provide enough heat transfer capacity for the intended NGNP application. Plate edges are sealed by various means, but for the NGNP application, process operating temperatures limit the available joining methods to high-temperature brazing or welding. By sealing the edges and providing two separated flow paths, heat can be directly transferred from one fluid to another through a single barrier (plate) on either side, as shown in Figure 5-3 (Fisher and Sindelar 2008).

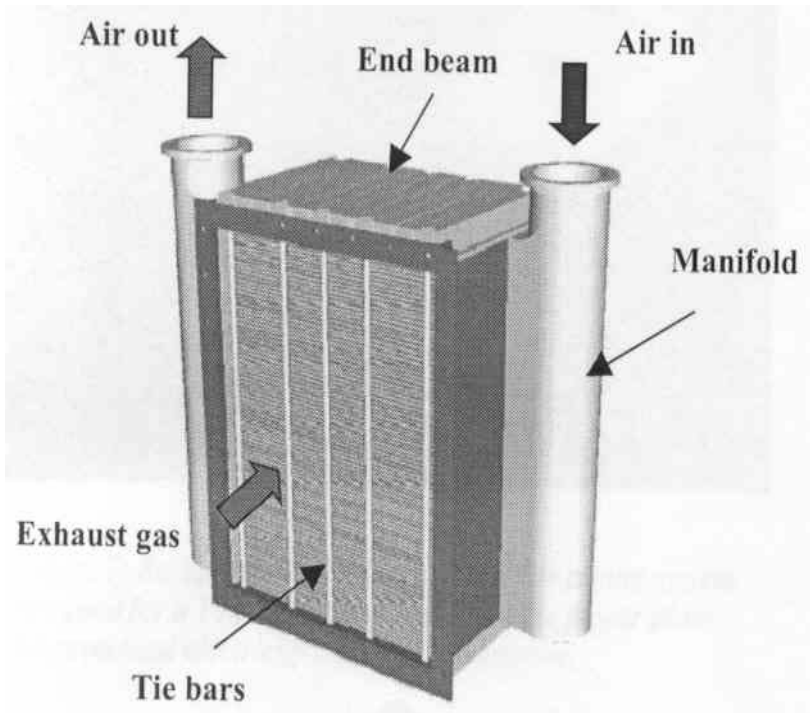

Figure 5-3. Plate type heat exchanger. Laser welded pairs of plates, stacked to form flow paths between the welded pairs. Installed in a $100 \mathrm{~kW}$ (e) micro-gas-turbine generating plant (Fisher and Sindelar 2008) 


\subsubsection{Plate and Fin Heat Exchanger}

Plate and fin heat exchangers are formed by stacking flat metal plates alternately with corrugated metal plates (fins). Metal bars are placed around the perimeters between pairs of plates to support the stack and seal the edges, except for inlet and outlet passages (Sherman and Chen 2008). Heat transfer occurs as hot and cold fluids flow through the fins between alternate flat plates. Corrugated plates are secondary heat transfer surfaces, adding surface area and turbulence to the fluid flow (dependent on configuration) for greater heat transfer to the plates. Large numbers of plate and fin heat exchangers have been joined by brazing since the 1940s, but more recently, manufacturers have also used diffusion bonding for plate and fin models, as can be seen in Figure 5-4 (Fisher and Sindelar 2008). Both stainless steel and titanium plate and fin heat exchangers have been produced for service where conditions of higher temperature and/or pressure exist. A plate and fin heat exchanger with the arrangement of flat plates separated by corrugated spacers in order to increase the contact surface area between the plates is shown in Figure 5-5. Figure 5-6 shows a diffusion-bonded titanium plate fin heat exchanger being testing for possible NGNP use (Sherman and Chen 2008).

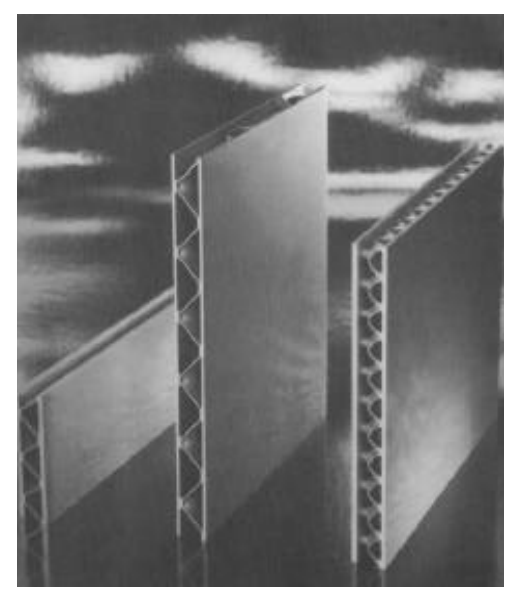

Figure 5-4. Elements of diffusion bonded plate and fin heat exchanger (Fisher and Sindelar 2008).

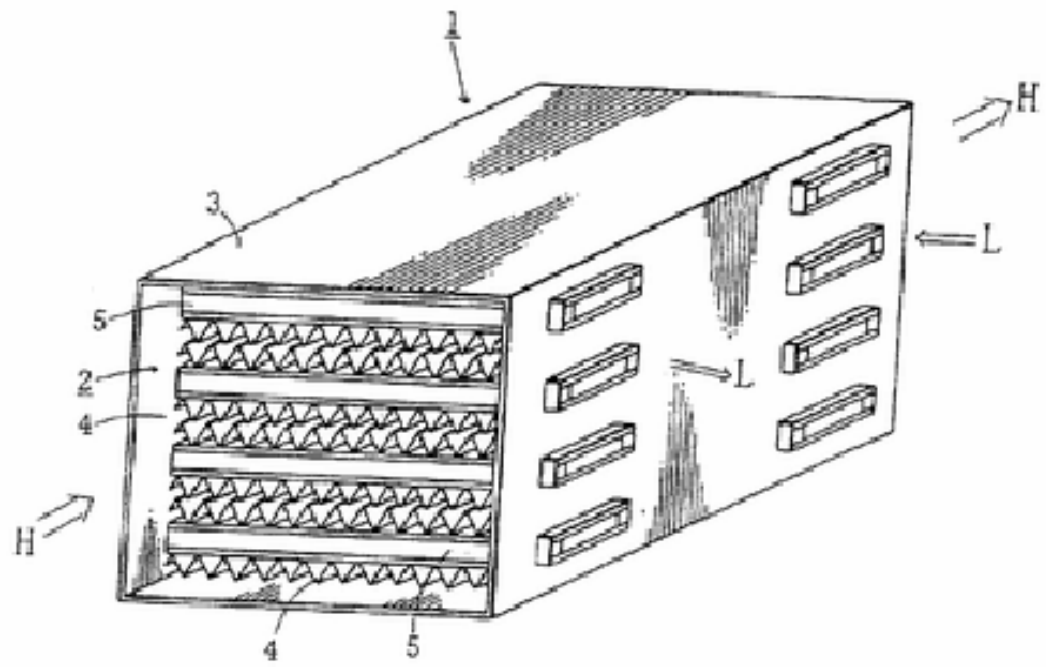

Figure 5-5. Plate-fin heat exchanger (Sherman and Chen 2008). 


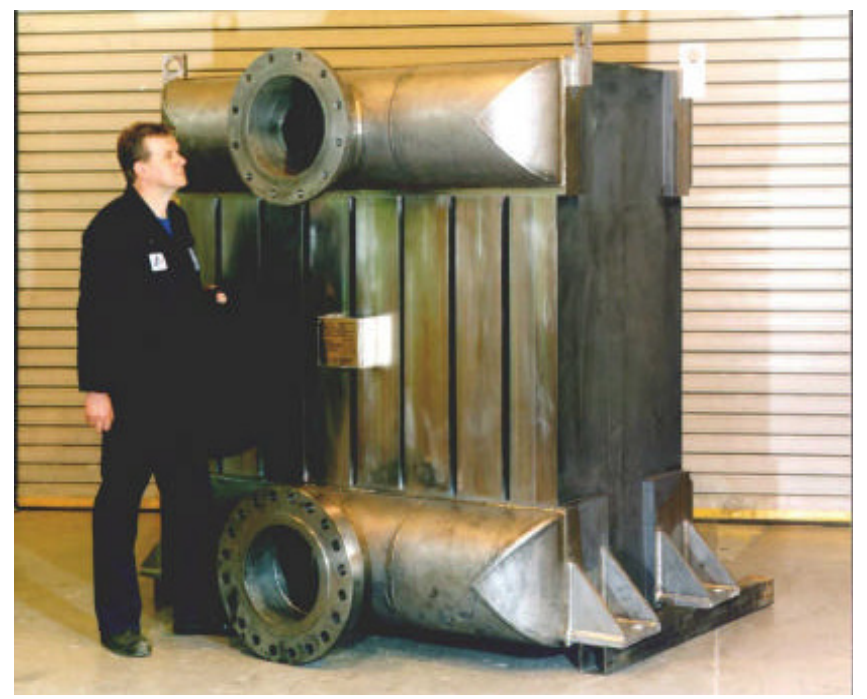

Figure 5-6. Diffusion-bonded titanium plate-fin heat exchanger. ${ }^{\mathrm{c}}$

\subsubsection{Printed Circuit Heat Exchanger}

A PCHE is a relatively new concept that has only been commercially manufactured by Heatric ${ }^{\mathrm{TM}}$ since 1985. Interestingly, the PCHE was virtually unmentioned in the heat exchanger literature until the late 1990s. PCHEs are robust heat exchangers that combine compactness, low pressure drop, high effectiveness, and the ability to operate with a very large pressure differential between hot and cold sides (Heatric ${ }^{\mathrm{TM}}$ Homepage 2007). These heat exchangers are especially well suited where compactness is important. The Heatric ${ }^{\mathrm{TM}}$ heat exchanger falls within the category of CHEs because of its high surface density area $\left(>2,500 \mathrm{~m}^{2} / \mathrm{m}^{3}\right)$ (Heatric ${ }^{\mathrm{TM}}$ Homepage 2007). In particular, it is generally categorized as a printed circuit heat exchanger (Hesselgreaves 2001). As the name PCHE implies, this is the same technique as the one developed for producing standard printed circuit boards for electronic equipment. In the first step of the manufacturing process, the fluid passages are photochemically etched into both sides of a metal plate (Figure 5-7).
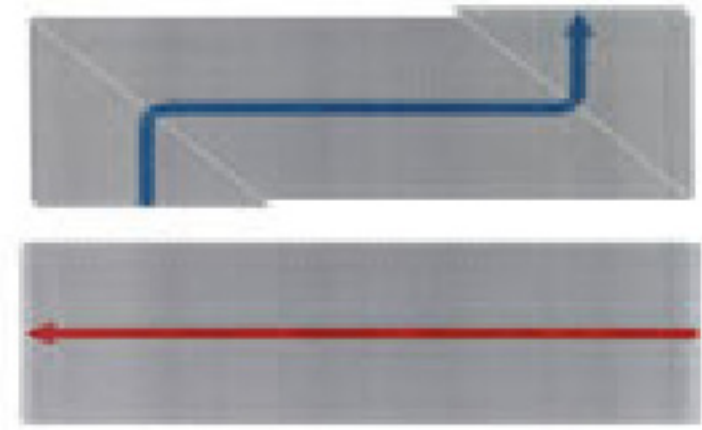

Figure 5-7. First step - plate passages (Heatric ${ }^{\mathrm{TM}}$ Homepage 2007).

The etched-out plates are thereafter joined by diffusion bonding, which is the second step and results in extremely strong all-metal heat exchanger cores (Figure 5-8). Normally, only one side of each plate is etched-out. The diffusion bonding process allows grain growth, thereby essentially eliminating the interface at the joints, which in turn acquire parental metal strength. Because of diffusion bonding, its expected lifetime exceeds that of any other heat exchanger, based on a brazed structure (Dewson 2003).

Plates for primary and secondary fluids are stacked alternately and formed into a module by diffusion bonding (Figure 5-9). Modules may be used individually or joined with others to achieve the needed energy transfer capacity between fluids.

c. "Diffusion-Bonded Titanium Plate-Fin Heat Exchanger," available at http://www.iaea.org/inis/aws/htgr/fulltext/gtpcs_11.pdf accessed on August 28, 2008. 


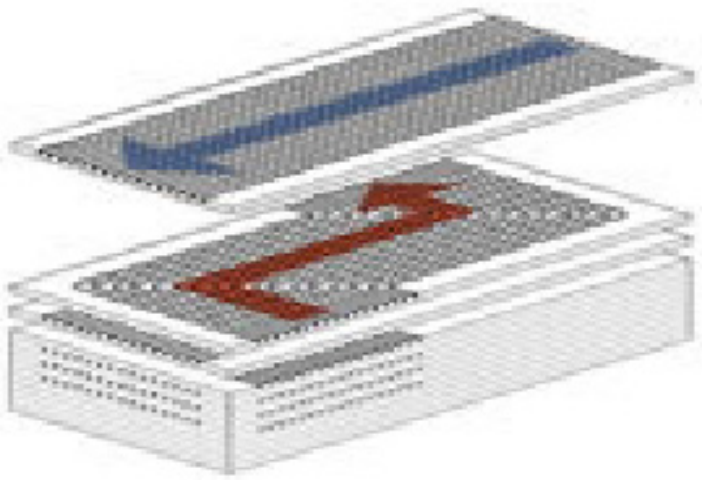

Figure 5-8. Second step - diffusion bonding of plates (Heatric ${ }^{\mathrm{TM}}$ Homepage 2007).

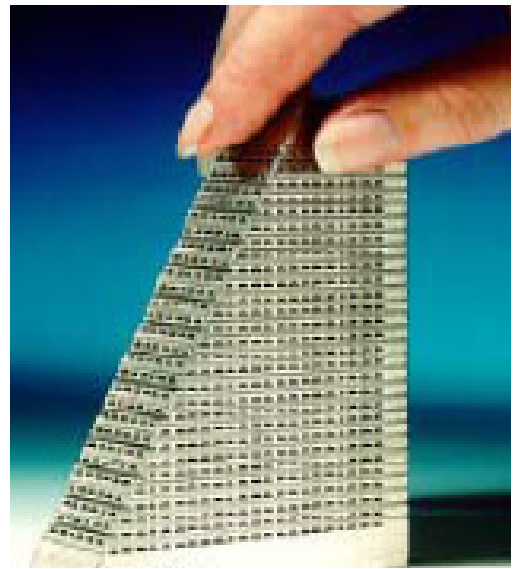

Figure 5-9. Diffusion bonded printed circuit heat exchanger section (Heatric ${ }^{\mathrm{TM}}$ Homepage 2007).

A stack of etched-out plates that have been bonded together comprise a block as a third step. The complete heat exchanger core is composed by welding together as many of these blocks as the thermal duty (flow capacity) of the heat exchanger requires (Figure 5-10).

The flow passages typically have a semicircular cross section as shown in Figure 5-11, and may also be radially corrugated as needed (Figure 5-12). Their width and depth vary between $1.0-2.0 \mathrm{~mm}$ and $0.5-1.0 \mathrm{~mm}$, respectively (Heatric ${ }^{\mathrm{TM}}$ Homepage 2007; Haynes 2002).

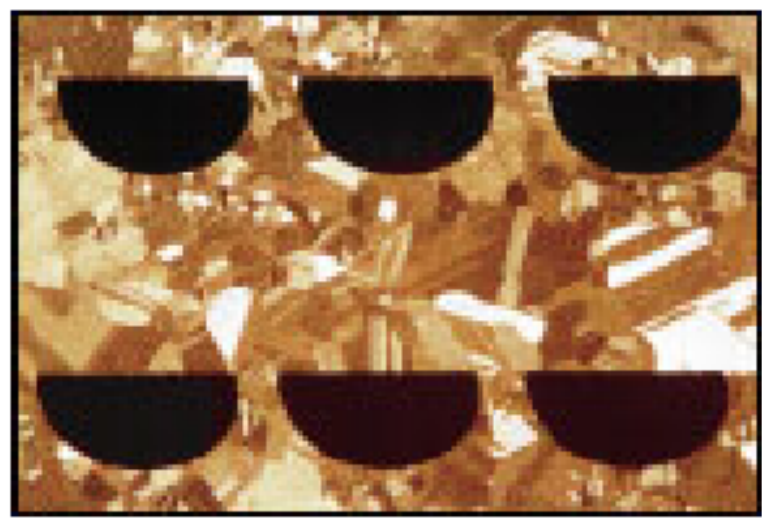

Figure 5-11. Cross sectional view of the semi circular passages (Heatric ${ }^{\mathrm{TM}}$ Homepage 2007).

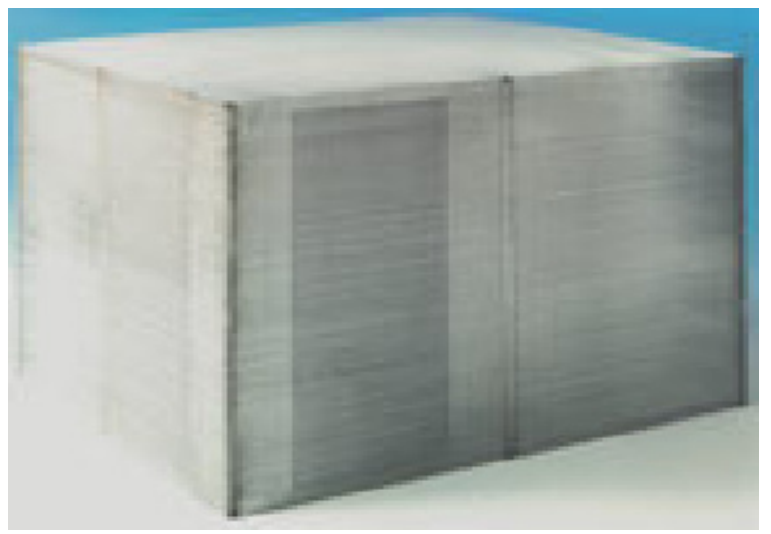

Figure 5-10. Third step - block composed of diffusion bonded plates (Heatric ${ }^{\mathrm{TM}}$ Homepage 2007).

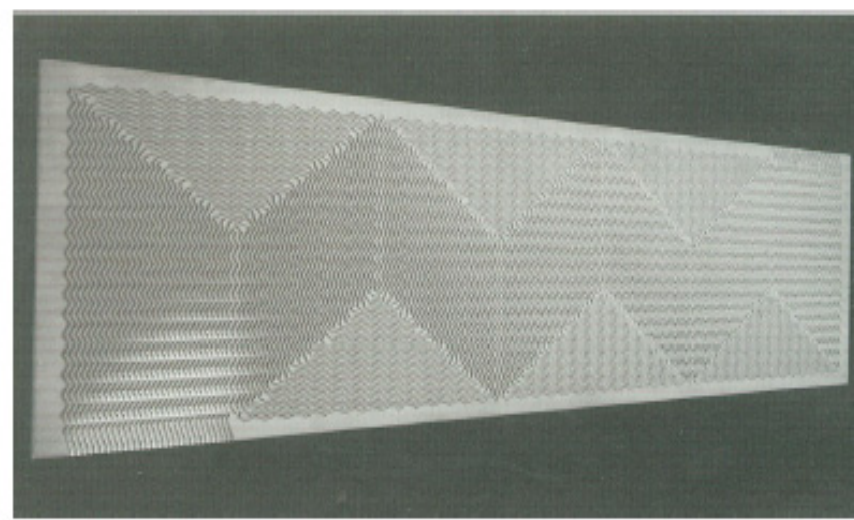

Figure 5-12. Side view of passage shapes (Hesselgreaves 2001). 
Figure 5-13 shows the finished heat exchanger, and Figure 5-14 shows the flow paths in a typical Heatric $^{\mathrm{TM}}$ design.

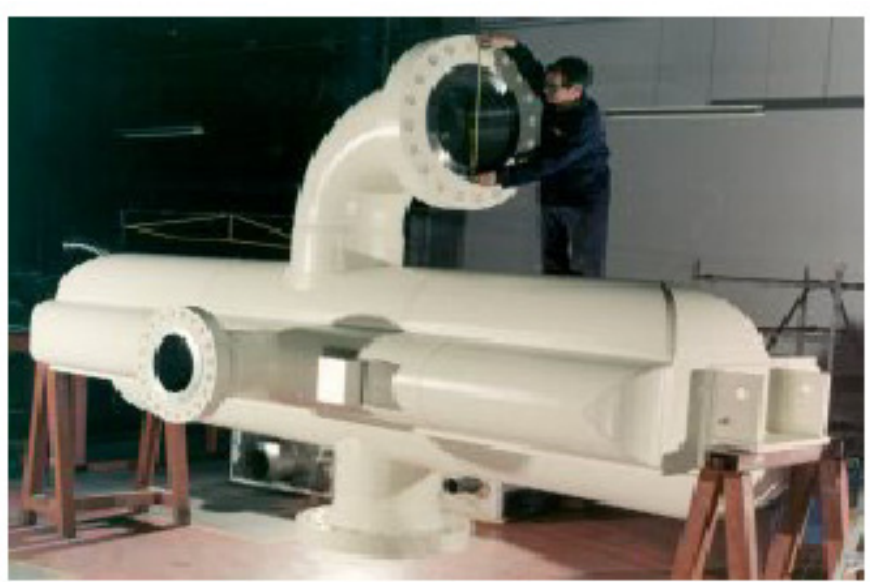

Figure 5-13. Finished heat exchanger (Heatric ${ }^{\mathrm{TM}}$ Homepage 2007).

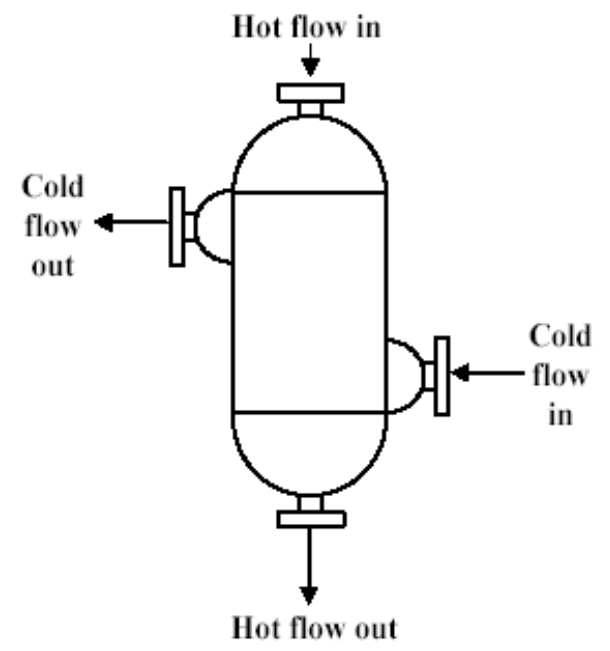

Figure 5-14. Fluid flow paths (Gezelius 2004).

Several unique characteristics contribute to the superior performance of the PCHEs. The most distinctive ones are the high allowable pressure and temperature limits in combination with the compactness of the heat exchanger. Specifically, the manufacturing company claims that, as a result of its original design, Heatric ${ }^{\mathrm{TM}}$ heat exchangers are able to operate at pressures up to $50 \mathrm{MPa}$ and at temperatures not exceeding $900^{\circ} \mathrm{C}$ (Heatric ${ }^{\mathrm{TM}}$ Homepage 2007). To allow operation under such extreme conditions, the materials commonly employed in PCHE include austenitic stainless steel, titanium, and nickel (pure/alloys), all of which are corrosion resistant (Hesselgreaves 2001). Carbon steel is typically not used for two reasons (Hesselgreaves 2001). First, because of the small channel diameter, the heat exchangers are designed for essentially zero corrosion allowance in order to avoid channel blockage. Second, carbon steel is unsuitable for diffusion bonding. Regarding mechanical considerations, Heatric ${ }^{\mathrm{TM}}$ heat exchangers are based on the American Society of Mechanical Engineers (ASME) design code Section VIII Division I and ASME Section III for non-nuclear and nuclear applications, respectively (Heatric ${ }^{\mathrm{TM}}$ Homepage 2007). Heatric ${ }^{\mathrm{TM}}$ has supplied heat exchangers in the shaded area of Figure 5-15.

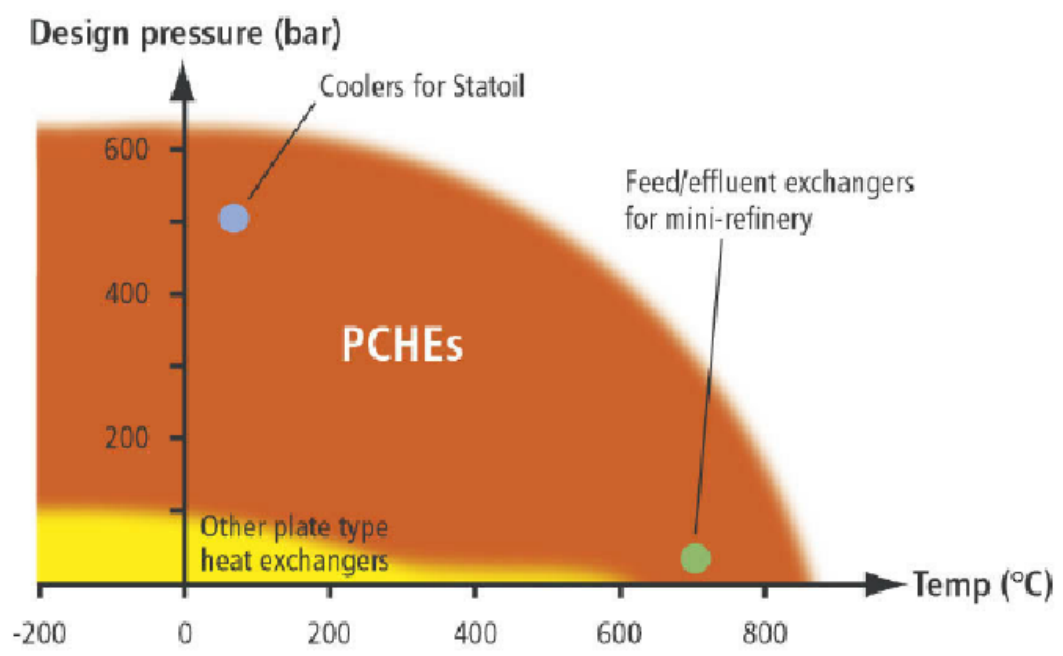

Figure 5-15. Current operating experience of Heatric ${ }^{\mathrm{TM}}$ PCHEs (Gezelius 2004). 
In addition to the wide operating range, the great potential of the PCHE is also illustrated by its enhancing safety features. As a result of its construction, it does not use or contain any gaskets or braze material. Consequently, the risk of leaks or fluid incompatibility is substantially reduced. In particular, the risk of leaks in a Heatric ${ }^{\mathrm{TM}}$ heat exchanger is approximately two orders of magnitude lower than for any other heat exchanger thanks to its continuous passage (Dewson 2003). For gas-gas applications, fouling ${ }^{\mathrm{d}}$ does not constitute a significant problem in the Heatric ${ }^{\mathrm{TM}}$ type heat exchangers. As a result of high operating temperature, the amount of moisture present to agglomerate particles is negligible or even nonexistent, leaving the microchannels free from discontinuities (Dewson 2003). Consequently, there are no dead spots in the straight channels where particles would be prone to adhere to the passage wall and cause serious fouling problems. Flexibility of allowed fluid types is another distinguishing feature of Heatric $^{\mathrm{TM}}$ heat exchangers. The versatility is particularly shown in the area of allowed fluid types and flow configurations. The variety of fluids for which PCHEs are a feasible choice includes liquids, gases, and boiling and condensing two-phase flow (Heatric ${ }^{\mathrm{TM}}$ homepage 2007). The design also allows multifluid integration (multi-stream capacity). The most commonly employed flow configurations include counterflow, crossflow, co-flow, or any combination of these as shown in Figure 5-16.
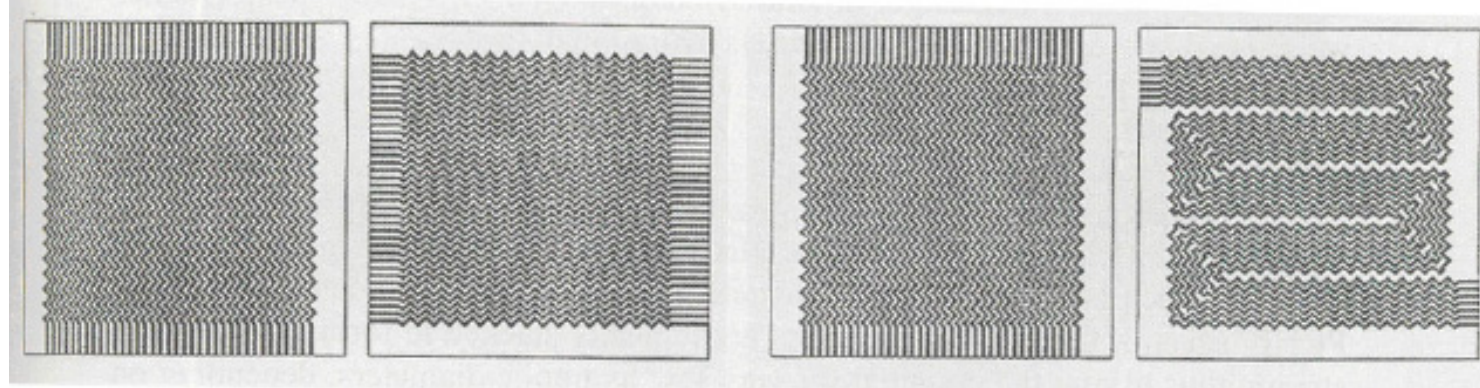

Figure 5-16. Simple crossflow (left) and cross-counterflow (right) configuration (Hesselgreaves 2001).

Lastly, size and pressure drop considerations also favor PCHE. Because of the compactness provided by its design, the volume of the Heatric ${ }^{\mathrm{TM}}$ type heat exchanger is normally between 4 and 6 times smaller than that of the standard heat exchanger type designed for the same thermal duty and pressure drop (Heatric ${ }^{\mathrm{TM}}$ Homepage 2007). With respect to mass, the Heatric ${ }^{\mathrm{TM}}$ heat exchanger has an average mass-to-duty ratio in tones/MW of 0.2 , as compared to 13.5 for a shell-andtube heat exchanger (Dewson 2003). Obviously, this reduction in size will cut the material and handling cost noticeably. The characteristic shape and the reduced size of PCHEs are demonstrated in the Figure 5-17. The actual design does not put any constraints on the heat exchanger with regard to the pressure drop. The flow channels are usually short, which compensates for the narrow passages (Heatric ${ }^{\mathrm{TM}}$ Homepage 2007).

PCHEs are "compact" relative to conventional heat exchangers, but they are

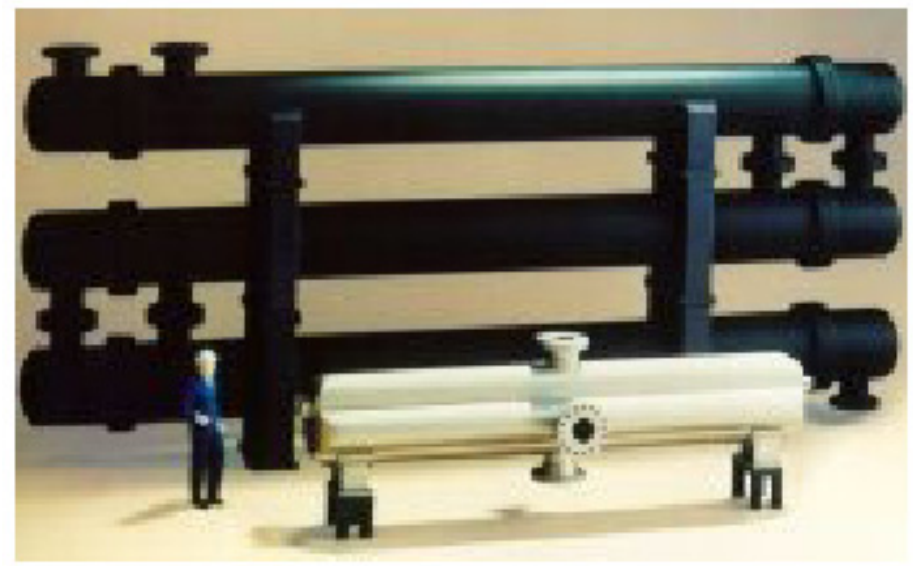

Figure 5-17. PCHE in front of a shell-and-tube heat exchanger designed for the same thermal duty and pressure drop (Heatric ${ }^{\mathrm{TM}}$ Homepage 2007).

d. The deposition of contaminates over time forms an insulating layer on the heat transfer surface, thus reduces heat transfer. 
not necessarily small. Single units of up to 100 tons have been manufactured, and clearly these are only compact in comparison to the 500-ton alternatives (Johnston and Haynes 2007).

\subsubsection{Single and Two-phase Spiral Heat Exchanger}

A SHE is constructed by rolling two relatively long metal strips around a mandrel to form two concentric spiral channels. Spacers are fixed to the sheets to keep them offset from each other a predetermined distance (forming flow channels). The channels are alternately welded on opposite ends to form a hot and cold channel. Welding the channels eliminates the potential for any cross-contamination of fluids as shown in Figure 5-18 (Katzel 2000). Heat transfer characteristics can be enhanced through manipulation of channel dimensions (such as by varying the diameter of the pipe) and surface modification by adding roughness to the pipe. The hot fluid enters at the center of the SHE and flows outward in a spiral path to the outlet on the periphery. Cold fluid simultaneously enters the peripheral header and flows countercurrent to the hot fluid toward the center; the entrance and exit of the hot and cold fluid could be switched, depending on the application. Due to the curvature of the tube, a centrifugal force is generated as the fluid flows through the circular channels. Secondary flow induced by the centrifugal force and secondary flow effects (eddy currents and vortices) have significant ability to enhance the heat transfer rate. At velocities that would be laminar in straight tubes, turbulence is achieved in the SHE because of continuous spiral channels, thus enhancing convective heat transfer. The spiral geometry also minimizes the potential for fouling to occur because any buildup in the channel results in an increase in local velocity at that point, an action that tends to flush the deposit away. The flow paths and a schematic of the SHE are shown in Figure 5-19. SHEs are fabricated in accordance with the ASME Section 8, Division 1, Pressure Vessel Codes (Bailey 1994). Most commonly used metals are carbon steel, stainless steel, titanium, or any other metal that can be cold formed, rolled, and welded. When a SHE requires cleaning, all heat transfer surfaces are readily accessible by simply removing the heads.

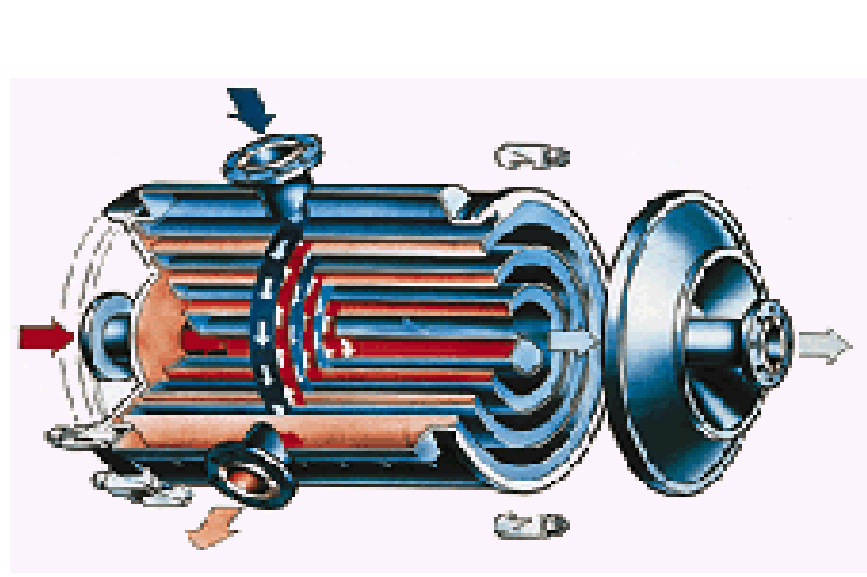

Figure 5-18. Schematic of a SHE (Katzel 2000).

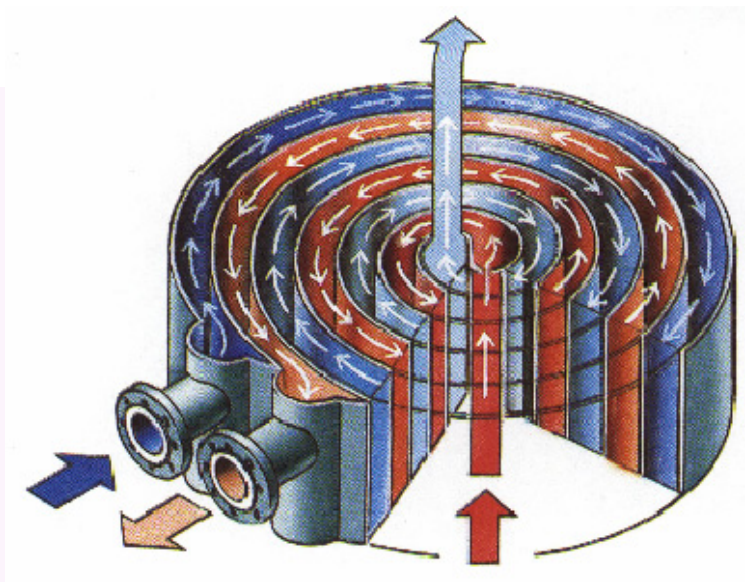

Figure 5-19. SHE with counter flow arrangement (Sherman and Chen 2008).

The spiral countercurrent design enables high heat-transfer rates and low fouling tendencies. The mechanical design of the SHE also enables easy maintenance and simplified inspection. For shell and tube heat exchangers, the Log Mean Temperature Difference (LMTD) correction factor becomes very small $(<<1)$ when there are close temperature approaches (the hot outlet temperature approximates the cold inlet temperature and the cold outlet temperature approximates the hot inlet temperature, respectively). SHEs, being completely countercurrent, have an LMTD correction factor of 1.0 and thus, do not have an LMTD penalty (Sabharwall et al. 2007 (ii)). Figure 5-20 shows a SHE being manufactured, and Figure 5-21 shows a completed SHE (Fisher and Sindelar 2008). 

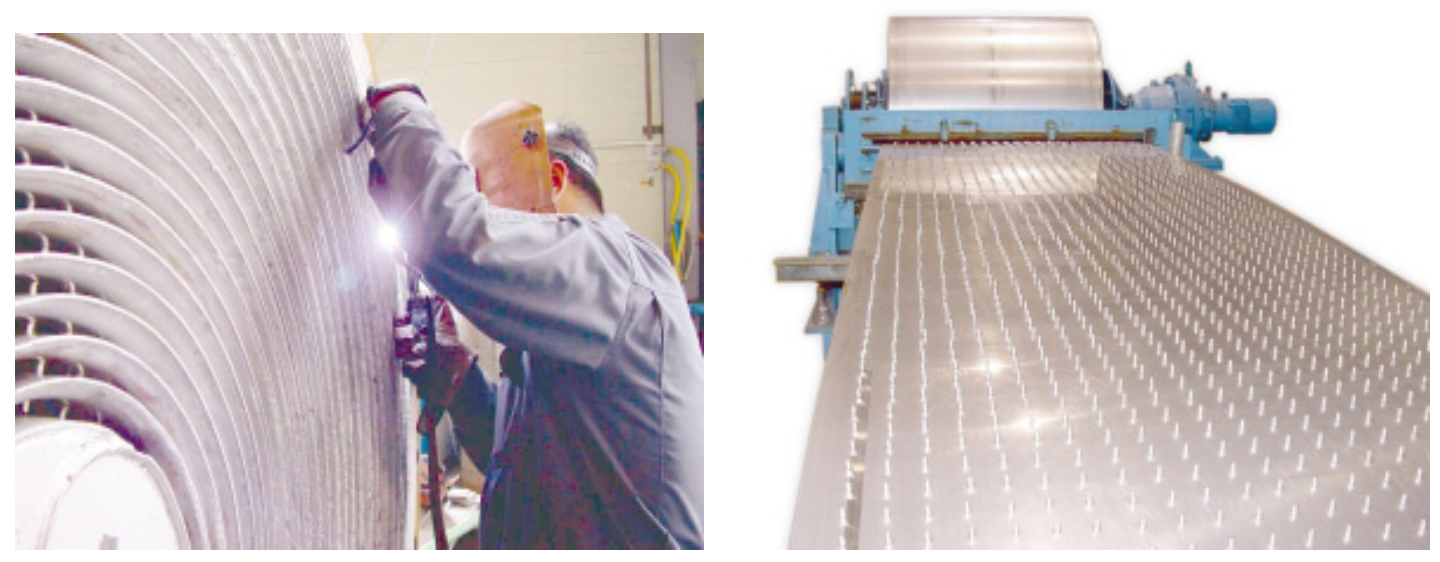

Figure 5-20. Manufacturing of a SHE (Fisher and Sindelar 2008).

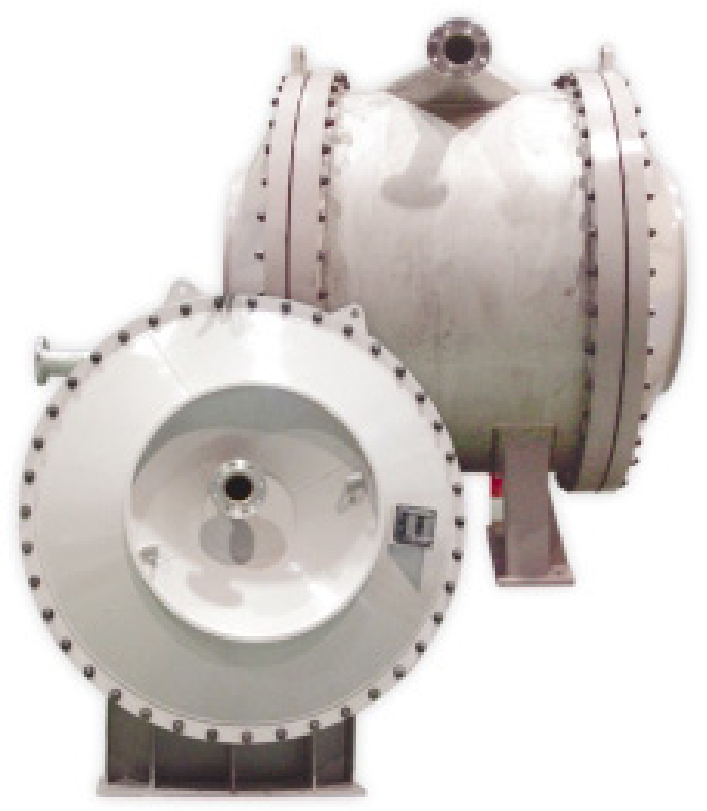

Figure 5-21. SHE (Fisher and Sindelar 2008).

\subsubsection{Evaporator and Condenser (SHE)}

Phase-change heat exchangers could be conventional shell and tube or SHEs. Using SHEs as the evaporator and condenser for the thermosyphon would enhance the heat transfer characteristics when compared to straight tube counter current heat exchangers. A conventional single phase SHE is shown in Figure 5-22. Thermal transport by both the evaporator and condenser is very similar; the only difference is in the direction of flow for the hot and cold fluid. In the case of an evaporator, hot fluid will enter at the center and flow toward the periphery, while the cold fluid will enter at the periphery and flow toward the center, as illustrated in Figure 5-22. For the condenser section, hot fluid will enter at the periphery and will move inward. The SHE shown in Figure 5-22 is not considered ideal for phase change heat transfer because the flow area remains constant and does not accommodate changes in specific volume (Sabharwall and Gunnerson 2008). 


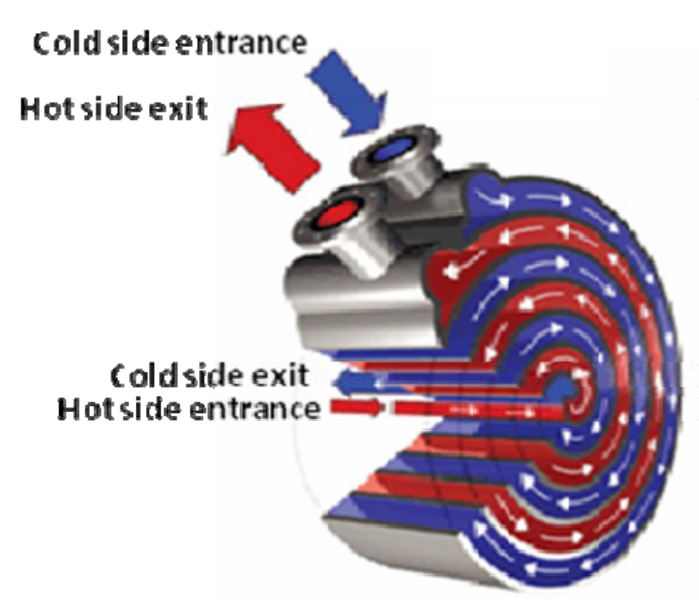

Figure 5-22. Schematic of a SHE (Modified from www. alfalaval.com). ${ }^{\mathrm{e}}$

The specific volume change from convective evaporation and condensation is better accommodated by the evaporative SHE design as shown in Figure 5-23. Liquid flows into the 'eye' of the spiral, gains heat, boils, and the vapor exits from the spiral 'horn' for transport to the distant condenser of the industrial end-user.

\subsubsection{Shell and Tube Heat Exchanger}

The shell and tube heat exchanger is the most common type found in industry. This exchanger is generally built of a bundle of round tubes mounted in a cylindrical shell with the tube axis parallel to that of the shell. Hot fluid flows inside the tubes and the cold fluid flows across and along the tubes. The major components of this exchanger are tubes (or tube bundles), shell, front-end head, rear-end head, baffles, and tube sheets. In a shell and tube heat exchanger, the diameter of the outer shell is greatly increased, and a bank of tubes rather than a single central tube is used, as shown in Figure 5-24

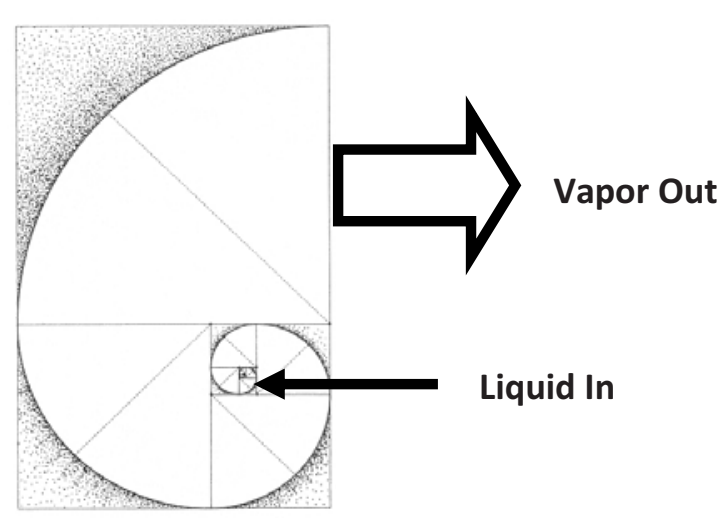

Figure 5-23. Evaporative SHE. (Sherman and Chen 2008). Fluid is distributed to the tubes through a manifold and tube sheet. To increase heat transfer efficiency, further modifications to the flow paths of the outer and inner fluids can be accomplished by adding baffles to the shell to increase fluid contact with the tubes, and by creating multiple flow paths or passes for the fluid flowing through the tubes (Sherman and Chen 2008). Shell and tube exchangers are classified and constructed in accordance with the widely used Tubular Exchange Manufacturers Association (TEMA) standards (TEMA 2007) and ASME boiler and pressure vessel codes (Shah and Sekulic 2003).

e. "Schematic of a spiral heat exchanger," available at www.alfalaval.com accessed on $25^{\text {th }}$ July 2007. 


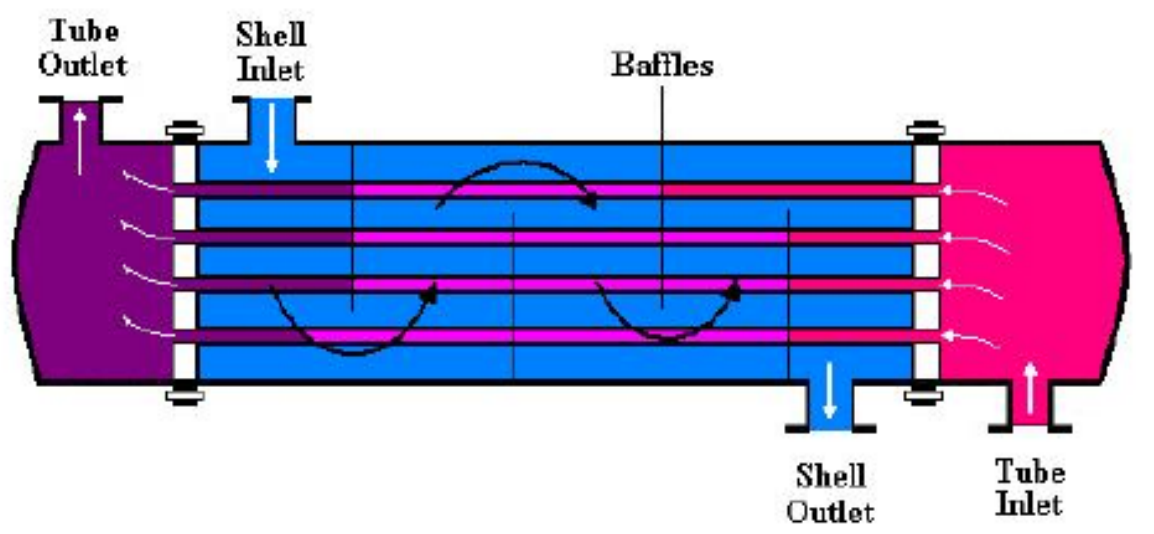

Figure 5-24. Shell and tube heat exchanger with baffles (Sherman and Chen 2008).

\subsection{Summary}

Irrespective of the NGNP reactor type (i.e., prismatic core or pebble bed) and the resultant coolant, the key to high efficiency is a highly effective heat exchange. An efficient design of the intermediate heat exchanger is critical for effective utilization of the energy generated in the NGNP. A CHE was therefore chosen for this application. CHEs are characterized by large surface area-to-volume ratios. The CHEs being considered for NGNP intermediate loop are as follows:

- Plate type heat exchanger

- Plate and fin heat exchanger

- PCHE

- SHE

- Shell and tube heat exchanger (conventional heat exchanger).

The significant characteristics of CHEs are low heat losses because of compactness, close temperature approach, and less pumping power compared to the conventional heat exchanger. 


\section{PHASE CHANGE HEAT TRANSFER ANALYSIS}

\subsection{Liquid Metal Phase Change Heat Exchanger}

Liquid metals are attractive as the secondary heat transfer medium for transferring the thermal energy of NGNP to a process plant. Liquid metals have high thermal conductivities, very low Prandtl numbers, and typically have a high heat transfer coefficient. Further, they behave as Newtonian fluids and are elementary substances that do not decompose. The normal boiling points of these metals are also high, and hence the liquid metal systems can be operated at near atmospheric pressures. Coupling liquid metal heat exchangers with nuclear reactors, such as was used in the submarine SEAWOLF, is a known and proven technology. Research related to the vaporization of liquid metals has been quite extensive (Irvine and Hartnett 1966, Martenelli 1947).

With the exception of Martinelli's pioneering work (Martenelli 1947), the major advances in liquid metal technology during the past period were primarily focused on development of equipment, especially pumps and instrumentation, for successful operation of liquid metal systems. The development of nuclear reactor technology has intensified the interest in liquid metals because of their ideal transport properties.

Convection heat transfer data for turbulent flow is available for many liquid metals (Hsia 1970, Deev et al. 1967, Hoffman et al. 1962, Borishanskii 1965, and Kakac and Spalding 1979). Some acceptable equations have been developed, but only limited information is available for boiling sodium. The objective of this work is to analyze the heat transfer and pressure drop characteristics of a heat exchanger for the evaporator section of a thermosyphon using boiling sodium as the secondary heat transfer medium. Overall heat transfer and pressure drop are determined, and detailed analytical solution is presented for the phase-change heat exchanger. Sodium is selected as the heat transfer medium because it is among the most promising media for transporting heat from the NGNP to a hydrogen plant (Sabharwall et al. 2007 (ii)).

The conservation of energy is applied to fluid flowing through the duct. Unessential complications are eliminated by introducing simplifications and idealizations that are both reasonable and generally accepted. The flow is considered incompressible (for single phase) and fully developed. Thermo-physical properties are not dependent on temperature for the given section $\left(\mathrm{L}_{1}, \mathrm{~L}_{2}\right.$, and $\left.\mathrm{L}_{3}\right)$, but do vary from section to section (Sabharwall et al. 2009 (ii)). The pressure drop prediction for two-phase flow was based on a homogeneous equilibrium model (HEM), i.e., the liquid and vapor velocities are uniform within the area and also both of the phases are in thermodynamic equilibrium.

\subsection{Mathematical Model Development}

The key difference between turbulent forced convection for liquid metals and nonmetallic fluids is the difference in relative magnitudes of molecular and turbulent conduction. With nonmetallic fluids significant temperature gradients will tend to be localized immediately adjacent to the duct wall, except for low Reynolds numbers and Prandtl numbers near unity. With liquid metals, significant temperature gradients can extend over the entire duct cross section. The important consequence of this difference between liquid metals and nonmetallic fluids in turbulent flows is that temperature distributions in the latter are relatively insensitive to local changes at the duct walls and thus to boundary conditions and duct shape. Liquid metal temperature distributions, however, can be quite sensitive to boundary conditions (Schumacher 1960). 
In this analysis, the boiling section $\left(\mathrm{L}_{2}\right)$ is divided into various subsections such that quality in each section varies between a complete liquid state to a complete vapor state. MATLAB code is written for the development and better understanding of phase change heat exchangers using liquid metal $(\mathrm{Na})$ as the coolant. In this code for a two-phase regime, the micro-convective mechanism associated with over-all flow and the micro-convective mechanism associated with bubble growth in the liquid film are taken into account. For a single phase regime, based on fluid temperature and properties, the overall heat transfer coefficient is determined and, based on the Reynolds number value, appropriate fluid friction factor value is determined (an important value since it determines the pressure drop for a given flow rate and geometry).

\subsubsection{Convective Boiling Heat Transfer for Liquid Metal (Sodium)}

The ideal rate of convective heat transport through a pipe without losses, modeled in terms of enthalpy, can be written as:

$$
Q^{\prime \prime}=\Delta \mathrm{h} \rho \mathrm{V}=\frac{\dot{\mathrm{m}}}{\mathrm{A}} \Delta \mathrm{h}
$$

Two-phase heat transfer by a heat exchanger has the advantage of high enthalpy transport that includes the sensible heat of the liquid, the latent heat of vaporization, and possible vapor superheat. In contrast, single-phase forced convection transports only the sensible heat of the fluid. Additionally, vaporphase velocities within a heat exchanger can be much greater than single-phase liquid velocities within a forced convective loop.

$$
\begin{aligned}
& \mathrm{Q}^{\prime \prime}=\frac{\dot{\mathrm{m}}}{\mathrm{A}} \mathrm{C}_{\mathrm{P}, \mathrm{L}} \Delta \mathrm{T}_{\mathrm{L}} \quad \text { (single phase) } \\
& \mathrm{Q}^{\prime \prime}=\frac{\dot{\mathrm{m}}}{\mathrm{A}}(\underbrace{\mathrm{C}_{\mathrm{P}, \mathrm{L}} \Delta \mathrm{T}_{\mathrm{L}}}_{\text {Sensible heat of the liquid }}+\underbrace{\mathrm{h}_{\mathrm{fg}}}_{\text {Latent heat of vaporization }}+\underbrace{\mathrm{C}_{\mathrm{P}, \mathrm{V}} \Delta \mathrm{T}_{\mathrm{V}}}_{\text {Vapor Superheat }})
\end{aligned}
$$

The mass flow rate is obtained from the following expression:

$$
\dot{\mathrm{m}}=\frac{\mathrm{Q}}{\mathrm{C}_{\mathrm{P}, \mathrm{L}} \Delta \mathrm{T}_{\mathrm{L}}+\mathrm{h}_{\mathrm{fg}}+\mathrm{C}_{\mathrm{P}, \mathrm{V}} \Delta \mathrm{T}_{\mathrm{V}}}
$$

where

$$
\begin{aligned}
& \Delta \mathrm{T}_{\mathrm{L}}=\mathrm{T}_{\text {bo }}-\mathrm{T}_{\text {in }} \\
& \Delta \mathrm{T}_{\mathrm{V}}=\mathrm{T}_{\text {ou }}-\mathrm{T}_{\text {bo }}
\end{aligned}
$$

The counter current heat exchanger is used in the analysis with liquid metal $(\mathrm{Na})$ flowing through one side and helium gas flowing through the other. The Na side of the pipe is divided into three sections, exhibiting a different flow regime. The $\mathrm{L}_{1}$ section refers to the section where $\mathrm{Na}$ is in the vapor phase, the $\mathrm{L}_{2}$ section refers to the section where $\mathrm{Na}$ is in two-phase regime, and the $\mathrm{L}_{3}$ section refers to the section where $\mathrm{Na}$ is in liquid phase (see Figure 6-1). 


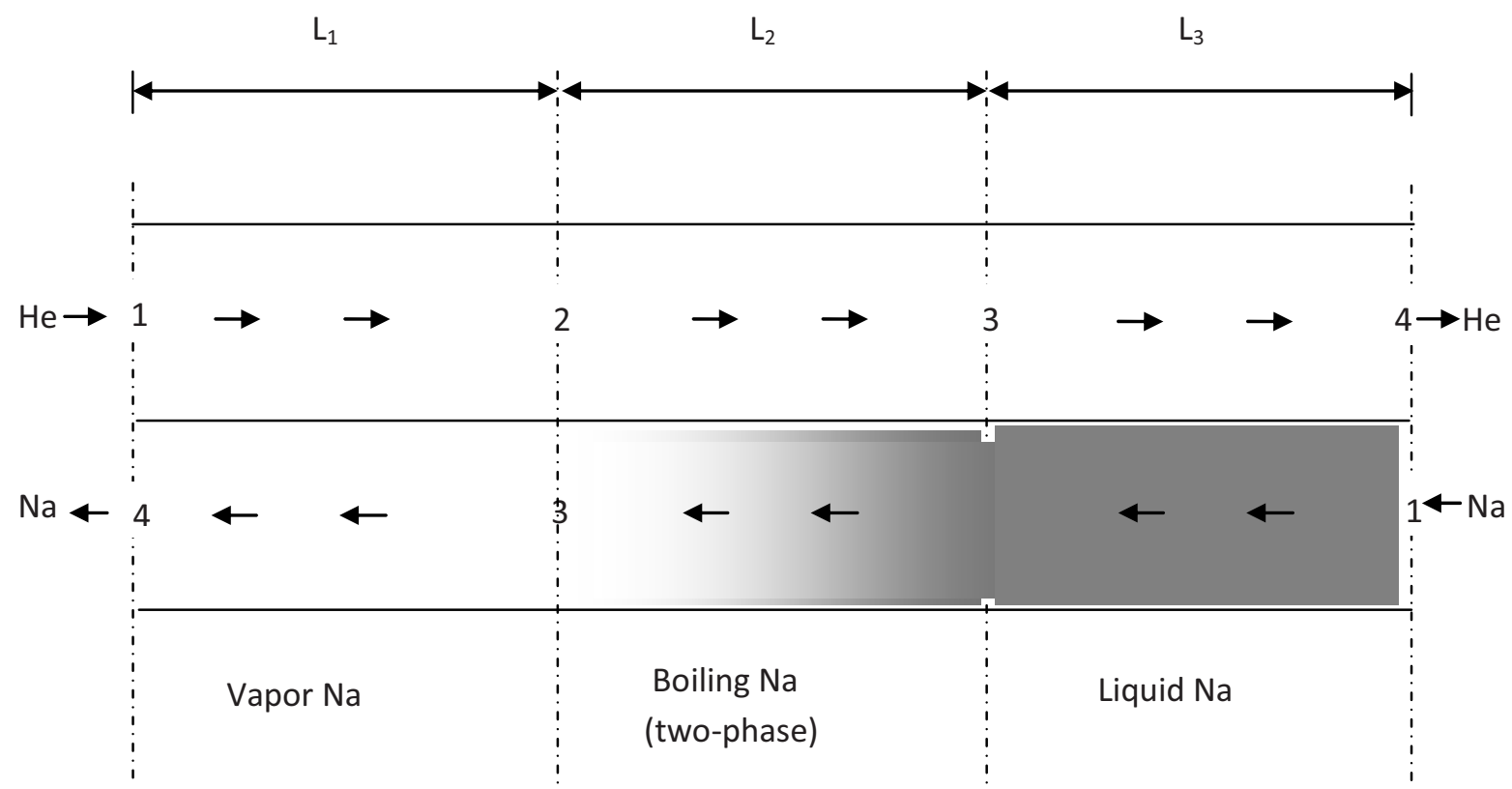

(a) Overall Process

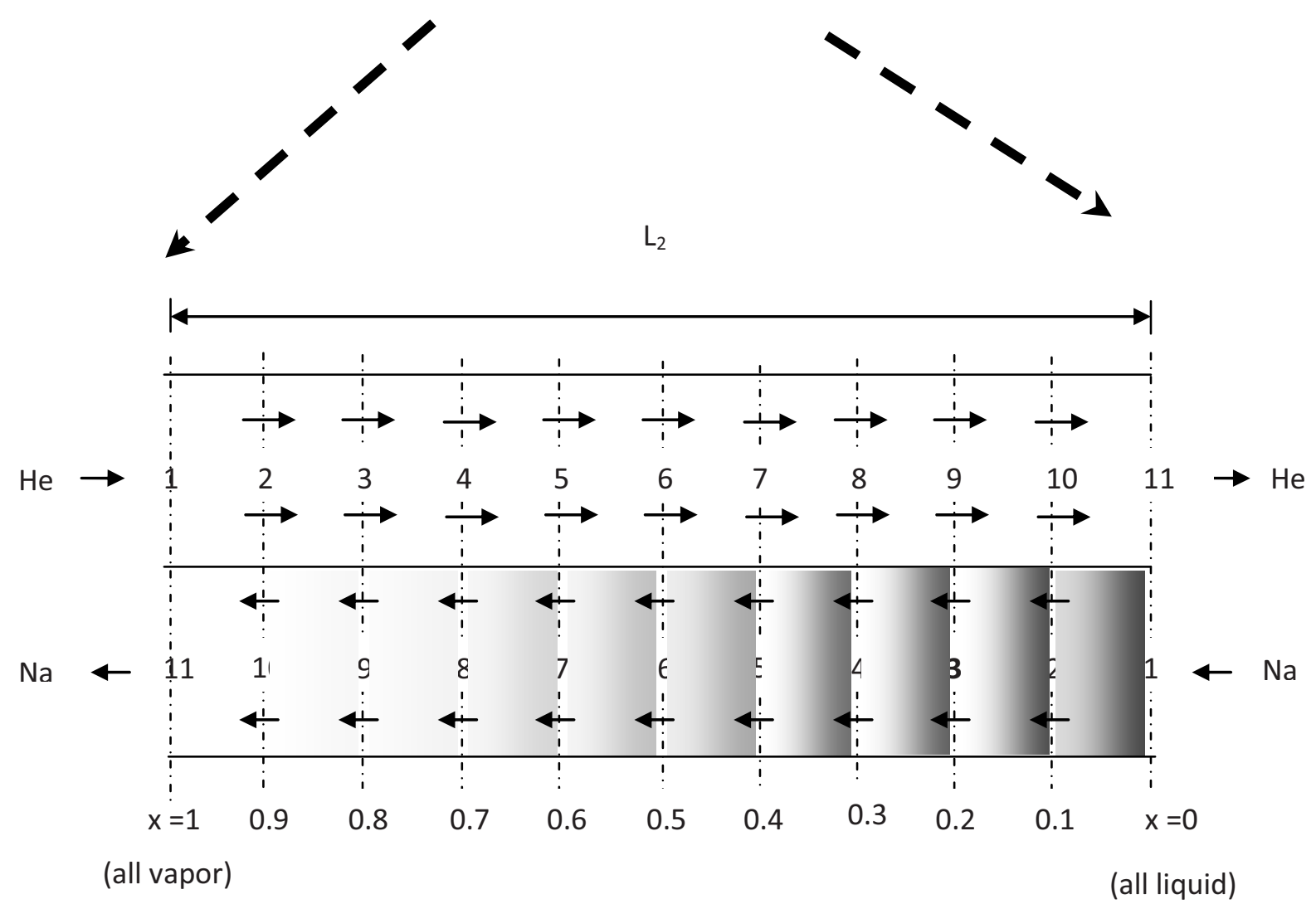

(b) Expanded view of two-phase

Figure 6-1. Schematic of the phase change heat exchanger. 
The process heat available from NGNP is $50 \mathrm{MW}$. The key assumptions in this analysis are as follows:

- Process heat available from NGNP is $50 \mathrm{MW}$

- Flow is steady (fluid properties are independent of time)

- Fluid density is treated constant in the single-phase regime, but does vary in the two-phase regime with varying quality

- Friction factor is considered as constant with passage flow length for single-phase regions, but does vary for the two-phase regime

- Body force is only caused by gravity, but is neglected because of horizontal position

- There are no energy sinks or sources along a streamline; flow stream mechanical energy dissipation is idealized as zero

- Inlet temperature of helium is assumed to be $1,300 \mathrm{~K}$ (outlet temperature from NGNP)

- Inlet temperature for $\mathrm{Na}$ is assumed to be $393 \mathrm{~K}$ (based on minimum temperature required to carry out Bunsen reaction which is the lowest in the SI process)

- Outlet temperature for $\mathrm{Na}$ is assumed to be 1,223 K (for higher efficiency of hydrogen production)

- Properties of helium are kept constant (because the temperature drop is not that significant) throughout the analysis, but the properties of $\mathrm{Na}$ vary depending on the section

- Resistance to conduction of heat across the boundary of primary and secondary fluids is negligible.

In a heat exchanger the maximum vapor velocity one can reach corresponds to Mach 1 . The limitation of such flow is similar to a converging-diverging nozzle with constant mass flow rate. This choked flow condition is a fundamental limit on the axial vapor flow in a heat exchanger. Having the vapor velocity equal to sonic will maximize the heat transfer but lead to propagation of a shock wave in the system. Therefore, in the analysis, we assumed the vapor velocity of helium equal to half its sonic velocity. The helium duct diameter was obtained such that operation is at half the sonic velocity of helium $(882.5$ $\mathrm{m} / \mathrm{sec})$. The outlet temperature of the helium duct was varied such that a positive value for $\operatorname{LMTD}\left(\Delta \mathrm{T}_{\mathrm{m}}\right)$ for helium was obtained as was a low value for effective heat transfer area and pressure drop.

From energy balance in the entire section (from Figure 6-1 (a)), is shown

$$
\begin{aligned}
& \mathrm{Q}=\dot{\mathrm{m}}_{\mathrm{Na}} \mathrm{Cp}_{\mathrm{Na}, \mathrm{L}}\left(\mathrm{T}_{\mathrm{Na}, 2}-\mathrm{T}_{\mathrm{Na}, 1}\right)+\dot{\mathrm{m}}_{\mathrm{Na}} \mathrm{h}_{\mathrm{fg}}+\dot{\mathrm{m}}_{\mathrm{Na}} \mathrm{Cp}_{\mathrm{Na}, \mathrm{V}}\left(\mathrm{T}_{\mathrm{Na}, 4}-\mathrm{T}_{\mathrm{Na}, 3}\right) \\
& \dot{\mathrm{m}}_{\mathrm{Na}}=\frac{\mathrm{Q}}{\mathrm{Cp}_{\mathrm{Na}, \mathrm{L}}\left(\mathrm{T}_{\mathrm{Na}, 2}-\mathrm{T}_{\mathrm{Na}, 1}\right)+\mathrm{h}_{\mathrm{fg}}+\mathrm{Cp}_{\mathrm{Na}, \mathrm{V}}\left(\mathrm{T}_{\mathrm{Na}, 4}-\mathrm{T}_{\mathrm{Na}, 3}\right)}
\end{aligned}
$$

Now from the energy balance for each individual section $\left(\mathrm{L}_{1}, \mathrm{~L}_{2}\right.$, and $\left.\mathrm{L}_{3}\right)$ is shown

$$
\begin{aligned}
& \mathrm{Q}_{\mathrm{L}_{1}, \mathrm{He}}=\dot{\mathrm{m}}_{\mathrm{He}} \mathrm{Cp}_{\mathrm{He}}\left(\mathrm{T}_{\mathrm{He}, 1}-\mathrm{T}_{\mathrm{He}, 2}\right)=\dot{\mathrm{m}}_{\mathrm{Na}} \mathrm{Cp}_{\mathrm{Na}, \mathrm{V}}\left(\mathrm{T}_{\mathrm{Na}, 4}-\mathrm{T}_{\mathrm{Na}, 3}\right) \\
& \mathrm{Q}_{\mathrm{L}_{2}, \mathrm{He}}=\dot{\mathrm{m}}_{\mathrm{He}} \mathrm{Cp}_{\mathrm{He}}\left(\mathrm{T}_{\mathrm{He}, 2}-\mathrm{T}_{\mathrm{He}, 3}\right)=\dot{\mathrm{m}}_{\mathrm{Na}} \mathrm{h}_{\mathrm{fg}} \\
& \mathrm{Q}_{\mathrm{L}_{3}, \mathrm{He}}=\dot{\mathrm{m}}_{\mathrm{He}} \mathrm{Cp}_{\mathrm{He}}\left(\mathrm{T}_{\mathrm{He}, 3}-\mathrm{T}_{\mathrm{He}, 4}\right)=\dot{\mathrm{m}}_{\mathrm{Na}} \mathrm{Cp}_{\mathrm{Na}, \mathrm{L}}\left(\mathrm{T}_{\mathrm{Na}, 2}-\mathrm{T}_{\mathrm{Na}, 1}\right)
\end{aligned}
$$




\subsubsection{Heat Transfer Coefficients Estimation}

\subsubsection{Helium}

Convective heat transfer coefficient for helium is calculated as

$\mathrm{Nu}_{\mathrm{He}}=0.022\left(\operatorname{Re}_{\mathrm{He}, \mathrm{D}_{\mathrm{h}}}\right)^{0.8}\left(\operatorname{Pr}_{\mathrm{He}}\right)^{0.5}$ (Kays and Crawford 1993)

$\mathrm{h}_{\mathrm{He}}=\frac{\mathrm{Nu}_{\mathrm{He}} \mathrm{K}_{\mathrm{He}}}{\mathrm{D}_{\mathrm{hHe}}}$

The friction factor for fully developed flow in circular pipes, as a function of Reynolds number $\operatorname{Re}_{D}$ and relative wall roughness, was first presented in 1944 (Moody 1944). This can also be applied to noncircular ducts by using the equivalent diameter $\left(D_{e}\right)$ as shown in Figure 6-2.

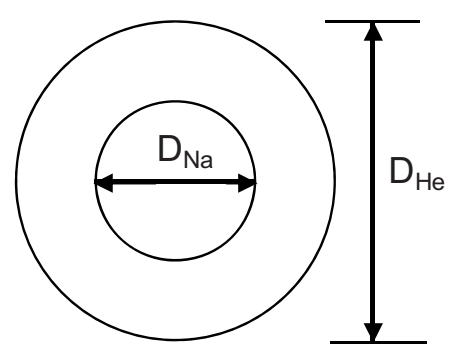

Figure 6-2. Concentric pipe for annulus flow of $\mathrm{Na}$ inside of $\mathrm{He}$.

The double pipe configuration shown in Figure 6-2 has helium flowing inside the annulus and $\mathrm{Na}$ flowing outside the annulus. For a fluid flowing inside an annulus, the flow area is evidently given (as shown in Figure 6-2) as

$$
A_{f}=\frac{\pi}{4}\left(\mathrm{D}_{\mathrm{He}}^{2}-\overline{\mathrm{D}}_{\mathrm{Na}}^{2}\right)
$$

Friction in pressure drop calculations results from the resistance of the outer pipe and is also affected by the outer surface of the inner pipe. The total wetted perimeter is thus

$$
\begin{aligned}
& P_{w}=\pi\left(\mathrm{D}_{\mathrm{He}}+\overline{\mathrm{D}}_{\mathrm{Na}}\right) \\
& \mathrm{L}_{\mathrm{He}}=\mathrm{L}_{\mathrm{Na}}
\end{aligned}
$$

(the total length of both primary and secondary sides is equal)

The well known relationship between pressure drop and friction factor is usually expressed as

$$
\Delta \mathrm{P}_{\mathrm{He}}=\frac{4 \mathrm{f} \rho_{\mathrm{He}}\left(\mathrm{L}_{\mathrm{He}}\right)\left(\mathrm{V}_{\mathrm{He}}\right)^{2}}{2 \mathrm{D}_{\mathrm{e}, \mathrm{He}}}
$$


Overall heat transfer coefficient can be determined by

$$
\mathrm{U}_{\mathrm{i}}=\frac{1}{\left(\frac{1}{\mathrm{~h}_{\mathrm{He}_{\mathrm{i}}}}\right)+\left(\frac{1}{\mathrm{~h}_{\mathrm{Na}_{\mathrm{i}}}}\right)}
$$

In Equation (6-18) the effect of conduction was neglected because it was not found to be substantial ( $3 \%$ of heat transfer resistance on the helium side, for Alloy 617 at 1,300 K).

The heat transfer coefficient for $\mathrm{Na}$ cannot be calculated using a single equation because phase change is involved. Therefore, there are three distinct regions (as shown in Figure 6-1). Length for each section is calculated using the following expression:

$$
\mathrm{L}_{\mathrm{i}}=\frac{\mathrm{Q}_{\mathrm{i}}}{\left(\mathrm{U}_{\mathrm{i}}\right)\left(2 \pi \mathrm{R}_{\mathrm{Na}_{\mathrm{i}}}\right)\left(\Delta \mathrm{T}_{\mathrm{m}_{\mathrm{i}}}\right)}
$$

Pressure drop is estimated using the following equation:

$$
\Delta \mathrm{P}_{\mathrm{i}}=\frac{4 \mathrm{f} \rho(\mathrm{L})(\mathrm{V})^{2}}{2 \mathrm{D}_{\mathrm{h}}}
$$

\subsubsection{Sodium (Vapor Phase)}

Sonic velocity is the maximum velocity at which the fluid can be pumped. The rationale used to decrease by half the sonic velocity instead of using full sonic velocity is to avoid shock wave propagation in the system and to reduce erosion. Using thermo-physical properties of $\mathrm{Na}$ (at 1,200 K, average temperature between $\mathrm{T}_{\mathrm{Na}, 4}$ and $\mathrm{T}_{\mathrm{Na}, 3}$ ), corresponding Re and Pr numbers for the vapor section are obtained. The traditional Nusselt number correlation, when applied to liquid metals, will lead to inaccuracies, but there are possible extensions done to the correlations that are based on experiments such that they offer more accurate engineering design and heat transfer analyses. The classic expression for computing the local Nusselt number for fully developed turbulent flow in a smooth circular tube is the Dittus-Boelter equation, which is valid for $0.6 \leq \operatorname{Pr} \leq 160$, which cannot be used for liquid metals. The Dittus-Boelter equation contains a condition regarding the direction of heat transfer, but tends to over predict the $\mathrm{Nu}$ number for gases by at least $20 \%$, and under predicts the Nu number for higher Pr number fluids by $7-10 \%$ (Kays and Crawford 1993).

For liquid metals the value of the Prandtl number is normally less than 0.1 , ranging down to $<0.001$. The high thermal conductivity of these fluids accounts for the very low Pr number. Also, the very high thermal conductivity accounts for the unusual heat-transfer characteristics of liquid metals. An empirical equation that corresponds fairly well to the available experimental data for heat transfer inside turbulent flow inside tubes for liquid metals (Sleicher and Rouse 1975) is

$\mathrm{Nu}=6.3+0.0167 \operatorname{Re}^{0.85} \operatorname{Pr}^{0.93} \quad$ (constant heat rate)

The heat-transfer coefficients in fully developed turbulent flow of liquid metals (in smooth tubes with uniform heat flux at the wall) are given by (Lubarsky and Kaufman 1955) as

$\mathrm{Nu}=0.625(\operatorname{Re} \operatorname{Pr}) 0.4 \quad$ (uniform heat flux)

Equation (6-22) is valid for $10^{2} \leq \mathrm{Pe} \leq 10^{4}$. 
A preferable relation when compared with the one given above for constant heat rate ${ }^{15)}$ is given as

$\mathrm{Nu}=4.82+0.0185 \mathrm{Pe} 0.827 \quad$ (constant heat rate)

Equation (6-23) is valid for $10^{2} \leq \mathrm{Pe} \leq 10^{4}$.

The following relation was proposed for calculation of heat transfer to liquid metals in tubes with constant wall temperature (Seban and Shimazaki 1951), such that the Pe $>10^{2}$

$\mathrm{Nu}=5+0.025(\operatorname{Re} \operatorname{Pr}) 0.8 \quad$ (constant wall temperature)

$\mathrm{Nu}_{\mathrm{Na}_{\mathrm{v}}}=6.3+0.0167\left(\mathrm{Re}_{\mathrm{Na}_{\mathrm{v}}, \mathrm{D}_{\mathrm{h}}}\right)^{0.85}\left(\mathrm{Pr}_{\mathrm{Na}_{\mathrm{v}}}\right)^{0.93}$

The analysis will use Equation (6-25) because it corresponded well with the experimental data (Kays and Crawford 1993) and is valid for all fluids with a low Pr number as follows:

$\mathrm{h}_{\mathrm{Na}_{\mathrm{v}}}=\frac{\mathrm{Nu}_{\mathrm{Na}_{\mathrm{v}}} \mathrm{K}_{\mathrm{Na}_{\mathrm{v}}}}{\mathrm{D}_{\mathrm{h}, \mathrm{Na}_{\mathrm{v}}}}$

The overall heat transfer coefficient for the $\mathrm{L}_{1}$ section can be determined by using Equation (6-18).

Length of the heat exchanger is calculated using the following equations:

$$
\begin{aligned}
\Delta \mathrm{T}_{1, \mathrm{Na}_{\mathrm{v}}} & =\mathrm{T}_{\mathrm{He}, 1}-\mathrm{T}_{\mathrm{Na}, 4} \\
\Delta \mathrm{T}_{2, \mathrm{Na}} & =\mathrm{T}_{\mathrm{He}, 2}-\mathrm{T}_{\mathrm{Na}, 3} \\
\Delta \mathrm{T}_{\mathrm{m}, \mathrm{Na}_{\mathrm{v}}} & =\frac{\left(\Delta \mathrm{T}_{1, \mathrm{Na}_{\mathrm{v}}}-\Delta \mathrm{T}_{2, \mathrm{Na}_{\mathrm{v}}}\right)}{\ln \left(\frac{\Delta \mathrm{T}_{1, \mathrm{Na}_{\mathrm{v}}}}{\Delta \mathrm{T}_{2, \mathrm{Na}_{\mathrm{v}}}}\right)}
\end{aligned}
$$

Now, using Equations (6-19) and (6-20), the length and the pressure drop for this section can be determined, respectively.

\subsubsection{Sodium (Liquid Phase)}

Using thermo-physical properties of $\mathrm{Na}$ (at $775 \mathrm{~K}$, average temperature between $\mathrm{T}_{\mathrm{Na}, 1}$ and $\mathrm{T}_{\mathrm{Na}, 2}$ ) the corresponding Nu number is obtained using Equation (6-25) as follows:

$\mathrm{h}_{\mathrm{Na}_{\mathrm{L}}}=\frac{\mathrm{Nu}_{\mathrm{Na}_{\mathrm{L}}} \mathrm{K}_{\mathrm{Na}_{\mathrm{L}}}}{\mathrm{D}_{\mathrm{h}, \mathrm{Na}_{\mathrm{L}}}}$

Overall heat transfer coefficient for $\mathrm{L}_{3}$ section can be determined by using Equation (6-18).

Similarly, for the pressure drop calculation for $\mathrm{Na}_{\mathrm{L}}$ :

$\Delta \mathrm{T}_{1, \mathrm{Na}_{\mathrm{L}}}=\mathrm{T}_{\mathrm{He}, 3}-\mathrm{T}_{\mathrm{Na}, 2}$ 


$$
\begin{aligned}
& \Delta \mathrm{T}_{2, \mathrm{Na}}= \mathrm{T}_{\mathrm{He}, 4}-\mathrm{T}_{\mathrm{Na}, 1} \\
& \Delta \mathrm{T}_{\mathrm{m}, \mathrm{Na}_{\mathrm{L}}}=\frac{\left(\Delta \mathrm{T}_{1, \mathrm{Na}_{\mathrm{L}}}-\Delta \mathrm{T}_{2, \mathrm{Na}_{\mathrm{L}}}\right)}{\ln \left(\frac{\Delta \mathrm{T}_{1, \mathrm{Na}_{\mathrm{L}}}}{\Delta \mathrm{T}_{2, \mathrm{Na}_{\mathrm{L}}}}\right)}
\end{aligned}
$$

Now, using Equations (6-19) and (6-20), the length and the pressure drop for this section can be determined, respectively.

\subsubsection{Convective Boiling Heat Transfer for Two-phase $\mathrm{Na}$}

A number of experimental studies in convective boiling heat transfer report data on systems using water, organic fluids, and even liquid metals. One of the first major works in this area was accomplished in 1952 by Rohsenow, who obtained local boiling coefficients for water in upward vertical flow through a 1-inch tube. Dengler and Addoms proposed the following empirical correlation for local boiling coefficients for water in an upward vertical tube (Dengler and Addoms 1956):

$$
\mathrm{h}=3.5 \frac{\mathrm{F}_{\mathrm{DA}} \mathrm{h}_{\mathrm{L}}}{\left(\mathrm{X}_{\mathrm{tt}}\right)^{0.5}}
$$

where $h_{L}^{\prime}$ is evaluated by the conventional Dittus-Boelter equation

$$
\mathrm{h}_{\mathrm{L}}=0.023 \frac{\mathrm{K}}{\mathrm{D}}(\operatorname{Re})^{0.8}(\operatorname{Pr})^{0.4}
$$

Local boiling coefficients for a number of organic liquids in single-tube vertical boilers were reported by Guerrieri and Talty in 1956. In 1959 (Bennett 1959), data for water flowing vertically in annular test sections were compared to the data with both the correlations (Dengeler and Addoms 1956, Guerrieri et al. 1956) but, in each case, considerable scatter was found. Bennett et al. (1959) then proposed their own correlation where the local heat flux (q/A), was used as a multiplicative correction factor:

$h=0.64 \frac{h_{L}}{\left(X_{t t}\right)^{0.74}}\left(\frac{q}{A}\right)^{0.11}$

It is postulated that two basic mechanisms are involved in the heat transfer process for boiling of saturated fluids with flow: (1) a macroconvective mechanism and (2) a microconvective mechanism. It is further postulated that these two mechanisms are additive in their contributions to total heat transfer, which was first suggested in 1952 by Rohsenow and later used and further developed by Chen in 1963 (i). The macroconvective mechanism is associated with over-all flow and the microconvective mechanism is associated with bubble growth in the annular liquid film. Bubble growth is a very complex phenomenon depending on various influences and forces. The heat from the heating surface proceeds to the boundary layer, superheats the layer, and is finally consumed as the latent heat of vaporization for the phase change. These two mechanisms interact with each other - the presence of vapor strongly influences macroconvective heat transfer, and conversely, the presence of flow modifies bubble motion and consequently affects microconvective heat transfer.

Considering first the macroconvective mechanism, it was recognized that at the two limits of 0 and $100 \%$ quality, the macroconvective heat transfer should be described by the Dittus-Boelter type of correlation. It was then postulated that in the two-phase region where both liquid and vapor are present, 
the macroconvective heat transfer should still be described by a modified form of the Dittus-Boelter equation for water and organic fluids (Chen 1963 (i)).

$\mathrm{h}_{\text {macro }}=0.023 \frac{\mathrm{K}}{\mathrm{D}}(\operatorname{Re})^{0.8}(\operatorname{Pr})^{0.4}$

In the previous equation, the $\mathrm{Pr}, \mathrm{Re}$, and $\mathrm{K}$ represent effective values associated with the two-phase fluid. In the case of ordinary fluids, not liquid metals, the Pr number of the liquid and of the vapor are normally of the same magnitude. Based on the proposed methodology (Chen 1963 (ii)) for calculation of convective boiling heat transfer to liquid metals, a method for calculating boiling coefficients is developed. Two-dimensionless functions ( $\mathrm{S}$ and $\mathrm{F}$ ) were introduced to account for the suppression of bubble growth due to flow and for the increase in convective turbulence resulting from two-phase flow. These two correlating functions were determined empirically from available data and are presented graphically in Figures 6-3 and 6-4.

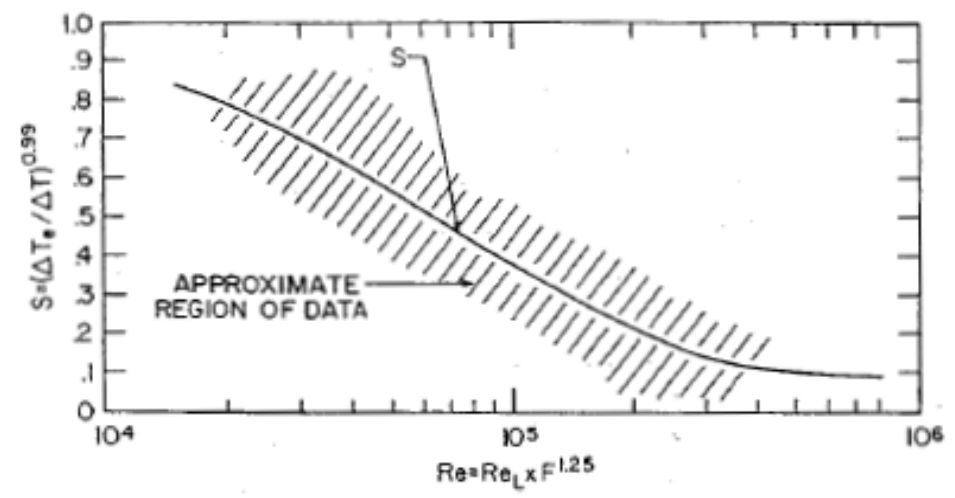

Figure 6-3. Suppression factor (S) (Chen 1963(ii)).

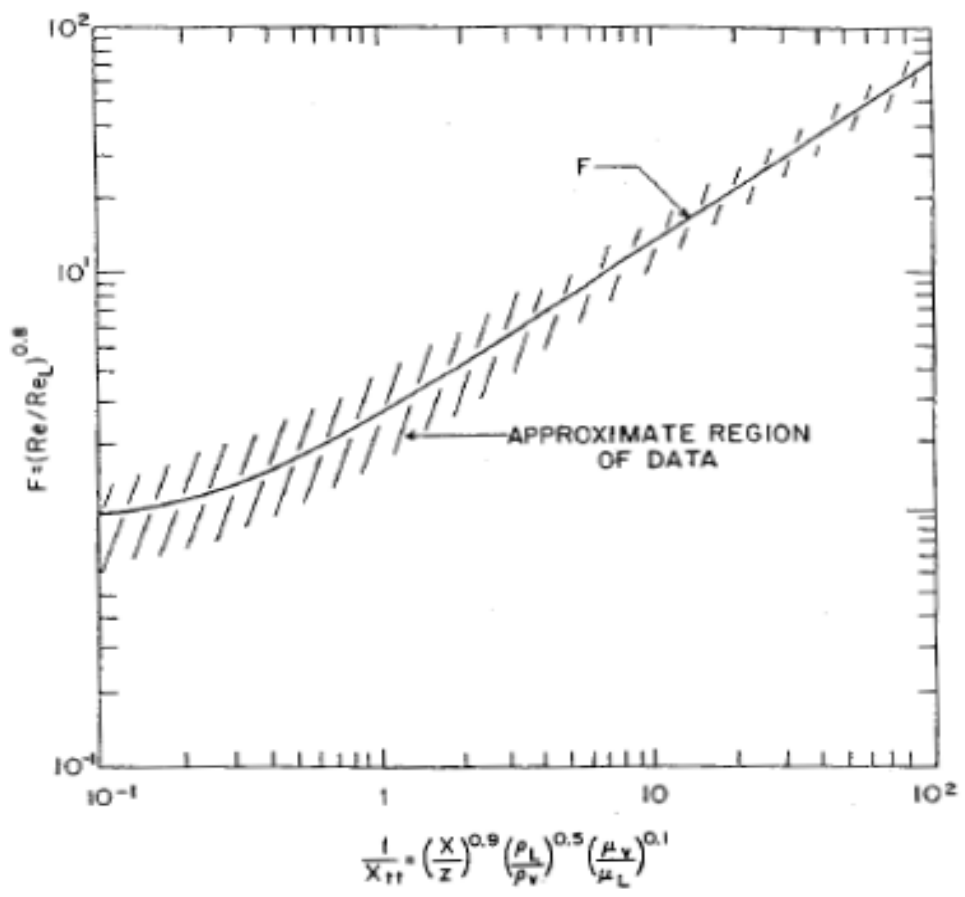

Figure 6-4. Reynolds number factor (F) (Chen 1963 (ii)). 
The analysis (Forster and Zuber 1955) was used as the basis for the formulation of a microconvective mechanism of heat transfer. The analysis was derived for the case of pool boiling and resulted in the following equation for the boiling Nusselt number:

$$
\begin{aligned}
& \mathrm{Nu}_{\mathrm{bo}}=0.0015\left(\mathrm{Re}_{\mathrm{bo}}\right)^{0.62}\left(\operatorname{Pr}_{\mathrm{L}}\right)^{0.33}=\frac{\mathrm{h}_{\mathrm{bo}} \mathrm{r}_{\mathrm{b}}}{\mathrm{K}_{\mathrm{L}}} \\
& \mathrm{r}_{\mathrm{b}}=\frac{\Delta \mathrm{T}}{\mathrm{h}_{\mathrm{fg}} \rho_{\mathrm{V}}}\left(\frac{2 \pi \mathrm{K}_{\mathrm{L}} \rho_{\mathrm{L}} \mathrm{C}_{\mathrm{p}, \mathrm{L}} \sigma}{\Delta \mathrm{P}}\right)^{0.5}\left(\frac{\rho_{\mathrm{L}}}{\mathrm{g} \Delta \mathrm{P}}\right)^{0.25} \\
& \operatorname{Re}_{\mathrm{bo}}=\frac{\pi \mathrm{K}_{\mathrm{L}} \mathrm{C}_{\mathrm{p}, \mathrm{L}}}{\mu_{\mathrm{L}}}\left(\frac{\rho_{\mathrm{L}} \Delta \mathrm{T}}{\rho_{\mathrm{V}} \mathrm{h}_{\mathrm{fg}}}\right)^{2}
\end{aligned}
$$

These equations are based on the premise that the Re number for microconvective boiling heat transfer is governed by the growth rate of bubbles.

The process of heat transfer to a boiling liquid is quite complex, especially evident in the case of convective boiling with net generation of vapor. Under these conditions, heat transfer is affected by the various flow parameters and the vapor quality, as well as by the parameters pertinent in pool boiling. As illustrated in Figure 6-5 for the case of boiling from a superheated wall, whether in pool boiling or convective boiling, the degree of superheat is actually not constant across the boundary layer. Because of this, the Re number used is an effective Re number representative of some mean, effective superheat. The difference between this effective superheat and the wall superheat is small for the case of pool boiling and was neglected in derivation (Forster and Zuber 1955). This difference cannot be neglected in the case of convective boiling since the temperature gradient is now dependent on flow rates and vapor quality and would generally be much steeper than in the corresponding pool-boiling case with the same wall superheat. That is why, in the present analysis, the length of the boiling section $\left(\mathrm{L}_{2}\right)$ is discretized into various small sections such that effect of vapor quality can be included in the analysis.

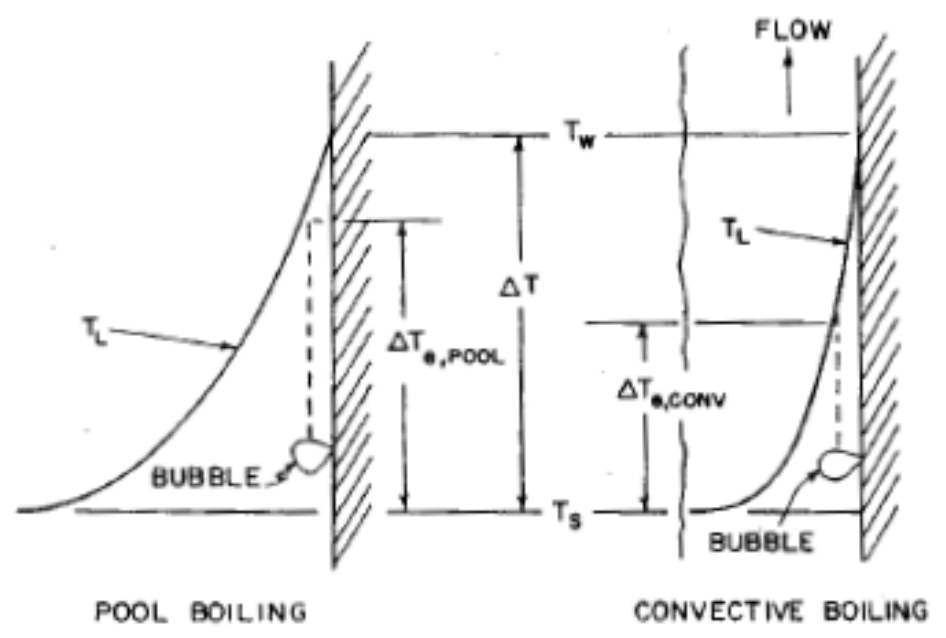

Figure 6-5. Temperature profiles for pool boiling and for convective boiling with same total superheat (Chen 1963 (i)). 
As stated earlier, the microconvective mechanism is associated with bubble growth in the annular liquid film and the corresponding heat transfer coefficient can be obtained by:

$$
\begin{aligned}
& \mathrm{h}_{\text {micro }}=0.00122 \frac{\mathrm{K}_{\mathrm{L}}^{0.79} \mathrm{C}_{\mathrm{P}, \mathrm{L}}^{0.45} \rho_{\mathrm{L}}^{0.49} \Delta \mathrm{T}^{0.24} \Delta \mathrm{P}_{1}^{0.75} \mathrm{~g}^{0.25}}{\sigma^{0.5} \mu_{\mathrm{L}}^{0.29} \mathrm{~h}_{\mathrm{fg}}^{0.24} \rho_{\mathrm{V}}^{0.24}} \times \mathrm{S} \\
& \mathrm{S}=\left(\frac{\Delta \mathrm{T}_{\mathrm{e}}}{\Delta \mathrm{T}}\right)^{0.99}
\end{aligned}
$$

where $\Delta \mathrm{T}_{\mathrm{e}}$ is the effective superheat for bubble growth in the annular liquid film and $\mathrm{s}$, called the suppression function, approaches unity at zero flow rate and zero at infinite flow rate. It was postulated, subject to experimental verification, that in all ranges of flow ' $S$ ' can be represented as a function of the local two-phase Re number, as shown in Figure 6-3. In extending this theory to the case of boiling liquid metals, it is assumed that the microconvective heat transfer can still be described by Equation (6-41). This assumption is based on indications that the pool-boiling theory (Forster and Zuber 1955) from which Equation (6-41) was derived appears to be applicable for liquid metals as well as for ordinary fluids.

For the current analysis for convective boiling of liquid metals, it is proposed that the following modified form of the Lyon-Martinelli equation be used (Chen 1963(ii)):

$$
\mathrm{h}_{\text {macro }}=\left[\delta+0.024\left(\mathrm{~F} \mathrm{Re}_{\mathrm{L}}^{0.8}\right)\left(\beta \operatorname{Pr}_{\mathrm{L}}\right)^{\alpha_{0}}\right]\left(\frac{\gamma_{1} \mathrm{~K}_{\mathrm{L}}}{\mathrm{D}}\right)
$$

The values of the four parameters $\alpha_{0}, \beta, \gamma_{1}, \delta$ are listed in Table 6-1.

Table 6-1. Parameters in macroconvective equation (Chen 1963 (ii)).

\begin{tabular}{|c|c|c|c|}
\hline Symbol & Liquid Metal & Vapor & Two-Phase \\
\hline$\delta$ & 7 & 0 & $7 Z^{\varepsilon}$ \\
\hline$\gamma_{1}$ & 1 & $\mathrm{~K}_{\mathrm{v}} / \mathrm{K}_{\mathrm{L}}$ & $\mathrm{Z}^{\varepsilon}+\left(\mathrm{K}_{\mathrm{v}} / \mathrm{K}_{\mathrm{L}}\right)\left(1-\mathrm{Z}^{\varepsilon}\right)$ \\
\hline$\beta$ & 1 & $\mathrm{Pr}_{\mathrm{v}} / \mathrm{Pr}_{\mathrm{L}}$ & $\mathrm{Z}^{\varepsilon}+\left(\operatorname{Pr}_{\mathrm{v}} / \mathrm{Pr}_{\mathrm{L}}\right)\left(1-\mathrm{Z}^{\varepsilon}\right)$ \\
\hline$\alpha_{0}$ & 0.8 & 0.4 & $0.4\left(1-\mathrm{Z}^{\varepsilon}\right)$ \\
\hline $\mathrm{F}$ & 1 & $\left(\mathrm{Re}_{\mathrm{v}} / \mathrm{Re}_{\mathrm{L}}\right)^{0.8}$ & $\left(\mathrm{Re} / \mathrm{Re}_{\mathrm{L}}\right)^{0.8}=\mathrm{f}\left(1 / \mathrm{X}_{\mathrm{tt}}\right)$ \\
\hline
\end{tabular}

At the limit of 0\% quality, Equation (6-43) reduces to the conventional Lyon-Martinelli equation descriptive of single-phase liquid metal heat transfer. At the other limit of 100\% quality, Equation (6-43) becomes the Dittus-Boelter equation for vapor phase heat transfer. In the region of mixed quality where both liquid and vapor are present, it is proposed that the four parameters denoted by Greek letters assume values intermediate between the single-phase values, as shown in Table 6-1. The exponential parameter, $\varepsilon$, is a measure of the nonuniformity of phase distribution in the flow pattern. Should the distribution be uniform in such a way that the two-phase values for the parameters are simple arithmetic proportions of the single-phase values, then $\varepsilon$ is unity, which is also the value taken in this analyses. In the case of interest, where liquid is concentrated on the channel wall as an annular film, it is expected that liquid properties would dominate, and $\varepsilon$ approaches zero. The exact value for $\varepsilon$ will have to await empirical determination. The function $\mathrm{F}$ is a measure of the effectiveness of two-phase momentum transfer as compared to the corresponding liquid-phase momentum transfer. F can be correlated against the Martinelli parameter. The recommended correlation is reproduced in Figure 6-4 (above). 
From Equations (6-41) and (6-43), with values of the parameters obtained from Table 6-1, the total convective boiling heat transfer can then be obtained as the sum of the two interacting contributions,

$\mathrm{h}=\mathrm{h}_{\text {micro }}+\mathrm{h}_{\text {macro }}$

\subsubsection{Pressure Drop Evaluation for $\mathrm{Na}$ (Boiling) Region}

The determination of the pressure drop is important for heat exchanger design because the fluid needs to be pumped through the exchanger, the pumping power is proportional to the exchanger pressure drop, and the heat transfer rate can be influenced significantly by the saturation temperature change for an evaporating/condensing fluid if there is a large pressure drop associated with the flow (Sabharwall et al. 2009 (iv)). This is because saturation temperature changes with changes in saturation pressure and in turn affects the temperature potential for heat transfer. The core pressure drop is determined separately on each side (for helium and $\mathrm{Na}$ ). It consists of one or more of the following contributions:

- Frictional losses associated with fluid flow over the heat transfer surface

- Momentum effect (pressure drop or rise due to the fluid density changes in the core)

- Pressure drop associated with sudden contraction and expansion at the core inlet and outlet

- Gravity effect due to the change in elevation between the inlet and outlet of the exchanger.

As mentioned earlier, the rate of change of the static pressure is the change of three components due to acceleration, friction, and gravity (Todreas and Kazimi 2000):

$$
\begin{aligned}
& -\frac{\mathrm{dp}}{\mathrm{dz}}=\left(\frac{\mathrm{dp}}{\mathrm{dz}}\right)_{\text {accleration }}+\left(\frac{\mathrm{dp}}{\mathrm{dz}}\right)_{\text {friction }}+\left(\frac{\mathrm{dp}}{\mathrm{dz}}\right)_{\text {gravity }} \\
& \left(\frac{d p}{d z}\right)_{\text {accleration }}=\frac{d}{d z}\left(\frac{G_{m}^{2}}{\rho_{m}}\right) \\
& \left(\frac{\mathrm{dp}}{\mathrm{dz}}\right)_{\text {friction }}=\frac{1}{\mathrm{~A}_{\mathrm{z}}} \int_{\mathrm{P}_{\mathrm{z}}} \tau_{\mathrm{w}} \mathrm{dP}_{\mathrm{z}}=\frac{\overline{\tau_{\mathrm{w}}} \mathrm{P}_{\mathrm{z}}}{\mathrm{A}_{\mathrm{z}}}
\end{aligned}
$$

The friction pressure gradient for two-phase flow can be expressed in a general form similar to single-phase flow:

$$
\begin{aligned}
& \left(\frac{d p}{d z}\right)_{\text {friction }}=\frac{1}{A_{z}} \int_{P_{z}} \tau_{w} d P_{z}=\frac{\overline{\tau_{w}} P_{z}}{A_{z}}=\frac{f_{T P}}{D_{e, z}}\left[\frac{G_{m}^{2}}{2 \rho_{m}}\right] \\
& \left(\frac{d p}{d z}\right)_{\text {gravity }}=\rho_{m} g \cos \theta
\end{aligned}
$$

The pressure drop for single phase can easily be obtained from Equation (6-20), but for evaluation of the pressure drop in a two-phase flow there are several models that one can use. This analysis uses a HEM where the velocity of the liquid equals that of vapor, the two velocities are uniform within the area, and the two phases are in thermodynamic equilibrium. 


$$
\begin{aligned}
& \mathrm{V}_{\mathrm{m}}=\frac{\mathrm{G}_{\mathrm{m}}}{\rho_{\mathrm{m}}} \\
& \frac{1}{\rho_{\mathrm{m}}}=\frac{\mathrm{x}}{\rho_{\mathrm{V}}}+\frac{1-\mathrm{x}}{\rho_{\mathrm{L}}}
\end{aligned}
$$

From Equations (6-46) and (6-51), because $\mathrm{G}_{\mathrm{m}}$ is constant for a constant area channel, the HEM acceleration pressure gradient is given by:

$$
\begin{aligned}
& \left(\frac{d p}{d z}\right)_{\text {acceleration }}=G_{m}^{2} \frac{d}{d z}\left[\frac{1}{\rho_{L}}+\left(\frac{1}{\rho_{\mathrm{V}}}-\frac{1}{\rho_{\mathrm{L}}}\right) x\right] \\
& \left(\frac{d p}{d z}\right)_{\text {acceleration }}=G_{m}^{2}\left[\frac{d v_{L}}{d z}+x\left(\frac{d v_{V}}{d z}-\frac{d v_{L}}{d z}\right)+\left(v_{V}-v_{L}\right) \frac{d x}{d z}\right]
\end{aligned}
$$

If $\mathrm{v}_{\mathrm{V}}$ and $\mathrm{v}_{\mathrm{L}}$ are assumed independent of $\mathrm{z}$, i.e., liquid is assumed to be incompressible and $\mathrm{v}_{\mathrm{g}}$ is discretized such that it does not change within each subsection, then

$$
\left(\frac{\mathrm{dp}}{\mathrm{dz}}\right)_{\text {acceleration }}=\mathrm{G}_{\mathrm{m}}^{2}\left[\left(\mathrm{v}_{\mathrm{v}}-\mathrm{v}_{\mathrm{L}}\right) \frac{\mathrm{dx}}{\mathrm{dz}}\right]=\mathrm{G}_{\mathrm{m}}^{2} \mathrm{v}_{\mathrm{fg}} \frac{\mathrm{dx}}{\mathrm{dz}}
$$

For HEM, Equation (6-48) for the friction pressure gradient reduces to

$$
\left(\frac{\mathrm{dp}}{\mathrm{dz}}\right)_{\text {friction }}=\frac{\mathrm{f}_{\mathrm{TP}}}{\mathrm{D}_{\mathrm{e}}}\left(\frac{\mathrm{G}_{\mathrm{m}}^{2}}{2 \rho_{\mathrm{m}}}\right)
$$

Thus the total pressure drop when gas compressibility is accounted for is obtained by substituting in Equation (6-45) from Equations (6-47), (6-51), and (6-52) and rearranging to show

$$
-\left(\frac{d p}{d z}\right)_{\text {HEM }}=\frac{\frac{f_{\text {TP }}}{D_{e}}\left(\frac{G_{m}^{2}}{2 \rho_{m}}\right)+G_{m}^{2} v_{f g} \frac{d x}{d z}+\rho_{m} g \cos \theta}{\left(1+G_{m}^{2} x \frac{\partial v_{\mathrm{V}}}{\partial p}\right)}
$$

In this case the heat exchanger is horizontally located such that the gravitational effect can be neglected, i.e.,

$$
-\left(\frac{d p}{d z}\right)_{\text {HEM }}=\frac{\frac{f_{\mathrm{TP}}}{D_{\mathrm{e}}}\left(\frac{\mathrm{G}_{\mathrm{m}}^{2}}{2 \rho_{\mathrm{m}}}\right)+\mathrm{G}_{\mathrm{m}}^{2} \mathrm{v}_{\mathrm{fg}} \frac{\mathrm{dx}}{\mathrm{dz}}}{\left(1+\mathrm{G}_{\mathrm{m}}^{2} \mathrm{x} \frac{\partial \mathrm{v}_{\mathrm{V}}}{\partial \mathrm{p}}\right)}
$$


The friction pressure drop multiplier for HEM is defined (Todreas and Kazimi 2000) as

$\varphi_{\mathrm{fo}}^{2}=\frac{\rho_{\mathrm{L}}}{\rho_{\mathrm{m}}} \frac{\mathrm{f}_{\mathrm{TP}}}{\mathrm{f}_{\mathrm{L}}}=\left[1+\mathrm{x}\left(\frac{\rho_{\mathrm{L}}}{\rho_{\mathrm{V}}}-1\right)\right]\left[1+\mathrm{x}\left(\frac{\mu_{\mathrm{L}}}{\mu_{\mathrm{V}}}-1\right)\right]^{-0.25}$

Therefore,

$\mathrm{f}_{\mathrm{TP}}=\left(\frac{\mathrm{f}_{\mathrm{L}} \rho_{\mathrm{m}}}{\rho_{\mathrm{L}}}\right)\left[1+\mathrm{x}\left(\frac{\rho_{\mathrm{L}}}{\rho_{\mathrm{V}}}-1\right)\right]\left[1+\mathrm{x}\left(\frac{\mu_{\mathrm{L}}}{\mu_{\mathrm{V}}}-1\right)\right]^{-0.25}$

Generally, $\varphi_{\text {fo }}^{2}$ increases with decreasing pressure and higher quality, and the inclusion of the viscosity effect is particularly significant for high quality conditions.

\subsection{Results and Discussion}

The various operating conditions and heat transfer coefficient for the helium side are shown in Table 6-2.

Table 6-2. Heat transfer and geometric parameters for helium duct.

\begin{tabular}{|l|c|}
\hline $\mathrm{T}_{\mathrm{i}}(\mathrm{K})$ & 1300 \\
\hline $\mathrm{T}_{\mathrm{o}}(\mathrm{K})$ & 1182 \\
\hline Diameter $(\mathrm{m})$ & 1.551 \\
\hline$\dot{m}_{\mathrm{He}}(\mathrm{kg} / \mathrm{sec})$ & 81.59 \\
\hline $\mathrm{Q}_{\mathrm{L}_{1}, \mathrm{He}}(\mathrm{W})$ & $1.57 \mathrm{E}+06$ \\
\hline $\mathrm{Q}_{\mathrm{L}_{2}, \mathrm{He}}(\mathrm{W})$ & $3.81 \mathrm{E}+07$ \\
\hline $\mathrm{Q}_{\mathrm{L}_{3}, \mathrm{He}}(\mathrm{W})$ & $1.03 \mathrm{E}+07$ \\
\hline $\mathrm{h}_{\mathrm{He}}\left(\mathrm{W} / \mathrm{m}^{2} \mathrm{~K}\right)$ & 354.74 \\
\hline
\end{tabular}

As mentioned earlier, there is a sonic velocity limitation at which one can achieve maximum heat transfer in a heat exchanger. In this mathematical model the velocity of the vapor is fixed to go at a constant rate of half the sonic velocity. Tables 6-3 and 6-4 show the heat transfer parameters obtained for both single and two-phase. The diameter of the Na duct for both liquid and vapor phase were selected by fixing the mass flow rate, which was evaluated in a previous section, and operating at half the sonic velocity for vapor and at $1 \mathrm{~m} / \mathrm{sec}$ for liquid phase. For the boiling Na section $\left(\mathrm{L}_{2}\right)$ the diameter is varied such that the change in quality could be incorporated as the diameter varied from liquid to vapor phase, which can be seen in Table 6-4.

The heat transfer coefficient of $\mathrm{Na}$ is high when in the boiling regime, and is an order of magnitude higher than what would be expected in a free convection (Deev et al. 1967). In this counter current arrangement, the heat transfer parameter is solely governed by He, which the following equation shows

$$
\frac{1}{\mathrm{U}}=\frac{1}{\mathrm{~h}_{\mathrm{He}}}+\frac{1}{\mathrm{~h}_{\mathrm{Na}}}
$$

Table 6-3. Single phase parameters (operating at Vs/2).

\begin{tabular}{|c|c|c|c|c|c|c|c|c|}
\hline Section & Phase & $\mathrm{T}_{\mathrm{i}}(\mathrm{K})$ & $\mathrm{T}_{\mathrm{o}}(\mathrm{K})$ & Diameter $(\mathrm{m})$ & Velocity $(\mathrm{m} / \mathrm{sec})$ & $\dot{\mathrm{m}}_{\mathrm{Na}}(\mathrm{kg} / \mathrm{sec})$ & $\mathrm{h}_{\mathrm{Na}}\left(\mathrm{W} / \mathrm{m}^{2} \mathrm{~K}\right)$ & $\mathrm{U}\left(\mathrm{W} / \mathrm{m}^{2} \mathrm{~K}\right)$ \\
\hline $\mathrm{L}_{1}$ & Single Phase Vapor & 1156 & 1223 & 0.294 & 378.5 & 9.794 & 641.14 & 228.38 \\
\hline $\mathrm{L}_{3}$ & Single Phase Liquid & 393 & 1156 & 0.122 & 1 & 9.794 & $7.25 \mathrm{E}+03$ & 338.19 \\
\hline
\end{tabular}


Table 6-4. Two-phase boiling Na parameters (operating at Vs /2 \&Q $\mathrm{L}_{\mathrm{L}}$ ).

\begin{tabular}{|c|c|c|c|}
\hline Quality & Diameter $(\mathrm{m})$ & $\mathrm{h}_{\text {Na Boiling }}\left(\mathrm{W} / \mathrm{m}^{2} \mathrm{~K}\right)$ & $\mathrm{U}\left(\mathrm{W} / \mathrm{m}^{2} \mathrm{~K}\right)$ \\
\hline 0.05 & 0.138 & $8.37 \mathrm{E}+06$ & 354.725 \\
\hline 0.15 & 0.153 & $8.43 \mathrm{E}+06$ & 354.725 \\
\hline 0.25 & 0.169 & $8.06 \mathrm{E}+06$ & 354.724 \\
\hline 0.35 & 0.184 & $7.60 \mathrm{E}+06$ & 354.723 \\
\hline 0.45 & 0.2 & $7.12 \mathrm{E}+06$ & 354.722 \\
\hline 0.55 & 0.216 & $6.64 \mathrm{E}+06$ & 354.721 \\
\hline 0.65 & 0.231 & $6.19 \mathrm{E}+06$ & 354.719 \\
\hline 0.75 & 0.247 & $5.76 \mathrm{E}+06$ & 354.718 \\
\hline 0.85 & 0.262 & $5.37 \mathrm{E}+06$ & 354.716 \\
\hline 0.95 & 0.278 & $5.01 \mathrm{E}+06$ & 354.714 \\
\hline
\end{tabular}

Operating at higher pressure will raise the boiling point temperature of $\mathrm{Na}$ such that it will boil at a much higher temperature than 1,156 K. Figure 6-6 shows a pressure drop for the entire system, which is not that high, so the design could still be optimized. The design has been optimized such that it has a lower pressure drop and similar heat transfer coefficient, if not better. This case was operated at a different velocity, keeping the net mass flow rate constant and finalizing the condition, which is described in Tables 6-5 and 6-6. The heat transfer is this case is also solely dictated by He, as seen in the earlier case for the same reason as explained previously.

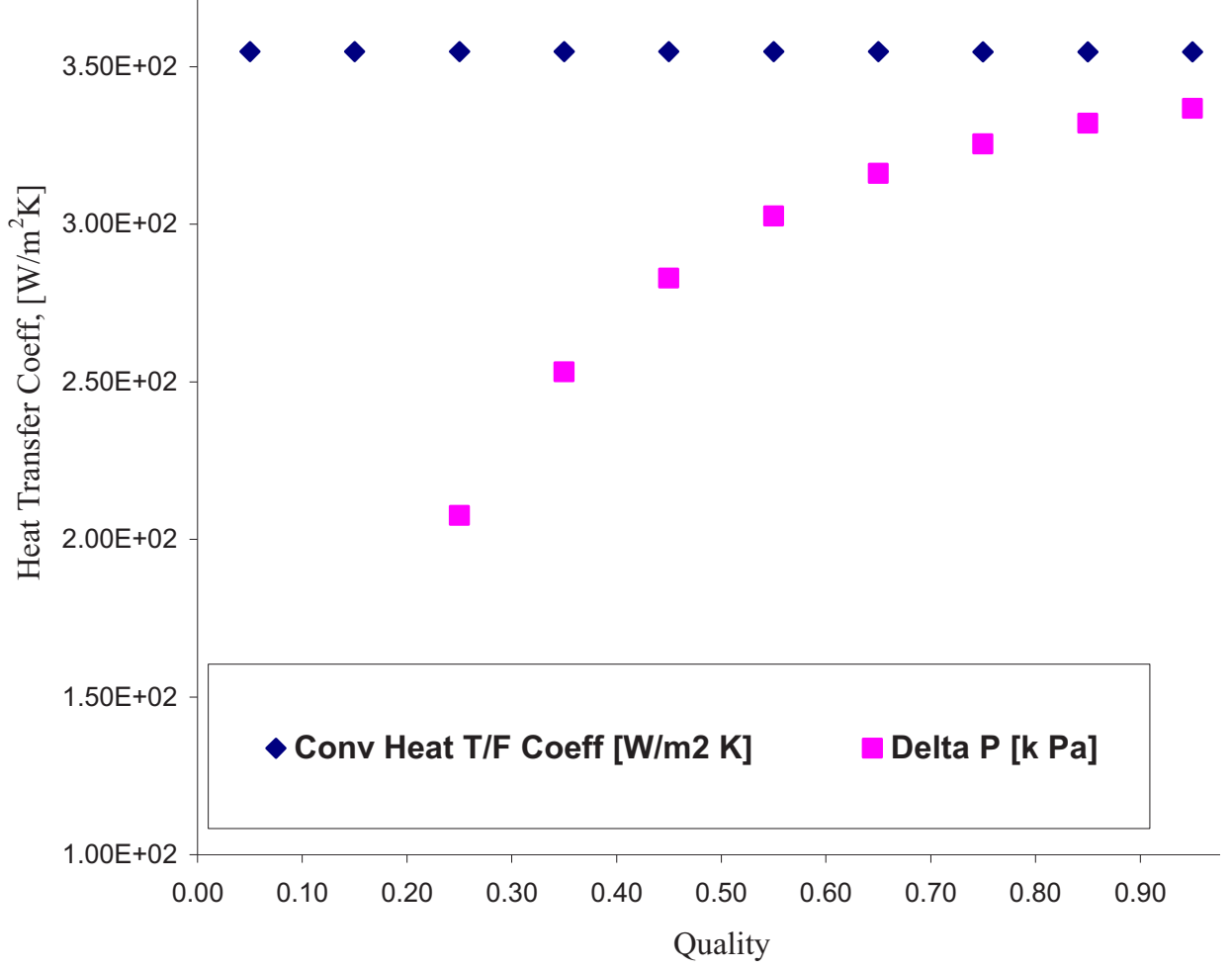

Figure 6-6. Overall heat transfer characteristics operating at Vs/2 and at 1,300 K. 
Table 6-5. Single phase parameters (improved design).

\begin{tabular}{|c|c|c|c|c|c|c|c|c|}
\hline Section & Phase & $\mathrm{T}_{\mathrm{i}}(\mathrm{K})$ & $\mathrm{T}_{\mathrm{o}}(\mathrm{K})$ & Diameter $(\mathrm{m})$ & Velocity $(\mathrm{m} / \mathrm{sec})$ & $\mathrm{m}_{\mathrm{Na}}(\mathrm{kg} / \mathrm{sec})$ & $\mathrm{h}_{\mathrm{Na}}\left(\mathrm{W} / \mathrm{m}^{2} \mathrm{~K}\right)$ & $\mathrm{U}\left(\mathrm{W} / \mathrm{m}^{2} \mathrm{~K}\right)$ \\
\hline $\mathrm{L}_{1}$ & Single Phase Vapor & 1156 & 1223 & 0.47 & 150 & 9.794 & 272.276 & 154.04 \\
\hline $\mathrm{L}_{3}$ & Single Phase Liquid & 393 & 1156 & 0.122 & 1 & 9.794 & $7.25 \mathrm{E}+03$ & 338.19 \\
\hline
\end{tabular}

Table 6-6. Two-phase boiling Na parameters (improved design).

\begin{tabular}{|c|c|c|c|}
\hline Quality & Diameter $(\mathrm{m})$ & $\mathrm{h}_{\text {Na Boiling }}(\mathrm{W} / \mathrm{m} 2 \mathrm{~K})$ & $\mathrm{U}(\mathrm{W} / \mathrm{m} 2 \mathrm{~K})$ \\
\hline 0.05 & 0.154 & $8.19 \mathrm{E}+06$ & 354.724 \\
\hline 0.15 & 0.185 & $8.12 \mathrm{E}+06$ & 354.724 \\
\hline 0.25 & 0.217 & $7.67 \mathrm{E}+06$ & 354.723 \\
\hline 0.35 & 0.248 & $7.16 \mathrm{E}+06$ & 354.722 \\
\hline 0.45 & 0.28 & $6.65 \mathrm{E}+06$ & 354.721 \\
\hline 0.55 & 0.311 & $6.17 \mathrm{E}+06$ & 354.719 \\
\hline 0.65 & 0.343 & $5.72 \mathrm{E}+06$ & 354.717 \\
\hline 0.75 & 0.375 & $5.30 \mathrm{E}+06$ & 354.716 \\
\hline 0.85 & 0.406 & $4.92 \mathrm{E}+06$ & 354.714 \\
\hline 0.95 & 0.438 & $4.58 \mathrm{E}+06$ & 354.712 \\
\hline
\end{tabular}

On comparing Figures 6-6 and 6-7, $\Delta \mathrm{p}$ shows the significant drop while the overall heat transfer coefficient remains unchanged.

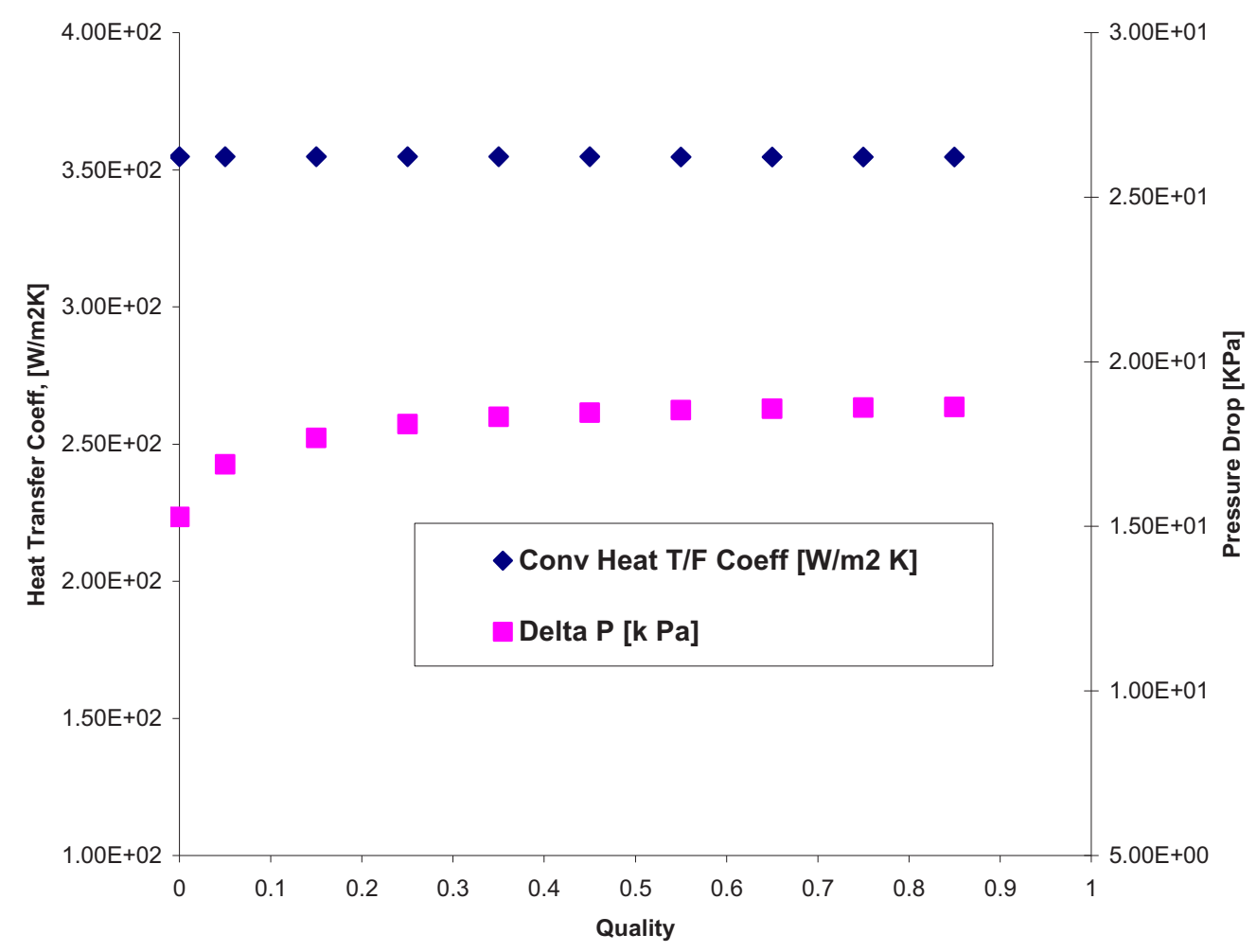

Figure 6-7. Overall heat transfer characteristics operating at improved condition at 1,300 K. 
For $\operatorname{Pr}<<1$, as in the case of $\mathrm{Na}$ (in liquid state), the change of $\mathrm{Nu}$ with the Re is very gradual, reflecting the influence of the high molecular thermal diffusivity, as can be seen from the log-log plot in Figure 6-8.

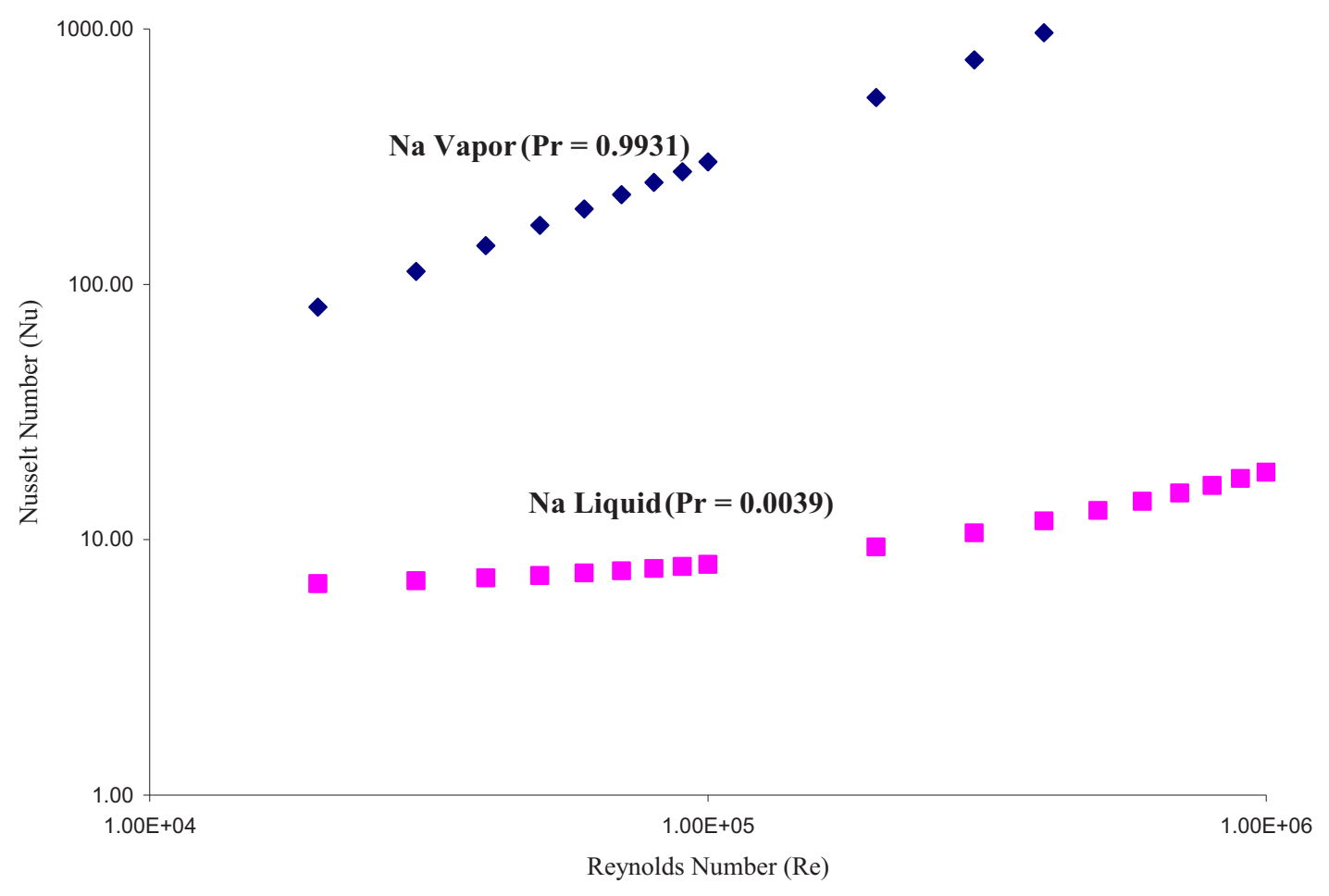

Figure 6-8. Nusselt number dependence on Reynolds number for Na liquid metal.

\subsection{Analysis at Lower Temperature}

The operating temperature dictates the best suited coolant for a given operation. The following analysis was at $900^{\circ} \mathrm{C}(1,173 \mathrm{~K})$ and at $850^{\circ} \mathrm{C}(1,123 \mathrm{~K})$, so that process heat from the reactor can be utilized for other heat applications. At the given temperatures $\mathrm{Na}$ is not as effective as $\mathrm{NaK}$ eutectic, especially to achieve a phase change (at $850^{\circ} \mathrm{C}$ ) as can be seen from Table 6-7. Na doesn't boil till $883^{\circ} \mathrm{C}$ at atmospheric pressure.

Table 6-7. Properties of working fluids.

\begin{tabular}{|c|c|c|}
\hline Liquid Metal & $\mathrm{T}_{\text {melting }}(\mathrm{K})$ & $\mathrm{T}_{\text {boiling }}(\mathrm{K})$ \\
\hline $\mathrm{Na}$ & 370.8 & 1156 \\
\hline $\mathrm{K}$ & 336.7 & 1033 \\
\hline NaK Eutectic & 262 & 1057 \\
\hline
\end{tabular}

The eutectic mixture as shown in Figure 6-9 of $\mathrm{Na}$ and $\mathrm{K}$ is the combination of 32 atom percent of $\mathrm{Na}$ and 68 atom percent of $\mathrm{K}$ in the mixture. 


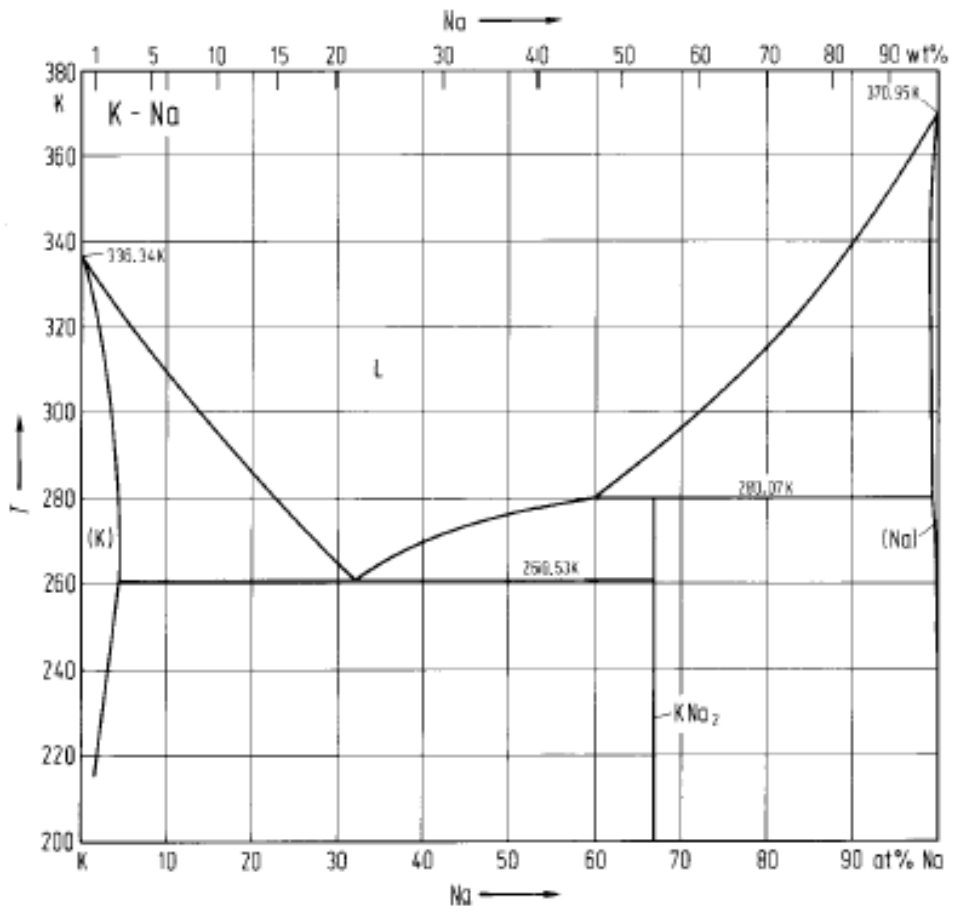

Figure 6-9. Phase diagram of NaK (Bale 1982).

A similar analysis was carried out for $\mathrm{NaK}$ eutectic and the following heat transfer characteristics were obtained, as can be seen from Figures 6-10 and 6-11.

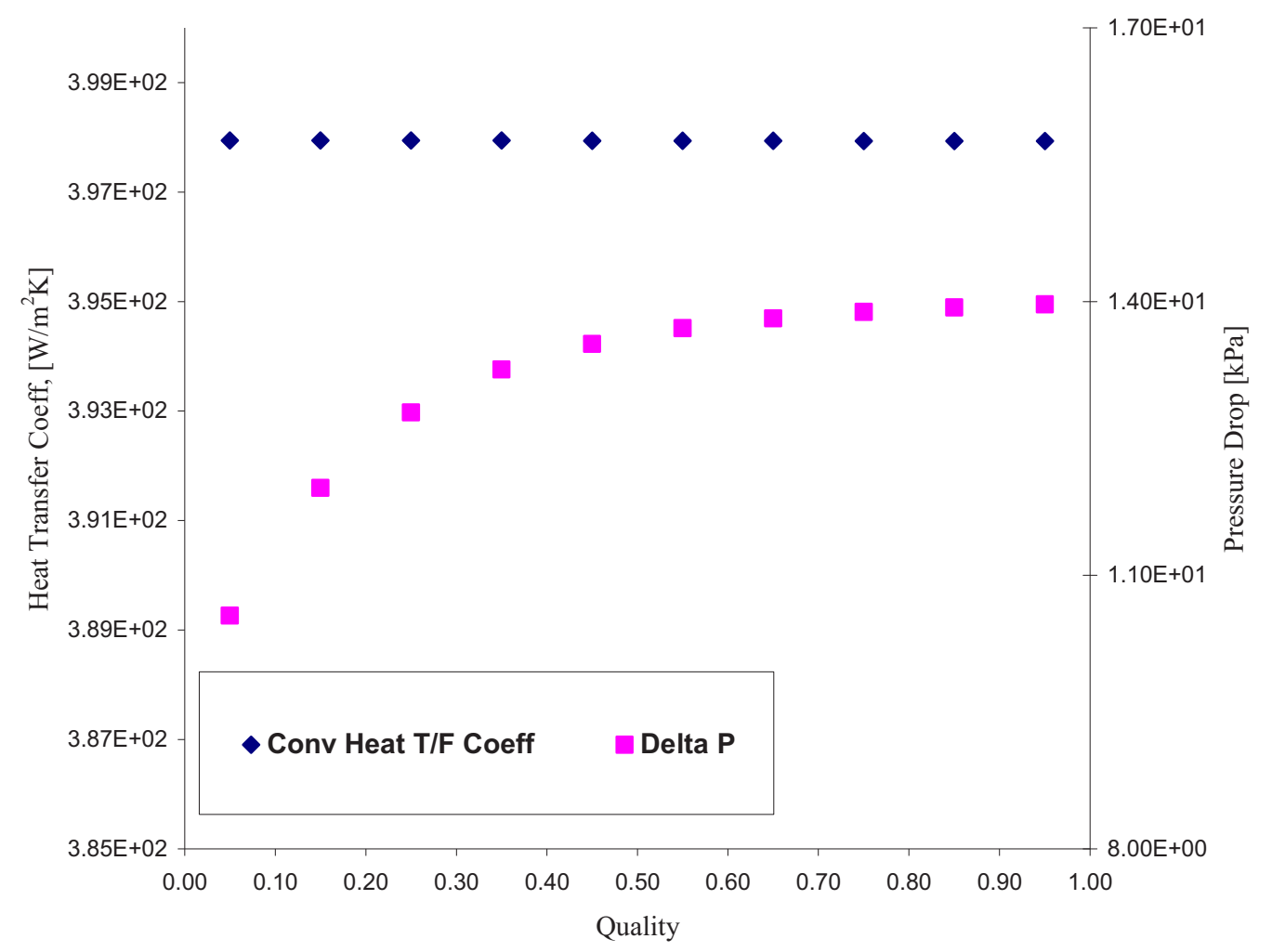

Figure 6-10. Overall heat transfer characteristics operating at 1,173 $\mathrm{K}$ for NaK eutectic. 


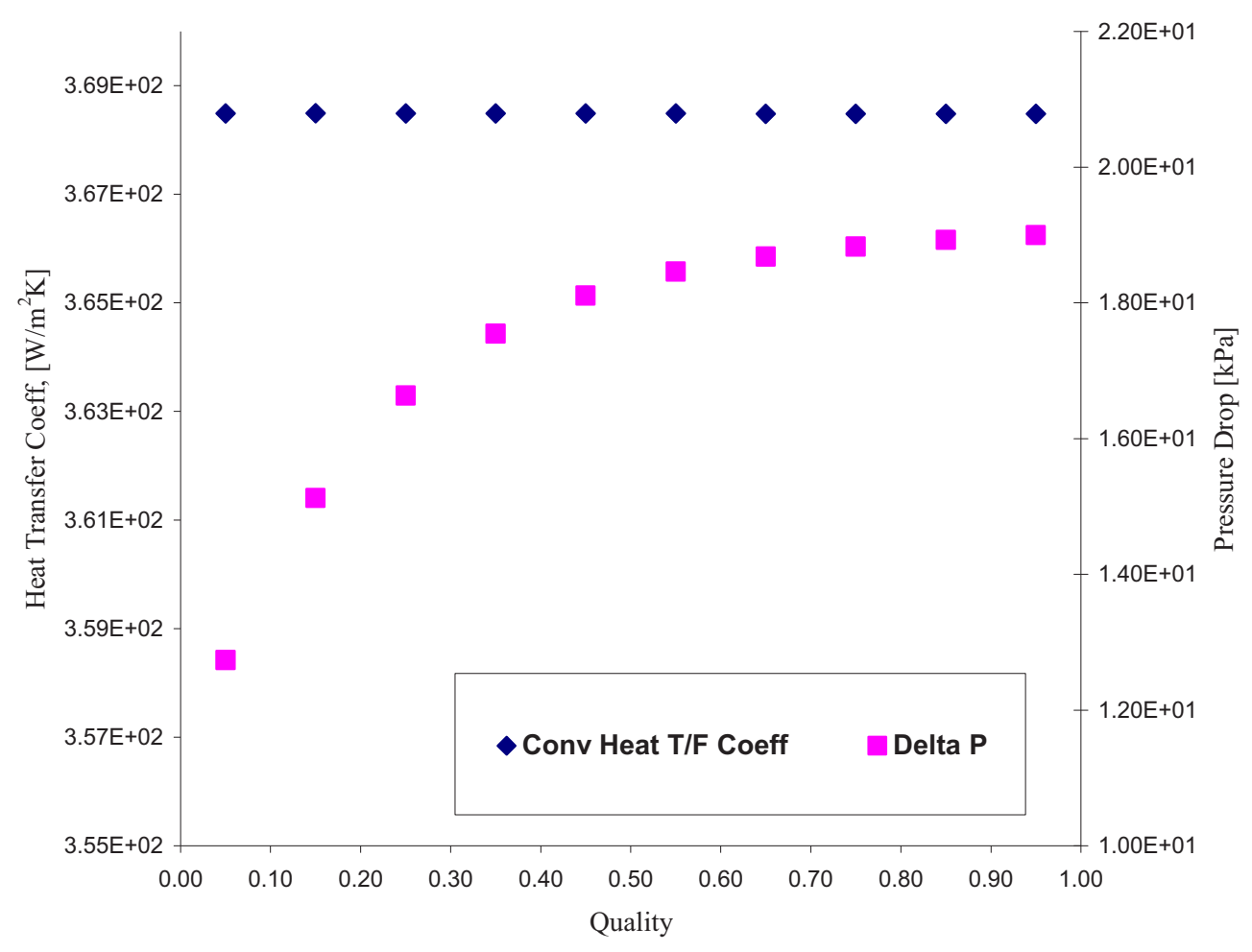

Figure 6-11. Overall heat transfer characteristics operating at 1,123 $\mathrm{K}$ for $\mathrm{NaK}$ eutectic.

In order to further enhance the heat transfer parameters for the phase change heat exchanger (evaporator and condenser), a mathematical model of a SHE was developed in MATLAB and compared with the straight tube design. The further salient features of SHE are discussed in the next section.

\subsection{Spiral Phase Change Heat Exchanger}

According to Coons et al. (1947), the SHE was first introduced by Rosenblad in Sweden in 1930. However, Boothroyd (1997) reported that the SHE concept was first proposed in the late nineteenth century. Many other countries have followed suit and have found a wide application to various occasions of heat exchange owing to such advantages as compact design, easy fabrication, high efficiency, and small heat losses. While little design data exists in the open literature, SHE manufacturers (e.g., Alfa Laval Thermal) maintain empirical correlations for estimating heat transfer and pressure drop in their proprietary libraries. Still, correlations need to be accessible to the public and general enough for most applications. Better insight into the flow and heat transfer characteristics of SHE are also needed.

The SHE is formed by continuously bending two flat metal plates into a spiral as shown in Figure 6-12. Spacing studs can be placed between the plates to allow support during the bending process and to provide resistance against fluid pressure differences. In the counter flow mode of operation, one of the working fluids flows through a spiral in the direction of increasing radius of curvature, while the fluid in the adjacent duct flows through the other spiral in the direction of decreasing radius of curvature.

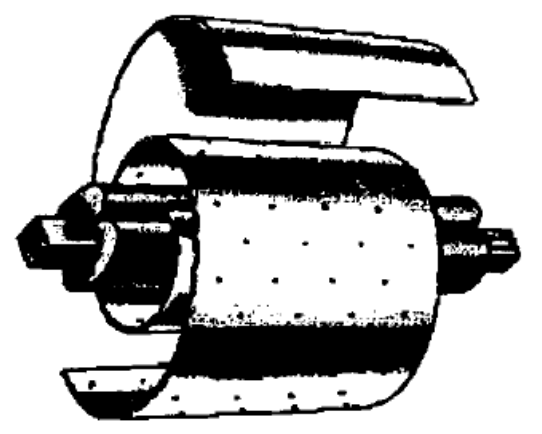

Figure 6-12. Plate forming process of SHE (Egner 2003). 
According to Coons et al. (1947), the SHE has gone through design refinements and innovations so that it is now used in all types of heat transfer applications. Typical applications for these heat exchangers involve:

- Cooling and heating of highly viscous fluids or process liquids

- Handling of sludge, slurries, and liquids with fibers or solids in suspension.

SHEs can be found in many industrial and manufacturing processes as noted by Minton (1970). Important advantages offered by these devices include:

- Compactness

- High resistance to fouling

- High heat transfer due to centrifugal forces

- Simple flow passages ideal for heating or cooling sludge or slurry

- Turbulent flow heat transfer is high compared to tubular heat exchangers

- Ease of cleaning.

SHEs are also used in municipal wastewater plants for their ability to handle fluids containing solids and fibers with minimal fouling. Lines (1991) points out that municipalities use SHEs because they offer high thermal efficiency (due to counter-flow mode) at low capital investment. Lines also reported that SHEs are used for lubrication oil cooling and clarifier effluent cooling/heat recovery.

\subsubsection{SHE Theory, Design, and Performance}

Coons et al. (1947) tested five different SHEs and collected data on pressure, temperature, velocity, mass flow rate, and pressure drop for the heating and cooling of oil, water, brine, and steam. For spiral exchangers operating under laminar flow conditions, the average suggested Nusselt number correlation was

$\mathrm{Nu}=8.4\left(\frac{\dot{\mathrm{m}} \mathrm{C}_{\mathrm{p}}}{\mathrm{K} \mathrm{L}}\right)^{0.2}$

They also observed that at any given value of Reynolds number the heat transfer coefficient in a spiral exchanger was at least $35 \%$ higher than would be expected in a straight tube exchanger, concluding that under turbulent flow conditions the Dittus-Boelter equation could be used for the calculation of average heat transfer coefficients. They also reported that turbulent flow conditions started at Reynolds numbers between 1,400 and 1,800 .

$$
\begin{aligned}
\mathrm{Nu} & =0.023(\mathrm{Re})^{0.80}(\mathrm{Pr})^{\mathrm{m}} \\
\mathrm{m} & =0.3 \text { for cooling } \\
\mathrm{m} & =0.4 \text { for heating }
\end{aligned}
$$

Zhang et al. (1988) developed a computational method for the thermal design of the SHE. The local heat transfer coefficient was calculated by using a heat transfer relation that takes into account the local duct curvature. A set of simple algebraic equations was used to solve for the temperature of the fluids at both the inlet and outlet of the elements and then to solve for the overall heat transfer coefficient. After an experiment and comparison to their computational model they recommended the following formulation, 
which is suitable to calculate the convective heat transfer coefficients in the channels for liquid-to-liquid in turbulent flow, the region of design operating conditions $(\operatorname{Re}>5000)$.

$$
\begin{aligned}
\mathrm{Nu} & =0.023(\mathrm{Re})^{0.80}(\operatorname{Pr})^{\mathrm{m}} \varepsilon_{\mathrm{R}} \\
\mathrm{m} & =0.3 \text { for heating } \\
\mathrm{m} & =0.4 \text { for cooling } \\
\varepsilon_{\mathrm{R}} & =1+10.3\left(\frac{\mathrm{D}_{\mathrm{H}}}{\mathrm{R}}\right)^{3}
\end{aligned}
$$

Although this formula was originally used to evaluate the convective heat transfer coefficients in a curved tube, it was also found suitable for a curved duct of rectangular cross section. The reason is because the heat transfer in a curved duct flow is enhanced by secondary motion just as in a curved tube, although the detail mechanism may be different. The comparison showed that the variations between the computational and the experimental results are within 2 to $8.5 \%$, which was considered satisfactory for the purpose of application in the design of commercial heat exchangers. The values of overall heat transfer coefficients obtained from computations are generally slightly higher than the values obtained from experimental data. The reason for these variations was primarily $\varepsilon_{R}$, which reflects the correction for the enhancement of heat transfer by the curved channels. If a more relevant expression can be determined, the predicted result would become more accurate. Finally, the authors recommended an empirical formula for heat transfer in the SHE, which was determined from the experimental data by the following well known Wilson method:

$$
\begin{aligned}
\mathrm{Nu} & =0.10027(\mathrm{Re})^{0.682}(\mathrm{Pr})^{\mathrm{n}} \\
\mathrm{n} & =0.3 \text { for cooling } \\
\mathrm{n} & =0.4 \text { for heating }
\end{aligned}
$$

where $8,000<\operatorname{Re}<80,000$. Comparison of computational and experimental results showed good agreement for design purposes. This empirical formula can be used to estimate roughly the performance of SHE within the given Reynolds number range.

Chowdhary et al. (1985) numerically calculated the temperature distribution in a SHE to obtain the effectiveness and LMTD correction factor $F_{c}$. The effectiveness and temperature correction factor $F_{c}$ were calculated as a function of the number of transfer units, number of spiral turns, and the heat capacity ratio. They observed that LMTD correction factors, when plotted against the ratio of number of transfer units per number of spiral turns, could be represented by a hyperbolic tangent function:

$$
\mathrm{F}_{\mathrm{c}}=\frac{\mathrm{N}}{\mathrm{NTU}} \tanh \frac{\mathrm{NTU}}{\mathrm{N}}
$$

The correlations stated earlier are for higher Pr fluids. No correlation is available for a SHE with a low Pr fluid, such as liquid metals, therefore, the suggested correlation to determine heat transfer characteristics for the SHE with liquid metal is

$$
\mathrm{Nu}=6.3+0.0167(\operatorname{Re})^{0.85}(\operatorname{Pr})^{0.93} \varepsilon_{\mathrm{R}}
$$


The correlation takes into account the bending of the curved duct, which is essential for accurate the heat transfer characteristics of the SHE. Equation (6-66) is restricted to low Pr fluids and only applies for constant heat rate conditions. The low Pr number fluids are all liquid metals and have values of the Pr number less than 0.1 ranging down to less than 0.001 .

SHEs are being used in a variety of processes because of their advantages in performance and maintenance. Despite their potential and proven capabilities, information regarding their design is limited and any data is proprietary. Furthermore, no quantitative insight regarding the fluid flow and heat transfer phenomena has been published from prior work in this area. The main objective for this analysis is to see the overall benefit of choosing the spiral geometry over straight tube geometry for a phase change heat exchanger.

\subsubsection{Geometric Characteristics of SHEs}

This section describes the essential equations for geometrically calculating a SHE. The central section of the SHE is divided into two semicircles by a partition plate, the diameter of $d_{11}$ is linked to the passage with a width of $b_{1}$, and that is linked to $b_{2}$ being $d_{21}(\mathrm{Wu} 2003$ ). Cold and hot media can flow in their respective passage to exchange heat, depending on the assigned role of either evaporator or condenser for the thermosyphon. As can be seen from Figure 6-13, the lengths of all the rounds of the semicircled spiral, from inner to outer, form a series of numbers with equi-difference, the common difference $2 \pi t$, and the sum of the numbers as the length of the semicircled spiral (Wu 2003):

$$
L=N \times \pi\left(\mathrm{d}_{\mathrm{fl}}+\frac{t}{2}\right)+\frac{N(N-1)}{2} \times 2 \pi t
$$

Hence, the number of rounds of the semicircled spiral is

$$
N=\frac{-\left(\mathrm{d}_{\mathrm{f} 1}-\frac{t}{2}\right)+\sqrt{\left(\mathrm{d}_{\mathrm{fl}}-\frac{t}{2}\right)^{2}+\frac{4 t L}{\pi}}}{2 t}
$$

The diameter difference between the two coterminous semicircles shown in Figure 6-13 is $t=b_{1}+b_{2}+2 \delta_{t}$, where $\delta_{t}$ is the thickness of the spiral plate. If the initial semicircle diameter of the central line for the spiral passage (i.e., $\mathrm{d}_{\mathrm{f} 1}$ ) is available, Equation (6-68) can be rewritten as

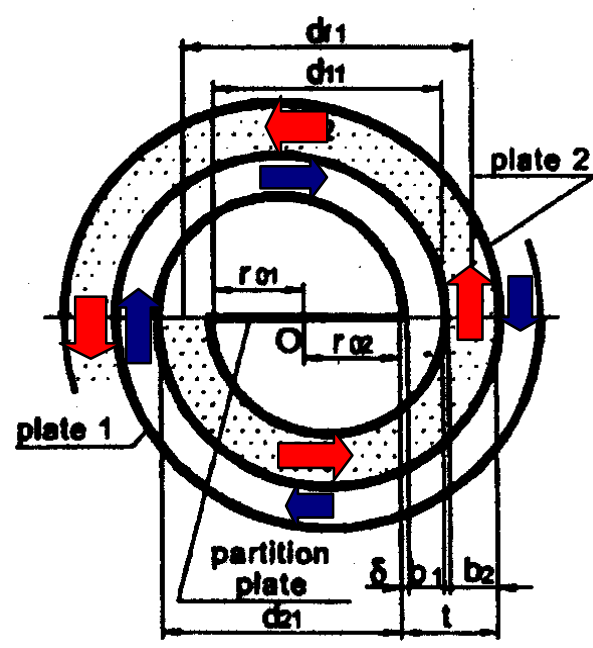

Figure 6-13. Detailed schematic of a SHE (Modified from Wu 2003).

$$
\mathrm{N}_{\mathrm{di}}=\frac{-\left(\mathrm{d}_{\mathrm{f} 1}-\frac{\mathrm{t}}{2}\right)+\sqrt{\left(\mathrm{d}_{\mathrm{f} 1}-\frac{\mathrm{t}}{2}\right)^{2}+\frac{4 \mathrm{tL}_{\mathrm{f}}}{\pi}}}{2 \mathrm{t}}=\mathrm{n}_{\mathrm{di}}+\mathrm{n}_{\mathrm{odi}}
$$

where $\mathrm{n}_{\mathrm{di}}$ is an integer, and $\mathrm{n}_{\text {odi }}$ is a decimal, while $\mathrm{n}_{0}$ can be calculated through the formula where $\mathrm{n}_{\text {odi }}$ lies. 
When $0.5 \geq \mathrm{n}_{\text {odi }} \geq 0$ then

$$
\mathrm{n}_{0}=\frac{\mathrm{L}_{\mathrm{f}}-\left[\pi \mathrm{tn}_{\mathrm{di}}^{2}+\pi\left(\mathrm{d}_{\mathrm{f} 1}-\frac{\mathrm{t}}{2}\right) \mathrm{n}_{\mathrm{di}}\right]}{\pi\left(\mathrm{d}_{\mathrm{f} 1}+2 \mathrm{n}_{\mathrm{di}} \mathrm{t}\right)}
$$

When $\mathrm{n}_{\text {odi }}>0.5$ then

$$
\mathrm{n}_{0}=\frac{\mathrm{L}_{\mathrm{f}}-\left[\pi \mathrm{tn}_{\mathrm{di}}^{2}+\pi\left(\mathrm{d}_{\mathrm{fl}}-\frac{\mathrm{t}}{2}\right) \mathrm{n}_{\mathrm{di}}\right]}{\pi\left(\mathrm{d}_{\mathrm{f} 1}+\left(2 \mathrm{n}_{\mathrm{di}}+1\right) \mathrm{t}\right)}
$$

The length of the spiral plates can vary according to the initial diameters of the inner or outer lateral lines. From Figure 6-13, we can obtain the following equations, which are used to determine the number of rounds for the spiral passage $(\mathrm{Wu} 2003)$ :

$$
\begin{aligned}
& \mathrm{d}_{11}=\mathrm{r}_{01}+\mathrm{r}_{02}+\delta_{\mathrm{t}}+\mathrm{b}_{1} \\
& d_{21}=r_{01}+r_{02}+\delta_{\mathrm{t}}+b_{2} \\
& \mathrm{~d}_{\mathrm{f} 1}=\mathrm{d}_{21}+\mathrm{b}_{1}+2 \delta_{\mathrm{t}} \\
& r_{01}=\frac{d_{11}}{2}-\frac{t}{4} \\
& r_{02}=\frac{d_{21}}{2}-\frac{t}{4}
\end{aligned}
$$

The diameter difference between the two coterminous semicircles in a SHE can be written as

$$
t=b_{1}+b_{2}+2 \delta_{\mathrm{t}}
$$

Equations (6-72)-(6-76) are dependent on each other, which makes this a stiff and linearly-coupled problem, meaning the values are linearly dependent on each other. The solution to such a problem could be obtained, but only in terms of each other, thus the initial semicircle diameter of the inner lateral line for spiral plate $2\left(d_{21}\right)$ value is assumed and is kept constant throughout.

Power iteration methodology is used to determine the effect of the bends in the spiral. As an initial estimate, a value of radius of curvature for the spiral geometry is taken. Based on the estimated value, $\varepsilon_{R}$ is determined and further multiplied with $\mathrm{Nu}$ correlation to capture the effect of the spiral. Furthermore, effective heat transfer coefficient, effective length, and area are calculated. According to Wongwises and Naphon, the average radius of curvature value can be determined as (Wu 2003)

$$
R_{N}=\left[R_{o}+(2 N-1) \alpha_{\mathrm{r}} \pi\right]
$$


where $\mathrm{R}_{\mathrm{o}}$ is the minimum spiral-coil radius, $\mathrm{N}$ is the coil turn number, and $\alpha_{\mathrm{r}}$ is the rate of change of radius, which can be expressed as

$\alpha_{r}=\frac{b_{1}+b_{2}+2 \delta_{\mathrm{t}}}{2 \pi}$

The above equation is based on an arc of $2 \pi$ as a circle. In this case, the rate of change of radius comes out to be a constant as the width of the SHE passages are constant. A tolerance of $1 \mathrm{e}-6$ is set for the relative error value in radius of curvature such that after this criteria is met, this value of radius or curvature enable us to determine the value of $\varepsilon_{\mathrm{R}}$.

As discussed in detail, Equation (6-21) can only be used for straight tube geometry. To use it for spiral geometry, the bend effect must be taken into account, which modifies Equation (6-21) to

$\mathrm{Nu}=6.3+0.0167 \operatorname{Re}^{0.85} \operatorname{Pr}^{0.93} \varepsilon_{\mathrm{R} .} \quad$ (constant heat rate)

where,

$\varepsilon_{\mathrm{R}}=1+10.3\left(\frac{\mathrm{D}_{\mathrm{h}}}{\mathrm{R}_{\mathrm{N}}}\right)^{3}$

Equation (6-81) is a suggested correlation to determine heat transfer characteristics for SHE with liquid metal. Similarly, Equation (6-82) was recommended by (Zhang et al. 1988) to calculate convective heat transfer coefficients in the channels for liquid-to-liquid service in turbulent flow as

$$
N u=0.023(\operatorname{Re})^{0.8}(\operatorname{Pr})^{m} \varepsilon_{R}
$$

where

$$
\begin{aligned}
& \mathrm{m}=0.3 \text {, for heating } \\
& \mathrm{m}=0.4 \text {, for cooling. }
\end{aligned}
$$

This formula was originally used to evaluate the convective heat transfer coefficients in a curved tube, but was also found suitable for a curved duct of rectangular cross-section well. The reason is that the heat transfer in a curved duct flow is enhanced by secondary motion just like in a curved tube, although the detailed mechanism may be different (Zhang et al. 1988). In this analysis, the $\varepsilon_{\mathrm{R} .}$ value changes depending on the fluid conditions and flow regime (phase). As discussed previously, about the limitation of thermosyphon performance, $\mathrm{Na}$ vapor is operated at half of sonic velocity such that the mass flow rate of $\mathrm{Na}$ is kept constant throughout. Operating at such a high velocity does enhance the heat transfer but also leads to greater pressure drop. Therefore in order to get benefits from both heat transfer and pressure drop, the liquid $\mathrm{Na}$ and vapor $\mathrm{Na}$ were operated at a velocity at which a lower pressure drop (described in previous section) and a moderate/high heat transfer coefficient are achieved. Equation (6-80) is used for spiral geometry and comparison with straight tube heat transfer and pressure drop; see Figure 6-14.

Figure 6-14 shows the benefit of the spiral geometry for both the heat transfer coefficient (increment of $10 \%$ ) and pressure drop (slightly better). The reason behind the lower pressure drop for spiral geometry is because the effective length required for spiral geometry is $0.96 \%$ less than straight tube geometry because of a higher convective heat transfer coefficient. Thus, using a SHE as an evaporator and also as a condenser for the thermosyphon design is strongly recommended. 


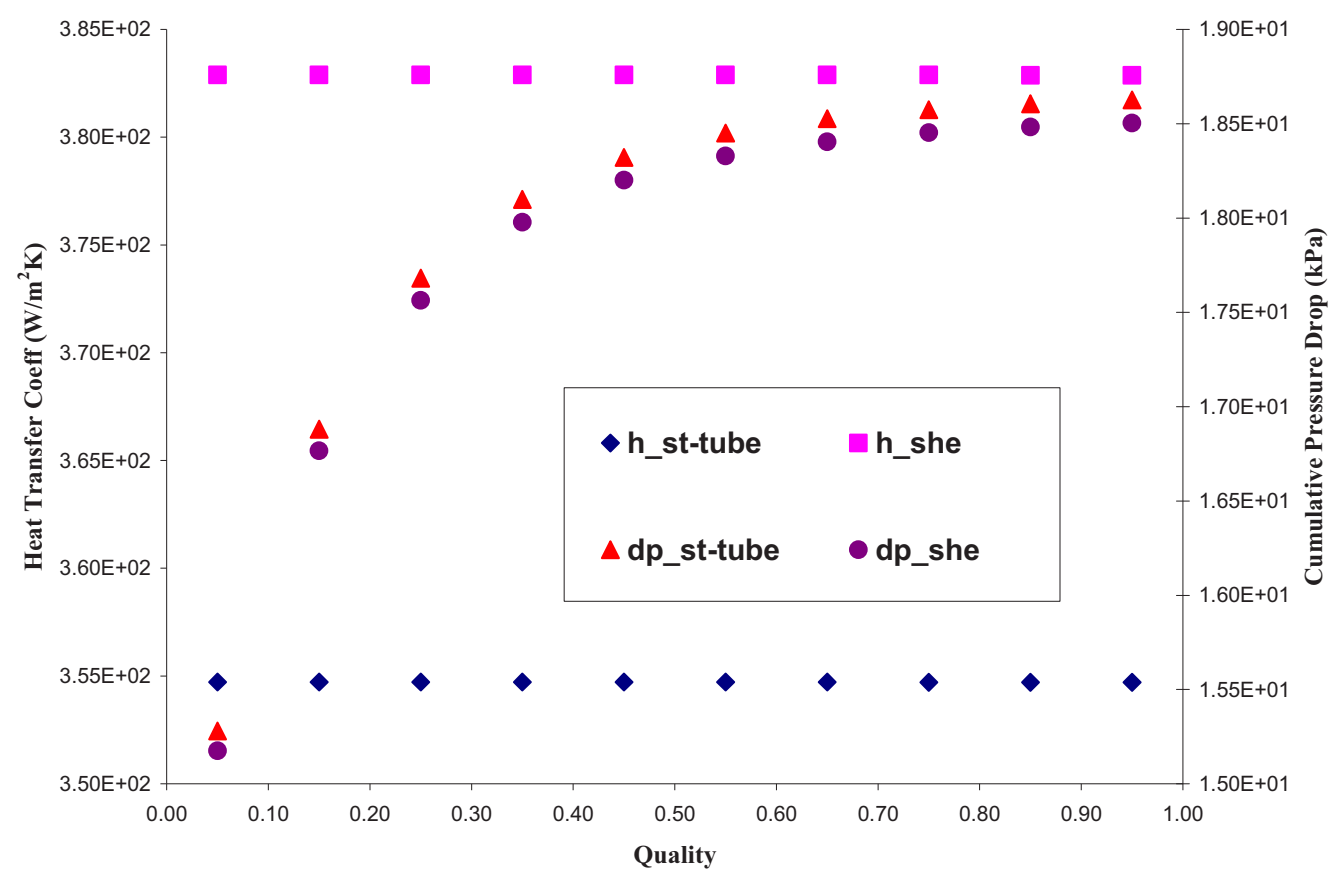

Figure 6-14. Heat transfer characteristics for straight tube and SHE operating at 1,300 K.

\subsection{Summary}

Liquid metals remain in liquid state at higher temperatures compared to conventional fluids like water and various organic coolants; this makes the design of a CHE possible. One of the key advantages of using liquid metals as the coolant is that they do not require operation at high pressure in order to obtain high temperatures. These advantages, especially the high heat transfer, are compelling enough to maintain research interest in using a liquid metal as the coolant for the intermediate heat exchanger in the NGNP. This analysis proposes the straight tube and spiral phase change counter current heat exchanger as the best-suited design, such that we have a lower overall pressure drop and a moderate/high overall heat transfer coefficient.

The correlation developed by Chen (1963(ii)) is at present the best available for the saturated forced convective boiling regions for liquid metals. The convective component is calculated from a modified form of the Lyon-Martinelli equation. The method proposed by Chen is used for a two-phase boiling regime, which is based on the concept of additive, interacting mechanisms of micro and macroconvective heat transfer. In order to design the phase change heat exchanger, this study gives an overall design methodology to evaluate the overall heat transfer coefficient and the corresponding pressure drop, which are the most essential parameters when designing a heat exchanger. 
This page intentionally left blank 


\section{HIGH TEMPERATURE MATERIALS}

\subsection{High Temperature Materials}

The candidate materials used in the construction of a thermosyphon and in the construction of a CHE will need to be available in the appropriate product forms, be capable of being welded, and be suitable for use at temperatures up to $1,000^{\circ} \mathrm{C}$. Based on the overall evaluation of mechanical properties, Alloy 617 is the most suitable material for the construction of a thermosyphon; it is the only material that has the appropriate combination of mechanical, physical, and corrosion resistance properties. It will be necessary to develop and qualify inspection procedures and techniques that apply to the materials of construction for thermosyphon and CHE technology. Hosier and Tillack introduced Alloy 617 in 1972 as a solid-solution Alloy with good strength intended for very-high-temperature service. In the 1975-1976 time-frame, Japanese researchers (Hosoi and Abe 1975; Kitagawa et al. 1976) reported results of their work on Alloy 617 tested under air and helium with various contaminants. The usual approach in designing a highstrength alloy for extreme temperature service has been to include a significant amount of the heavy and expensive element tungsten. Through extensive research, a tungsten-free nickel-base Alloy 617 has been developed that has an exceptional combination of stress-rupture strength and oxidation resistance at temperatures over $980^{\circ} \mathrm{C}$. The alloy has properties comparable to those of tungsten-containing alloys but with lower weight, decreased cost, and greatly improved metallurgical stability. The alloy also has excellent resistance to a wide range of corrosive environments, and it is readily formed and welded by conventional techniques. The high nickel and chromium content makes the alloy resistant to a variety of both reducing and oxidizing media. The aluminum, in conjunction with chromium, provides oxidation resistance at high temperatures. Solid-solution strengthening is imparted by the cobalt and molybdenum. The combination of high strength and oxidation resistance at temperatures over $980^{\circ} \mathrm{C}$ make Alloy 617 an attractive material for constructing a thermosyphon. Thermal expansion of Alloy 617 is lower than that of most other austenitic alloys, reduced stresses are found in the structure from differential expansion when the alloy is coupled with carbon steels or low-alloy steels. The main characteristics of Alloy 617 are:

- Exceptional high-temperature strength, particularly stress-rupture strength at temperatures above $982^{\circ} \mathrm{C}$. Several available alloys had good high-temperature strength, but an even higher strength level along with a combination of other factors was sought

- Metallurgical stability during extended exposure to intermediate temperatures

- Good weldability - a characteristic necessary for an alloy to be usable in a variety of applications

- Low cost, which provides a high strength-per-dollar ratio that appeals to both users and the producers.

Candidate materials being considered for the construction of thermosyphons and CHEs are shown in Table 7-1. Alloy $800 \mathrm{H}$ has a unique advantage in that it is approved under ASME Code Section II Subsection $\mathrm{NH}$ for use up to $760^{\circ} \mathrm{C}$. The remaining alloys would all require code approval, before being used for any high temperature application.

Table 7-1. Candidate material for construction of a thermosyphon (Dewson and Li 2005).

\begin{tabular}{|l|l|l|l|}
\hline Alloys & $\left.\mathbf{T}^{\text {max }} \mathbf{(}^{\mathbf{0}} \mathbf{C}\right)$ & $\mathbf{S}_{\mathbf{d}}^{\mathbf{8 9 8}} \mathbf{( M P a )}$ & Nominal Compositions (wt\%) \\
\hline 617 & 982 & 12.4 & $52 \mathrm{Ni}-22 \mathrm{Cr}-13 \mathrm{Co}-9 \mathrm{Mo}-1.2 \mathrm{Al}$ \\
\hline 556 & 898 & 11 & 21Ni-30Fe-22Cr-18Co-3Mo-3W-0.3Al \\
\hline $800 \mathrm{HT}$ & 898 & 6.3 & $33 \mathrm{Ni}-42 \mathrm{Fe}-21 \mathrm{Cr}$ \\
\hline $800 \mathrm{H}$ & 898 & 5.9 & $33 \mathrm{Ni}-42 \mathrm{Fe}-21 \mathrm{Cr}$ \\
\hline 330 & 898 & 3.3 & Fe-35Ni-19Cr-1.25Si \\
\hline 230 & 898 & 10.3 & $57 \mathrm{Ni}-22 \mathrm{Cr}-14 \mathrm{~W}-2 \mathrm{Mo}-0.3 \mathrm{Al}-0.05 \mathrm{La}$ \\
\hline $\mathrm{HX}$ & 898 & 8.3 & $47 \mathrm{Ni}-22 \mathrm{Cr}-9 \mathrm{Mo}-18 \mathrm{Fe}$ \\
\hline $253 \mathrm{MA}$ & 898 & 4.9 & $\mathrm{Fe}-21 \mathrm{Cr}-11 \mathrm{Ni}-0.2 \mathrm{~N}$ \\
\hline
\end{tabular}


Alloy 617 has the highest design temperature $\left(982^{\circ} \mathrm{C}\right)$ of these alloys and therefore becomes worthy of further consideration as a candidate material for construction of a thermosyphon. Design temperature alone is not the sole basis for material selection; consideration must also be given to the allowable design stress at temperatures shown in Figure 7-1.

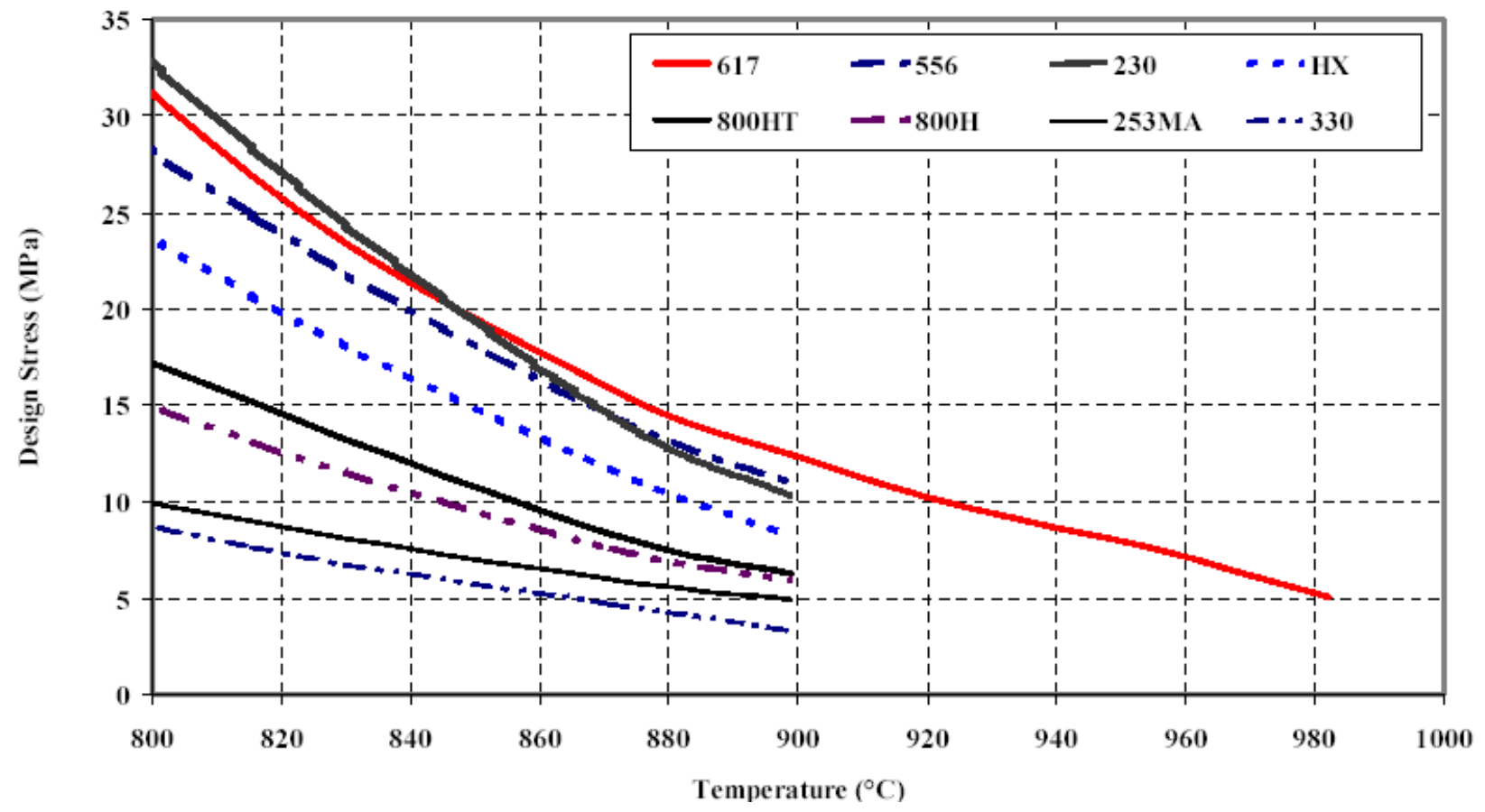

Figure 7-1. Comparison of ASME allowable stress for high temperature alloys (Li et al. 2006).

\subsection{Ductility and Creep Rupture Life}

Based on Figure 7-1, the design stress at $898^{\circ} \mathrm{C}$ (the temperature for which the data is available) for the metals tested range from 12.4 MPa (Alloy 617) to $3.3 \mathrm{MPa}$ (Alloy 330). Long term exposure $(8,000 \mathrm{hrs})$ to high temperatures may cause alloys to alter their microstructure (Dewson and Li 2005). From the ductility standpoint the best four candidates are shown in Table 7-2.

Table 7-2. Candidate material ranking based on ductility (Dewson and Li 2005).

\begin{tabular}{|c|l|}
\hline Alloys & Ductility \\
\hline 617 & Excellent \\
\hline 230 & Very Good \\
\hline 556 & Good \\
\hline HX & Fair \\
\hline
\end{tabular}

The creep rupture stress for these alloys at high temperatures can be associated with the ASME allowable stress. Alloy 617 exhibits the highest level of creep strength at high temperatures. At test conditions of $982^{\circ} \mathrm{C}$ and $14 \mathrm{MPa}$, the creep rupture life is shown in Table 7-3. 
Table 7-3. Candidate material ranking based on creep rupture life (Dewson and Li 2005).

\begin{tabular}{|c|c|}
\hline Alloys & Creep Rupture Life \\
\hline 617 & $10,000 \mathrm{hrs}$ \\
\hline 556 & $7,500 \mathrm{hrs}$ \\
\hline 230 & $5,000 \mathrm{hrs}$ \\
\hline $\mathrm{HX}$ & $2,400 \mathrm{hrs}$ \\
\hline
\end{tabular}

Alloy 617 displays exceptionally high levels of creep-rupture strength, even at temperatures of $980^{\circ} \mathrm{C}$ and above. That characteristic, combined with good resistance to oxidizing and carburizing atmospheres, makes the alloy especially suitable for long-term, high-stress use at elevated temperatures. Figure 7-2 shows the creep strength of solution-annealed Alloy 617 at temperatures to $1,095^{\circ} \mathrm{C}$. The rupture strength of solution-annealed material over the same temperatures is shown in Figure 7-3.

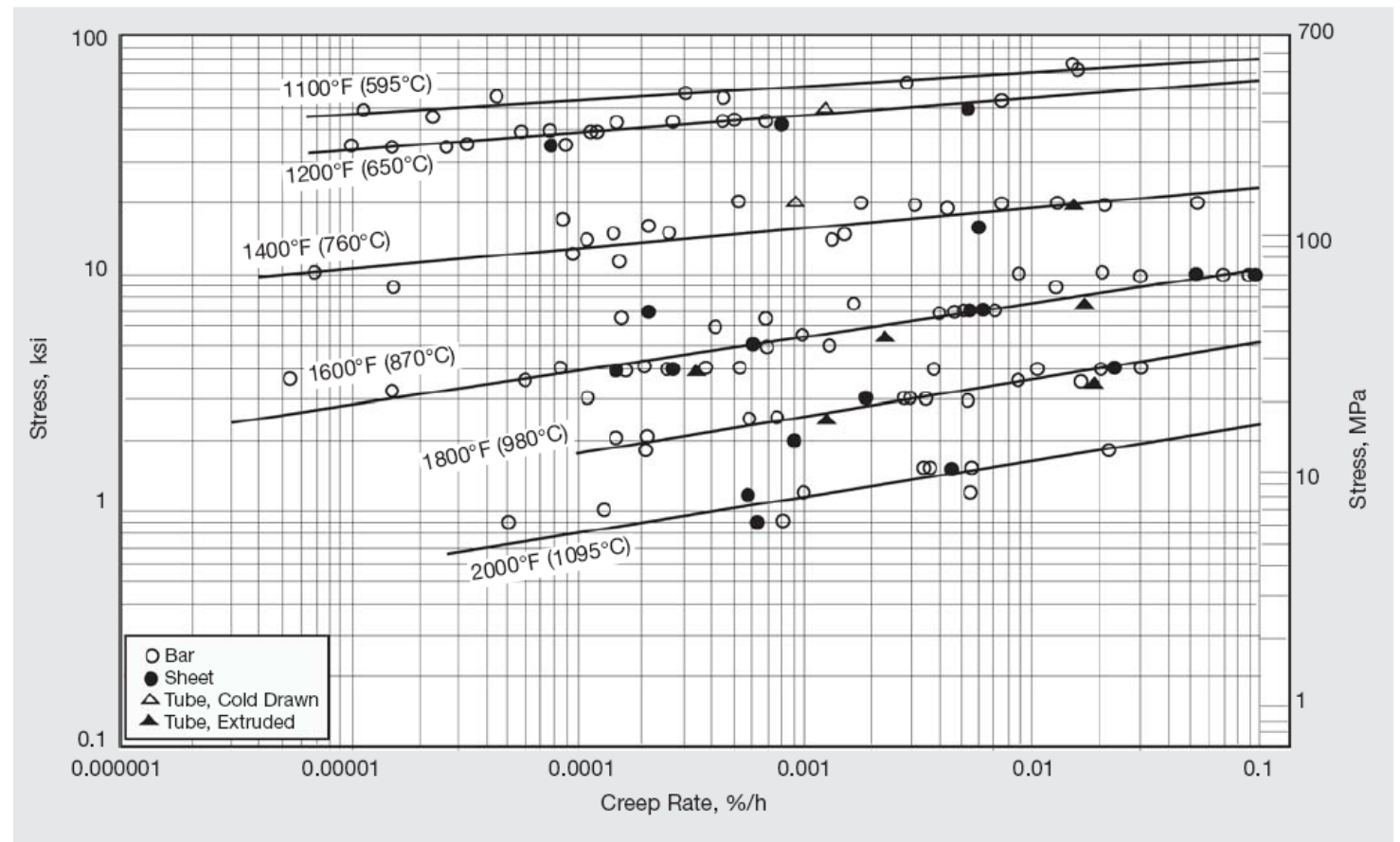

Figure 7-2. Creep strength of solution-annealed Alloy 617 (www.specialmaterials.com). ${ }^{\mathrm{f}}$

f. "High Temperature Materials," available at www.specialmaterials.com, accessed on $14^{\text {th }}$ August, 2007. 


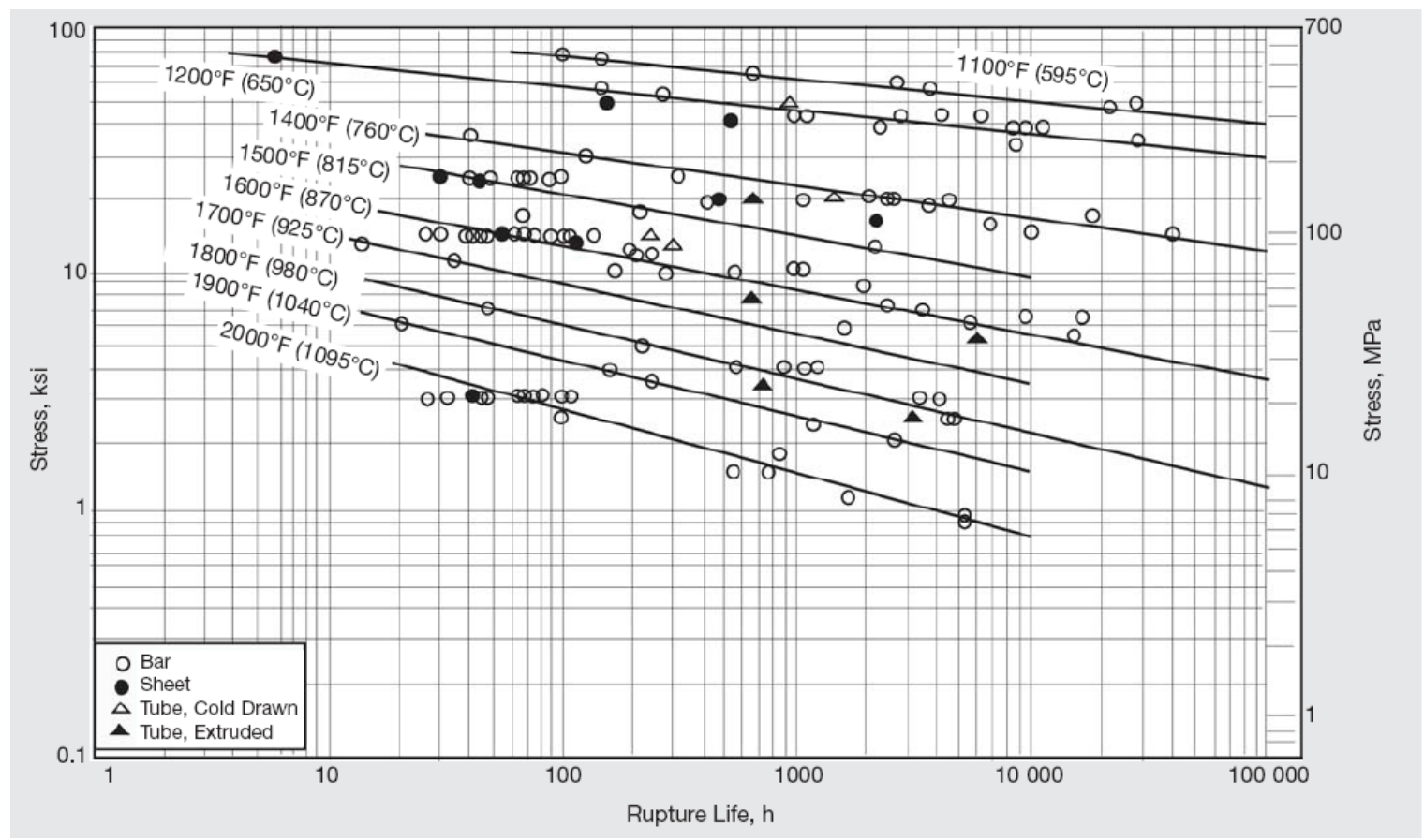

Figure 7-3. Rupture strength of solution-annealed Alloy 617 (www.specialmaterials.com).

The ideal candidate material should have high thermal conductivity and low thermal expansion, as can be seen from Figures 7-4 and 7-5. Irrespective of the material, low thermal conductivity and coefficient of thermal expansion are significant parameters when consideration is given to the operating temperature. Both of these properties impact the selection and design criteria.

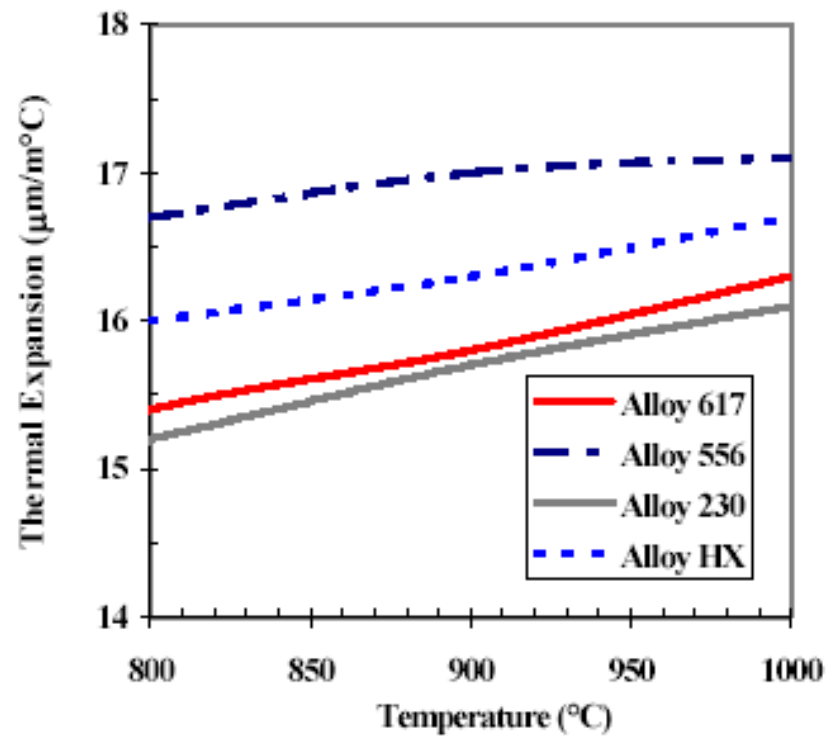

Figure 7-4. Thermal expansion for the various alloys at elevated temperatures (Dewson and Li 2005). 


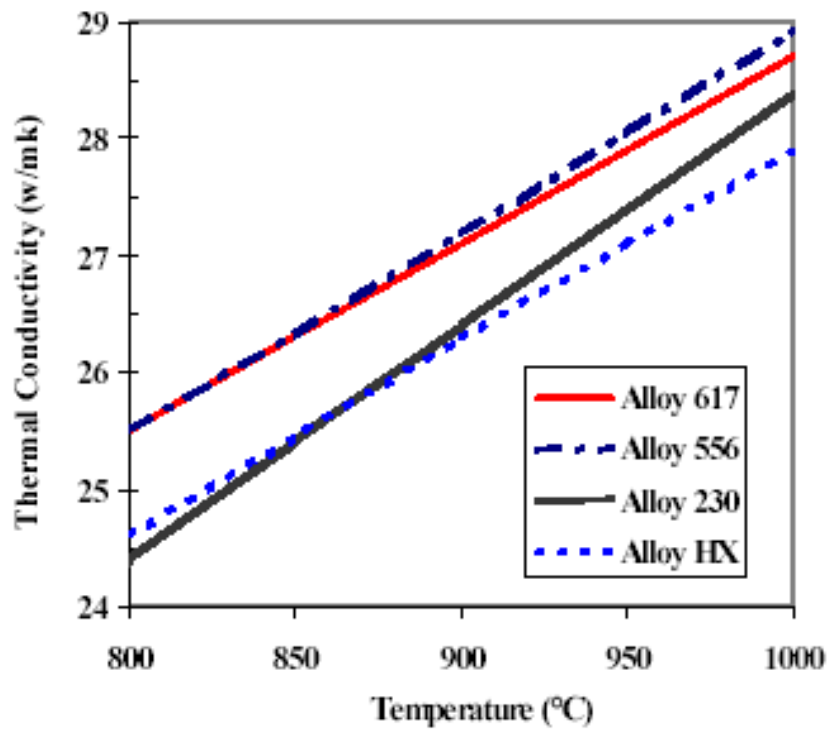

Figure 7-5. Thermal conductivity for the various alloys at elevated temperatures (Dewson and Li 2005).

\subsection{Effects of Constituents for Alloy 617}

Both the aluminum and chromium contents of the alloy are relatively high to provide the required oxidation resistance. Molybdenum and cobalt are effective solid-solution strengtheners. The alloy will not age-harden when exposed to intermediate temperatures for relatively short periods of time, such as the aging treatments used for precipitation-hardenable nickel alloys. Some high-temperature alloys depend on tungsten for their properties. In the development of Alloy 617, tungsten was considered undesirable because it would increase both the density and the cost of the final product. Tungsten also tends to form detrimental phases after prolonged exposure to intermediate temperatures. The relatively low density of Alloy 617 provides a high strength-to-weight ratio. The nominal composition yields a density of a $0.302 \mathrm{lb} / \mathrm{cu}$ in. $(8.36 \mathrm{~g} / \mathrm{cu} \mathrm{cm})$. This value compares favorably with the $0.305 \mathrm{lb} / \mathrm{cu}$ in. $(8.44 \mathrm{~g} / \mathrm{cu} \mathrm{cm})$ density of Alloy 625 and is significantly lower than the densities of tungsten-containing alloys.

\subsection{Corrosion Resistance}

Nickel-based alloys generally have good nitridation resistance due to the low solubility of nitrogen in these alkaline metals (Dewson and Li 2005). Figure 7-6 shows nitrogen absorption after 168 hours at $648^{\circ} \mathrm{C}$ in flowing ammonia. Although the ammonia data is not directly comparable with a heat exchanger or thermosyphon environment, it demonstrates that Alloy 617 has the second best nitriding resistance after 230 of the alloys considered.

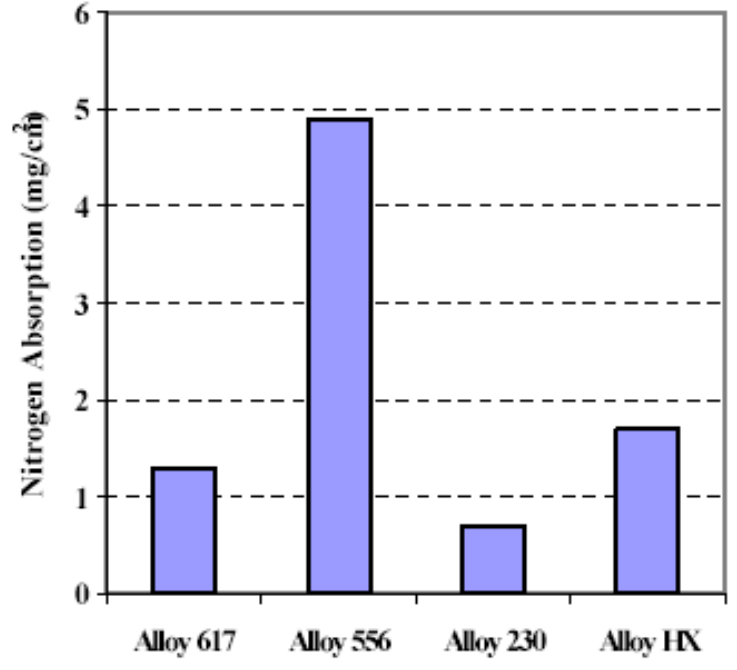

Figure 7-6. Comparison of nitriding resistance (Dewson and Li 2005). 


\subsection{Fabrication}

Alloy 617 has good fabricability; forming, machining, and welding are carried out by standard procedures for nickel alloys. Techniques and equipment for some operations may be influenced by the alloy's strength and work-hardening rate. The behavior of an alloy during fabrication activities such as forming, machining, and welding can be one of the most critical factors in whether or not an alloy is chosen for the construction of a thermosyphon.

\subsection{Hot and Cold Forming}

Alloy 617 has good formability, but it requires relatively high forces because of its inherent strength at elevated temperatures. The temperature range for heavy forming or forging is 1,010 to $1,205^{\circ} \mathrm{C}$. Light working can be done at temperatures down to $925^{\circ} \mathrm{C}$. Alloy 617 is readily cold-formed by conventional procedures, although its work-hardening rate, shown in Figure 7-7, is high. For best results, the alloy should be cold-formed in the fine-grain condition and frequent intermediate anneals should be used. Annealing for cold-forming should be done at $1,040^{\circ} \mathrm{C}$.

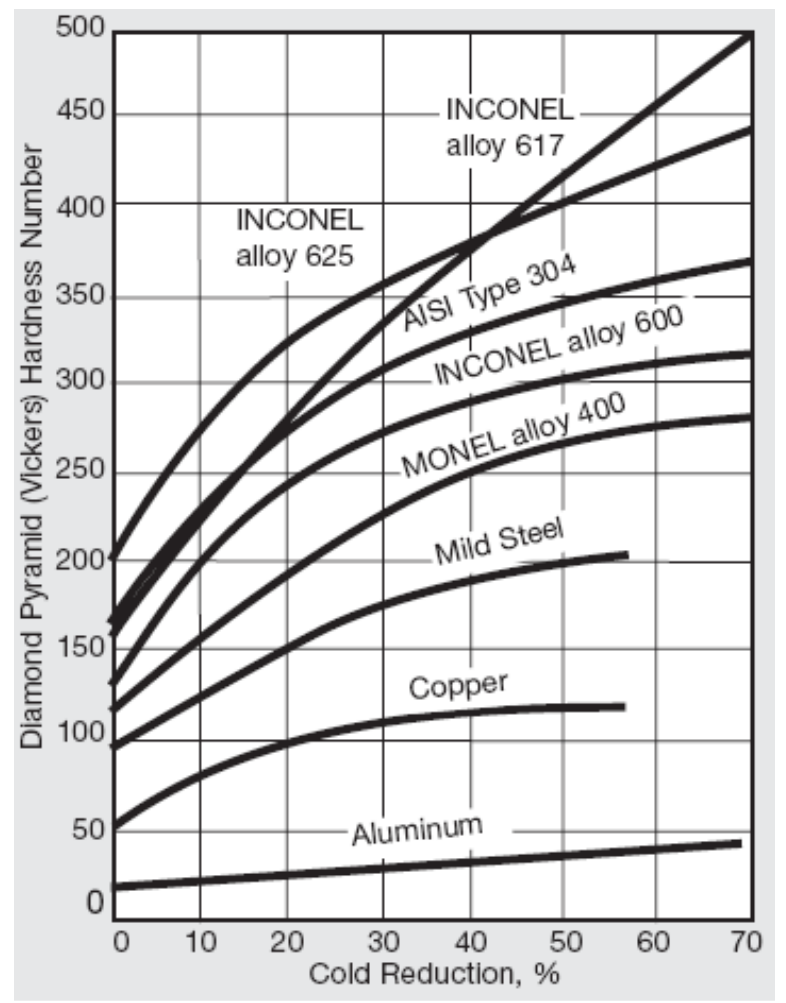

Figure 7-7. Effect of cold reduction on hardness (www.specialmaterials.com).

\subsection{Summary}

The candidate materials used in the construction of a thermosyphon and in the construction of intermediate heat exchangers will need to be available in the appropriate product forms, be bondable, and be suitable for use at high temperatures. Based on the evaluation of mechanical and chemical properties, Alloy 617 is perhaps the most suitable material for the construction because it is the only alloy identified that has the appropriate combination of mechanical, physical, and corrosion-resistance properties at elevated temperatures. 


\section{CONCLUSIONS AND FUTURE WORK}

\subsection{Conclusions}

- The success of the NGNP will depend in part on the correct selection of the heat transport devices, such as a thermosyphon and high integrity CHE.

- The thermosyphon is a primary choice for high temperature applications requiring the transport of large amounts of thermal power from a nuclear reactor at a small temperature difference between the heat source and the heat sink.

- One significant advantage of heat transfer by thermosyphon is the characteristic of nearly isothermal phase change heat transport, making the thermosyphon an ideal candidate for applications where the temperature gradient is limited and high delivery temperatures are required, as in hydrogen production.

- High power throughputs are possible with $\mathrm{Na}$ and $\mathrm{Li}$ thermosyphons at $1,000^{\circ} \mathrm{C}$. Above $1,300^{\circ} \mathrm{C}, \mathrm{Li}$ is the better choice for a working fluid, because of its low vapor pressure and high latent heat of vaporization.

- Large-scale hydrogen production through thermochemical cycles powered by nuclear heat is also popular because of two major context changes: the prospect of a transition to a hydrogen-based economy and the prospects for development of Generation IV, high temperature gas reactors. Among the thermochemical cycle options, the SI option, which is fully thermo-chemical, is the most promising in terms of efficiency and cost.

- The demands of a high-temperature Brayton cycle challenge the boundaries of existing heat exchanger technology for service in nuclear systems. Irrespective of the NGNP reactor type (i.e., prismatic core or pebble bed) and the resultant coolant, the key to high process heat efficiency is high effectiveness heat exchange.

- The main advantage of employing a CHE for the intermediate loop is the lower total pressure drop when compared with conventional designs, due in part to the shorter flow path. The purpose for selecting a CHE is also to maximize the heat transfer surface area per volume of heat exchanger. This has the benefit of reducing the heat exchanger size making it more economical from a materials-ofconstruction and facility footprint perspective. Using spiral phase-change CHEs as the evaporator and condenser for the thermosyphon would enhance the heat transfer characteristics when compared to straight tube counter current heat exchangers.

- The candidate materials used in the construction of a thermosyphon and in the construction of intermediate heat exchangers will need to be available in the appropriate product forms, be bondable, and be suitable for use at high temperatures. Based on the evaluation of mechanical and chemical properties, Alloy 617 is perhaps the most suitable material for the construction because it is the only alloy identified that has the appropriate combination of mechanical, physical, and corrosion resistance properties at elevated temperatures.

- It is important to choose insulation wisely and use it adequately. Any insulation used must effectively limit the flow of heat through the insulation by radiation, convection, and conduction. There are many factors to consider when thinking about insulation. Evaluating the optimum thickness of the insulation is very important so that it is used to achieve a better, more effective and economical performance of the thermal device. Insulation can be used to regulate process temperatures, protect workers from serious injury, and save thousands of dollars in energy costs.

- Using a thermosyphon as the thermal transport device may offer savings by lowering energy consumption, equipment investment costs, and maintenance costs. 
- Accurate performance predictions of liquid metal thermosyphon startup behavior are required to build reliable and efficient thermal control systems for high temperature process heat transfer from NGNP to a hydrogen plant.

- It will be necessary to develop and qualify inspection procedures and techniques that apply to the materials of construction and CHE technology.

- This report provides insight and options useful in the design and development of an NGNP process heat recovery system using a thermosyphon. It does not claim to address or even anticipate all possible safety issues.

\subsection{Future Work}

- The high latent heat of vaporization of liquid metal working fluids makes them a preferable choice for transporting high thermal energy, but at the same time their melting temperatures are higher, signifying the importance of carrying out an analysis for the thermosyphon startup from frozen state.

- Thermosyphon operation involves a series of complex processes related to phase change heat transfer, two-phase flow, and interfacial phenomena. The theoretical analysis should therefore be validated with some experimental work before this design is implemented in NGNP.

- Although a considerable database already exists for a two-phase thermosyphon, some of the data are incomplete and cannot be used to verify the herein mentioned design, primarily because of the difference in operating temperature conditions. Additional data at high temperatures are needed to not only delineate stable and unstable regions of operation, but also to guide the analyst in the construction of the model for the prediction of steady-state and transient system behavior.

- Since there are many variables and unknowns involved in the material compatibility with liquid metals, any laboratory testing should simulate conditions as expected in service. Actual heat exchanger materials, which are never completely homogeneous and without flaws, and parts formed and joined (especially by welding), which are not without stresses and imperfections, should be used as laboratory samples in the tests. Such high heat transfer rates mostly produces very high thermal gradients across the metal tubes, usually requiring all welds to be quality welds, and thermal expansion to be provided for. Actual flow and thermal gradient conditions, which may also have a very marked effect, should be duplicated. Carrying out such tests would give a better understanding of system failure resulting from material behavior at high temperatures.

- In the future the effects of gravitational body forces should be carried out for the horizontal SHE compared to a vertical SHE, as the latter may incur less loss.

- Correlations to determine the heat transfer characteristics for the SHE with liquid metal should be experimentally validated.

- Study the effects of studs and sculptured surfaces on friction and heat transfer in spiral ducts. The use of studs within the SHE promotes turbulence and acts as fins. 


\section{REFERENCES}

Amidieu, M., Aucel, S., Giovannini, R. and Moschetti, B., "The Heat Pipe Network of TDF1/TV-SAT: Review of the Development at Completion," Proceedings of the $6^{\text {th }}$ International Heat Pipe Conference, Vol. II, Grenoble, France, May 25-29, pp 386-393 1987.

Bailey, K. M., "Understanding Spiral Heat Exchangers," Chemical Engineering Progress, pp 59-63, 1994.

Bale, C. W., "Bull Alloys Phase Diagrams 3," pp 313-318, 1982.

Bansal, R. K., "Fluid Mechanics and Hydraulic Machines," Laxmi Publications, 1983.

Barenblatt, G. I., "Scaling, self-similarity, and intermediate asymptotic," Cambridge University Press, 1996.

Bennett, J. A. R., Collin, J. G., Pratt, H. R. C., and Thornton, J. D., "Heat Transfer to Two-Phase Gas Liquid Systems," AERE Report AERE-R3159, 1959.

Bergles, A. E., Collier, J. G.., Delhaye, J. M., Hewitt, G. F. and Mayinger, F., "Two-Phase Flow and Heat Transfer in the Power and Process Industries," Hemisphere Publishing Corporation, 1981.

Bienert, W. B., "Nuclear Wastes in Comparison with Other Heat Sources for Deicing Bridges, Ramps and Pavements," FHWA-DTM-70-6, 1970.

Boothroyd, A., "International Encyclopedia of Heat and Mass Transfer," CRC Press, New York, pp 1044-1046, 1997.

Bontemps, A., Goubier, C., Marquet, C., Solecki, J. C. and Nardi, C., "Performance Limit of a Toulene Loaded, Closed Two-Phase Thermosyphon," Proceedings of the 6th International Heat Pipe Conference, Vol. II, Grenoble, France, May 25-29, pp 634-640, 1987.

Borishanskii, V. M, Zhokhov, K. A., Andreevskii, A. A., Putilin, M. A., Kozyrev A. P., Shneiderman, L. L., "Heat Transfer in Boiling Alkali Metals," Atomnaya Energiya, 19[2], in Russian, pp 191-193, 1965.

Bystrov, P. V., Kagan, D. N., Krechetova, G. A. and Shpilrain, E. E., "Liquid-Metal Coolants for Heat Pipes and Power Plants," Hemisphere Publishing Corporation, 1990.

Casarosa, C. and Dobran, F., "Experimental Investigation and Analytical Modeling of a Closed TwoPhase Thermosyphon with Imposed Convection Boundary Conditions," International Journal of Heat and Mass Transfer, Vol. 31, pp 1815-1833, 1988.

Chen, K. S., Chen, Y. Y., Shiao, S. W. and Wang, P. C., "An Experimental Study of Steady-State Behavior of a Two-Phase Natural Circulation Loop," Energy Convers. Mgmt., Vol. 31, pp 553-559, 1991.

Chen, J. C., "A Correlation for Boiling Heat Transfer to Saturated Fluids in Convective Flow," ASME, 63-HT-34, 1963 (i).

Chen, J., "A Proposed Mechanism and Method of Correlation for Convective Boiling Heat Transfer with Liquid Metals," Brookhaven National Laboratory, BNL 7319, 1963 (ii).

Chen, M. M. and Faghri, A., "An Analysis of the Vapor Flow and the Heat Conduction Through the Liquid-Wick and Pipe Wall in a Heat Pipe with Single or Multiple Heat Sources," International Journal of Heat and Mass Transfer, Vol. 33, No. 9, pp 1945-1955, 1990.

Cheng, K. C. and Zarling, J. P., "Applications of Heat Pipes and Thermosyphons in Cold Regions," Vol. II, Begell House, pp 1-32, 1993. 
Chowdhary, K., Linkmeyer, H., Bassiouny, M. K., and Martin, H., "Analytical Studies on the Temperature Distribution in Spiral-Plate Heat Exchanger," Chemical Engineering Process, Vol. 19, pp 183-190, 1985.

Coons, K. W., Hargis, A. M., Hewes, P. Q., and Weems, F. T., "Spiral Heat Exchanger Heat-Transfer Characteristics," Chemical Engineering Progress, Vol. 43, No. 8, pp 405-414, 1947.

Collier, J. G., and Thome, J. R., "Convective Boiling and Condensation,” Third edition, Oxford University Press, 1996.

Davis, C., Oh, C., Barner, S., and Sherman D. W., "Thermal-Hydraulic Analyses of Heat Transfer Fluid Requirements and Characteristics for Coupling A Hydrogen Production Plant to a High-Temperature Nuclear Reactor," INL/EXT-05-00453, 2005.

Deev, V. I., Dubrovskii, G. P., Kokorev, L. S., Novikov, I. I., Petrovichev, V. I., "Heat Transfer in Free-Convection Sodium Boiling,” Translated from Atomnaya Energiya, 22, pp 49-51, 1967.

Dengeler, C. E., and Addoms, J. N., "Heat Transfer Mechanism for Vaporization of Water in a Vertical Tube," Chemical Engineering Progress Symposium Series, 52[18], pp 95-103, 1956.

Dewson, S. J., "The Development of High Efficiency Heat Exchangers for Helium Gas Cooled Reactors," Report \# 3213, International Conference on Advanced Nuclear Power Plants (ICAP), Cordoba, Spain, 2003.

Dewson, S. J., and Li, X., "Selection Criteria for The High Temperature Reactor Intermediate Heat Exchanger," Proceedings of ICAPP '05, Seoul, Korea, Paper 5333, May 15-19, 2005.

Dickinson, T., "Performance Analysis of a Liquid Metal Heat Pipe Space Shuttle Experiment," Masters' Thesis, Air Force Institute of Technology, Ohio, 1996.

Dobran, F., "Heat Pipe Research and Development in Americas," Heat Recovery System \& CHP, Vol. 9 , pp 67-100, 1989.

Egner, M., "Computation of Fluid Flow and Heat Transfer in Spiral and Constant-Radius Curved Channels," Ph.D., thesis, University of Kansas, Lawrence, 2003.

Feldman, K. T., "Investigation of Passive Pressure-Pumped Thermosyphons," Proceedings of the $6^{\text {th }}$ International Heat Pipe Conference, Vol. II, Grenoble, France, May 25-29, pp 665-670, 1987.

Fink, J. K. and Leibowitz, L., "Thermodynamic and Transport Properties of Sodium Liquid and Vapor," $A N L / R E-95 / 2,1995$.

Fisher, D. L., and Sindelar, R. L., "Compact Heat Exchanger Manufacturing Technology Evaluation," Savannah River Nuclear Solutions, SRNS-STI-2008-00014, Savannah River Site, Aiken, South Carolina, 2008.

Forster, H. K., and Zuber, N., "Dynamics of Vapor Bubbles and Boiling Heat Transfer," AIChE Journal, $1[4]$, pp 531-535, 1955.

Gaugler, R. S. US Patent 2350348. Appl. 21 Dec, 1942. Published 6 June 1944.

Gerak, A., Horvath, L., Jelinek, F. and Zboril, V., "Examples of Heat Pipe Application in Chemical, Electrical and Other Industries," Proceedings of the $6^{\text {th }}$ International Heat Pipe Conference, Vol. II, Grenoble, France, May 25-29, pp 676-684, 1987.

Gezelius, K., "Design of Compact Intermediate Heat Exchangers for Gas Cooled Fast Reactors," Bachelors' \& Masters' Thesis, Massachusetts Institute of Technology, June 2004.

Grover, G. M., U.S. Patent 3229759. 2nd December, 1963. Evaporation-Condensation Heat Transfer Device, 1963. 
Gross, U., "Reflux Condensation Heat Transfer Inside a Closed Thermosyphon," International Journal of Heat and Mass Transfer, Vol. 35, No. 2, pp 279-294, 1992.

Grief, R., "Natural Circulation Loops,” Journal of Heat Transfer, Vol. 110, pp 1243-1258, 1988.

Guerrieri, S. A., and Talty, R. D., "A Study of Heat Transfer to Organic Liquids in Single-Tube, Natural-circulation, Vertical-tube Boilers," Chemical Engineering Progress Symposium Series, 52[18], pp 69-77, 1956.

Gunnerson, F. S., and Cronenberg. A. W., "On the Thermodynamic Superheat Limit for Liquid Metals on its Relation to the Leidenfrost Temperature," Journal of Heat Transfer, 100, pp 734-737, November 1978.

Gunnerson, F. S., Sabharwall, P., and Sherman, S., "Comparison of Sodium Thermosyphon with Convective Loop," Proceedings of the 2007 AIChE Conference, Salt Lake City, November 2007.

Gunnerson, F. S., and Sanderlin, F. D., "A Controllable, Wickless Heat Pipe Design for Heating and Cooling," Fundamentals of Heat Pipes, ASME HTD-Vol. 278, 1994.

Haider. S. I., Joshi. Y. K., and Nakayama. W., "A Natural Circulation Model of the Closed Loop, Two-Phase Thermosyphon for Electronics Cooling," Journal of Heat Transfer, 124, pp 881-890, 2002.

Harley, C., and Faghri, A., "Complete Transient Two-Dimensional Analysis of Two-Phase Closed Thermosyphons Including the Falling Condensate Film," Journal of Heat Transfer, Vol. 116, pp 418, 1994.

Haynes, B. S., "High-Effectiveness Micro-Exchanger Performance," AIChE 2002 Spring National Meeting, New Orleans, 2002.

Haynes, F. D., Zarling, J. P. and Gooch, G. E., "Performance of a Thermosyphon with a 37-meter-long Horizontal Evaporator," Cold Regions Science and Technology, Vol. 20, No. 3, pp 261, 1992.

Hesselgreaves, J. E., "Compact Heat Exchangers, Selection, Design and Operation," First edition, Pergamon, 2001.

Heatric $^{\mathrm{TM}}$ Homepage, available online at http://www.heatric.com accessed on $14^{\text {th }}$ November, 2007.

Hoffman, H. W., and Krakoviak, A. I., "Forced-Convection Saturation Boiling of Potassium at Near-Atmospheric Pressure," Proceedings of High Temperature Liquid-Metal Heat Transfer Technology Meeting, BNL 756 (C-35), (Brookhaven National Laboratory), 1962.

Hoogers, G., Ed., “Fuel Cell Technology Handbook,” CRC Press, New York, 2003.

Hori, M. and Spitalnik, J., "Nuclear Production of Hydrogen- Technologies and Perspective for Global Deployment," International Nuclear Societies Council, November 2004.

Hosier, J. C., and Tillack, D. J., "Inconel Alloy 617- A New High Temperature Alloy,” Metals Engineering Quarterly, pp 51-55, August 1972.

Hosoi, Y., and Abe, S., "The Effect of Helium Environment on Creep Rupture Properties of Inconel 617 at $1000^{\circ} \mathrm{C}, "$ Metallurgical Transactions, Vol. 6A, pp 1171-1178, June 1975.

Hou, Z. and Wen, Y., "Heat Pipe Operating in a Spin Satellite," Proceedings of the $6^{\text {th }}$ International Heat Pipe Conference, Vol. II, Grenoble, France, May 25-29, pp 439-442, 1987.

Hsia, E. S., "Forced Convective Annular-Flow Boiling with Liquid Mercury under wetted and swirl flow conditions," Winter Annual Meeting of American Society of Mechanical Engineers, pp 76-83, 1970.

International Atomic Energy Agency, Hydrogen as an Energy Carrier and Its Production by Nuclear Power, IAEA-TECDOC-1085, May 1999. 
Irvine, T., and Hartnett, J., “Advances in Heat Transfer," Academic Press, 3, 1966.

Johnson, M. A., Pena, J., and Mesler, R. B., "Bubble shapes in nucleate boiling," Chemical Engineering Program Symposium Services, 62, 1966.

Johnston, A. M., and Haynes B. S., "Design Considerations For Compact Heat Exchangers," Heatric Internal Report, 2007.

Kakac, S., and Spalding, D. B., "Turbulent Forced Convection in Channels and Bundles: Theory and Applications to Heat Exchangers and Nuclear Reactors," Hemisphere Publishing Corporation, New York, 2, 1979.

Katzel, J., "Heat Exchangers Basics," Plant Engineering, April 2000.

Kays, W. M., and Crawford, K. E., "Convective Heat and Mass Transfer," McGraw-Hill, Inc., New York, 1993.

Kern, D. Q., "Process Heat Transfer,” McGraw-Hill International Book Company, 1982.

Kim, B. H. and Peterson, G. P., "Theoretical and Physical Interpretation of Entrainment Phenomenon in Capillary-Driven Heat Pipes Using Hydrodynamic Instability Theories," International Journal of Heat and Mass Transfer, Vol. 37, No. 17, pp 2647-2660, 1994.

Kitagawa, M., "Some Problems in Developing the High Temperature Design Code for a 1.5 MWT Helium Heat Exchanger, Elevated Temperature Design Symposium," American Society of Mechanical Engineers, New York, NY, pp 33-40, 1976.

Larminie, J. and Dicks, A. "Fuel Cell Systems Explained,” Wiley, New York, 2000.

Lee, Y. and Mital, U., “A Two-Phase Closed Thermosyphon,” International Journal of Heat and Mass Transfer, Vol. 15, pp 1695-1707, 1972.

Li, X., Pierres Le, R., and Dewson, S. J., "Heat Exchangers for the Next Generation of Nuclear Reactors," Proceedings of ICAPP '06 Reno, NV USA, Paper 6105, June 4-8, 2006.

Lines, J. R., "Heat Exchangers in Municipal Wastewater Treatment Plants," WATER/Engineering \& Management, pp 28-29, 1991.

Lock, G. S. H., “The Tubular Thermosyphon,” Oxford University Press, 1992.

Lock, G. S. H. and Fu, "Observations on an Evaporative Elbow Thermosyphon," Journal of Heat Transfer, Vol. 115, pp 501-503, 1993.

Lubarsky, B., and Kaufman, S. J., "Review of experimental investigations of liquid metal heat transfer," NACA Tech. Note 3336, 1955.

Lyon, R. N., "Liquid Metals Handbook, The Committee on the Basic Properties of Liquid Metals," Second edition, Office of Naval Research, Department of Navy, June 1952.

Ma, T., Liu, X. and Wu, J., "Flow Patterns and Operating Limits in Two-Phase Closed Thermosyphon," Proceedings of the $6^{\text {th }}$ International Heat Pipe Conference, Vol. II, Grenoble, France, pp 576-581, May 25-29, 1987.

Martenelli, R. C., "Heat Transfer to Molten Metals,” Trans. ASME, 69, pp 947-956, 1947.

Minton, P. E., "Designing Spiral-Plate Heat Exchangers," Chemical Engineering, Vol. 77, pp 103-112, 1970.

Mitsuma, H., Imai, R., Suzuki, H., Ido, Y., Kawashima, J., Ishibashi, T. and Kuriyama, Y., "Development of Light Weight Payload Radiator with Heat Pipes for a 2-ton Geostationary Satellite," Proceedings 
of the $6^{\text {th }}$ International Heat Pipe Conference, Vol. II, Grenoble, France, May 25-29, pp 368-373, 1987.

Moody, L. F., "Friction factors for pipe flow," Trans. ASME, 66, 1944.

Munzel, W. D., "Heat Pipes for Heat Recovery from Exhaust Gas of a Diesel Engine in a Passenger Car," Proceedings of the $6^{\text {th }}$ International Heat Pipe Conference, Vol. II, Grenoble, France, May 25-29, pp 740-743, 1987.

Negishi, K. and Sawada, T., "Heat Performance of an Inclined Two-Phase Closed Thermosyphon," International Journal of Heat and Mass Transfer, Vol. 26, No. 8, pp 1207-1213, 1983.

Noie, S. H., "Heat Transfer Characteristics of a two-phased closed thermosyphon," Applied Thermal Engineering, Vol. 25, pp 495-506, March 2005.

NGNP Preliminary Project Plan, Document ID: PLN-2489, June 2007.

Nguyen - Chi, H., and Groll, M., "Entrainment or Flooding Limit in a closed- two phase Thermosyphon," Advances in Heat Pipe Technology, Reay, D. A., ed., Pergamon Press, New York, pp 147-162, 1981.

Ohashi, K., Hayakawa. H., Yamada. M., Hayashi. T., and Ishii. T., "Preliminary Study on the Application of the Heat Pipe to the Passive Decay Heat Removal System of the Modular HTR," Progress in Nuclear Energy, 32, 587-594, 1998.

Peterson, G. P. and Bage, B. K., "Entrainment Limitations in Thermosyphons and Heat Pipes," Journal of Energy Resource Technology, Vol. 113, pp 147-153, 1991.

Peterson, G. P., Duncan, A. B. and Weichold, M. H., "Experimental Investigation of Micro Heat Pipes Fabricated in Silicon Wafers," Journal of Heat Transfer, Vol. 115, pp 751-756, 1993.

Reay, D. and Kew, P., "Heat Pipes: Theory Design and Applications," Fifth edition, ButterworthHeinemann, Elsevier, 2006.

Reed, J. G. and Tien, C. L., "Modeling of the Two-Phase Closed Thermosyphon," Journal of Heat Transfer, Vol. 109, pp 722-730, 1987.

Richter, R. and Gottschild, J. M., "Thermodynamic Aspects of Heat Pipe Operation," Journal of Thermophysics and Heat Transfer, Vol. 8, No. 2, pp 334-340, 1994.

Rohsenow, W. M., "Heat Transfer, A Symposium," Engineering Research Institute, University of Michigan, Ann Arbor, Michigan, 1952.

Roesler, S. and Groll, M., "Measurement of the Condensate Structure in Closed Two-Phase Thermosyphons," Proceedings of the $7^{\text {th }}$ International Heat Pipe Conference, Vol. I, Minsk, pp 69-80, May 1990.

Sabharwall, P., Reyes, J. N., Woods, B., Peterson, R., and Wu, Q., "Effects of Fluid Axial Conduction on Liquid Metal Natural Circulation and Linear Stability," Masters' Thesis, Oregon State University, 2004.

Sabharwall, P., Sherman, S., Utgikar, V., and Gunnerson, F., "Alternate Intermediate Heat Exchanger Design for Nuclear Hydrogen Production," Proceedings of the 2007 National American Nuclear Society Conference, Boston, June $24^{\text {th }}$ to $28^{\text {th }}, 2007$ (i).

Sabharwall, P., Gunnerson, F., Tokuhiro, A. Utgikar, V., Weaver, K., and Sherman, S., "Theoretical Design of a Thermosyphon for a Process Heat Removal from Next Generation Nuclear Plant (NGNP) for Production of Hydrogen," INL/EXT-07-13433, Department of Energy, 2007 (ii). 
Sabharwall, P., and Gunnerson, F., "Engineering Design Elements of a Two-Phase Thermosyphon for the Purpose of Transferring NGNP Thermal Energy to a Hydrogen Plant," Journal of Nuclear Engineering and Design, 2008 (Submitted).

Sabharwall, P., Patterson, M. W., and Gunnerson, F., "Theoretical Design of a Thermosyphon for Process Heat Transfer from NGNP to Hydrogen Plant," Journal of Nuclear Engineering and Design (Special Issue), 2009 (i) (Accepted).

Sabharwall, P., Utgikar, V., Tokuhiro, A., and Gunnerson, F., "Design of Liquid Metal Phase Change Heat Exchanger for Next Generation Nuclear Plant Process Heat Application," Journal of Nuclear Science and Technology, 2009 (ii) (Accepted).

Sabharwall, P., Utgikar, V., and Gunnerson, F., "Effect of Mass Flow Rate on the Convective Heat Transfer Coefficient: Analysis for Constant Velocity and Constant Area Case," Journal of Nuclear Technology, Vol. 166, May 2009 (iii).

Sabharwall, P., Utgikar, V., and Gunnerson, F., "Dimensionless Numbers in Boiling Fluid Flow for Thermosyphon and Heat Pipe Heat Exchangers," Journal of Nuclear Technology, 2009 (iv) (Accepted).

Schumacher, K. B., “Liquid Metal Heat Exchangers,” Naval Engineering Journal, 1960.

Seban, R. A., and Shimazaki, T. T., "Heat transfer to a fluid flowing turbulently in a smooth pipe with walls at constant temperature," Trans. ASME, 73, 803, 1951.

Shah, R. K., and Sekulic S. P., "Fundamentals of Heat Exchanger Design," John Wiley and Sons, 2003.

Sherman, S. R., and Chen Y., "Heat Exchanger Testing Requirements and Facility Needs for the NHI/ NGNP Project,” WSRC-STI-2008-00152, April 2008.

Shiraishi, M., Kikuchi, K., and Yamanishi, T., "Investigation of Heat Transfer Characteristics of a Two-Phase Closed Thermosyphon," Advances in Heat Pipe Technology, Reay, D. A., ed., Pergamon Press, New York, pp 95-104, 1981.

Silverstein, C. C., "Design and Technology of Heat Pipes for Cooling and Heat Exchange," Hemisphere Publishing Corporation, 1992.

Single, O. P., "Engineering Thermodynamics,” Macmillan India Limited, 1990.

Sleicher, C. A., and Rouse, M. W., "A Convenient Correlation for Heat Transfer to Constant and Variable Property Fluids in Turbulent Pipe Flow," Journal of International Heat and Mass Transfer, 18, pp 677-683, 1975.

Sockalingam, K. C., "Performance Characteristics and Optimization of Water Heat Pipes," PhD Thesis, University of California, Berkeley, 1972.

Soumerai, H., "Practical Thermodynamic Tools for Heat Exchanger Design Engineers," Wiley \& Sons, 1987.

Tamaki, M., Yoneyama, A., Ikeda, Y., Ohkubo, K. and Matsumoto, G., "Observation of Working Fluid in a Heat Pipe by Neutron Radiography," Proceedings of the $7^{\text {th }}$ International Heat Pipe Conference, Vol. II, Minsk, pp 67-74, May 1990.

TEMA, 2007, Standards of the Tubular Exchanger Manufacturers Association, $9^{\text {th }}$ Edition, order at http://www.tema.org

Terdtoon, P., Shiraishi, M., and Murakami, M., "Investigation of Effect of Inclination Angle on Heat Transfer Characteristics of Closed Two-Phase Thermosyphon," Proceedings of the 7th International Heat Pipe Conference, Vol. II, Minsk, pp 517-524, May 1990. 
Todreas, N., and E., Kazimi, M. S., "Nuclear Systems I," Third edition, Taylor \& Francis, New York, 2000.

Wang, J. C. Y. and Ma, Y., "Condensation Heat Transfer Inside Vertical and Inclined Thermosyphons," Journal of Heat Transfer, Vol. 113, pp 777-780, 1991.

Wu, D., "Geometric Calculations for the Spiral Heat Exchanger," Chemical Engineering Technology, 26, 2003.

Yildiz, B. and Kazimi, M. S., "Nuclear Energy for Hydrogen and Hydrogen-Based Liquid Fuels Production,” MIT-NES-TR-001, Massachusetts Institute of Technology, September 2003.

Zhang, N., Jiao, Z., and Ni, Z., "A Computational Method for Thermal Design of Spiral Plate Heat Exchanger," Proceedings of the 1988 Heat Transfer Conference, ASME HTD-96, Vol. I, pp 445-449, 1988.

Zuo, Z. J. and Gunnerson, F. S., "Heat Transfer Analysis of an Inclined Two-Phase Closed Thermosyphon," Journal of Heat Transfer, 1995.

Zuo, Z. J. and Gunnerson, F. S., "Numerical Modeling of the Steady-State Two-Phase Closed Thermosyphon," International Journal of Heat and Mass Transfer, Vol. 37, No. 17, pp 2715-2722, 1994 (i).

Zuo, Z. J. and Gunnerson, F. S., "Numerical Study of the Thermosyphon Flooding Limit," Fundamentals of Heat Pipes, ASME HTD-Vol. 278, pp 47-55, 1994 (ii).

Zuo, Z., "Theoretical and Experimental Investigation of the Thermosyphon," PhD Thesis, University of Central Florida, 1995. 